Gisele da Silva Craveiro

\title{
Um ambiente de execução para suporte à programação paralela com variáveis compartilhadas em sistemas distribuídos heterogêneos
}

Tese apresentada à Escola Politécnica da Universidade de São Paulo para obtenção do título de Doutor em Engenharia Elétrica. 
Gisele da Silva Craveiro

\section{Um ambiente de execução para suporte à programação paralela com variáveis compartilhadas em sistemas distribuídos heterogêneos}

Tese apresentada à Escola Politécnica da Universidade de São Paulo para obtenção do título de Doutor em Engenharia Elétrica.

Área de concentração:

Sistemas Digitais

Orientadora:

Profa. Dra. Liria Matsumoto Sato 
"E é sempre melhor o impreciso que embala que o certo que basta, Porque o que basta acaba onde basta, e onde acaba não basta, E nada que se pareça com isto devia ser o sentido da vida..." Álvaro de Campos (Fernando Pessoa) 


\section{Agradecimentos}

Agradeço a Deus pelas inúmeras oportunidades concedidas e por sua constante presença.

Agradeço à Profa. Liria Matsumoto Sato por me ensinar a mais valiosa lição desse trabalho de doutorado e que carregarei para vida: "o mais importante são as pessoas". Sua dedicação, orientação segura e apoio nos momentos delicados me ensinou mais que qualquer livro ou artigo.

Agradeço à minha família e amigos pela compreensão de minhas ausências.

Agradeço a todos os meus companheiros do LASB. Especialmente sou grata pela determinante ajuda técnica de Mário D. Marino e do prof. Edson T. Midorikawa. Hélio Marci e Eudenia X. Menezes merecem uma especial menção pelo esforço despendido nessa etapa final de formatação do texto.

Agradeço o Departamento de Engenharia de Computação da Escola Politécnica da USP pela infra-estrutura fornecida.

Agradeço o inestimável apoio que a Fundação de Amparo à Pesquisa do Estado de São Paulo (processo 98/11999-7) forneceu através de recursos materiais e dos comentários construtivos e estimulantes recebidos nas avaliações. 


\section{RESUMO}

$\mathrm{O}$ avanço na tecnologia de hardware está permitindo que máquinas SMP de 2 a 8 processadores estejam disponíveis a um custo cada vez menor, possibilitando que a incorporação de tais máquinas em aglomerados de PC's ou até mesmo a composição de um aglomerado de SMP's sejam alternativas cada vez mais viáveis para computação de alto desempenho. O grande desafio é extrair o potencial que tal conjunto de máquinas oferece. Uma alternativa é usar um paradigma híbrido de programação para aproveitar a arquitetura de memória compartilhada através de multithreading e utilizar o modelo de troca de mensagens para comunicação entre os nós. Contudo, essa estratégia impõe uma tarefa árdua e pouco produtiva para o programador da aplicação. Este trabalho apresenta o sistema CPAR-Cluster que oferece uma abstração de memória compartilhada no topo de um aglomerado formado por nós mono e multiprocessadores. O sistema é implementado no nível de biblioteca e não faz uso de recursos especiais tais como hardware especializado ou alteração na camada de sistema operacional. Serão apresentados os modelos, estratégias, questões de implementação e os resultados obtidos através de testes realizados com a ferramenta e que apresentaram comportamento esperado. 


\section{ABstraCt}

The advance in hardware technologies is making small configuration SMP machines (from 2 to 8 processors) available at a low cost. For this reason, the inclusion of an SMP node into a cluster of PCs or even clusters of SMPs are becoming viable alternatives for high performance computing. The challenge is the exploitation of the computational resources that these platforms provide. A hybrid programming paradigm which uses shared memory architecture through multithreading and also message passing model for inter node communication is an alternative. However, programming in such paradigm is very hard. This thesis presents CPAR-Cluster, a runtime system, that provides shared memory abstraction on top of a cluster composed by mono and multiprocessor nodes. Its implementation is at the library level and doesn't require special resources such as particular hardware or operating system modifications. Models, strategies, implementation aspects and results will be presented. 


\section{CONTEÚDO}

Agradecimentos $\quad$ iii

Resumo iv

$\begin{array}{lll}\text { Abstract } & \text { v }\end{array}$

1 Introdução $\quad 1$

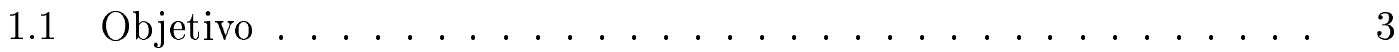

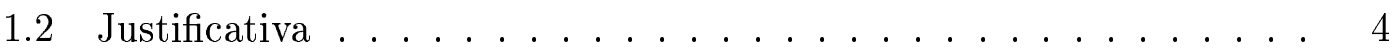

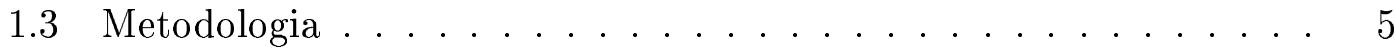

1.4 Organização do texto . . . . . . . . . . . . . . 6

2 Os Sistemas de Memória Distribuída Compartilhada $\quad 7$

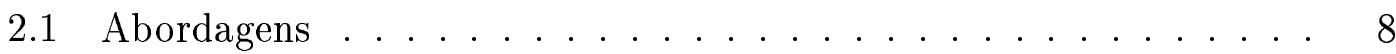

2.2 Decisões de Projetos . . . . . . . . . . . . . 9

2.2.1 Estrutura e granulosidade . . . . . . . . . . . . 10

2.2.2 Semântica da coerência e consistência . . . . . . . . . . 11

2.2.3 Escalabilidade ................. 14

2.2.4 Heterogeneidade .................. 14

2.3 Implementações . . . . . . . . . . . . . . . . . . . . . . . . 16

2.3.1 Acesso e localização de dados . . . . . . . . . 16

2.3.2 Protocolo de coerência . . . . . . . . . . . . 17

2.4 Alguns trabalhos relacionados . . . . . . . . . . . . . . . 18

2.4.1 Protocolo Home-based para nós SMP . . . . . . . . . 18

2.4 .2 Nomad . . . . . . . . . . . . . . 19

2.4.3 SCore e Omni OpenMP . . . . . . . . . . 20

2.4.4 O compilador e o ambiente de execução para linguagem $\mathrm{CxC} 21$

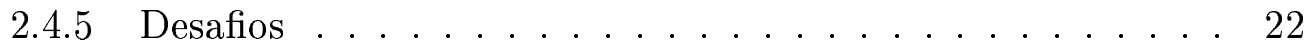

3 A Linguagem CPAR $\mathbf{2 5}$

3.1 A Linguagem CPAR . . . . . . . . . . . . . . . 26

3.1.1 Granulosidade do paralelismo . . . . . . . . 26

3.1.2 Blocos Paralelos ................ 26

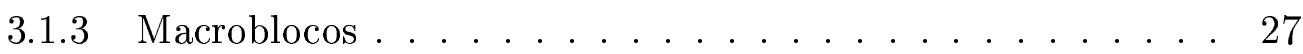

3.1.4 Macrotarefas .................... 27

3.1.5 Microtarefas .................. 29

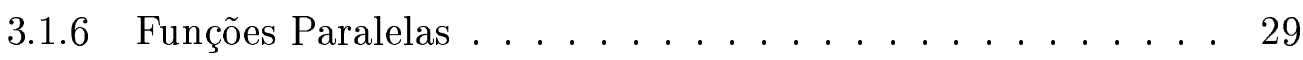

3.1.7 Variáveis Compartilhadas ............ 30 
3.1.8 Passagem de Mensagem . . . . . . . . . . . . . 30

3.1.9 Mecanismos de Sincronização . . . . . . . . . . 32

3.2 Sistemas de programação para CPAR . . . . . . . . . . . . . . 34

3.2.1 Sistema de programação para memória compartilhada . . . . 34

3.2.2 Sistema de programação para multicomputadores heterogêneos 35

3.2.3 Sistema CPAR sobre PVM . . . . . . . . . . . 37

4 Modelo do Sistema CPAR-Cluster $\quad 39$

4.1 Modelo de Execução . . . . . . . . . . . . . . . . 40

4.1 O Executor ....................... 42

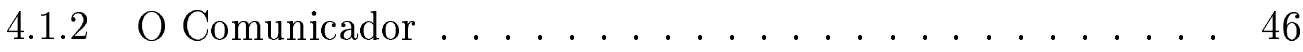

4.1.3 Variáveis Compartilhadas ............. 46

4.1 .4 O Emissor . . . . . . . . . . . . . . 49

4.2 Escalonamento de macro e microtarefas . . . . . . . . . . . . . . 53

4.2.1 Escalonamento das macrotarefas . . . . . . . . . 53

4.2.2 O escalonamento das iterações . . . . . . . . . . . 54

5 Implementação do Sistema $\quad \mathbf{5 7}$

5.1 Questões de projeto e implementação . . . . . . . . . . . . . 57

5.1 .1 Paralelismo por threads . . . . . . . . . 57

5.1 .2 PVM ou MPI? ................. 58

5.2 Etapas da implementação . . . . . . . . . . . . . . . . 59

5.3 Definição da sintaxe e tratamento dos arquivos do usuário . . . . . 60

5.3.1 O programa do usuário . . . . . . . . . . . . 61

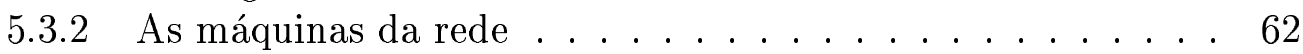

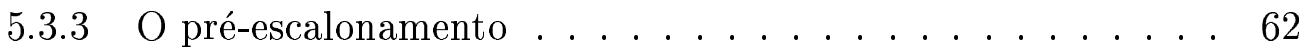

5.4 Execução em rede heterogênea . . . . . . . . . . . . 63

5.4.1 Descrição de um conjunto de máquinas heterogêneas . . . . 63

5.4 .2 A geração dos executáveis . . . . . . . . . . 6 65

5.5 A configuração do sistema . . . . . . . . . . . . 65

5.5.1 A tabela de nós ................... 66

5.5.2 A tabela de tarefas ................. 67

5.6 O escalonamento de tarefas e o balanceamento de carga dos nós . . 68

5.6.1 A ativação das tarefas . . . . . . . . . . . . 69

5.7 A execução das microtarefas . . . . . . . . . . . . . . . . 69

5.7.1 A implementação do escalonamento das iterações . . . . . . 72

5.8 As variáveis compartilhadas dentro do sistema . . . . . . . . . . . 75

5.8.1 A representação dos objetos . . . . . . . . . . . . 75

5.8 .2 A atualização de um elemento . . . . . . . . . 80

5.8.3 O protocolo de propagação de atualização . . . . . . . . . 85

5.9 Mecanismos de sincronização e exclusão mútua . . . . . . . . . . . . 92

5.9 .1 Semáforos . . . . . . . . . . . . . . 92

5.9.2 Barreiras Wait_Task e Wait_All . . . . . . . . . . 93

5.10 Coordenação e finalização . . . . . . . . . . . . . . . 93 
6 Análise dos Resultados 95

6.1 Descrição dos Testes . . . . . . . . . . . . . . . 95

6.1 .1 Metodologia . . . . . . . . . . . . . . 96

6.1.2 Multiplicação de Matrizes . . . . . . . . . . . . . . . 97

6.1.3 Versão com atualização em um nó (Global Mestre) . . . . . 99

6.1.4 Versão sem Variáveis Compartilhadas (Local) . . . . . . . 99

6.1.5 O Problema do Caixeiro Viajante . . . . . . . . . . . 102

6.2 Resultados Obtidos e Análise . . . . . . . . . . . . . . . . . 104

6.2.1 Sobrecarga imposta pela troca de mensagens de atualização 104

6.2.2 Sobrecarga imposta pela coordenação do forall . . . . . . . 117

6.2 .3 Escalonamento de iterações . . . . . . . . . . . . . . . . 117

6.2.4 Semáforos . . . . . . . . . . . . . . . . . . . 119

7 Conclusões 120

7.1 Conclusões do trabalho . . . . . . . . . . . . . . 120

7.2 Contribuições . . . . . . . . . . . . . . . . . . . . . 121

7.3 Trabalhos futuros . . . . . . . . . . . . . . . . . 122

$\begin{array}{ll}\text { Referências } & 124\end{array}$

$\begin{array}{ll}\text { A O Algoritmo de Escalonamento } & 128\end{array}$

B Código CPAR TSP 131

C Códigos expandidos dos programas de teste 138

C.1 Tabela de Variáveis Compartilhadas dos programas de multiplicação de matrizes . . . . . . . . . . . . . . . . 138

C.1.1 O arquivo de prototipação . . . . . . . . . . 138

C.1.2 O arquivo de declaração e a tabela . . . . . . . . . 138

C.2 Multiplicação de Matrizes versão com atualização em todos os nós e sem variável auxiliar . . . . . . . . . . . . . . . . . . 139

C.3 Multiplicação de Matrizes versão com atualização em todos os nós e com variável auxiliar . . . . . . . . . . . . . . . . . . 144

C.4 Multiplicação de Matrizes versão com atualização somente no mestre e com variável auxiliar . . . . . . . . . . . . . . . . 149

C.5 Multiplicação de Matrizes versão sem envio de mensagem de atualização e com variável auxiliar . . . . . . . . . . . . . . . . 154

C.6 Tabela de Variáveis Compartilhadas do programa TSP . . . . . . 158

C.6.1 O arquivo de prototipação . . . . . . . . . . 158

C.6.2 O arquivo de declaração e a tabela . . . . . . . . . . 159

C.7 A expansão do programa CPAR TSP . . . . . . . . . . . . 160 


\section{Lista DE Figuras}

1.1 Um esquema de memória compartilhada distribuída. . . . . . . . 2

2.1 Speedup da multiplicação de matrizes no ambiente CxC [I., 2003]. . 22

3.1 Sintaxe da construção cobegin-coend. . . . . . . . . . . . . . 27

3.2 Sintaxe de macrobloco. . . . . . . . . . . . . 27

3.3 Sintaxe de especificação de uma macrotarefa. . . . . . . . . . . 28

3.4 Sintaxe do corpo de uma macrotarefa. . . . . . . . . . . . . . . 28

3.5 Sintaxe de ativação de uma macrotarefa. . . . . . . . . . . . . . . 28

3.6 Sintaxe de um laço paralelo. . . . . . . . . . . . . . 29

3.7 Sintaxe da construção parbegin-parend. . . . . . . . . . . . 29

3.8 Sintaxe da declaração de função paralela. . . . . . . . . . . . . . 30

3.9 Sintaxe da declaração de função que faz referência a uma função paralela. . . . . . . . . . . . . . 30

3.10 Sintaxe da declaração de variável compartilhada. . . . . . . . . . . 30

3.11 Rotinas de manipulação de variável compartilhada dinâmica. . . . . 31

3.12 Primitivas de passagem de mensagem. . . . . . . . . . . . 31

3.13 Primitivas de manipulação de semáforos. . . . . . . . . . . . . . . . . 32

3.14 Primitivas de manipulação de eventos. . . . . . . . . . . . . . . . . . . 33

3.15 Sintaxe de monitor. . . . . . . . . . . . . . . 33

3.16 Compilação de um programa em CPAR. . . . . . . . . . . . . 34

3.17 Modelo de execução proposto por Sato [Sato, 1995] . . . . . . . 36

3.18 Modelo de execução proposto por Iguma [Iguma, 1997] . . . . . . . 37

4.1 Modelo de execução do CPAR-Cluster. . . . . . . . . . . . . . . 42

4.2 Distribuição de tarefa no modelo de execução. . . . . . . . . . . . . 44

4.3 Notificação do término de tarefa no modelo de execução. . . . . . . 45

4.4 Exemplos da ocorrência de pontos de sincronização para atualizações de variáveis compartilhadas. . . . . . . . . . . . 48

4.5 Atualização de variáveis compartilhadas no modelo de execução. . . 51

4.6 Atualização de variáveis compartilhadas em nós multiprocessadores. 52

4.7 Esqueleto do algoritmo de escalonamento. . . . . . . . . . . 55

5.1 As etapas de implementação do sistema. . . . . . . . . . . . 60

5.2 O fluxo de um programa em CPAR. . . . . . . . . . . . . . 61

5.3 Exemplo de arquivo de especificação da rede. . . . . . . . . . . . . 62

5.4 Exemplo de arquivo de pré-escalonamento. . . . . . . . . . 63

5.5 A geração do código executável para o sistema distribuído. . . . . . 65

5.6 Estrutura de dados da tabela de nós. . . . . . . . . . . . 66 
5.7 Estrutura da tabela de tarefas. . . . . . . . . . . . . 67

5.8 A execução de um forall. . . . . . . . . . . . . . 70

5.9 A expansão de um forall. . . . . . . . . . . . . . . . 70

5.10 A ordenação dos eventos que compõem a sincronização imposta pela barreira. ...................... 71

5.11 A sintaxe do laço paralelo com escalonamento dinâmico em CPAR. 73

5.12 A expansão do laço paralelo com escalonamento dinâmico. . . . . . 74

5.13 A ordenação dos eventos que compõem o controle de blocos no escalonamento dinâmico. . . . . . . . . . . . 74

5.14 Exemplo de definição de tipos e declaração de variáveis compartilhadas em um programa CPAR. . . . . . . . . . 79

5.15 Estrutura da Tabela de Variáveis Compartilhadas. . . . . . . . . . . 79

5.16 Exemplo das informações enviadas em uma atualização de variável compartilhada. ................. 8 83

5.17 Regiões da memória que armazenam a atualização, manipuladas pelo processo Emissor e thread Executor. . . . . . . . . . 84

5.18 Recebimento de mensagem de atualização pelo processo Comunicador e escrita em área compartilhada com thread Executor de um nó. . . . . . . . . . . . . . . . . . 84

5.19 Pontos de propagação de atualização de variável dentro da função principal do programa do usuário. . . . . . . . . . . . 87

5.20 Manipulações de variáveis compartilhadas dentro de uma macrotarefa. 88

5.21 Pontos de propagação de atualização de variável dentro de uma macrotarefa. . . . . . . . . . . . . . 9 90

5.22 Sintaxe CPAR para declaração de variáveis compartilhadas segundo a estratégia de distribuição. . . . . . . . . . . . . . . . . 91

6.1 O ambiente utilizado na realização dos testes. . . . . . . . . . . 97

6.2 Programa CPAR que calcula a multiplicação de matrizes quadradas com a utilização de variáveis compartilhadas globais e com distribuição total. . . . . . . . . . . . . . . . . 98

6.3 Programa CPAR que calcula a multiplicação de matrizes quadradas com a utilização de variáveis globais compartilhadas e com distribuição total. Há exploração da localidade. . . . . . . . . . . . . 100

6.4 Programa CPAR que calcula a multiplicação de matrizes quadradas com a utilização de variáveis globais compartilhadas e com distribuição central. Há exploração da localidade. . . . . . . . . . . . . . 101

6.5 Programa CPAR que calcula a multiplicação de matrizes quadradas com a utilização de variáveis globais privadas. Há exploração da localidade. . . . . . . . . . . . . . . 103

6.6 Tempo de execução médio das versões de multiplicação de matrizes de ordem 2000 sobre diferentes configurações. . . . . . . . . . . 105

6.7 Speedup obtido na execução das versões de multiplicação de matrizes de ordem 2000 sobre diferentes configurações. 
6.8 Tempo de execução médio das versões de multiplicação de matrizes de ordem de 100 a 2000 sobre a configuração formada por uma máquina SMP com quatro processadores . . . . . . . . . . . 106

6.9 Tempo de execução médio das versões de multiplicação de matrizes de ordem de 100 a 2000 sobre a configuração formada por dezesseis máquinas monoprocessadoras. . . . . . . . . . . . . . 107

6.10 Tempo de execução médio das versões de multiplicação de matrizes de ordem de 100 a 2000 sobre a configuração formada por oito máquinas SMP com dois processadores. . . . . . . . . . . . 116

6.11 Comparação dos tempos médios de execução da multiplicação de matrizes utilizando estratégias de escalonamento dinâmico e estático.118 


\section{LisTA DE TABELAS}

2.1 Alguns sistemas DSM [Nitzberg and Lo, 1991]. . . . . . . . . 15

4.1 Estrutura de mapeamento do armazenamento de variáveis compartilhadas. . . . . . . . . . . . . . . . 47

5.1 Tipos de dados definidos pelo padrão ANSI [Schildt, 1990] e pelo padrão MPI [LAM/MPI, 2003]. . . . . . . . . . . . . 76

5.2 Tabela de Variáveis Compartilhadas do exemplo (Figura 5.14). . . . 81

6.1 Tempo médio de execução, sobre um nó quad, da multiplicação de matrizes seqüencial e mais as três versões utilizando forall estático. Speedup calculado sobre os tempos da multiplicação. . . . . . . . 108

6.2 Tempo médio de execução, sobre um nó dual, da multiplicação de matrizes seqüencial e mais as três versões utilizando forall estático. Speedup calculado sobre os tempos da multiplicação. . . . . . . 109

6.3 Tempo médio de execução, sobre dois nós duais, da multiplicação de matrizes seqüencial e mais as três versões utilizando forall estático. Speedup calculado sobre os tempos da multiplicação. . . . . . . . 110

6.4 Tempo médio de execução, sobre quatro nós duais, da multiplicação de matrizes seqüencial e mais as três versões utilizando forall estático. Speedup calculado sobre os tempos da multiplicação. . . . 111

6.5 Tempo médio de execução, sobre quatro nós mono, da multiplicação de matrizes seqüencial e mais as três versões utilizando forall estático. Speedup calculado sobre os tempos da multiplicação. . . . 112

6.6 Tempo médio de execução, sobre oito nós duais, da multiplicação de matrizes seqüencial e mais as três versões utilizando forall estático. Speedup calculado sobre os tempos da multiplicação. . . . . . . 113

6.7 Tempo médio de execução, sobre oito nós mono, da multiplicação de matrizes seqüencial e mais as três versões utilizando forall estático. Speedup calculado sobre os tempos da multiplicação. . . . . . . . . 114

6.8 Tempo médio de execução, sobre dezesseis nós mono, da multiplicação de matrizes seqüencial e mais as três versões utilizando forall estático. Speedup calculado sobre os tempos da multiplicação. . . . 115

6.9 Tempo médio de execução, sobre um nó quad oito nós duais e dezesseis nós mono, da multiplicação de matrizes seqüencial e mais as três versões utilizando forall estático. . . . . . . . . . . . . 116 
6.10 Tempo médio de execução, sobre um nó quad, dezesseis nós mono e oito nós duais, da versão de multiplicação de matrizes de ordem 2000, com atualização em nó central e variados tamanhos de blocos para o forall dinâmico. Comparação do tempo médio obtido para a mesma versão de multiplicação, sobre a mesma plataforma, mas com utilização do forall estático. . . . . . . . . . . . 118

6.11 Tempo médio de execução em segundos do TSP para 23 cidades em diversas configurações . . . . . . . . . . . . . . . 119 


\section{Capítulo 1}

\section{INTRODUÇÃO}

O desenvolvimento contínuo de processadores mais poderosos e de tecnologias de chaveamento mais rápidas têm levado os sistemas paralelos e distribuídos a ocupar um lugar de destaque como sendo uma solução promissora para aplicações que demandam alto desempenho. Infelizmente, o desenvolvimento de software para tais sistemas não tem acompanhado esse progresso, pois constitui uma tarefa árdua e pouco produtiva.

Buscando características altamente desejáveis, como a programabilidade e a produtividade, é utilizado o paradigma de memória compartilhada. Ele oferece uma facilidade de implementação que pode ser estendida para uma rede, onde as aplicações têm sido atualmente implementadas via troca de mensagens.

Um sistema de memória compartilhada distribuída (Distributed Shared Memory, DSM) consiste em uma coleção de computadores independentes conectados por uma rede de alta velocidade. O DSM tenta combinar as vantagens de duas classes de sistemas: sistemas de memória compartilhada e sistemas de memória distribuída.

Os sistemas de memória compartilhada possuem uma única memória física global que é igualmente acessível por todos os processadores do sistema, levando a uma maior portabilidade da aplicação. Os sistemas de memória distribuída consistem em múltiplos nós de processamento, cada um com seu módulo de memória e que comunicam-se através de passagem de mensagem.

Os sistemas DSM implementam a abstração de memória compartilhada sobre um sistema fracamente acoplado formado por várias máquinas conectadas por uma 
rede de interconexão (vide Figura 1.1). Muitos DSMs escondem os mecanismos de comunicação do programador da aplicação, o que simplifica o processo de projeto do software. Conseqüentemente, os DSMs podem combinar as vantagens da facilidade de programação e portabilidade típicas de sistemas de memória compartilhada, com a escalabilidade e o custo efetivo de sistemas de memória distribuída.

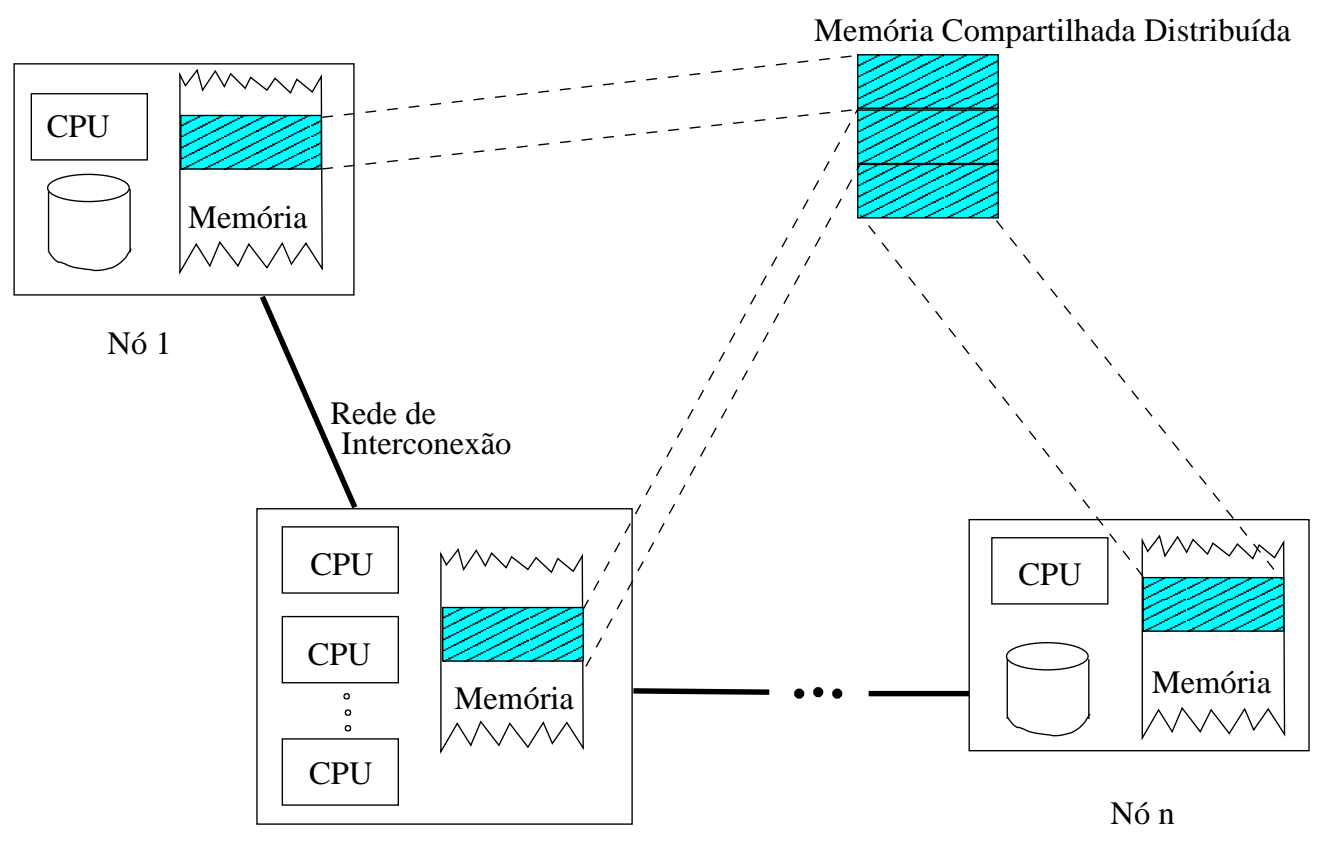

Nó 2

Figura 1.1: Um esquema de memória compartilhada distribuída.

Usando mecanismos para replicação e comunicação de dados, os sistemas de memória compartilhada distribuída, os DSM's, emulam a existência de um espaço de endereçamento global ao qual todos os processos têm acesso e, assim, tornando a comunicação inter-processos mais fácil.

Os DSM's constituem uma área de pesquisa ativa desde o meados dos anos 80 [Nitzberg and Lo, 1991] apesar dos fundamentos (coerência da memória cache e gerenciamento da memória) terem sido apresentados há muito mais tempo.

Em 1986, Kai Li publicou sua tese de doutorado intitulada "Shared Virtual Memory on Loosely Coupled Microprocessors", um dos trabalhos mais significativos do início da pesquisa em DSM. Por mais de uma década, vários trabalhos foram publicados e muitos avanços dessa área foram estendidos a outras, tais como, sistemas distribuídos baseados em objetos, sistemas operacionais, além da melhoria 
do próprio desempenho dos DSMs.

\subsection{Objetivo}

Esse trabalho propõe e implementa um sistema de execução para dar suporte à programação paralela, com acesso transparente a variáveis compartilhadas em um sistema distribuído heterogêneo, denominado CPAR-Cluster. Os esforços foram feitos de maneira que esse sistema fosse o mais eficiente possível, para que contribuísse na melhoria do desempenho de aplicações paralelas.

O sistema apresenta as seguintes características:

- execução em ambientes distribuídos heterogêneos na quantidade de processadores e também na capacidade de processamento (velocidade, capacidade de memória, etc.) de cada nó,

- oferecimento de mecanismos de sincronização e primitivas para explicitar paralelismo da aplicação,

- consistência dos dados transparente e

- estratégias para minimizar o tráfego de mensagens.

No tratamento das características mencionadas têm-se as principais contribuições:

- proposição de novas estratégias de atualização de variáveis compartilhadas de acordo com a distribuição de dados,

- apresentação de critérios de distribuição de dados que otimizem o desempenho da aplicação e

- elaboração de uma política de escalonamento das tarefas e de processamento, de maneira que seja explorado todo o potencial de uma rede composta por máquinas mono e multiprocessadoras. 


\subsection{Justificativa}

Esse trabalho pretende enfocar duas áreas e um mesmo problema: a extração do melhor desempenho das máquinas paralelas sem que isso sacrifique a programabilidade e, assim, obter maior produtividade no desenvolvimento de programas paralelos.

Para ajudar nessa tarefa intrincada foi criada a abstração de memória compartilhada em sistemas paralelos de memória distribuída. Apenas isso já constitui um grande avanço, mas o desejável seria a incorporação de aspectos de engenharia de software e de linguagens de programação. Verifica-se um grande esforço por parte da comunidade que desenvolve software básico para dar suporte às aplicações paralelas, mas ainda há muito por ser feito.

Um ponto relevante é a análise de estratégias que explorem o potencial de uma tendência crescente na área do processamento paralelo: a computação de custo efetivo dos clusters ou aglomerados de computadores, que são multiprocessadores de memória distribuída interconectados por uma rede de alta velocidade.

Recentemente, as redes de alta velocidade e os microprocessadores atuais têm tornado as redes de estações de trabalho (NOW, Network of Workstations) cada vez mais um veículo atrativo para computação paralela de custo efetivo. Clusters/redes de computadores (estações de trabalho ou PCs) construídos por hardware e software de baixo custo têm uma grande responsabilidade pela redefinição do conceito de supercomputação. Resumindo, os clusters estão tornando-se uma alternativa interessante aos MPPs (Massive Parallel Processors) e supercomputadores em muitas áreas de aplicação [Dietz, 1998].

Pelos motivos apresentados, uma grande contribuição é esperada no sentido de tratar a exploração da capacidade total de um sistema heterogêneo composto por máquinas mono e multiprocessadoras. 


\subsection{Metodologia}

Na tentativa de extração de um alto desempenho de uma plataforma constituída por variadas arquiteturas sem que haja sacrifícios à escalabilidade, portabilidade e principalmente programabilidade, foi feita inicialmente uma pesquisa bibliográfica sobre sistemas de memória compartilhada distribuída.

Durante essa etapa foi estudado o trabalho de Liria M. Sato [Sato, 1995] que apresenta uma proposta de sistema programação para uma rede heterogênea, bem como uma implementação dessa proposta por Denise Iguma [Iguma, 1997].

Analisando diferentes abordagens, estratégias e implementações, concluiu-se que um sistema de memória compartilhada distribuída, implementado no nível de biblioteca/compilador teria condições de explorar o poder computacional de um aglomerado de computadores heterogêneos.

Observou-se também nessa etapa que uma modelagem, projeto e implementação que contemplem a presença de arquiteturas multiprocessadoras na rede trariam ganhos notáveis à execução das aplicações paralelas sobre o sistema CPARCluster.

Tendo definido o tema de pesquisa, o escopo e a modelagem do sistema, prosseguimos o trabalho com a especificação das entidades a serem desenvolvidas e a implementação da proposta.

Avaliações periódicas ao longo da etapa de implementação indicaram a melhor forma para se viabilizar as estratégias contidas no nosso trabalho.

A validação do sistema acontece através de testes realizados na plataforma de trabalho disponível no Laboratório de Arquitetura e Software Básico da Escola Politécnica da USP.

A plataforma citada é composta pelo seguinte conjunto de máquinas interligadas por uma rede Fast Ethernet:

- Um cluster de 08 microcomputadores, cada um com dois processadores AMD Athlon MP1800+, com clock de 1553 MHz, 1 Gbyte de memória RAM.

- Um cluster de 16 computadores dotados, cada um deles, de um processador 
Celeron, com clock de $434 \mathrm{MHz}, 128$ Mbytes de RAM e memória cache de 128 Kbytes.

- Um servidor Intel SC450 NX, com quatro processadores Pentium II Xeon $400 \mathrm{MHz}, 256 \mathrm{MB}$ de memória RAM e 1MB de cache.

\subsection{Organização do texto}

O primeiro capítulo desse texto apresentou o problema, a motivação e a metodologia necessárias para alcançar os objetivos pretendidos no presente trabalho de doutorado.

O Capítulo 2 faz uma revisão de conceitos sobre os sistemas de memória compartilhada distribuída, abrangendo considerações de projeto e implementação.

A linguagem CPAR é de extrema relevância ao nosso trabalho e é discutida no Capítulo 3.

O Capítulo 4 traz o modelo do sistema CPAR-Cluster de execução de programas com o paradigma de variáveis compartilhadas sobre uma rede de computadores distribuídos heterogêneos.

As questões de projeto e implementação do sistema são discutidas no Capítulo 5.

No Capítulo 6 são apresentados os resultados dos testes e os mesmos são analisados para se caracterizar o comportamento do sistema e verificar a validade das estratégias propostas e implementadas.

Finalmente, no Capítulo 7, são colocadas as conclusões do trabalho, suas contribuções e algumas sugestões de extensões e trabalhos futuros. 


\section{Capítulo 2}

\section{Os Sistemas de Memória}

\section{Distribuída COMPartilhada}

À medida que o avanço tecnológico fica mais próximo do limite físico dos processadores e da velocidade da memória, o uso de multiprocessadores para aumentar o poder computacional torna-se mais atraente. Nesse contexto, dois tipos de sistemas com processadores paralelos têm popularizado-se:

- Multiprocessadores fortemente acoplados: constituídos de várias CPU's e uma única memória física global. São mais fáceis de programar, contudo são limitados pelo gargalo do acesso à memória através do barramento.

- Multicomputadores de memória distribuída: formam uma coleção de computadores independentes interconectados por uma rede de alta velocidade. São sistemas que apresentam uma alta escalabilidade, porém não são tão amigáveis na programação.

Em relação ao modelo de programação, os sistemas de memória distribuída contavam somente com o paradigma de passagem de mensagem [Computing, 1994]. Essa realidade foi alterada com o advento da abstração de memória compartilhada nesses sistemas distribuídos, ou seja, é implementada uma abstração de memória compartilhada no topo dos sistemas de memória distribuída que utilizam passagem de mensagens, permitindo que os programadores beneficiem-se da programabilidade do paradigma de memória compartilhada preservando as vantagens de sistemas distribuídos. 


\subsection{Abordagens}

Um DSM provê memória compartilhada logicamente sobre uma rede de computadores sem o uso de memória compartilhada fisicamente. As primeiras abordagens particionavam o espaço de endereçamento em páginas lógicas, as quais eram distribuídas pelos nós do sistema. Através de um gerente de memória, os nós podem acessar qualquer página no espaço de endereçamento compartilhado, com a memória física local servindo também como uma cache de páginas. Tais sistemas são classificados como DSM baseado em bloco [Liang, 1997] pois a memória é particionada em blocos de tamanho fixo.

Tais DSM's são extensões de sistemas de memória virtual tradicional e, por isso, são implementados com recursos específicos das camadas do hardware e/ou do sistema operacional. O grande apelo desses sistemas é a transparência. As aplicações desenvolvidas originalmente para um computador convencional podem ser executadas no DSM sem mudanças. Os usuários podem tratar o sistema DSM como um multiprocessador de memória compartilhada que possui uma velocidade de comunicação mais baixa.

As desvantagens estão no grande esforço de implementação e em algumas questões de projeto. Uma delas é a escolha do tamanho do bloco, o qual não depende somente das características do sistema, mas também das aplicações. Não existe uma maneira sistemática para escolher esse parâmetro que afeta o tempo de transferência dos dados e a manutenção de informações dos dados.

Outra difícil questão de projeto é a heterogeneidade. Ela esbarra na dependência de máquina dessas implementações. Apesar da heterogeneidade permitir que um número maior de máquinas participem de uma computação, isso ainda não constitui uma vantagem em sistemas baseados em blocos, pois a sobrecarga da conversão dos dados ultrapassa o benefício obtido.

A segunda abordagem é representada pelos DSM's baseados em estrutura [Liang, 1997]. Esses sistemas particionam a memória em pequenas unidades que possuem dados relacionados logicamente. São implementados pelas camadas de compilador-linguagem ou biblioteca. 
Os sistemas nessa abordagem não apresentam uma transparência e um desempenho tão bons quanto os obtidos pelos sistemas baseados em bloco. Como os DSM's baseados em estrutura são implementados em um nível mais alto, são necessárias modificações na interação usuário-sistema com a definição de estilo, linguagem ou modelo de programação novos.

As características desejáveis que esses sistemas apresentam resultam da grande independência de máquina e flexibilidade. Como os DSM's baseados em estrutura são implementados sobre subsistemas de comunicação genéricos (PVM, MPI, TCP/IP) o esforço de desenvolvimento é reduzido drasticamente. O mais importante é que o ambiente obtido pode facilmente dar suporte à heterogeneidade.

A flexibilidade pode ser constatada pelo grande poder que os programadores têm para controlar a distribuição dos dados de acordo com as necessidades da aplicação. Outros importantes parâmetros também podem ser definidos como o tamanho do bloco, o método de acesso, o mecanismo de comunicação, o modelo de consistência de memória, etc.

A abstração de memória compartilhada é obtida da seguinte forma, de acordo com a camada onde está implementado o sistema DSM [Nitzberg and Lo, 1991]:

1. Implementações por hardware que estendem as técnicas tradicionais de $c a$ ching para arquiteturas escaláveis. Esse é o esquema DSM mais integrado, já que faz uso de hardware especializado para gerenciamento DSM.

2. Implementações por sistemas operacionais que alcançam o compartilhamento e a coerência através de mecanismos de gerenciamento de memória virtual.

3. Implementações por compilador/biblioteca onde os acessos compartilhados são convertidos automaticamente em primitivas de sincronização e coerência.

\subsection{Decisões de Projetos}

As dificuldades intrínsecas aos DSM's podem ser verificadas em implementações

de alguns sistemas. É muito interessante verificar como os projetistas lidam com 
questões como estrutura, granulosidade, acesso, semântica da coerência, escalabilidade e heterogeneidade.

Nessa seção, tais dificuldades são descritas e discutidas brevemente.

\subsubsection{Estrutura e granulosidade}

A estrutura e a granulosidade de um DSM estão relacionadas. A estrutura referese à apresentação na memória dos dados compartilhados. A maioria dos sistemas DSM's não estruturam a memória, a implementando simplesmente como um array de palavras. Outros sistemas utilizam uma estrutura de objetos, tipos de linguagem ou até memória associativa.

A granulosidade refere-se ao tamanho da unidade de compartilhamento: byte, palavra, página de memória ou uma estrutura de dados mais complexa.

Ivy [Li and Hudak, 1989], um dos primeiros DSM's transparentes, implementa a memória compartilhada como memória virtual. Essa memória era não estruturada e compartilhada por páginas de 1 Kbytes. Em sistemas implementados usando hardware de memória compartilhada da arquitetura subjacente, é conveniente escolher um número que seja múltiplo do tamanho da página como unidade de compartilhamento.

O sistema Mirage [Fleisch and Popek, 1989] estendeu a idéia de um único espaço de memória compartilhada para dar suporte ao esquema de segmentação paginada. Os usuários compartilham segmentos, que são regiões da memória que possuem tamanho arbitrário, enquanto que o sistema mantém o espaço compartilhado em páginas.

As implementações por hardware de DSM's compartilham unidades de granulosidade mais fina. Por exemplo, Dash [Lenoski et al., 1990] e Memnet [Delp, 1988] oferecem um compartilhamento não estruturado, mas a unidade de compartilhamento é de 16 e 32 bytes, respectivamente.

Por causa da localidade de referência presente nos programas de memória compartilhada, um processo tem mais chances de efetuar acessos uma região do seu espaço de endereçamento em um pequeno intervalo de tempo. Portanto, páginas 
maiores reduzem mais a sobrecarga de paginação. Por outro lado, isso também provoca contenção, pois quanto maior a página, maior é a probabilidade de mais de um processo acessá-la.

Uma página menor reduz a possibilidade de falso compartilhamento, que ocorre quando duas variáveis não relacionadas entre si estão localizadas na mesma página que aparecerá como compartilhada. Outro fator que afeta a escolha do tamanho da página é a manutenção de informações do diretório de páginas: quanto menor o tamanho de página, maior é o diretório.

Continuando com a descrição da estruturação da memória, vamos discutir a estruturação baseada em tipos de dados. Através desse método, a memória é estruturada como objetos em sistemas distribuídos orientados a objetos como Emerald e Clouds; ou como variáveis na linguagem fonte, como nos sistemas Shared DataObject Model e Munin. Por causa da grande variação do tamanho dos objetos e tipos de dados, a granulosidade varia de acordo com a aplicação. Mesmo sendo mais estruturados, esses sistemas ainda sofrem com o falso compartilhamento quando acessos a partes diferentes de um mesmo objeto são efetuados por processos distintos.

Outro método de estruturação é utilizado pelo Linda [Carriero and Gelernter, 1990]. É utilizado um modelo que estrutura a memória como se fosse um banco de dados, ordenando a memória compartilhada como uma memória associativa chamada espaço de tuplas. Essa estrutura permite que a localização de dados seja separada do seu valor, mas requer que os programadores utilizem funções de acesso especiais para interagir com o espaço de memória compartilhada, não oferecendo a transparência que está presente na maioria dos demais sistemas.

\subsubsection{Semântica da coerência e consistência}

Para que os programadores escrevam programas corretos em uma máquina de memória compartilhada, eles devem entender como as atualizações de memória são propagadas pelo sistema.

Para que o conjunto de caches locais que mantém os dados compartilhados, 
ofereça uma visão coerente de uma única memória é necessário um mecanismo de propagação dos valores recentemente escritos. A idéia mais intuitiva para a coerência da memória é a uma operação de leitura retornar sempre o valor escrito mais recentemente [Shi et al., 1998].

O problema é que "mais recente" em sistemas distribuídos é um conceito ambíguo. A ausência de um relógio global ao sistema impõe sérias dificuldades na obtenção de uma ordenação total dos eventos [Lamport, 1979]. Por essa razão e para melhorar o desempenho, alguns DSM's oferecem somente uma forma reduzida de coerência de memória.

A memória é dita coerente quando o sistema assegura que os dados compartilhados modificados por uma operação de escrita é acessível pelas operações de leitura, independente da localização dos processos lendo ou escrevendo os dados. A coerência da memória é desejável porque ao se permitir acessos a dados desatualizados, os mesmos podem levar a resultados de execução incorretos. Os protocolos de coerência da memória são métodos de propagação das mudanças para os dados compartilhados e replicados nos vários sítios.

Como exemplo de protocolos temos o Write-Invalidate (WI), Write-Broadcast (WB) [W. Hu and Tang, 1998]. Nos protocolos WI, sempre que um bloco é atualizado, todas as cópias nas caches dos demais nós deve ser invalidada. De forma análoga, no protocolo WB ocorre o envio de um bloco para todos os nós sempre que houver uma atualização ao mesmo. Um protocolo de coerência de cache é um mecanismo de propagação de atualizações para que seja mantida uma abstração de uma única memória compartilhada coerente.

Mas somente a coerência não garante que os dados estejam consistentes, pois somente são considerados diferentes eventos de diferentes processadores para uma mesma localidade, não é feita nenhuma restrição quanto a ordenação desses eventos, para essa finalidade é necessário um mecanismo que ofereça consistência de memória . Quando o acesso à memória compartilhada é controlado ou ordenado por mecanismos de sincronização tais como semáforos e locks, nós dizemos que a memória é consistente. Ao permitir que um processo leia dados que no mo- 
mento estão sendo atualizados por outro processo, corre-se o risco de destruir a consistência ou integridade da memória.

O conjunto dos acessos a memória permitidos forma o modelo de consistência. De forma bastante resumida, Shi [Shi et al., 1998] propõe a seguinte relação entre o modelo de consistência e o protocolo de coerência: o modelo de consistência, através do protocolo de coerência, propaga um novo estado da memória e, por meio da ordenação dos eventos, ele define quando esse novo estado será visível para os demais processadores. Esquematicamente:

modelo de consistência $=$ protocolo de coerência + ordenação de eventos em cada processador

Abaixo segue a descrição de alguns modelos de consistência. Para informações mais detalhadas são sugeridos [Shi et al., 1998, Marino, 2001, Buyya, 1999]:

1. Consistência estrita: uma leitura retorna o valor escrito mais recentemente.

2. Consistência seqüencial: o resultado de qualquer execução aparece como uma intercalação de operações de nós individuais quando executado em uma máquina seqüencial multithreaded, ou seja, um sistema está seqüencialmente consistente quando os acessos à memória compartilhada são ordenados de tal modo que todas as operações enxergam a cópia mais atualizada do dado compartilhado [Lamport, 1979].

3. Consistência de processador: as escritas de cada nó nunca são enviadas fora de ordem, mas a ordem de escrita pode ser observada de modo diferente.

4. Consistência fraca: o programador força a consistência usando operadores de sincronização que são garantidamente seqüencialmente consistentes.

5. Consistência de liberação: consistência fraca com dois tipos de operadores de sincronização: obtém (acquire) e libera (release).

6. Consistência de liberação relaxada: a propagação das modificações é postergada até o momento da operação de acquire. Um processo que faz tal operação garantidamente terá acesso a todas as modificações anteriores. 
7. Consistência de entrada: esse modelo difere-se do anterior ao associar variáveis compartilhadas a locks e barreiras e no momento da operação acquire determina muito mais rapidamente quais variáveis necessita.

A semântica de consistência relaxada permite acessos compartilhados mais efi-

cientes pelo fato de requerer menos sincronização e movimentação de dados. É bom observar que a adequação de um modelo de consistência depende dos requisitos da aplicação, pois um programa que depende de uma forma mais forte de coerência não executará corretamente em um sistema que apresenta somente uma forma mais fraca.

Um sumário dos modelos adotados em diversos sistemas é apresentada na Tabela 2.1.

\subsubsection{Escalabilidade}

Um benefício teórico dos sistemas DSM é que eles apresentam uma escalabilidade melhor que os multiprocessadores de memória compartilhada fortemente acoplados. Na prática, os limites de escalabilidade são reduzidos consideravelmente por dois fatores: gargalos centralizados, tal como um barramento dos multiprocessadores fortemente acoplados; e operações que necessitam de conhecimento global, como por exemplo, difusão ou armazenamento de diretórios que devem ser proporcionais ao número de nós.

\subsubsection{Heterogeneidade}

À primeira vista, o compartilhamento de memória entre duas máquinas com arquiteturas diferentes parece impossível. As máquinas podem nem ter a mesma representação para tipos de dados básicos.

Fica um pouco mais fácil quando um sistema DSM é estruturado em variáveis ou objetos na linguagem fonte. Dessa forma, um compilador pode adicionar rotinas de conversão para todos os acessos à memória compartilhada. O sistema Agora 


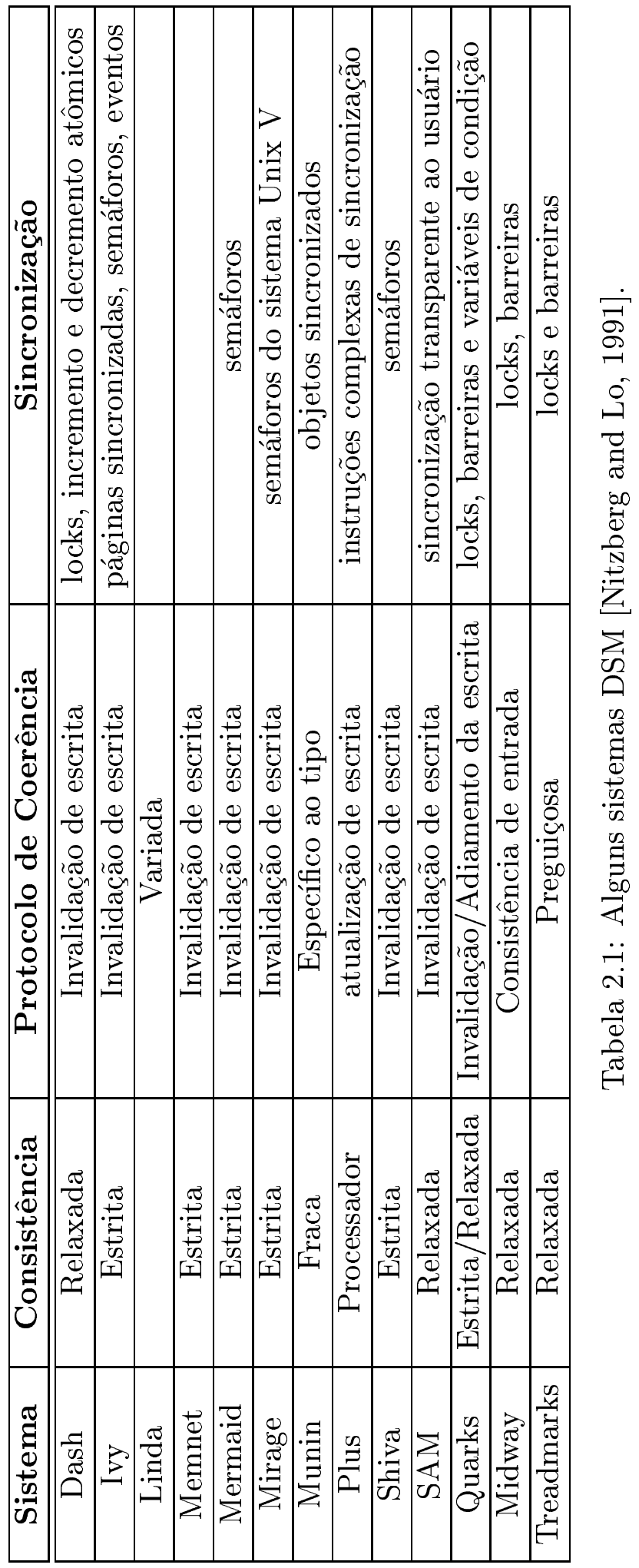


[Bisiani and Forin, 1988] trabalha sobre essa abordagem estruturando a memória em objetos compartilhados entre máquinas heterogêneas.

O sistema Mermaid [Zhu et al., 1992] utiliza o compartilhamento de páginas, onde cada página só pode conter um único tipo de dados. Sempre que uma página é movida, rotinas de conversão colocam os dados em um formato apropriado.

Apesar da heterogeneidade permitir que um número maior de máquinas participem de uma computação, constitui-se um desafio não impor uma grande sobrecarga da conversão, pois senão a mesma ultrapassará o benefício obtido.

\subsection{Implementações}

Um sistema DSM deve transformar automaticamente um acesso à memória compartilhada em comunicação inter-processo. Isso implica na localização e no acesso aos dados compartilhados, na manutenção da coerência e no deslocamento de dados. Um sistema DSM deve também ter esquemas adicionais para aumentar o desempenho. Além de tudo isso, os implementadores de DSM's que estão em camadas mais baixas devem moldar o sistema operacional para que dê suporte à sincronização de processos e gerenciamento da memória.

\subsubsection{Acesso e localização de dados}

Para compartilhar dados em um DSM, um programador deve poder encontrar e recuperar os dados que necessita. Se os dados não se deslocam pelo sistema e ocupam sempre uma única posição estática, eles são de fácil localização. As vantagens da localização estática são a simplicidade do esquema e a rapidez de acesso, mas apresenta a desvantagem de constituir um gargalo do sistema se os dados não são distribuídos de maneira apropriada.

Uma solução seria a migração automática dos dados do sistema, redistribuindo dinamicamente de acordo com a utilização, porém implicaria no encarecimento das operações de localização e acesso dos dados. O esquema mais simples para o caso de distribuição dinâmica é ter um controlador centralizado para manter a 
informação sobre todos os dados compartilhados, mas isso constituiria um gargalo que diminuiria o paralelismo e aumentaria a lentidão do sistema.

Ao invés de adotar essa solução, existe a possibilidade de se fazer a difusão de requisições de dados, mas além de não apresentar uma escalabilidade boa, os acessos seriam demorados, pois todos os nós, mesmo aqueles que não contém o dado, teriam que processar a mensagem de requisição.

\subsubsection{Protocolo de coerência}

Todos os sistemas DSM oferecem alguma forma de consistência da memória. Se os dados compartilhados não são replicados, a manutenção da consistência é trivial, assegurando uma forma estrita de consistência. Nesse esquema, um nó que mantém um dado compartilhado processa cada acesso na sequência que foi recebido. Infelizmente, essa serialização dos acessos aos dados cria um gargalo e prejudica a maior vantagem de um DSM que é o paralelismo.

Para aumentar esse paralelismo, os DSM's replicam os dados de maneira que várias leituras sejam executadas simultaneamente. A complicação de se manter a consistência é o preço que se paga pela maior disponibilidade dos dados.

Dois protocolos lidam com o problema da coerência das cópias: o da invalidação de escrita (write-invalidate) e o da atualização de escrita (write-update). No protocolo de invalidação de escrita, é possível ter muitas cópias de um dado que é somente de leitura, mas somente uma cópia para dado que é atualizável. O protocolo invalida todas as cópias, com a exceção de uma antes de uma operação de escrita prosseguir.

No esquema de atualização de escrita, uma operação de escrita atualiza todas as cópias de um dado, por isso esse algoritmo também é conhecido por ROWA (Read One, Write All). Essa idéia é bastante adequada para aplicações que apresentam um número muito superior de operações de leitura em relação as de escrita.

Li e Hudak [Li and Hudak, 1989] mostram que o protocolo de invalidação é mais adequado para uma grande variedade de aplicações. Eles rejeitaram o uso 
do protocolo de atualização de escrita com o raciocínio que a latência da rede o tornaria ineficiente. Trabalhos posteriores indicaram que o protocolo de atualização de escrita pode ser implementado eficientemente em ambientes de hardware apropriados, como é o caso do sistema Plus [Bisiani and Ravishankar, 1990].

\subsection{Alguns trabalhos relacionados}

Alguns trabalhos deram-nos valiosas direções no nosso estudo e justificam muitas decisões tomadas durante a elaboração do sistema. Eles serão discutidos nas seções seguintes.

\subsubsection{Protocolo Home-based para nós SMP}

Esse trabalho apresenta resultados interessantes quanto à exploração do desempenho em máquinas multiprocessadoras. São colocados protocolos SVM (Shared Virtual Memory) que suportam nós simétricos multiprocessadores (SMP, symetric multiprocessor). Além disso são apresentados os compromissos chave do projeto, sendo também discutidas as escolhas feitas. Como complemento é apresentada uma implementação sobre uma rede de 4 SMP's quad Intel Pentium Pro interconectados com Myrinet, bem como seus resultados de desempenho.

O HRLC-SMP (Home-based Protocol para nós SMP) busca o compartilhamento de hardware e um esquema preguiçoso (lazy) da seguinte forma. O compartilhamento do hardware e boa parte da sincronização é obtida através do compartilhamento de um espaço físico de endereçamento por todos os processos em um SMP. O aspecto preguiçoso desse modelo é implementado através de tabelas de páginas locais a cada processo.

O esquema de memória hierárquica em dois níveis nos parece bastante interessante. De um lado temos uma tabela compartilhada na memória pelos vários processadores de um SMP, sendo gerenciada pelo hardware de memória, fornecendo, assim, um melhor desempenho. Dessa forma, apenas uma cópia da tabela é mantida em um nó multiprocessador, o que facilita a atualização de cópias no 
sistema e diminui o tráfego gerado. Na outra camada estão tabelas que mantém informações locais e necessárias a cada processo, solução essa que simplifica o gerenciamento e agiliza o acesso.

As questões da heterogeneidade e tolerância a defeitos, também não são tratadas nesse trabalho. Outra grande diferença entre a nossa proposta e o trabalho apresentado em [Samanta et al., 1998] é a camada onde é implementado o DSM: na nossa abordagem pretendemos tratar o problema na camada de linguagemcompilador/biblioteca, ou seja é um DSM baseado em estrutura. No trabalho de Samanta et al. isso é feito através de mecanismos de gerenciamento de memória, o sistema é baseado em bloco.

Nossa escolha justifica-se principalmente pela heterogeneidade buscada no ambiente a ser desenvolvido, característica que torna-se inviável de ser implementada pela estratégia adotada em [Samanta et al., 1998].

\subsubsection{Nomad}

Nomad [Pinheiro and Bianchini, 1998] é uma ferramenta desenvolvida na UFRJ. Trata-se de um sistema operacional distribuído para clusters de estações uni e multiprocessadores que oferece características necessárias a um sistema operacional moderno, tais como: escalabilidade, escalonamento de aplicações, entrada e saída distribuídas, detecção e recuperação de falhas, distribuição da demanda por recursos do cluster, proteção entre processos e compatibilidade retroativa.

Em cada estação do cluster, o sistema está constituído de uma versão modificada de Linux, de um deamon e dois aplicativos. Segundo os autores, o número de modificações no núcleo do Linux foi pequeno, mas isso faz com que o sistema não seja portável e não dê suporte a plataformas heterogêneas.

Nossa proposta beneficia-se do fato que a camada onde será implementada, é o nível de compilador/biblioteca. Sistemas feitos no nível de hardware ou de sistema operacional apresentam uma rigidez maior, como discutido no Capítulo 2. 


\subsubsection{SCore e Omni OpenMP}

O consórcio japonês PC Cluster [Consortium, 2002], estabelecido em maio de 2001 e atualmente formado por mais de trinta empresas, controla dois grandes projetos na área do processamento paralelo para alto desempenho: SCore, um ambiente de programação paralela e Omni OpenMP, um DSM baseado em compilador para clusters de SMPs.

\section{SCore}

O sistema SCore [Tanaka et al., 1999] é um ambiente de programação paralela para estações de trabalho e clusters de PCs. O primeiro protótipo data de meados da década de 90 e atualmente está sendo mantido pelo consórcio citado. Atualmente, oferece as seguintes características:

- Abstração de memória compartilhada

- Variados paradigmas de programação: passagem de mensagem, memória compartilhada e multithreaded.

- Suporte à linguagem $\mathrm{MPC}++$.

- Suporte à programação: monitoração de atividade, detecção de deadlock e depuração.

- Escalonamento de tarefas.

- Migração de processos.

Para oferecer as características citadas vários componentes foram desenvolvidos e são sinteticamente descritos. PMv2 é uma biblioteca de comunicação que oferece drivers para Myrinet, Ethernet, UDP, Shmem. Existe um sistema operacional SCore-DP (Linux alterado). O SCASH é um DSM que implementa o modelo de consistência relaxada preguiçosa. 
Sobre essas camadas de software básico existe uma camada de comunicação com implementações do MPI e do PVM para esse sistema, respectivamente MPICHSCore e PVM-SCore. O programador para trabalhar sobre esse sistema utiliza a linguagem $\mathrm{MPC}++$, uma variação multi-threaded da linguagem $\mathrm{C}++$.

\section{O compilador Omni OpenMP}

O compilador Omni OpenMP [Sato et al., 1999] traduz programas em C e Fortran77 em código C com diretivas do OpenMP [OpenMP, 2003] para que depois seja feita a compilação desse código com um compilador nativo e seja ligado com a biblioteca em tempo de execução Omni OpenMP.

Para que seja possível compilador OpenMP para cluster de SMPs, estava em desenvolvimento. Trata-se de um DSM por estrutura que através da compilação e de um sistema em tempo de execução tenta otimizar a comunicação entre nós SMP de um cluster.

O modelo de programação paralela do OpenMP é voltado para máquinas de memória compartilhada. Para que programas em OpenMP sejam executados nesse sistema sobre uma plataforma distribuída, deve-se usar o DSM SCASH, um dos componentes do sistema SCore apresentado na seção anterior.

\subsubsection{O compilador e o ambiente de execução para lingua- gem $\mathrm{CxC}$}

A linguagem $\mathrm{CxC}$ (pronuncia-se $C$ by $C$ ) é uma variação paralela da linguagem $\mathrm{C}$

e foi desenvolvida pela empresa Engineered Intelligence [I., 2003]. Atualmente a empresa provê um compilador em um sistema de execução para essa linguagem.

A proposta é prover a execução de um programa escrito em $\mathrm{CxC}$ sobre uma rede composta por clusters formados por máquinas heterogêneas no número de processadores, no sistema operacional e na arquitetura.

Para isso deve ser instalado o sistema de execução da linguagem em cada nó, que implementa um DSM como um micronúcleo. Infelizmente não são oferecidas 


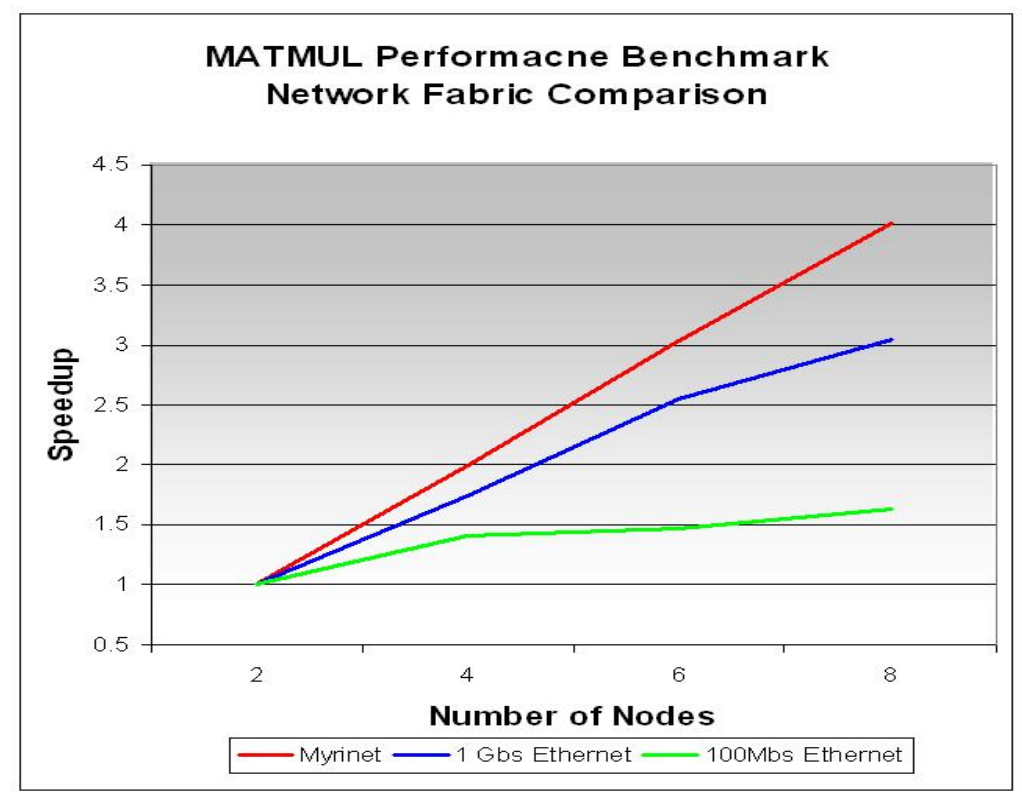

Figura 2.1: Speedup da multiplicação de matrizes no ambiente CxC [I., 2003].

informações detalhadas da arquitetura do software e nem das estratégias empregadas.

Na página web da empresa é possível obter informações adicionais. Atualmente a versão padrão do produto permite até 16 nós conectados e a versão profissional permite até 1024. Outra informação fornecida relaciona-se ao desempenho desse produto em um benchmark de multiplicação de matrizes, executado em oito nós monoprocessadores. O ganho de performance obtido é ilustrado na Figura 2.1.

\subsubsection{Desafios}

A idéia de implementar um espaço de endereçamento sobre uma rede de computadores já foi proposta a um certo tempo, como citado no Capítulo 1. Desde o início, os pesquisadores da área tiveram que lidar com sérias questões que afetavam o desempenho de tais sistemas: problemas com a granulosidade de coerência que podem levar ao falso compartilhamento ou à fragmentação, custo de cada operação de comunicação, sincronização cara feita com troca de mensagens, falta de página e a sobrecarga gerada pelo processamento do protocolo.

Basicamente, três camadas afetam o desempenho de um DSM: a aplicação, 
protocolo/modelo e a arquitetura de comunicação. Para aumentar o desempenho, vários trabalhos foram propostos e concentram-se principalmente nas duas últimas camadas:

- redução do tráfego e freqüência da comunicação através de novos modelos de consistência relaxada e implementações de protocolos;

- redução dos custos de comunicação através de suporte adicional de hardware na arquitetura de comunicação.

Tem-se chegado a uma certa maturidade de protocolos, direcionando-se agora os esforços da comunidade científica para a camada de aplicação e para a sinergia entre as camadas. Novas áreas estão sendo enfocadas, tais como [Iftode and Singh, 1999]: avaliação de desempenho direcionado à aplicação; reestruturação da aplicação para DSM e portabilidade de desempenho para diversas plataformas; melhorias no protocolos direcionadas aos gargalos de aplicações reais; interações de protocolo e sinergia com suporte da arquitetura; ferramentas de software para aumentar a programabilidade.

Mais especificamente sobre a pesquisa de DSM por software, importantes direções apontam para:

- comparação de DSM com recentes abordagens de software de memória compartilhada com granulosidade fina que não dependam tanto de modelos de consistência relaxada;

- utilização de nós multiprocessadores ao invés de nós monoprocessadores;

- escalabilidade.

\section{DSM por software de granulosidade fina}

Em [Iftode and Singh, 1999] há uma discussão sobre um estudo que compara abordagens de granulosidade fina e de página usando quatro protocolos de consistência diferentes em um variado conjunto de aplicações. 
Alguns resultados apontam que a reestruturação da aplicação ajudam em muito o desempenho, mas é necessário uma pesquisa adicional para determinar qual abordagem é superior (geralmente uma banda passante maior e custos de passagem de mensagem favorecem DSM's enquanto que uma latência mais baixa favorece uma abordagem de granulosidade fina).

\section{Utilização de aglomerados de computadores multiprocessadores}

A crescente facilidade de construção de clusters de máquinas multiprocessadoras, demanda por pesquisas que confirmem ou não a expectativa de aumento de desempenho do DSM sobre essa plataforma. Intuitivamente vê-se o ganho, pois em multiprocessadores a coerência e a sincronização são feitas via hardware.

Verificamos pelas tendências apresentadas (a granulosidade fina e utilização de clusters de máquina mono e multiprocessadoras), que nosso ambiente se encaixa nas direções apontadas pelos autores. 


\section{Capítulo 3}

\section{A Linguagem CPAR}

Muitos trabalhos influenciaram a proposta do sistema de programação com o paradigma de variáveis compartilhadas em sistemas distribuídos heterogêneos. Nesse capítulo, os mais marcantes serão descritos.

Historicamente, a linguagem CPAR [Sato, 1991] deu origem a trabalhos que tiveram como finalidade prover um sistema de execução para seu suporte. Ela foi projetada visando oferecer construções simples para a exploração do paralelismo em múltiplos níveis e permitindo a otimização do uso de localidade de memória.

Foram desenvolvidos uma biblioteca de rotinas e um pré-compilador que constituem o sistema de programação para a linguagem CPAR para computadores de memória compartilhada e que implementam as construções oferecidas pela linguagem.

A partir da linguagem de programação CPAR, numerosos projetos surgiram e um deles foi a proposição de um sistema de programação e processamento sobre uma rede heterogênea de computadores.

Posteriormente, a proposta recebeu algumas alterações e foi implementada sobre o sistema de comunicação PVM (Parallel Virtual Machine)[Iguma, 1997].

Os trabalhos mencionados constituem parte importante do núcleo do sistema proposto neste trabalho de doutorado e serão detalhados nas Seções 3.1(a CPAR), 3.2.1 (sistema para máquina de memória compartilhada), 3.2.2 (sistema para rede heterogênea) e 3.2.3 (implementação sobre o PVM). 


\subsection{A Linguagem CPAR}

A linguagem CPAR é uma extensão paralela da linguagem $\mathrm{C}$ que emprestou alguns elementos das linguagens Concurrent $\mathrm{C}$ e da ADA, tais como um modelo de programação de multitarefas e de passagem de mensagem.

\subsubsection{Granulosidade do paralelismo}

O modelo de programação da linguagem CPAR dá suporte a vários níveis de paralelismo, desde a granularidade mais grossa como a dos blocos e macrotarefas até a granularidade fina presente em laços paralelos. Nesse modelo estão presentes os seguintes elementos [Sato, 1991]:

- elemento seqüencial: porção de comandos executados seqüencialmente.

- macrotarefa: porção de código, no nível de subrotina, que pode ser executada simultaneamente a outras macrotarefas.

- microtarefa: nível mais fino de paralelismo seja nas iteração de um laço executadas simultaneamente, seja em um bloco de comandos que é executado paralelamente a outros blocos.

- blocos paralelos: porções do código da função principal que são executadas paralelamente.

- função principal do programa.

Nas próximas subseções serão resumidamente apresentadas as construções da linguagem CPAR.

\subsubsection{Blocos Paralelos}

Nessa construção da linguagem, vários blocos de comandos podem ser executados paralelamente. Cada bloco pode combinar comandos seqüenciais, chamadas a macrotarefas e blocos paralelos aninhados. A sintaxe é descrita na Figura 3.1. 


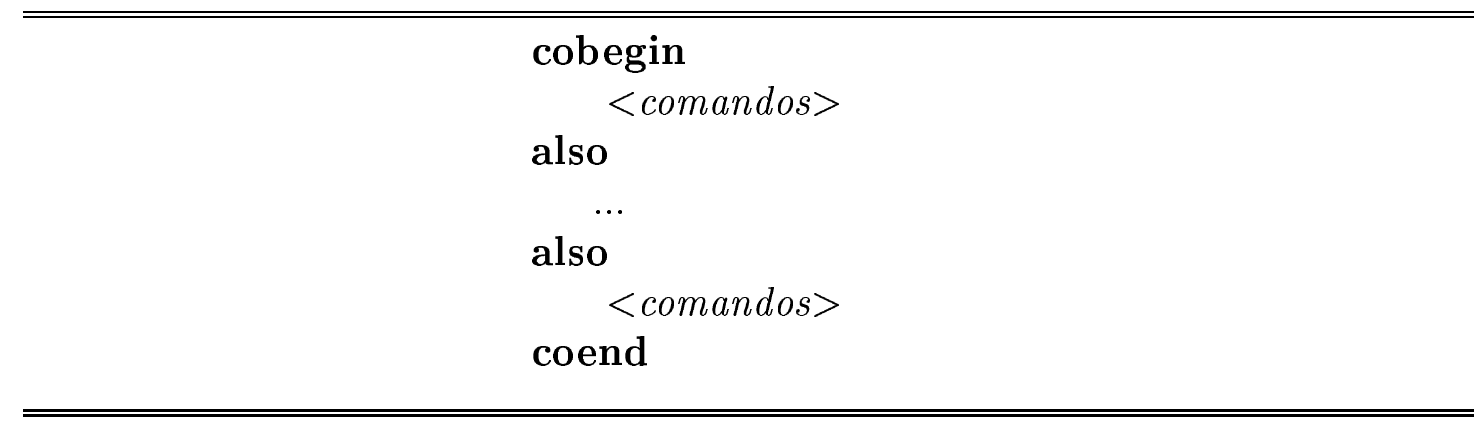

Figura 3.1: Sintaxe da construção cobegin-coend.

\subsubsection{Macroblocos}

Essa estrutura apresenta um grão de paralelismo grosso, no nível de programa. Ela pode conter blocos paralelos, macrotarefas e trechos seqüenciais. Um macrobloco pode ser referenciado somente dentro da função principal do programa (main()) e em outros macroblocos. A Figura 3.2 ilustra sua sintaxe geral.

\begin{tabular}{l}
\hline \hline $\begin{array}{l}\text { block <nome do bloco }> \\
\{<\text { declaraçôes de variáveis }> \\
<\text { comandos }>\end{array}$ \\
$\ldots$ \\
\hline
\end{tabular}

Figura 3.2: Sintaxe de macrobloco.

\subsubsection{Macrotarefas}

Como definido na Seção 3.1.1, uma macrotarefa apresenta a granularidade de paralelismo de uma subrotina. Além desse nível de paralelismo entre macrotarefas, ainda é oferecido o paralelismo intra-macrotarefa através de chamadas a microtarefas, que serão apresentadas na Seção 3.1.5.

As sintaxes de especificação, composição e ativação de uma macrotarefa, também conhecida por task, são descritas nas Figuras 3.3, 3.4 e 3.5, respectivamente. 
task spec < nome da macrotarefa $>(<$ parâmetros $>)$;

$\{<$ declaração das entradas $>\}$

Figura 3.3: Sintaxe de especificação de uma macrotarefa.

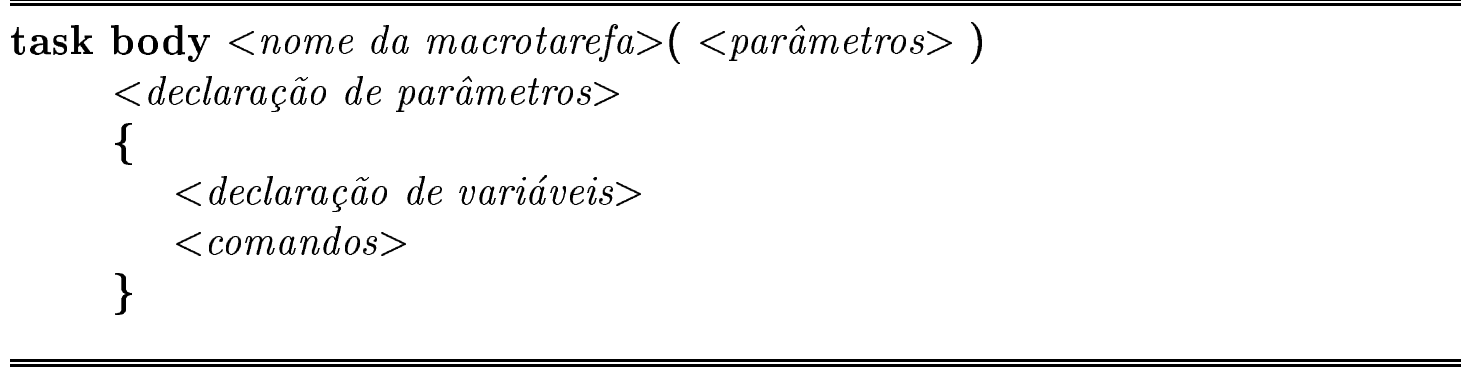

Figura 3.4: Sintaxe do corpo de uma macrotarefa.

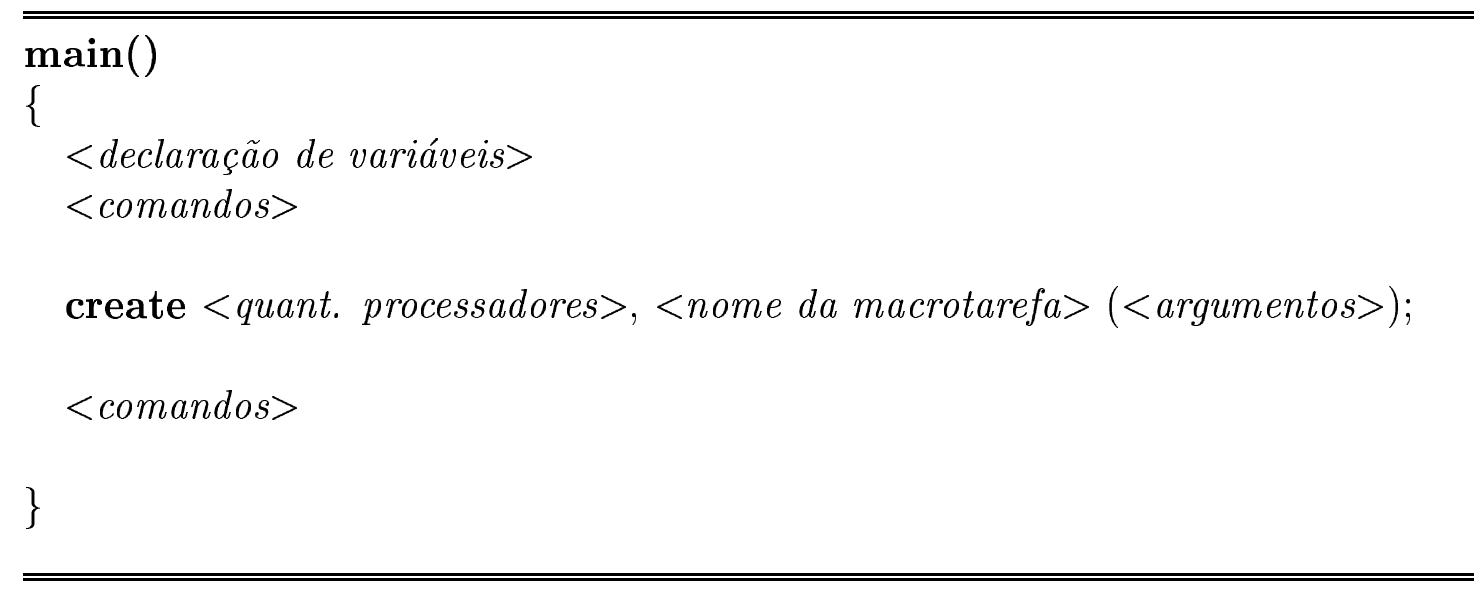

Figura 3.5: Sintaxe de ativação de uma macrotarefa. 


\subsubsection{Microtarefas}

A microtarefa oferece o nível mais fino de paralelismo da linguagem CPAR. De acordo com o código executado esse paralelismo pode ser:

- homogêneo, onde instruções iguais operam sobre dados distintos;

- heterogêneo, diferentes instruções são executadas.

No paralelismo homogêneo, presente no comando forall, as instruções são executadas pelo processadores aos quais foi atribuída a macrotarefa onde insere-se o laço paralelo. As iterações desse laço são divididas uniformemente entre eles sobre itens de dados distintos. A Figura 3.6 traz sua descrição.

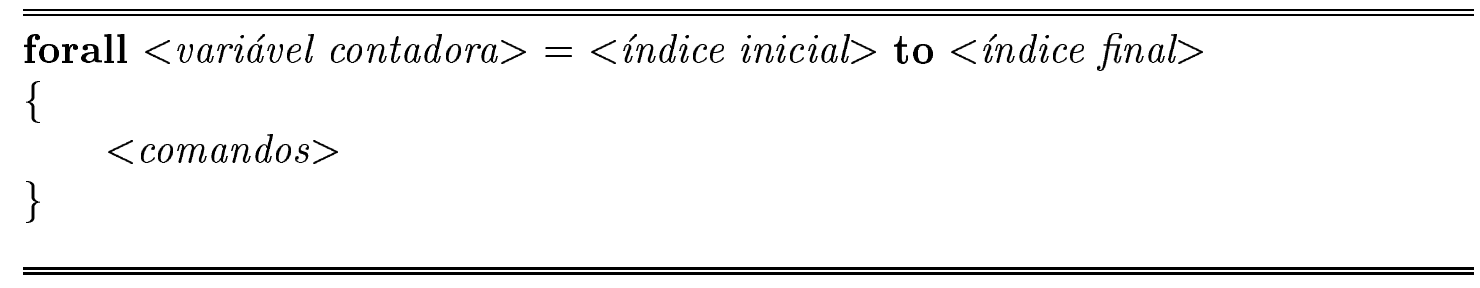

Figura 3.6: Sintaxe de um laço paralelo.

Para o caso do paralelismo heterogêneo, é oferecida a construção parbegin, onde várias microtarefas executam simultaneamente conjuntos distintos ou não de instruções. Sua sintaxe é descrita na Figura 3.7.

\begin{tabular}{l} 
parbegin \\
$<$ comandos $>$ \\
also \\
$\ldots$ \\
also \\
$<$ comandos $>$ \\
parend \\
\hline \hline
\end{tabular}

Figura 3.7: Sintaxe da construção parbegin-parend.

\subsubsection{Funções Paralelas}

Toda função que inclui construções paralelas, tais como blocos ou laços paralelos, deve ser declarada como uma função paralela. 


$$
<\text { tipo }><\text { nome da função }>() \text { par; }
$$

Figura 3.8: Sintaxe da declaração de função paralela.

As funções que referenciam funções paralelas devem ser declaradas de acordo coma sintaxe apresentada na Figura 3.9.

$$
<\text { tipo }><\text { nome da função }>() \text { spar; }
$$

Figura 3.9: Sintaxe da declaração de função que faz referência a uma função paralela.

\subsubsection{Variáveis Compartilhadas}

O identificador shared precedendo a declaração de uma variável indica que a mesma é compartilhada. A linguagem CPAR permite que o escopo seja global ou local. A sintaxe da declaração é ilustrada na Figura 3.10.

$$
\text { shared }<\text { tipo }><\text { nome da variável }>\text {; }
$$

Figura 3.10: Sintaxe da declaração de variável compartilhada.

As operações de criação, manipulação e remoção das variáveis compartilhadas globais e locais são transparentes ao programador.

Além das variáveis compartilhadas estáticas, a linguagem também oferece variáveis compartilhadas dinâmicas. Essas áreas de memória podem ser obtidas, associadas e liberadas segundo as primitivas apresentadas na Figura 3.11.

\subsubsection{Passagem de Mensagem}

A passagem de mensagem entre tarefas é realizada através de primitivas de envio e recebimento declaradas dentro da macrotarefa. Os comandos de envio, verificação e recepção de mensagens são ilustrados na Figura 3.12. 
$<$ identificador $>$ = cpar_shmget $(<$ tamanho em bytes $>)$;

//retorna um identificador que está associado a uma área compartilhada de tamanho em bytes.

$<$ endereço $>=$ cpar_shmat (<identificador $>$ );

//retorna um endereço,permitindo que um processo acesse esta área.

void cpar_shmdt (<endereço>);

//desassocia o processo à area obtida.

void cpar_shmrm (<identificador $>$ );

//libera a área de memória compartilhada.

Figura 3.11: Rotinas de manipulação de variável compartilhada dinâmica.

entry < nome da entrada> $<$ tipo da mensagem $>)$;

$/ /$ declaração de uma entrada.

send $<$ nome macrotarefa $>$. $<$ nome da entrada $>(<$ variável $>)$;

//envio de uma mensagem.

receive < nome da entrada>(<variável>);

$/ /$ recepção de uma mensagem.

state <nome da entrada>(<variável>);

//verificação de chegada de uma mensagem.

Figura 3.12: Primitivas de passagem de mensagem. 


\subsubsection{Mecanismos de Sincronização}

Os mecanismos de sincronização foram criados para que o acesso a recursos compartilhados não provoquem inconsistências na execução geral do sistema. Restringindo o acesso a um processo por vez à porção de código onde o recurso é utilizado, haverá uma execução mutuamente exclusiva no tempo e dessa forma resolve-se o problema da seção crítica.

Nas próximas subseções serão vistos alguns mecanismos oferecidos pela linguagem CPAR que implementam esse controle.

\section{Semáforos}

Um semáforo é uma variável inteira que, exceto na inicialização, somente é acessado por duas operações atômicas: lock e unlock. Quando esse contador assume o valor zero, indica que o recurso controlado por ele não está mais disponível, bloqueando assim todos os processos que estão tentando utilizá-lo. Esse bloqueio permanece até que o recurso seja liberado e o contador incrementado.

A linguagem CPAR oferece primitivas que criam, inicializam e removem semáforos, além das duas operações de bloqueio e desbloqueio mencionadas anteriormente. Na Figura 3.13 a sintaxe geral desses comandos é apresentada.

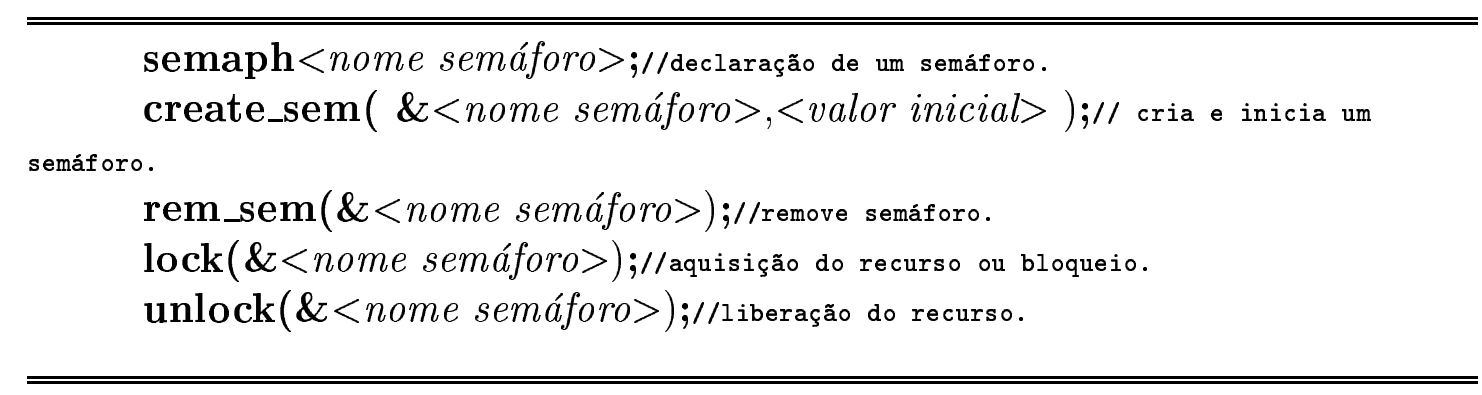

Figura 3.13: Primitivas de manipulação de semáforos.

\section{Eventos}

Um evento é uma variável que sinaliza para os processos a ocorrência de uma determinada condição que está sendo aguardada. A linguagem oferece primitivas 
para declarar, criar, remover eventos, além de manipulá-los através de atribuições, leitura e teste. A sintaxe das mesmas encontra-se na Figura 3.14.

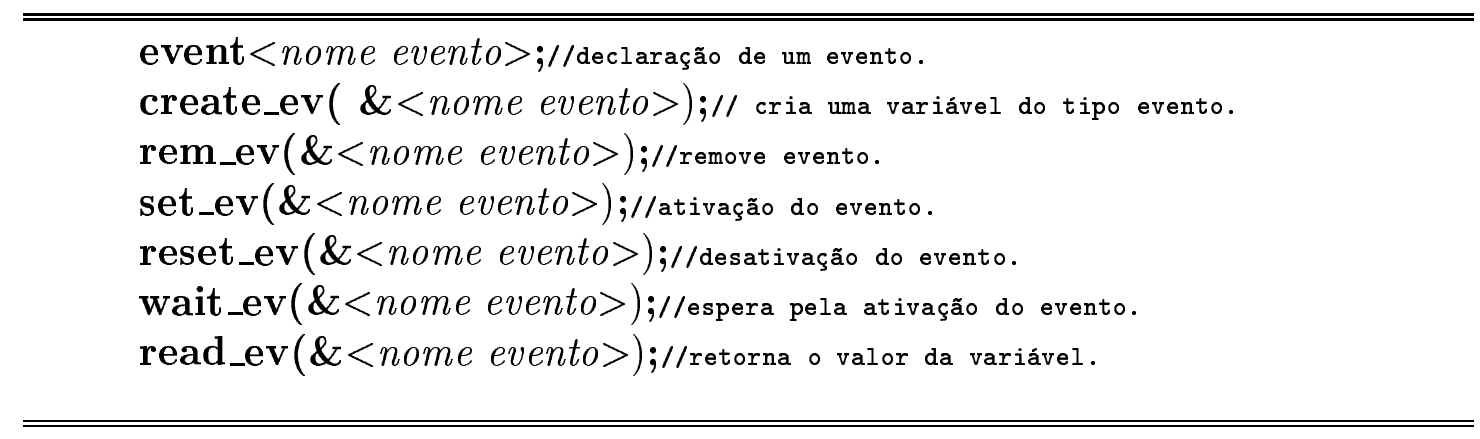

Figura 3.14: Primitivas de manipulação de eventos.

\section{Monitores}

Um monitor é mais uma construção de alto nível que provê a sincronização. Ele é caracterizado como uma coleção de estruturas de dados e de funções que operam sobre esses dados. Um monitor não pode ser ativado por vários processos simultaneamente, garantindo assim a propriedade de exclusão mútua. As variáveis declaradas no monitor somente podem ser referenciadas nesse escopo.

A linguagem CPAR oferece esse mecanismo, desde que observe-se a sintaxe da Figura 3.15 .

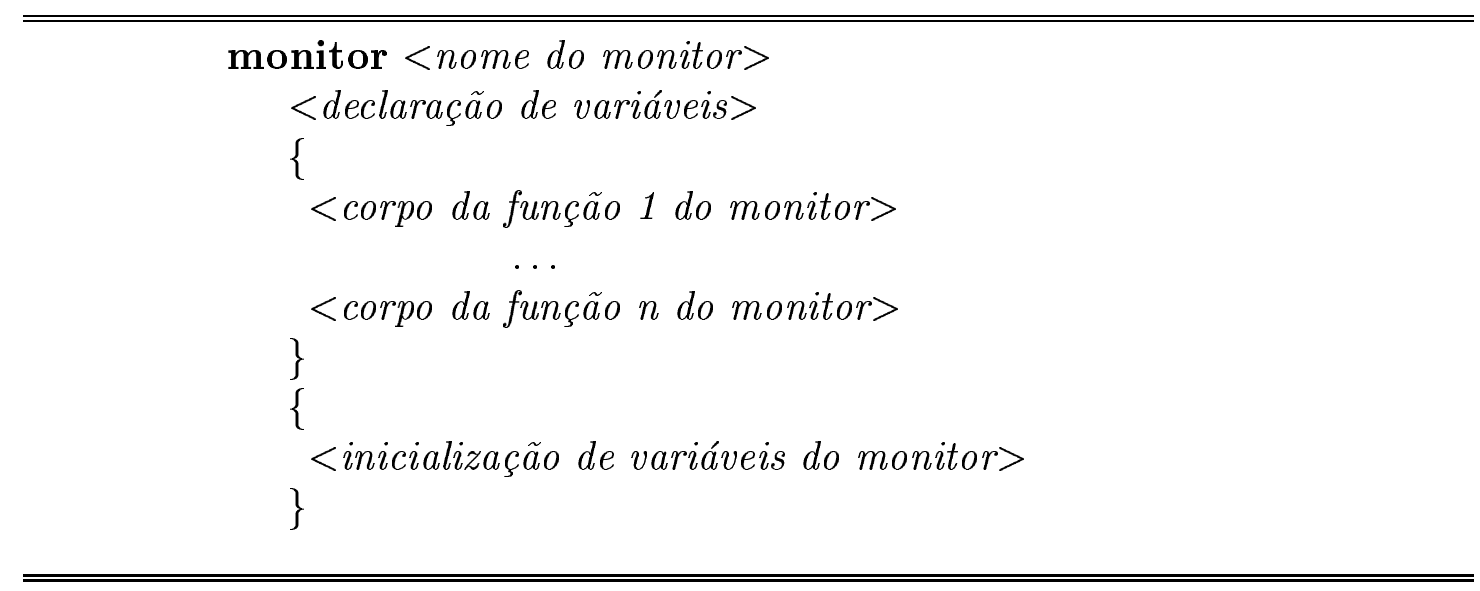

Figura 3.15: Sintaxe de monitor. 


\subsection{Sistemas de programação para CPAR}

Em [Sato, 1995] são propostos dois sistemas de programação e processamento para a linguagem CPAR: o primeiro é projetado para uma arquitetura de múltiplos processadores e memória compartilhada e a segunda abordagem propõe algumas estratégias para redes heterogêneas. As duas propostas serão discutidas nas Seções 3.2.1 e 3.2.2. Na Seção 3.2.3 é apresentada uma implementação da proposta para redes heterogêneas feita sobre PVM.

\subsubsection{Sistema de programação para memória compartilha-} da

O sistema CPAR para memória compartilhada constitui-se de:

- um pré-compilador que reconhece e trata as construções paralelas oferecidas pela linguagem, expandindo-nas com chamadas de rotinas da biblioteca e traduzindo-nas para código fonte $\mathrm{C}$;

- uma biblioteca de rotinas que gerencia o paralelismo através de chamadas ao sistema operacional e de funções internas ao sistema CPAR.

O programa executável é gerado através de qualquer compilador $\mathrm{C}$ disponível para a arquitetura onde será executada. Os passos de compilação de um programa fonte CPAR são apresentados na Figura 3.16.

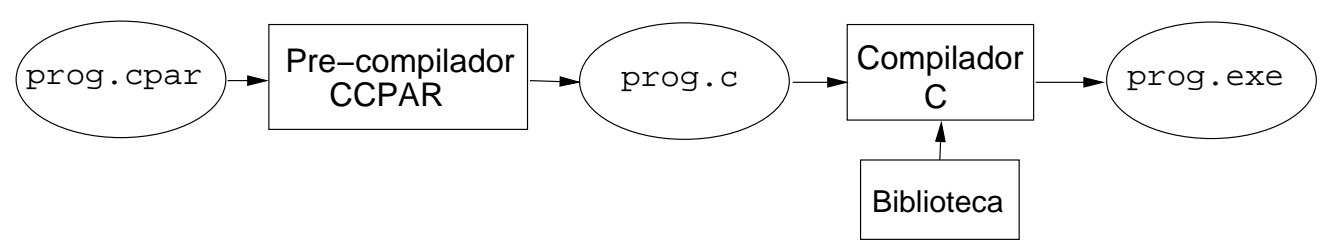

Figura 3.16: Compilação de um programa em CPAR. 


\subsubsection{Sistema de programação para multicomputadores he- terogêneos}

Esse sistema apresenta um modelo mestre-escravo de execução, ou seja, existe uma coordenação central que divide e distribui as tarefas e depois recebe e organiza os resultados parciais de cada escravo.

No modelo de execução proposto, um nó do sistema distribuído é composto pelas seguintes entidades:

\section{Memória Compartilhada}

Processo Principal: responsável pela execução do processamento em si.

Processo Comunicador: atualiza as variáveis e estruturas de controle do DSM.

Fila de Execução: área de memória compartilhada pelo principal e pelo comunicador. As identidades das tarefas a serem executadas são colocadas nessa fila.

As mensagens que circulam pelo sistema podem ser dos seguintes tipos:

- atualização de uma variável compartilhada;

- submissão de uma macrotarefa ou de um macrobloco à fila de execução;

- término de uma macrotarefa ou de um macrobloco.

- término de programa, o que força a liberação das estruturas envolvidas no nó executor.

A execução de uma macrotarefa é feita da seguinte forma. Primeiramente, os nós executores são escolhidos ou pelo usuário, através de um arquivo de distribuição que explicita quais tarefas devem executar em quais nós, ou pelo próprio sistema. Em um laço paralelo, as iterações são divididas uniformemente entre as microtarefas, às quais são atribuídos identificadores e posteriormente colocadas na fila de execução dos nós escravos designados. Após todas as providências de atualização das estruturas de controle e configuração do sistema, é iniciada a execução. 


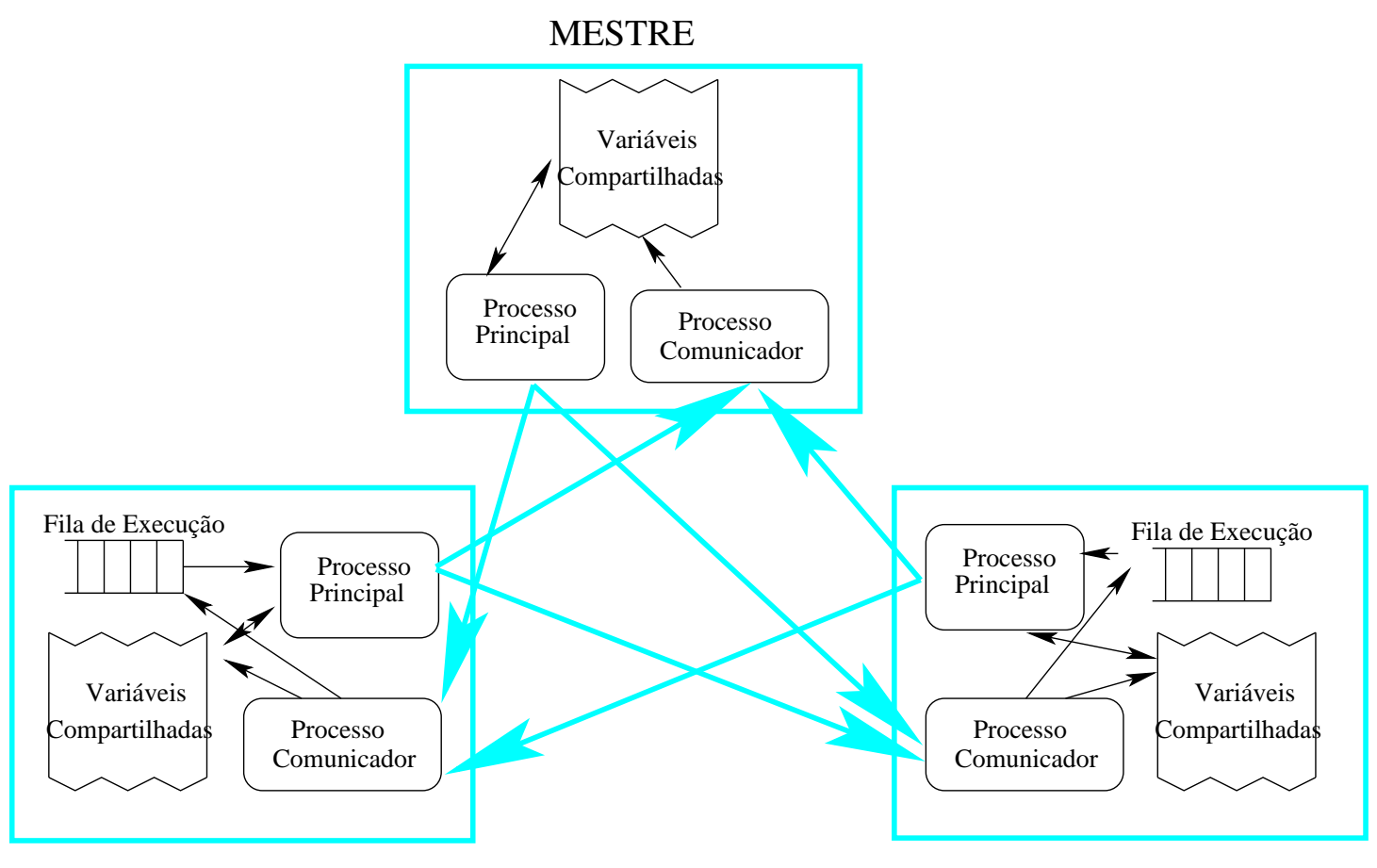

ESCRAVO 1

ESCRAVO 2

Figura 3.17: Modelo de execução proposto por Sato [Sato, 1995]

Os blocos paralelos recebem um tratamento similar aos laços paralelos, mas nesse caso a unidade de execução refere-se a um bloco.

Durante a execução de uma tarefa, são feitas atualizações às variáveis compartilhadas por todos os executores. Para manter a consistência, sem perdas significativas de desempenho causadas pelos custos de comunicação, foi escolhido o modelo de memória com consistência relaxada.

De acordo com a técnica, as atualizações são feitas em pontos estratégicos do programa, de forma que quando a variável for lida, a cópia local esteja atualizada. Para que leituras ou escritas concorrentes não provoquem um resultado inconsistente, toda atualização é feita no final da seção crítica. Os pontos de sincronização adotados para isso são: o final de uma iteração de um laço paralelo e o término de um bloco paralelo. 


\subsubsection{Sistema CPAR sobre PVM}

O modelo apresentado (Figura 3.17) é a base de outro modelo e implementação obtidos por Denise Iguma no seu trabalho de mestrado [Iguma, 1997]. A diferença com o modelo original está na adição de um processo enviador que, dessa forma, libera o processo principal da ocupação de envio de mensagens para outros nós. O enviador é responsável pelo empacotamento dos dados, entrega e controle do fluxo entre o processo principal e os comunicadores.

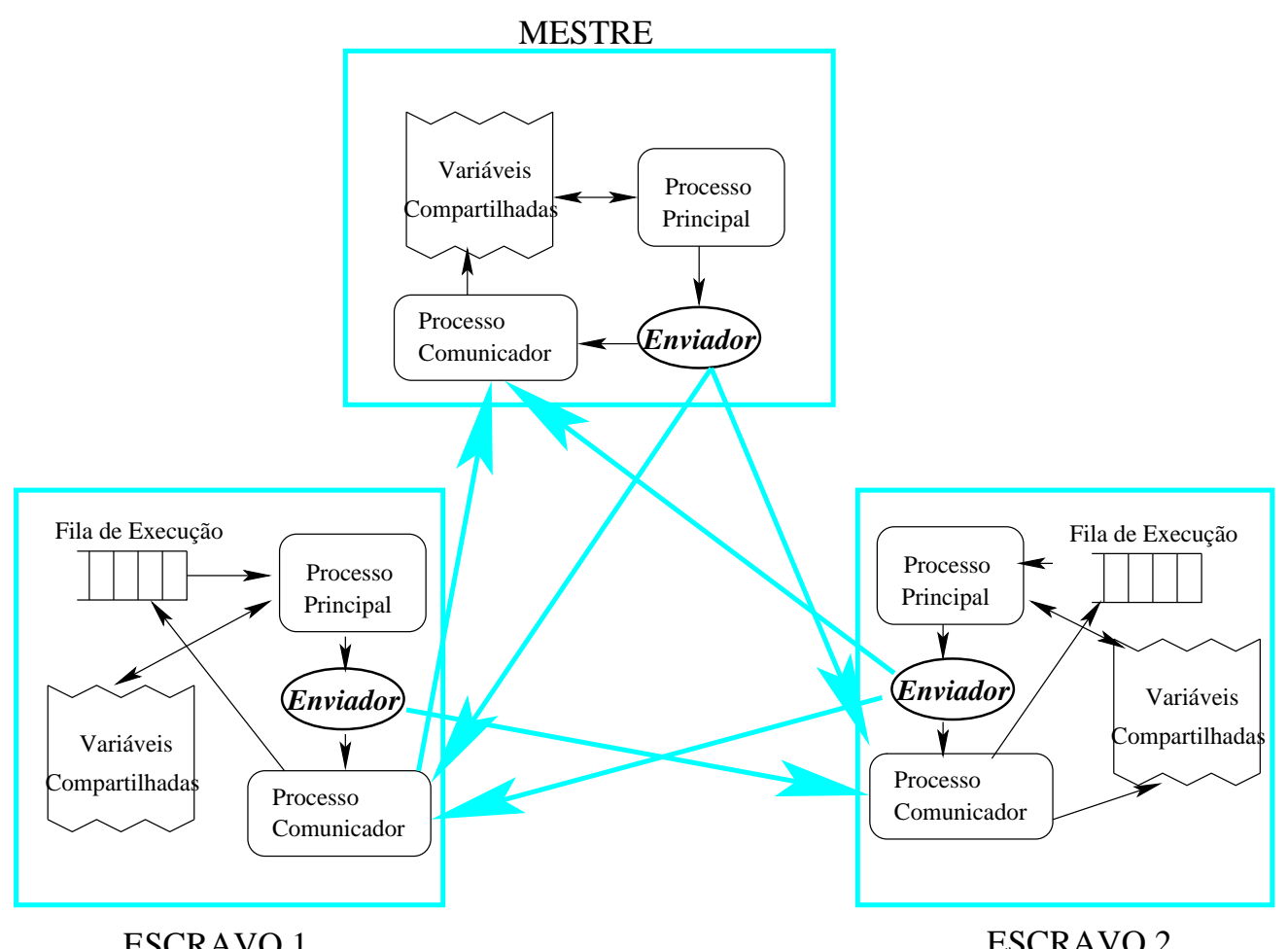

Figura 3.18: Modelo de execução proposto por Iguma [Iguma, 1997]

Esse sistema foi construído através de uma biblioteca desenvolvida para linguagem CPAR, utilizando primitivas do PVM para prover uma camada de comunicação. A grande maioria das propostas analisadas na Seção 3.2.2 foi implementada e algumas até foram alteradas no trabalho de Denise.

Com os testes e resultados obtidos, observou-se a viabilidade das estratégias propostas em [Sato, 1995], tais como:

- minimização da quantidade de mensagens pelo modelo de consistência escolhido; 
- tempo de latência na obtenção de dados remotos;

- modelo de execução mestre-escravo.

Além dos pontos apresentados, também foram propostas e implementadas outras contribuições:

- métodos para transferência de dados;

- garantia da efetivação das atualizações no sistema;

- modo de representação de variáveis que independe da arquitetura da máquina. 


\section{Capítulo 4}

\section{Modelo do Sistema}

\section{CPAR-Cluster}

No Capítulo 3 foram apresentados alguns trabalhos que constituem a base do sistema implementado neste trabalho, o CPAR-Cluster. A partir do estudo feito, compreendem-se melhor as características incorporadas, as alterações e, principalmente, as contribuições que distingüem o trabalho.

Este trabalho implementa e avalia o sistema CPAR-Cluster, um sistema para programação paralela, com o paradigma de variáveis compartilhadas sobre um sistema paralelo distribuído heterogêneo, composto por nós mono e multiprocessadoras.

Esse sistema baseia-se:

- nas construções paralelas oferecidas pela linguagem CPAR,

- em algumas estratégias sugeridas em [Sato, 1995] para um ambiente de programação sobre um sistema distribuído heterogêneo (não considerando arquiteturas multiprocessadoras) e

- as sugestões, comentários e discussões levantados no trabalho [Iguma, 1997] que analisou e implementou a proposta de [Sato, 1995] e que incorporou algumas modificações.

O principal diferencial do trabalho apresentado está na exploração do potencial de máquinas multiprocessadoras, o que praticamente impõem a proposição de novas 
estratégias e abordagens para as questões de distribuição de dados, escalonamento de tarefas, atualização de variáveis compartilhadas, entre outras.

Às características mencionadas devem somar-se: a transparência e a programabilidade oferecidas ao usuário. O grande desafio ao incorporar tantas qualidades desejáveis é não comprometer o principal objetivo para uma aplicação paralela: o desempenho.

Além dos aspectos mencionados, esse capítulo discute a estrutura do sistema implementado para programação paralela com variáveis compartilhadas em sistemas distribuídos heterogêneos. São apresentados na Seção 4.1 os modelos lógicos de execução, estruturas internas de configuração e algumas idéias para distribuição e atualização de dados.

\subsection{Modelo de Execução}

O modelo de execução do sistema CPAR-Cluster explora a presença de arquiteturas SMP na rede heterogênea. Ao contrário do modelo de execução presente nas propostas de [Sato, 1995, Iguma, 1997], que também podem ser emulados em máquinas SMP, ele aproveita a vantagem do espaço de endereçamento acessível aos múltiplos processadores, presente nessas máquinas para uma execução mais eficiente.

O modelo em um nó multiprocessador aproveita o maior poder de processamento da máquina e evita a sobrecarga de memória resultante das replicações de dados e por cópias remotas, pois os dados estariam disponíveis na memória compartilhada por todas as entidades do sistema. Pretende-se que isso resulte em um maior desempenho de uma grande faixa de aplicações.

Outro ganho do modelo reside sobre a exploração da localidade de dados que pode ser diretamente explicitada e, dessa forma, aproveitar de forma mais eficiente a capacidade de um nó SMP, tirando proveito no acesso local mais rápido dos dadose eliminando a comunicação na rede.

A execução é feita sobre um modelo mestre-escravo. A coordenação, distri- 
buição e recepção dos resultados parciais são realizadas pelo nó mestre. Aos nós escravos cabe a execução das tarefas enviadas pelo mestre.

No modelo de execução implementado, um nó do sistema distribuído contém as seguintes entidades:

Tabela de Variáveis Compartilhadas armazena as variáveis compartilhadas. É atualizada localmente pelo(s) executor(es). As atualizações remotas ficam sob a responsabilidade do processo comunicador.

Thread Executor: responsável pela execução do processamento de tarefas. Desempenha o mesmo papel do Processo Principal dos modelos apresentados no Capítulo 3.

Processo Comunicador: atualiza as variáveis, a fila de execução e estruturas de controle do DSM.

Fila de Execução: área de memória compartilhada pelo executor e pelo comunicador. As identidades das tarefas a serem executadas são colocadas nessa fila.

Processo Emissor responsável pelo empacotamento dos dados, entrega e controle do fluxo entre o Thread Executor e os processos comunicadores dos demais nós.

A Figura 4.1 exibe o modelo de execução do sistema CPAR-Cluster implementado e avaliado. Observe que no nó multiprocessador são criados tantos executores quanto o número de processadores. Tal informação é obtida junto ao usuário que a fornece através de um arquivo de configuração dos recursos disponíveis.

É importante salientar a transparência da atribuição de tarefas aos nós, ou seja, não haverá necessidade de alterar o código fonte para que isso ocorra. Convém notar, contudo, que é oferecida a opção do usuário de explicitar que determinada tarefa seja delegada a uma determinada máquina com um processador mais rápido ou a outra que seja multiprocessadora, por exemplo. Essa informação é obtida através de um arquivo contendo a atribuição de tarefas pelos nós disponíveis. 
Outro benefício para o programador é o gerenciamento transparente dessa execução que acontecerá sobre plataformas heterogêneas quanto ao número de processadores.

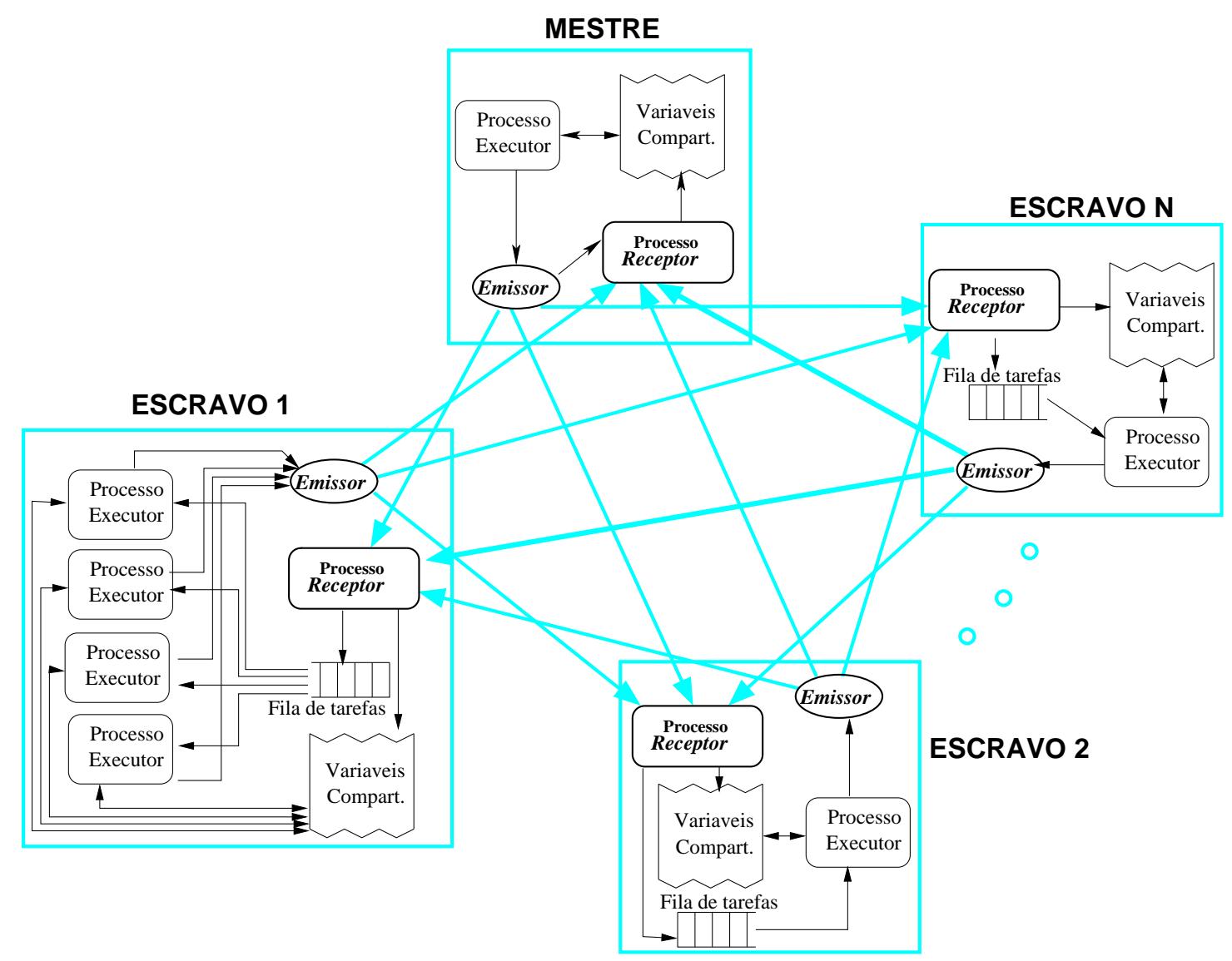

Figura 4.1: Modelo de execução do CPAR-Cluster.

Nas próximas seções segue-se a descrição mais detalhada de cada entidade que compõe o modelo, fazendo-se distinção entre aquelas que residem no mestre e nos nós escravos. Além dessa diferenciação, é feita a análise da influência de um ambiente de memória compartilhada e múltiplos processadores no modelo.

\subsubsection{O Executor}

O processo Executor Mestre realiza:

Criação dos nós escravos. A partir do nó mestre são ativadas as entidades e as estruturas de controle em cada nó escravo que compõem o modelo de execução. 
Montagem das tabelas de controle da execução. As estruturas de controle e configuração são montadas de acordo com informações fornecidas pelo usuário.

Execução do ramo principal. O fluxo de execução da função main do programa é de responsabilidade do executor mestre.

Escalonamento das tarefas para as filas de execução. Para executar laços paralelos ou blocos paralelos é necessário dividi-los em unidades uniformes às quais são atribuídos identificadores. Após a consulta das tabelas de configuração do sistema, é escolhido um conjunto de nós escravos que receberão essas unidades em suas filas de execução.

Sincronização dos escravos. Espera pelo término das tarefas atribuídas aos escravos.

Rotinas de finalização. Controle do término da execução do programa.

O Executor Escravo é responsável pela execução das tarefas, ou seja, retira da fila de execução as tarefas atribuídas pelo mestre e as executa. Além disso, também toma parte no processo de atualização de variáveis compartilhadas, descrito nas Seções 4.1.3 e 4.1.4.

Nos próximos parágrafos serão detalhadas algumas operações sobre os processos executores, detalhando o mecanismo de cada uma delas.

\section{Criação dos executores}

O número de executores criados em cada nó escravo é definido segundo as informações disponibilizadas pelo usuário sobre o sistema subjacente. Através de arquivos de configuração será possível determinar em quais máquinas executarse-á o modelo que visa a exploração de múltiplos processadores e da memória compartilhada.

Em um nó SMP são iniciados tantos executores escravos quanto o número de processadores presente na arquitetura. 


\section{Distribuição de tarefas}

Outra importante responsabilidade do executor mestre é a distribuição de porções de código a serem executadas pelos escravos. Essas unidades podem ser uma macrotarefa ou um macrobloco, mas genericamente serão denominadas tarefas.

De acordo com algumas configurações, obtidas junto ao usuário ou desenvolvidas pelo próprio sistema, é feito o escalonamento das tarefas para um conjunto de executores escravos.

A tarefa é enviada ao processo comunicador do nó escravo escolhido que a insere na fila de execução do nó. Estando o executor ocioso, ele retira a tarefa da fila e inicia sua execução.

No caso de um nó com múltiplos executores, juntamente com a identificação da tarefa é enviada a quantidade de instâncias desejadas. Dessa forma, a tarefa ficará na fila de execução até que o número de executores responsável por ela naquele nó seja obtido.

De acordo com a descrição feita nessa seção, é apresentada na Figura 4.2 um esquema de distribuição de tarefa no sistema CPAR-Cluster.

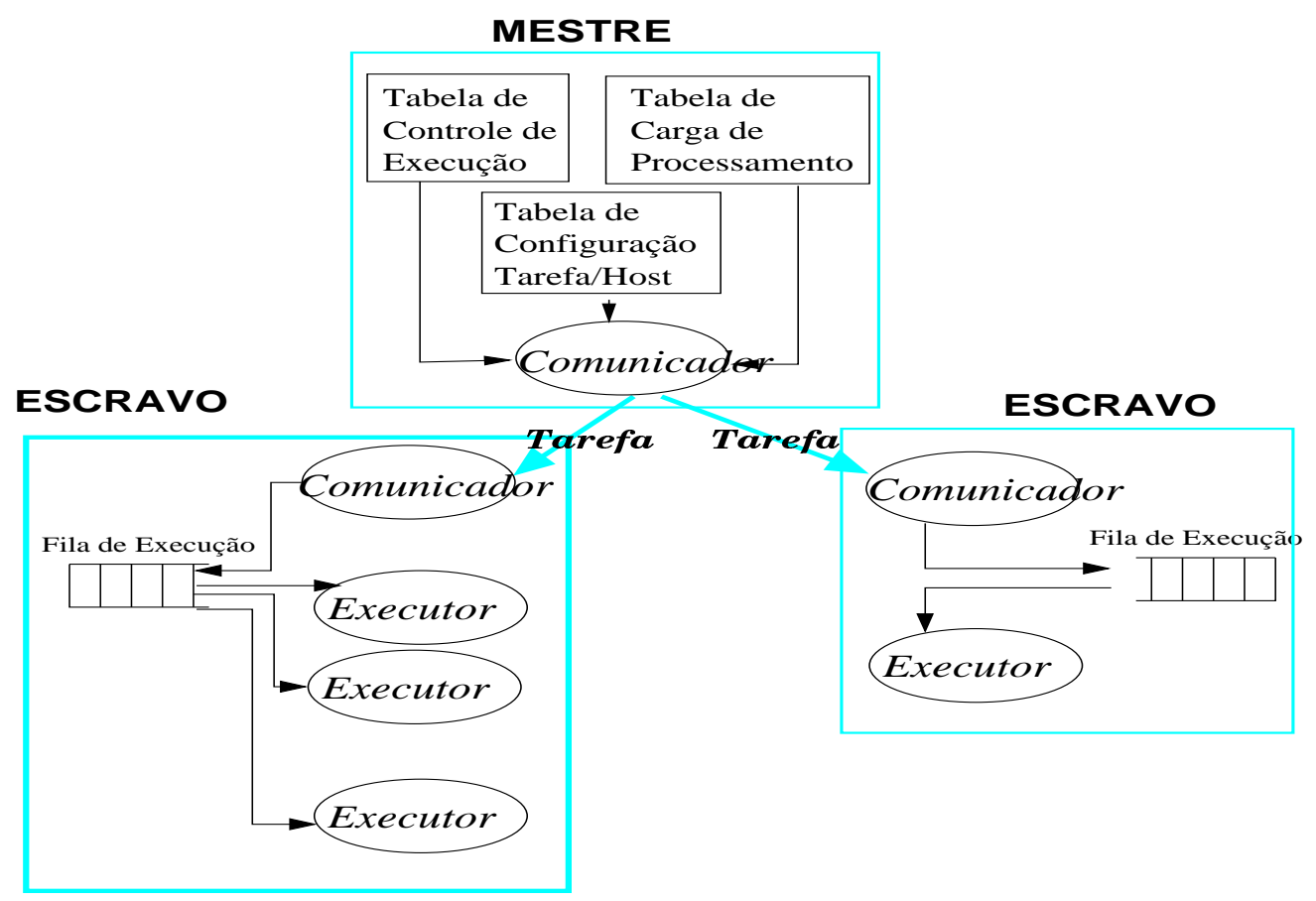

Figura 4.2: Distribuição de tarefa no modelo de execução. 


\section{Controle de execução de tarefas}

Ao final da execução de uma tarefa, várias estruturas do sistema devem ser atualizadas para que haja o prosseguimento da execução do programa. Para que isso ocorra é necessário um protocolo simples de notificação do fato entre o mestre e seus escravos.

O Executor Escravo sinaliza o término da execução da tarefa ao processo comunicador do nó e a partir desse ponto poderá retirar outras tarefas da fila de execução. O comunicador repassa a mensagem à entidade parceira presente no nó mestre.

O Comunicador Mestre fica então responsável por coletar todas as mensagens de término de tarefa e atualizar todas as estruturas do sistema que informam a situação da carga do sistema. Manter essas tabelas sempre atualizadas é de fundamental importância no escalonamento apresentado anteriormente e, por conseqüência, no desempenho geral do sistema.

A troca de mensagens realizadas com a finalidade do controle de execução das tarefas submetidas ao sistema está ilustrada na Figura 4.3.

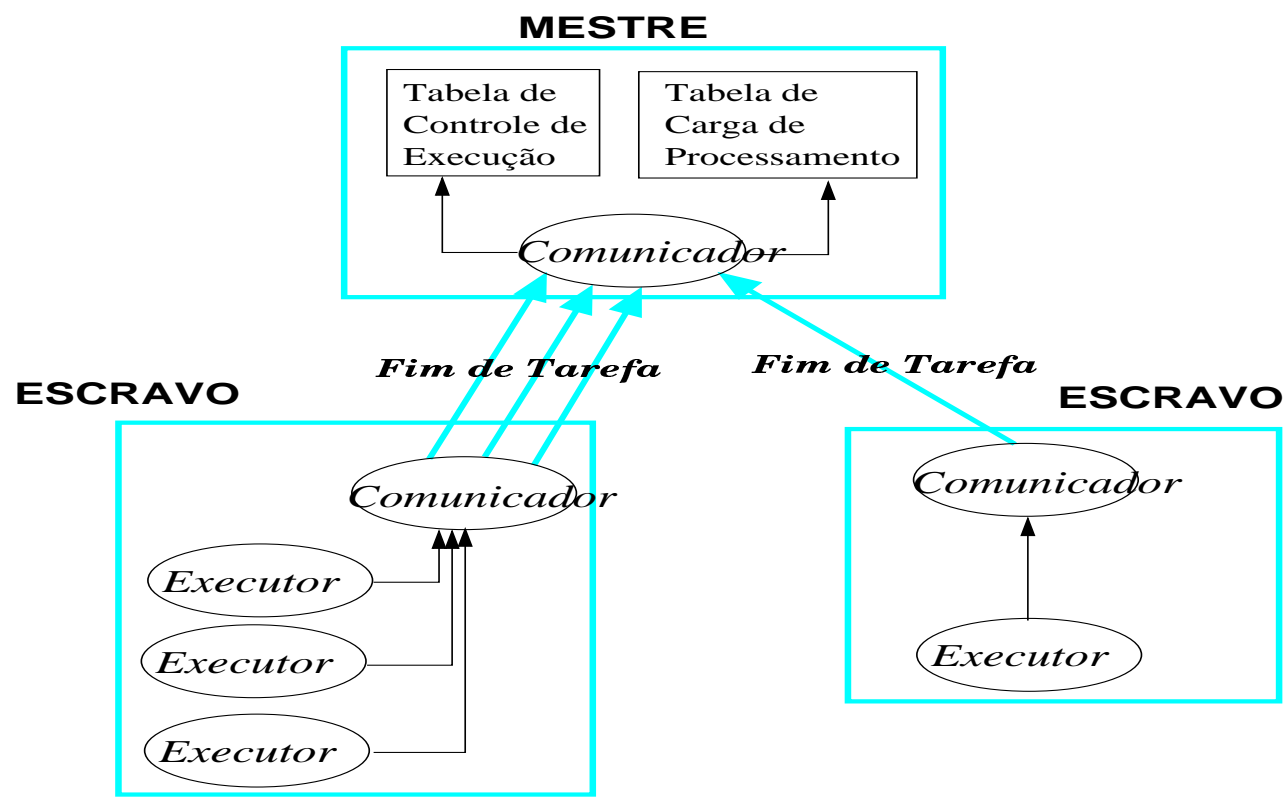

Figura 4.3: Notificação do término de tarefa no modelo de execução. 


\subsubsection{O Comunicador}

O processo Comunicador Mestre tém as seguintes responsabilidades:

Atualização das variáveis compartilhadas. Recebe os pacotes de atualizações remotas e deve efetivar essas alterações sobre as cópias das variáveis compartilhadas do seu local. Maiores detalhes serão apresentados nas Seções 4.1.3 e 4.1.4.

Término de uma tarefa. Realiza atualização da tabela de controle de macrotarefas e macroblocos. Esse tópico foi discutido na Seção 4.1.1.

O comunicador residente em cada escravo além de realizar a atualização de variáveis compartilhadas, também insere tarefa na fila de execução, conforme apresentado na Seção 4.1.1.

\subsubsection{Variáveis Compartilhadas}

Implementar um espaço de endereçamento global sobre uma rede heterogênea de forma transparente ao usuário não é uma tarefa trivial. Como visto no Capítulo 2, várias abordagens são exploradas, desde o nível de hardware até softwares que ocupam uma camada mais alta de abstração.

Pela abordagem escolhida neste sistema, as variáveis compartilhadas são tratadas através de comandos inseridos pelo compilador no código do programa. A atualização é feita sobre cada variável e não sobre a página de memória que a contém, como no caso das abordagens via sistema operacional.

As cópias das variáveis residem nos nós que a utilizarão como, por exemplo, no caso de uma variável compartilhada local a uma macrotarefa. Essa variável será atualizada em todos os nós responsáveis pela execução da macrotarefa.

Essa estratégia apresenta a vantagem de minimizar a troca de mensagens de atualização, conseqüentemente reduzindo o tempo de espera, pois, no momento da referência à variável, haverá uma cópia com conteúdo válido, garantido pelo modelo de consistência escolhido. 


\begin{tabular}{|l|l|l|l|l|l|l|}
\hline id. & tamanho & componente & dimensão & deslocamento & $\begin{array}{l}\text { id. da } \\
\text { memória } \\
\text { compartilha- } \\
\text { da }\end{array}$ & $\begin{array}{l}\text { flag de } \\
\text { envio }\end{array}$ \\
\hline
\end{tabular}

Tabela 4.1: Estrutura de mapeamento do armazenamento de variáveis compartilhadas.

A técnica utilizada que busca minimizar a sobrecarga de comunicação através de atualizações feitas em pontos estratégicos do programa é denominada consistência relaxada (vide Seção 2.2.2).

Nas seções seguintes serão detalhadas as questões relativas ao armazenamento, acesso e atualização das variáveis compartilhadas no sistema CPAR-Cluster.

\section{Armazenamento}

Em cada nó do sistema podem existir até duas áreas de variáveis compartilhadas. Elas diferirão de acordo com o escopo da declaração da variável: global ou local.

As variáveis compartilhadas globais estão armazenadas em uma área que é criada para todos os nós, no início da execução do programa. A estrutura que armazena informações utilizadas no mapeamento das variáveis compartilhadas para endereços na memória encontra-se na Tabela 4.1.

A tabela de mapeamento do endereço na memória das variáveis compartilhadas locais apresenta estrutura idêntica à Tabela 4.1, mas está presente somente nos nós onde residem os processos que executam a tarefa designada e permanecem ativas somente durante a execução da mesma.

\section{Acesso}

Para que a tabela fosse flexível o suficiente para armazenar a informação sobre estruturas multidimensionais ou registros com múltiplos campos, foi utilizado um algoritmo de deslocamento que permite o acesso ao item de dado desejado. Para tanto, é suficiente fornecer o endereço inicial da estrutura de dados e o deslocamento até o ponto necessário, independente da composição da variável.

A ordem das variáveis dentro de uma tabela é a mesma para todos os nós, a 
diferença está nos campos tamanho e conteúdo que dependem da representação interna de dados da máquina.

O algoritmo de deslocamento utilizado, bem como a discussão de alternativas ao cálculo está em [Iguma, 1997].

\section{Atualização}

Como explicado no início da Seção 4.1.3, a atualização de cada variável não é propagada imediatamente. Todas essas operações são armazenadas e empacotadas, para posteriormente serem enviadas. O momento do envio é determinado por pontos de atualização dentro do programa.

Na Figura 4.4 são apresentados os pontos de propagação das atualizações de variáveis compartilhadas: ao final da execução de um comando forall e ao final de uma seção crítica delimitada por lock/unlock.

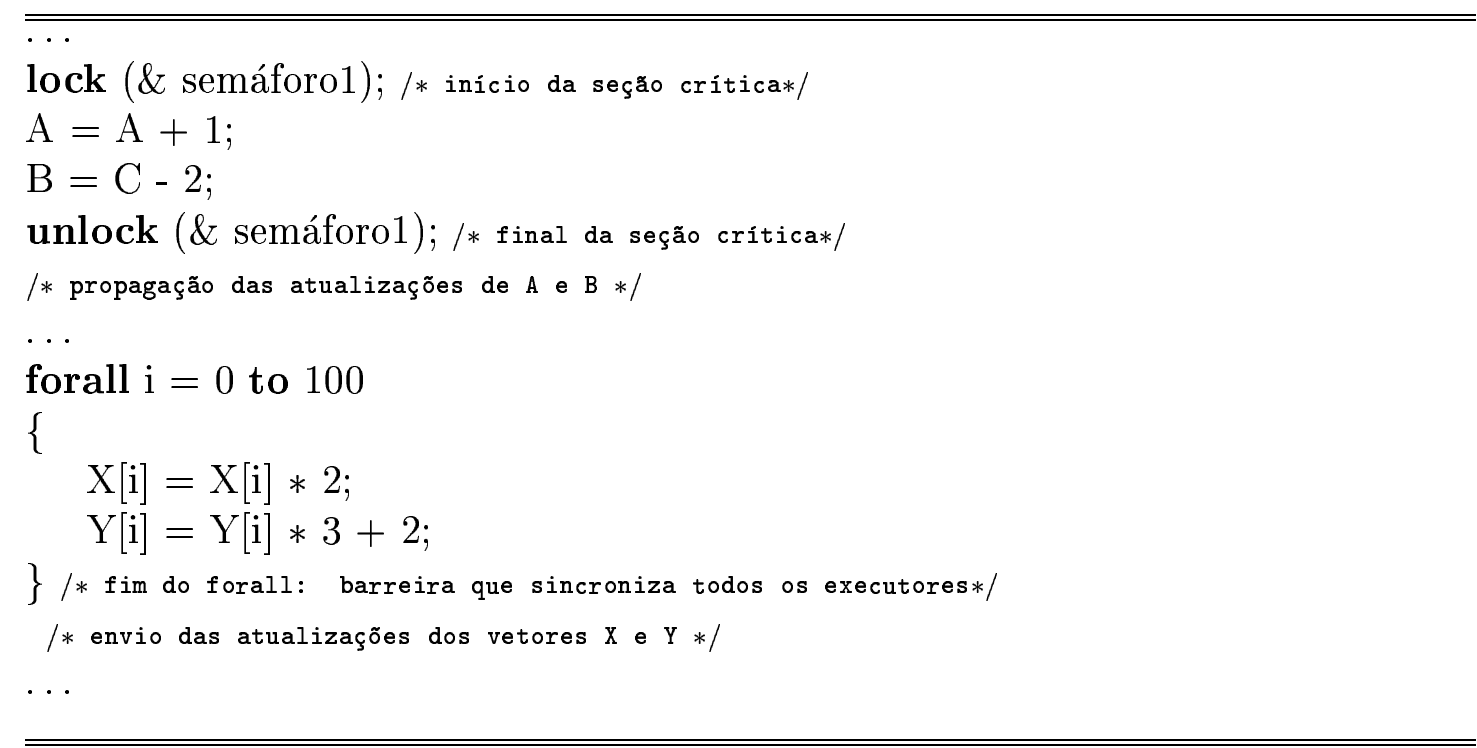

Figura 4.4: Exemplos da ocorrência de pontos de sincronização para atualizações de variáveis compartilhadas.

Em um programa que apresenta a concorrência ao acesso aos dados, é necessário garantir que uma operação de escrita não se sobreponha a outras operações de escrita ou leitura sobre o mesmo item de dados. Essa garantia é implementada através da inserção da referida operação em uma seção crítica, onde o controle é feito através da primitiva de sincronização conhecida como semáforo (Seção 3.1.9). 
As atualizações são realizadas no final da seção, ou seja, na operação de liberação do semáforo.

O outro ponto está presente no final de um laço paralelo. São permitidas as operações de leitura e escrita sobre as variáveis compartilhadas em iterações que não apresentam dependência de dados. Ou seja, a escrita de uma variável na iteração $i$ não afetará as operações realizadas nas iterações posteriores. Por essa razão, as atualizações podem ser armazenadas e somente propagadas após a barreira de sincronização presente no término do laço.

Cabe lembrar da responsabilidade do programador ao codificar um laço paralelo onde existe a dependência de dados entre as iterações. Ele deverá utilizar os mecanismos de sincronização adequados para que obtenha um resultado consistente. A transparência no tratamento subjacente de tal mecanismo, esta sim, é de responsabilidade do sistema CPAR-Cluster.

Em máquinas multiprocessadoras isso acontece de uma forma distinta. As atualizações ocorrem sobre uma área presente na memória compartilhada por todos os executores e por isso não há necessidade de um protocolo de envio das atualizações como descrito acima. As modificações realizadas são vistas por todos os processos, sem que haja o envio de mensagens. Apenas a implementação do sistema deve ser cuidadosa para que não ocorram inconsistências no acesso ou modificação dos itens de dados compartilhados.

Uma idéia mais completa de como funciona o protocolo de atualização de variáveis compartilhadas é apresentada na Seção 4.1.4, onde será discutido o papel do processo Emissor, de grande importância na propagação das alterações pelo sistema.

\subsubsection{O Emissor}

A maneira como é atualizada uma variável compartilhada faz com que o processo executor, ao enviar uma mensagem de atualização, espere por uma confirmação dos processos comunicadores dos nós para os quais enviou a mensagem. Dessa forma, além de assegurar a efetivação da atualização nos nós, também controla-se 
o fluxo de mensagens para os mesmos, pois um comunicador recebe por vez uma mensagem de atualização de um mesmo executor, a fim de não sobrecarregá-lo com mensagens.

Nessa estratégia, o executor fica suspenso à espera de confirmações dos comunicadores e poderia estar utilizando esse tempo processando a tarefa corrente se houvesse outro processo para cuidar do empacotamento, envio e controle do fluxo de mensagens.

A alternativa para isso é acrescentar mais uma entidade no modelo que fica encarregada de controlar o empacotamento, envio e controle de fluxo das mensagens a serem enviadas do executor para os demais processos comunicadores.

Esse novo processo é chamado de emissor e ele comunica-se com o executor do nó através de uma área de memória compartilhada entre eles que armazena a mensagem a ser enviada ao nó correspondente.

Um envio de um pacote ocorre quando foi completado o preenchimento dessa área destinada ao armazenamento de mensagem ou ao término da mensagem de atualização. Quando isso ocorre, o executor notifica o emissor do fato, que empacota a mensagem contida na área comum e envia-na ao destinatário indicado.

Para que uma mensagem de atualização não seja recebida antes que o comunicador termine de tratar outra mensagem vinda do mesmo nó, é feito um controle através de uma estrutura que reside na área compartilhada entre o executor e o emissor do nó.

O estado dessa estrutura indica: se o emissor espera por confirmação de algum comunicador, se todas as mensagens foram tratadas e se o executor aguarda para enviar uma mensagem a um comunicador que ainda não tratou a mensagem anteriormente enviada.

No caso da espera pelo tratamento de mensagem, o executor envia uma mensagem ao emissor indicando que deve ser feito o envio da mensagem contida na área compartilhada e que irá aguardar por confirmação do emissor para poder prosseguir com o processamento. O processo executor não poderá modificar o valor que se encontra na área compartilhada até que o emissor consiga empacotar e enviar 
tal mensagem.

Durante a execução de uma tarefa, o executor passa por pontos de sincronização onde ocorrem a propagação das atualizações de variáveis. Nesse momento ele verifica o estado da estrutura de controle do fluxo das mensagens. Se houver mensagem ainda não tratada, ele aguardará pela liberação do emissor.

Essa estratégia diminui o tempo de suspensão de um executor, permitindo que o mesmo fique livre para execução de tarefas. O fluxo e a atualização de dados ficariam ao cargo de outros processos.

A Figura 4.5 apresenta um esquema de atualização em dois nós do sistema. Uma atualização envolve as entidades executora e emissora do nó que está propagando a atualização e o comunicador do nó que recebe a mensagem de atualização.

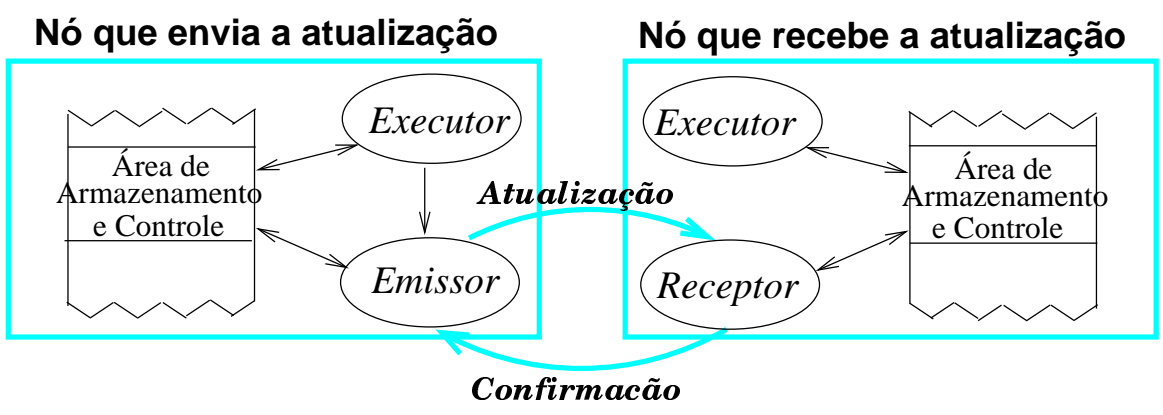

Figura 4.5: Atualização de variáveis compartilhadas no modelo de execução.

O esquema aparentemente não apresenta alterações para nós com múltiplos executores, como visto na Figura 4.6. Contudo, existe uma relevante diferença no caso da propagação para outros executores locais ao nó.

São considerados os seguintes aspectos na atualização de uma variável compartilhada por executores escravos de um mesmo nó:

- o processo emissor não é notificado,

- não há necessidade do envio de mensagem de atualização,

- o controle de acesso e alteração é feito pelo sistema operacional

Na atualização de uma variável compartilhada por executores remotos assumese que: 
Nó que envia a atualização

Atualização

Nó que recebe a atualização

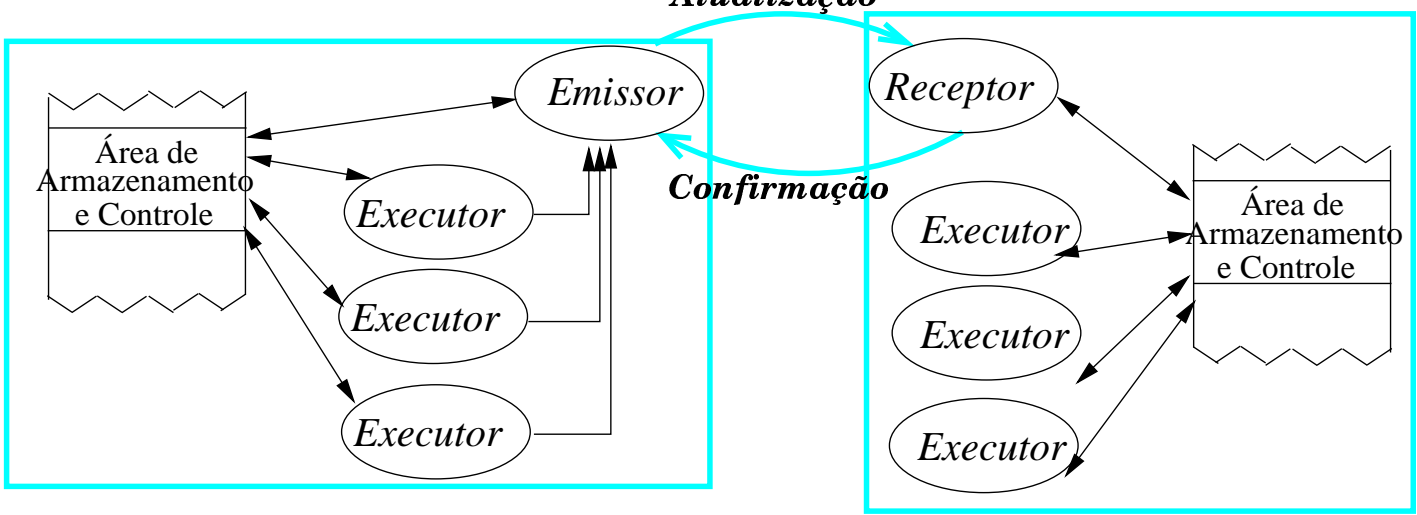

Figura 4.6: Atualização de variáveis compartilhadas em nós multiprocessadores.

- o executor reúne e empacota todas as atualizações,

- quando o pacote estiver pronto, ele notifica o processo emissor,

- mensagens são trocadas entre o emissor e o comunicador (atualização e confirmação),

- o controle é feito via comunicador (atualização da Área de Armazenamento e Controle de Variáveis Compartilhadas).

A atualização de uma variável compartilhada por executores locais e remotos segue a seguinte seqüência:

- as atualizações locais são comunicadas aos demais executores via memória compartilhada,

- as atualizações remotas seguem os mesmos passos do algoritmo anterior: o emissor envia para o comunicador do outro nó e fica aguardando por confirmação.

- o controle de todas as operações é mantido na Área de Armazenamento e Controle, não importando se a alteração foi local ou remota. 


\subsection{Escalonamento de macro e microtarefas}

A escolha adequada do local ao qual vai ser atribuída a execução de um grão de paralelismo é de fundamental importância na eficiência do sistema de execução. $O$ CPAR-Cluster oferece um escalonamento tanto no nível de macrotarefas como no nível de microtarefas.

\subsubsection{Escalonamento das macrotarefas}

No momento da execução de tarefas paralelas, é executado um algoritmo que tanto considera informações definidas pelo usuário para a distribuição, como também leva em consideração a carga de cada máquina. As situações analisadas pelo algoritmo podem ser sintetizadas em nove casos:

caso 1 não há especificação em arquivo para a tarefa. Essa é a situação de maior liberdade para o sistema em que será considerada, principalmente, a carga de cada máquina.

caso 2 sugestão da máquina: <nome da tarefa $><$ lista de máquinas $>$. O usuário tem a possibilidade de sugerir locais que serão ou não alocados de acordo com sua carga. Se houver alternativas de nós mais interessantes diferentes dos sugeridos, esses serão alocados.

caso 3 reserva de máquina: $<$ nome da tarefa $><$ lista de máquinas $>$ !. A imposição de local faz com que a tarefa entre na fila (ou de espera ou de execução, dependendo da carga do nó em questão).

caso 4 obrigatoriedade de execução da tarefa em máquina(s) paralela(s) de memória compartilhada: <nome da tarefa> SMP!. Na escolha está restrita ao subconjunto de máquinas de memória compartilhada.

caso 5 obrigatoriedade de arquitetura (SMP) e sugestão de máquina:

$<$ nome da tarefa> SMP! <lista de máquinas $>$. O algoritmo analisa se as sugestões serão as melhores escolhas no momento da execução. Se não forem, outras SMPs são escolhidas. 
caso 6 obrigatoriedade de arquitetura $(\mathrm{SMP})$ e de máquina:<nome da tarefa> SMP! <lista de máquinas>! Deve-se apenas obedecer a indicação do usuário.

caso 7 sugestão de execução sobre máquina(s) paralela(s) de memória compartilhada:

$<$ nome da tarefa $>$ SMP. As análises iniciam-se pelo subconjunto de SMPs, mas não conseguindo o número necessário de executores, parte-se para as máquinas monoprocessadoras.

caso 8 sugestão de arquitetura (SMP) e sugestão de máquina:<nome da tarefa> SMP <lista de máquinas>. Como no caso anterior, primeiro tenta-se atender à sugestão, se não for possível passa-se para as outras possibilidades.

caso 9 sugestão de arquitetura (SMP) e obrigatoriedade de máquina:

$<$ nome da tarefa > SMP < lista de máquinas $>$ !. Atende-se o requisito da(s) máquina(s),se ainda forem necessárias mais alocações, investiga-se as SMPs.

A seqüência dos testes pode ser vista em um esqueleto do algoritmo de escalonamento 4.7. Uma versão mais detalhada, mas ainda em alto nível, do algoritmo pode ser analisada na listagem em anexo ao documento.

Uma melhoria da estratégia considera o tempo que se gasta na execução da cada tarefa na fila de cada nó e o tempo decorrente da(s) tarefa(s) em execução. Além desse exame, poder-se-ia considerar outras informações sobre a capacidade computacional de cada nó como, por exemplo, tamanho da memória RAM, velocidade do processador, etc. Por restrições de tempo e do escopo de nosso trabalho, tais melhorias não estão previstas nessa implementação do sistema.

\subsubsection{O escalonamento das iterações}

As iterações de um laço paralelo são particionadas entre os executores de acordo com as seguintes estratégias de distribuição adequadas ao comando forall [Arantes, 1996]:

1. Escalonamento estático por bloco: neste caso, a quantidade de iterações a ser executada por cada processo é igual a $\lceil N / p\rceil$ iterações. 


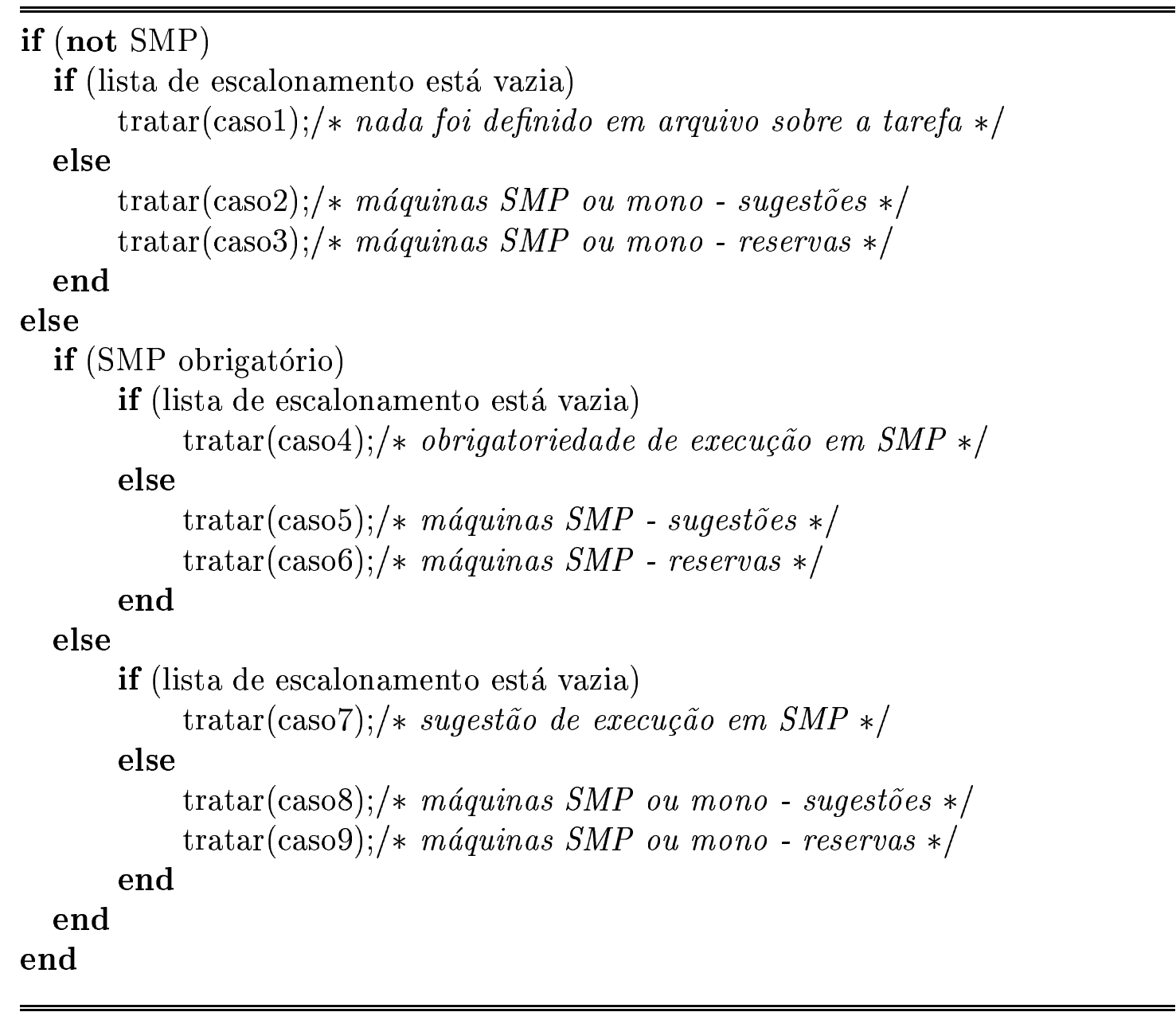

Figura 4.7: Esqueleto do algoritmo de escalonamento. 
2. Escalonamento dinâmico por bloco: inicialmente atribui-se uma quantidade de $k$ iterações a cada processo e, de acordo com o término do bloco, o executor verifica se há mais iterações a serem executadas. Caso haja mais iterações, outras $k$ lhes serão atribuídas.

3. Auto escalonamento guiado: o tamanho do bloco é iniciado em $\lceil N / p\rceil$ iterações e recalculado sempre que um novo bloco de iterações é atribuído a um processador, passando a valer $\left\lceil R_{i} / p\right\rceil$, onde $R_{i}$ é o número de iterações que ainda precisam ser executadas no instante $T_{i}$.

As duas primeiras estratégias de escalonamento foram implementadas e avaliadas neste trabalho. 


\section{Capítulo 5}

\section{IMPLEMENTAÇÃO DO Sistema}

Nesse capítulo é feita a apresentação do CPAR-Cluster sob a perspectiva da implementação aplicando as estratégias propostas e discutidas no Capítulo 4.

O sistema foi desenvolvido sobre a plataforma computacional do LASB, citado anteriormente na Seção 1.3. Utilizamos como sistema operacional o sistema Linux, distribuição RedHat. Na Seção 5.1 estaremos apresentando outros softwares indispensáveis à execução do trabalho. Na Seção 5.2 o esforço de implementação será visto de uma forma bastante geral, sendo dividido em duas grande etapas: o sistema de coordenação da execução e o módulo de atualização de variáveis. Nas seções que seguem, as atividades que compuseram cada uma das etapas serão apresentadas detalhadamente.

\subsection{Questões de projeto e implementação}

Nessa seção são apresentados outros sistemas que formam a base necessária à implementação de nosso trabalho. Cada um será rapidamente discutido e terá justificada a sua escolha.

\subsubsection{Paralelismo por threads}

Os processos leves ${ }^{1}$, ou threads, estão baseados na idéia de separação das características da execução do programa (contador de programa, pilha) dos recursos do sistema (memória, tabela de arquivos abertos). Um processo pode ser dividido em

\footnotetext{
${ }^{1}$ Do inglês light-weighted
} 
muitos threads que possuem os seus próprios contadores de programa e de pilha, mas compartilham todos os outros recursos do sistema [Silberschatz A., 2002].

Pela razão apresentada, operações sobre threads tais como, criação e troca de contexto, tém um tempo de execução menor que as operações correspondentes sobre processos.

Para implementação do modelo de execução sobre plataformas multiprocessadoras está sendo adotado o paralelismo por thread [Nichols et al., 1996]. A principal razão para essa decisão é o fato do espaço de endereçamento está normalmente disponível e não precisa ser alocado através de chamadas de sistema especiais.

\subsubsection{PVM ou MPI?}

A escolha da plataforma de comunicação é de importância crucial para o projeto. Essa plataforma, dentre outras coisas, deve oferecer ao sistema o seguinte suporte:

- máquina virtual que possibilite a exploração de plataformas heterogêneas que compõem o conjunto de máquinas disponíveis;

- permissão de acesso tanto transparente como explícito ao hardware;

- multiprogramação, seja em máquinas mono ou multiprocessadoras;

- modelo de passagem de mensagem.

O aspecto da heterogeneidade está se tornando cada vez mais importante para a computação de alto desempenho, já que os MPP's têm sido uma alternativa cada vez menos atraente em comparação aos aglomerados formados por máquinas mono e/ou multiprocessadoras (vide Capítulo 2).

Além dessa motivação, o uso de diferentes plataformas de maneira integrada pode oferecer um razoável poder computacional se considerarmos a utilização, por exemplo, dos ciclos ociosos dos equipamentos de uma organização. A utilização efetiva desse potencial depende diretamente de como a heterogeneidade é tratada pelo sistema subjacente. 
Tanto MPI (Message Passing Interface) [Forum, 1998] como PVM (Parallel Virtual Machine) [Geist et al., 1994] apresentam a característica da portabilidade, isto é, um programa escrito para uma arquitetura pode ser copiado para diferentes arquiteturas, compilado e executado sem modificações no código fonte [CSM, 1998].

A opção pelo MPI é justificada pelo fato de constituir um padrão. As implementações devem seguir uma especificação com uma semântica definida e somente o comportamento e as características podem ser mudados através do consenso de um fórum aberto onde participam vários segmentos da comunidade de computação.

\subsection{Etapas da implementação}

A Figura 5.1 apresenta uma visão geral da implementação e das duas grandes etapas que a constitui. Como optamos por uma abordagem incremental, primeiro estabelecemos toda a parte da configuração das máquinas, inicialização dos processos e threads e da distribuição e execução das tarefas.

Em um segundo momento fazemos todo o tratamento das variáveis compartilhadas: desde de a sua declaração, passando pelas manipulações de leitura e escrita até sua desalocação.

As principais atividades que compuseram o esforço de implementação do sistema são as seguintes:

- definição da sintaxe dos arquivos de configuração,

- geração dos executáveis,

- criação dos processos comunicadores e das threads executoras,

- tratamento dos arquivos de configuração,

- escalonamento das tarefas e balanceamento de cargas,

- envio e execução das macro e microtarefas,

- declaração e atualização das variáveis compartilhadas e 


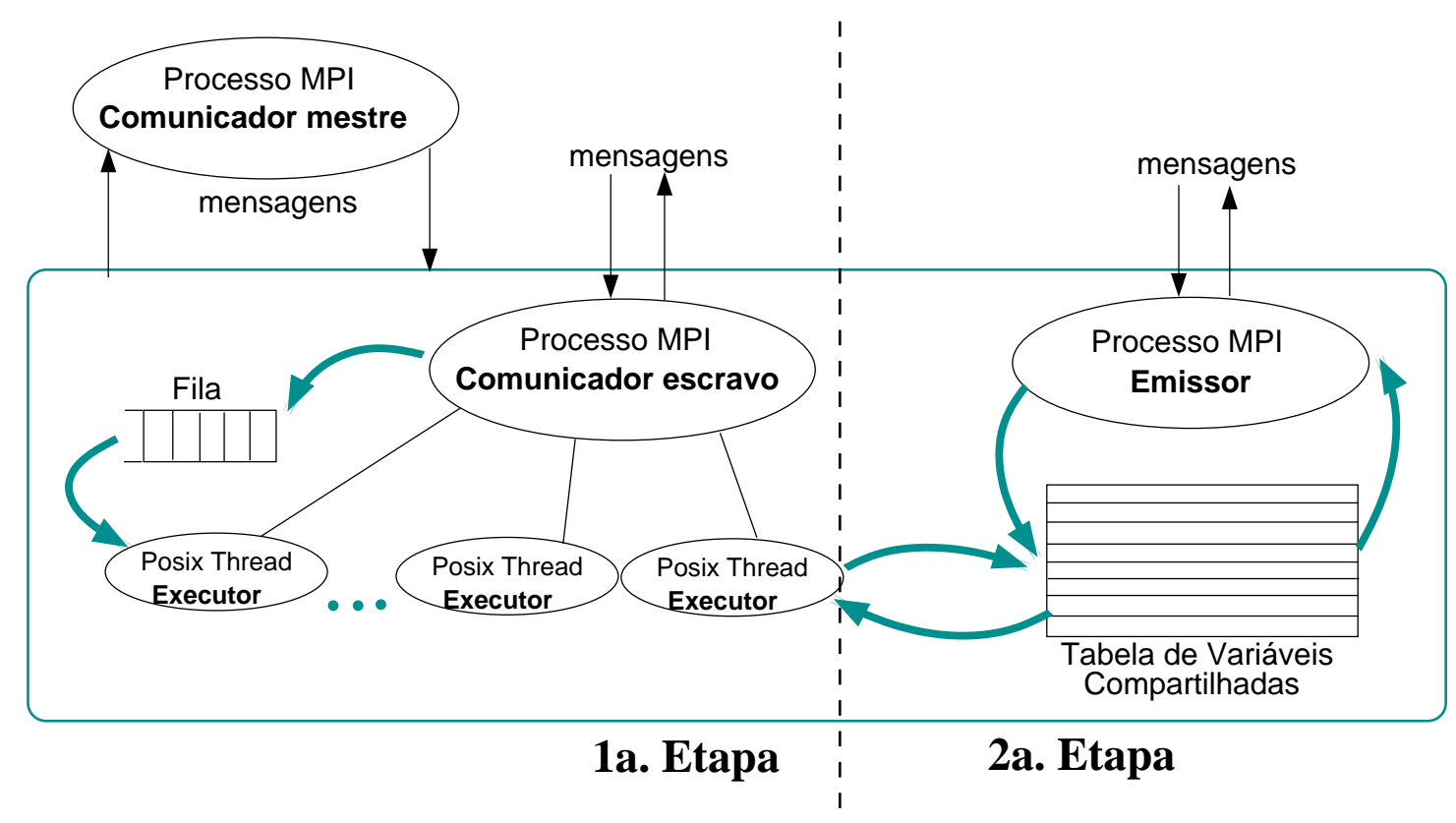

Figura 5.1: As etapas de implementação do sistema.

- finalização do sistema.

Nas seções seguintes serão detalhadas as atividades que compõem o desenvolvimento das duas etapas.

\subsection{Definição da sintaxe e tratamento dos arqui- vos do usuário}

O usuário submete ao sistema algumas tarefas a serem executadas sobre uma rede de computadores e, para isso, fará uso da linguagem de alto nível CPAR [Sato, 1995, Craveiro, 2001].

Além da especificação do trabalho a ser feito, o usuário também deve informar qual é a configuração da arquitetura das máquinas de sua rede, ou seja, ele especifica onde o trabalho será feito.

Existe um terceiro arquivo, no qual o usuário pode atribuir tarefas específicas a nós determinados por ele. É uma op̧̧ão dada ao usuário para que ele faça um pré-escalonamento das tarefas. 


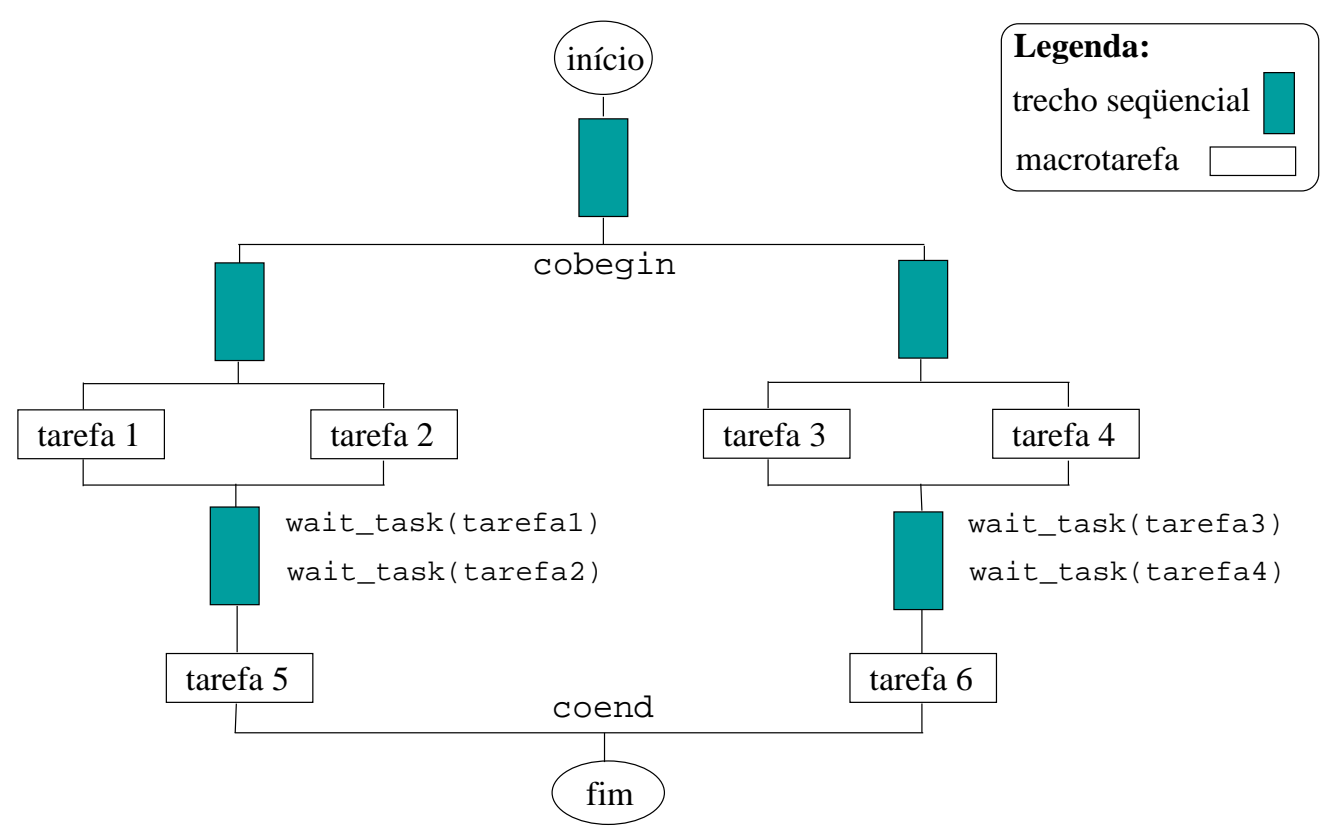

Figura 5.2: O fluxo de um programa em CPAR.

\subsubsection{O programa do usuário}

Esse é o arquivo que especifica o que deve ser feito. Para isso ele tem à disposição as construções da linguagem CPAR. Para explicitar tarefas paralelas existem os blocos paralelos (construção cobegin-coend), as macrotarefas (task) e as microtarefas (construções forall e funções paralelas). Somado a tudo isso são oferecidos mecanismos de sincronização (semáforos, eventos e monitores) e manipulação de variáveis compartilhadas, sejam locais ou globais. A Figura 5.2 ilustra o fluxo da execução de um programa em CPAR que utiliza macrotarefas.

O código do usuário passa por um pré-compilador que expande o mesmo em chamadas da biblioteca do sistema. Esse código intermediário é submetido a um compilador da linguagem $\mathrm{C}$ que esteja disponível para a arquitetura e sistema operacional. A geração do executável para uma máquina (não para um conjunto de máquinas) é feita atualmente conforme visto na Figura 3.16.

Para o caso do sistema CPAR-Cluster, no qual o código do usuário será executado sobre um conjunto de nós heterogêneos, algumas alterações necessárias serão discutidas na Seção 5.4 . 


\subsubsection{As máquinas da rede}

Esse arquivo informa onde deve ser disparado o sistema CPAR-Cluster que servirá de base para a execução do programa do usuário. É basicamente composto pelo nome da máquina e pela quantidade de processadores que possui. O nó mestre deve sempre ser especificado na primeira linha do arquivo, os demais serão considerados escravos. A sintaxe do arquivo é similar àquela adotada pelo pacote MPI-LAM (Local Area Multicomputer) [LAM/MPI, 2003] e está ilustrada no exemplo da Figura 5.3.

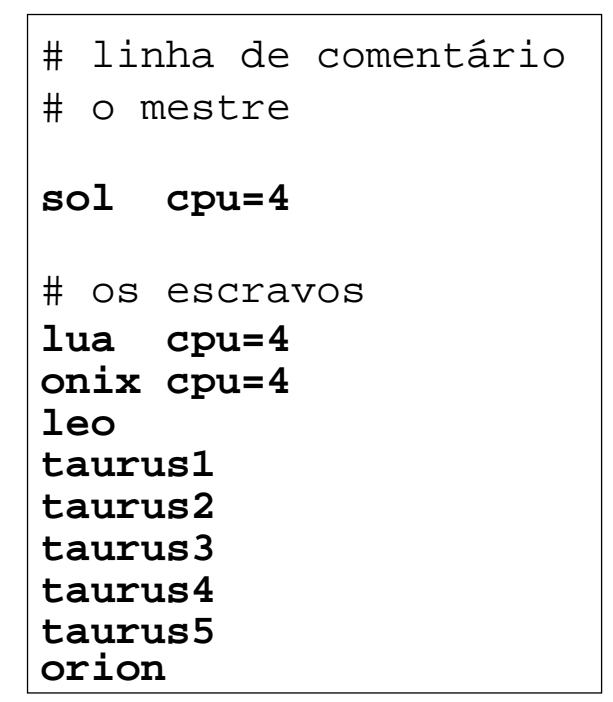

Figura 5.3: Exemplo de arquivo de especificação da rede.

\subsubsection{O pré-escalonamento}

O usuário tem condições de explicitar nesse arquivo onde deve ser feito o que, ou seja, em quais nós do sistema serão ou poderão ser executadas determinadas tarefas. Não é um arquivo obrigatório como os dois anteriormente apresentados. Para definir onde uma tarefa será executada, o usuário trabalha com duas possibilidades de indicação:

1. de arquitetura: se o nó é uma máquina com um ou vários processadores.

2. de nó específico: um nome ou uma lista de nomes de máquinas pode ser fornecida. 
Cada indicação pode ainda ter duas conotações. Ela pode ser interpretada pelo algoritmo escalonador como sugestão ou como obrigatoriedade. No primeiro caso, o algoritmo de escalonamento tem maior autonomia na escolha. Na situação de obrigatoriedade, permite-se que seja indicado que a tarefa seja realmente executada pelo nó especificado e, dessa forma, força-se que o sistema faça uma reserva da(s) máquina(s) para que a tarefa em questão tenha o recurso exigido.

O símbolo ! após a palavra reservada SMP indica a obrigatoriedade de execução em uma máquina de memória compartilhada. Se o símbolo vier depois do nome de uma máquina (ex. onix!), será feita a reserva da mesma para a tarefa. A sintaxe definida é ilustrada no exemplo da Figura 5.4.

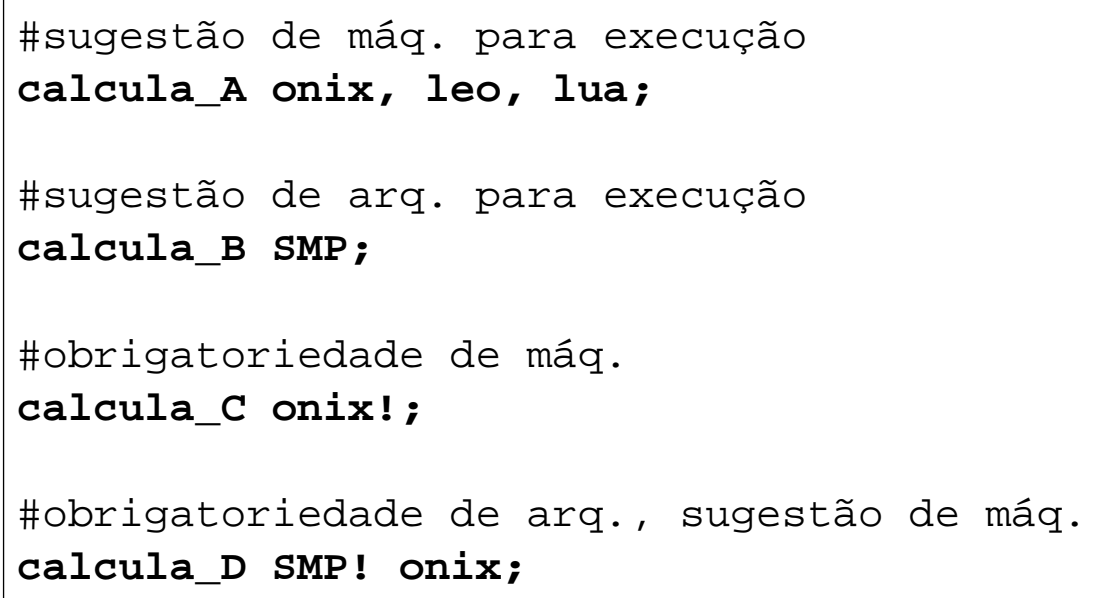

Figura 5.4: Exemplo de arquivo de pré-escalonamento.

\subsection{Execução em rede heterogênea}

Para discutir a estratégia de geração de um executável para um conjunto de máquinas heterogêneas é necessário antes ter o conhecimento dos fatores que serão determinantes ao seu sucesso.

\subsubsection{Descrição de um conjunto de máquinas heterogêneas}

Para definir o que é um cluster heterogêneo vamos partir do conceito inverso, porém mais intuitivo que é a homogeneidade. Um cluster homogêneo é um conjunto de 
nós constituídos por partes da mesma natureza. As partes em questão são:

- Arquitetura.

- Sistema Operacional (inclusive com a mesma distribuição e a mesma versão).

- Componentes de biblioteca, tais como libc ou glibc no Linux (com a mesma versão).

O primeiro requisito, a arquitetura, não refere-se somente à arquitetura do processador, mas também a organização do computador. Para dar apenas um exemplo, duas máquinas Pentium III com diferentes quantidades de memória RAM ou com velocidades de CPU diferentes poderiam ser consideradas heterogêneas.

Quanto ao requisito de mesmas bibliotecas, é importante fazermos algumas considerações sobre uma biblioteca de fundamental importância à execução do sistema proposto: MPI. Além de utilizarmos a mesma implementação (LAM) ainda temos que trabalhar com a mesma versão da ferramenta para todas as máquinas.

Um cluster heterogêneo apresenta nós distintos entre si em pelo menos um dos aspectos citados anteriormente. O conjunto de computadores abaixo é um exemplo de heterogeneidade:

Sol nó SMP com 4 processadores Pentium II Xeon $400 \mathrm{MHz}, 1 \mathrm{MB}$ de cache, 256 MB de RAM com o sistema operacional RedHat 7.0 e sem instalação de LAM/MPI.

Lua nó SMP com 4 processadores Pentium II Xeon $400 \mathrm{MHz}, 1 \mathrm{MB}$ de cache, 256 MB de RAM com o sistema operacional RedHat 8.0 e com LAM/MPI 6.5.9.

Onix nó SMP com 4 processadores Intel Pentium Pro $200 \mathrm{MHz}, 256 \mathrm{~KB}$ de cache, 256 MB de RAM com o sistema operacional RedHat 7.0 e LAM/MPI 6.5.1.

Leo nó AMD Duron $700 \mathrm{MHz}, 64 \mathrm{~KB}$ de cache, $256 \mathrm{MB}$ de RAM com o sistema operacional RedHat 7.0 e sem instalação de LAM/MPI.

Orion nó AMD K6 II 233 MHz, 64 KB de cache, 64 MB de RAM com o sistema operacional RedHat 7.1 e sem instalação de LAM/MPI. 


\subsubsection{A geração dos executáveis}

Para a execução em rede heterogênea, deve-se compilar o programa em cada uma das máquinas cujas características diferem uma das outras para que cada nó execute uma versão compatível com sua arquitetura, sistema operacional e bibliotecas. Como os executáveis devem estar em cada máquina, optou-se por compilar o programa em todos os locais que compõem a plataforma de trabalho e que está descrita no arquivo de configuração dos nós (vide Seção 5.3.2).

No nó mestre deverão existir três executáveis: o comunicador mestre, o comunicador escravo e o emissor. Os demais nós serão escravos e, portanto, necessitam apenas dos executáveis do comunicador escravo e do emissor. Os executores são threads geradas em tempo de execução dos comunicadores e por isso não há um executável associado a essa entidade do sistema.

Vale observar que o código do usuário passa por um pré-compilador que gera um código expandido e esse mesmo código é incorporado aos comunicadores. Todo o processo é mostrado na Figura 5.5.

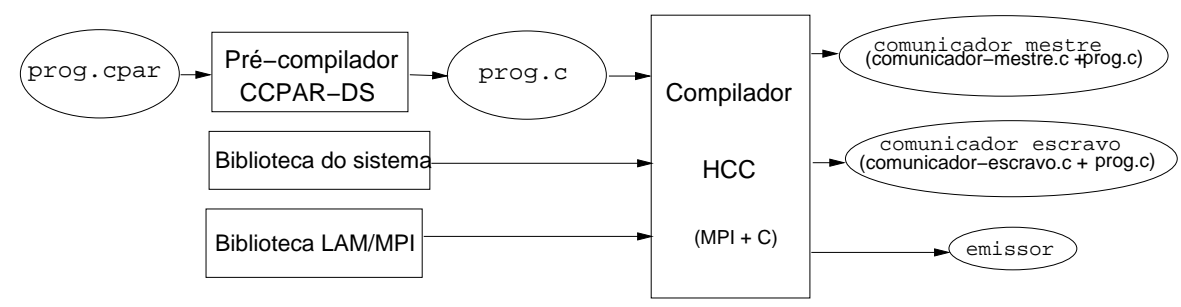

Figura 5.5: A geração do código executável para o sistema distribuído.

\subsection{A configuração do sistema}

As ações iniciais do comunicador mestre resumem-se na criação das threads executoras e no preenchimento de tabelas que controlam a declaração e execução das tarefas.

Na tabela de nós são armazenadas as cargas de cada nó do sistema. As informações da tabela de tarefas estão relacionadas à identificação e ao escalonamento das mesmas. 


\subsubsection{A tabela de nós}

O algoritmo de escalonamento de tarefas necessitará de algumas informações a respeito da capacidade e da carga existente em cada nó componente do sistema heterogêneo. Esses dados são obtidos na tabela de nós, cuja estrutura é apresentada na Figura 5.6.

\begin{tabular}{l}
$\begin{array}{c}\text { Identificador do nó } \\
\text { [índice] }\end{array}$ \\
\cline { 2 - 8 }
\end{tabular}

Figura 5.6: Estrutura de dados da tabela de nós.

Identificador do nó: informa o identificador do processo comunicador escravo residente no nó.

Nome do nó: cadeia de caracteres informada no arquivo de máquinas do usuário que especifica o nome do nó.

Número de CPU's: número inteiro que informa a quantidade de processadores no nó.

Ocupação: carga do sistema em um dado momento. Varia de 0 a 1 (100\%).

Tarefas em execução: lista dos identificadores das tarefas que estão sendo executadas pelo nó em um dado instante.

Fila de espera: tarefas que estão aguardando para serem executadas pelo nó.

Tamanho da fila de espera: variável que simplifica certas comparações realizadas pelo algoritmo de escalonamento.

Reservas: fila de tarefas que têm que ser executadas especificamente no nó.

O identificador único de cada nó é o índice da tabela. A seqüência de armazenamento dos nós é fornecida através do arquivo de máquinas informado pelo usuário (vide Seção 5.3.2). Por essa razão, a primeira linha (índice igual a um) 
Lista de escalonamento: estrutura que armazena os nós escolhidos, inicialmente, pelo usuário e, posteriormente, se necessário, pelo algoritmo de escalonamento do sistema. Cada elemento da lista é composto pela identificação do nó e a indicação de sugestão ou obrigatoriedade, definida pelo usuário no arquivo de distribuição de tarefas pelos nós (Seção 5.3.3).

O preenchimento da tabela é iniciado na declaração da tarefa, através do comando task_spec em CPAR e que é traduzido no código expandido a uma chamada da rotina def_task da biblioteca em desenvolvimento. Nesse momento é atribuído um identificador à tarefa, é preenchido o campo nome e o campo estado recebe o valor zero que indica declarado.

Os campos SMP, obrigatoriedade e a lista de escalonamento são completados no tratamento do arquivo de pré-escalonamento do usuário. Depois desse momento da configuração apenas a lista de escalonamento e o campo estado serão alterados. A primeira na ocasião da execução do algoritmo de escalonamento e o segundo nos momentos onde ocorre transição dos estados.

\subsection{O escalonamento de tarefas e o balanceamen- to de carga dos nós}

Passadas as etapas de configuração do sistema e de declaração de estruturas e tarefas do programa usuário, inicia-se a execução do ramo principal desse programa pelo comunicador mestre. Todos os trechos seqüenciais são de responsabilidade do mestre, mas ao encontrar a ativação, de uma tarefa paralela ele transferirá o fluxo da execução para seus escravos.

É no comando create <instâncias $>,<$ tarefa $>$ que inicia-se a escolha dos nós através do algoritmo que considera um cenário inicial fornecido pelo usuário e a situação da carga e capacidade de cada nó. Esse comando indica qual a tarefa a ser executada e quantas instâncias deverão ser geradas. O algoritmo deverá encontrar tantos executores quantas forem as instâncias pedidas e, para isso, ele deverá investigar a situação de cada nó naquele momento e se já há alguma indicação 
fornecida pelo usuário. Detalhes da estratégia adotada podem ser vistos na Seção 4.2.1.

\subsubsection{A ativação das tarefas}

Ao término do algoritmo de escalonamento de uma tarefa, todos os nós que são responsáveis pela execução da mesma foram escolhidos e serão notificados através de uma mensagem que parte do comunicador mestre para o comunicador escravo de cada local designado.

Dentre os nós escolhidos, um deles vai ser escolhido pelo mestre para desempenhar o papel de "pai" da tarefa. Esse nó especial terá a responsabilidade de sincronizar a execução do grupo, executar a parte seqüencial da tarefa e notificar o mestre do término da tarefa.

A mensagem de ativação de uma tarefa contém:

- a identificação de todos os nós executores,

- número de executores que residem naquele local e

- a indicação de "paternidade" da execução.

\subsection{A execução das microtarefas}

Na seção anterior foi discutida a estratégia de ativação de uma macrotarefa que foi implementada. Nessa seção, vamos apresentar alguns detalhes inerentes à execução de uma microtarefa, que representa o trecho de código com as operações paralelas de uma tarefa.

Na Figura 5.8(a) pode ser observado o corpo de uma tarefa especificada com a linguagem CPAR. Os trechos de código que não pertencem à construção que define uma microtarefa (seja forall ou parbegin) são executados seqüencialmente por um dos executores.

O nó escolhido como pai da tarefa é responsável pela execução desses trechos, bem como pela coordenação da execução da microtarefa. Ele controla as barreiras 
que sincronizam todos os executores filhos aos quais foi atribuída a tarefa. $\mathrm{O}$ esquema do fluxo de execução pode ser observado na Figura 5.8(b). O esquema de coordenação é ilustrado na Figura 5.8(c).

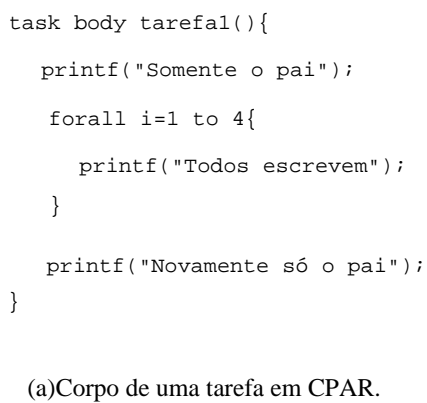

(a)Corpo de uma tarefa em CPAR.
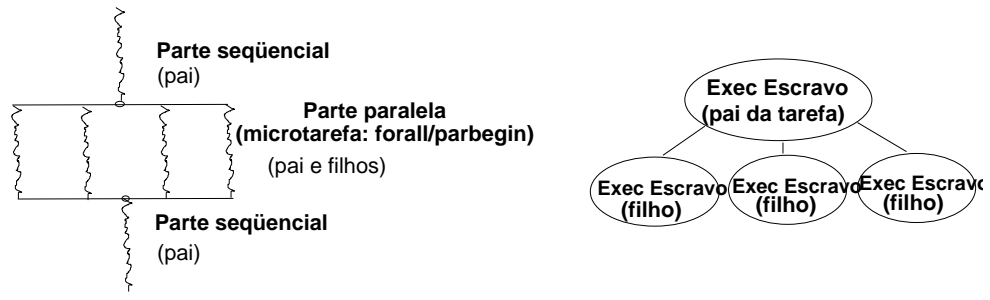

(b) Fluxos de execução e pontos de sincronização.

(c)Modelo de coordenação.

Figura 5.8: A execução de um forall.

O código resultante da pré-compilação que expande a tarefa escrita pelo programador com as rotinas de biblioteca oferecidas por este trabalho é apresentado na Figura 5.9.

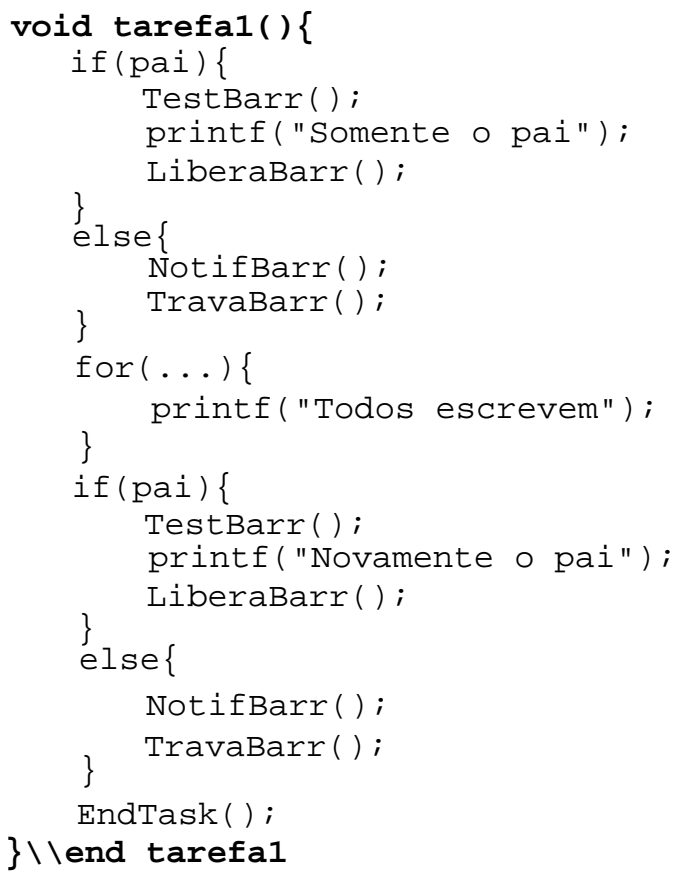

Figura 5.9: A expansão de um forall.

A rotina de biblioteca TestBarr() ao ser executada pelo pai da tarefa faz com que o executor fique travado até que o processo comunicador daquele nó receba 
todas as notificações vindas dos outros executores filhos. Sendo sinalizado que todos estão na barreira, o pai executa o trecho de código seqüencial e, ao término deste libera todos os filhos (LiberaBarr()) para que haja a execução do laço paralelo.

Os filhos ao executarem NotifBarr(), acionam o processo emissor dos respectivos nós para que ele envie uma mensagem de notificação da sincronização na barreira ao comunicador do nó onde reside o pai. Tendo sido enviada a notificação, o executor no papel de filho fica travado em TravaBarr() até que o comunicador do seu nó receba uma liberação vinda do pai (via o emissor daquele nó).

O protocolo descrito é ilustrado na Figura 5.10. Vale ressaltar que as setas pontilhadas não representam um envio de mensagem, é uma comunicação entre processos e thread que envolve semáforos e variáveis compartilhadas (buffers internos do sistema). As setas cheias são efetivamente mensagens enviadas via a camada de comunicação que implementa o padrão MPI.

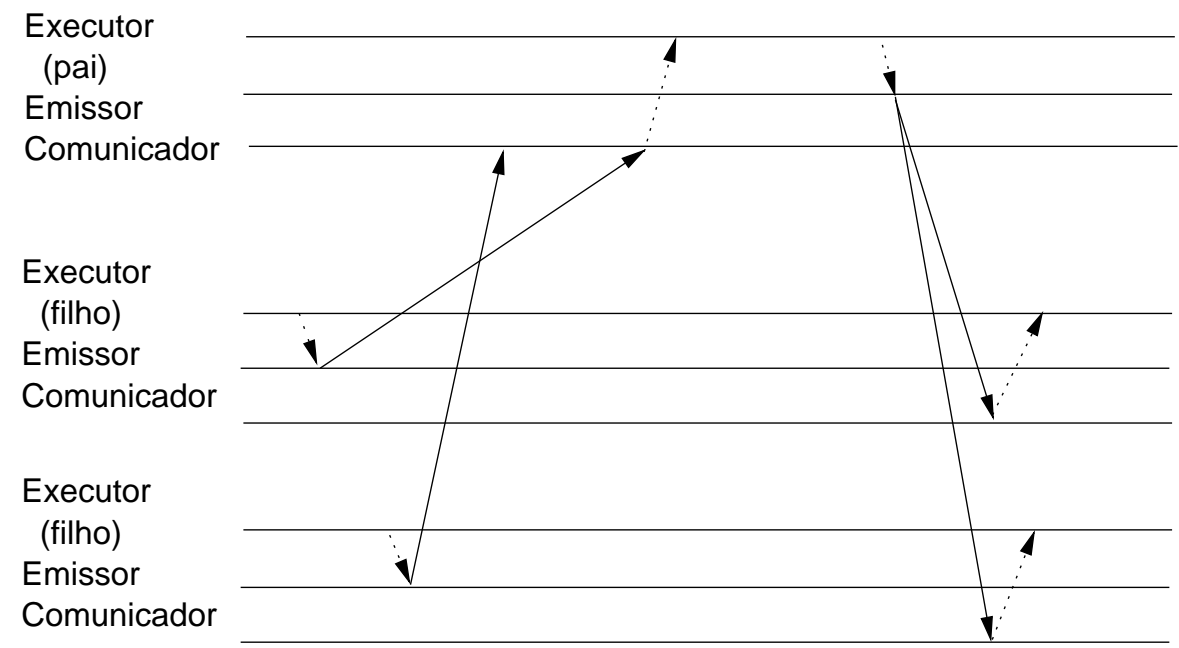

Figura 5.10: A ordenação dos eventos que compõem a sincronização imposta pela barreira.

Um importante detalhe omitido na Figura 5.9 merece maior discussão: como é realizado o particionamento das iterações que compõe um laço paralelo. Nas seções seguintes serão apresentadas duas estratégias de escalonamento, bem como as questões de implementação envolvidas para oferecê-las. 


\subsubsection{A implementação do escalonamento das iterações}

Como visto na Seção 4.2.2, o CPAR-Cluster implementa duas estratégias de divisão das iterações de um laço paralelo: o escalonamento estático por bloco e o escalonamento dinâmico por bloco. Nas próximas seções seguem-se questões relativas ao projeto e implementação das mesmas.

\section{O escalonamento estático}

De acordo com a Seção 5.6.1, todos nós participantes da execução de uma macrotarefa recebem as seguintes informações: número total de executores envolvidos, número de executores que residem naquele local e identificação do executor pai.

Cada executor ao sair da barreira de sincronização que antecede o laço paralelo faz o seguinte cálculo para determinar o seu bloco de iterações:

$$
\begin{aligned}
& \text { bloco }=\lceil(\text { final }- \text { inicial }+1) / \text { total de executores }\rceil \\
& \text { meu_inicial }=\text { inicial }+(\text { meu_id }-1) * \text { bloco }
\end{aligned}
$$

Dessa forma, o comando forall $i=$ inicial to final no código CPAR do usuário é traduzido no código expandido após a pré-compilação para:

for $($ itera $=$ meu_inicial; $($ itera $<($ meu_inicial + bloco $))$ G6 (itera $\leq$ final $)$; itera ++ )

Deve se ressaltar que, em tempo de execução, o tamanho do bloco atribuído a cada executor não é modificado durante as iterações do laço paralelo. Portanto, independente da capacidade computacional de cada nó, todos receberão a mesma carga de trabalho na estratégia de escalonamento estático.

Apesar da simplicidade de implementação dessa estratégia, ela não é muito indicada para explorar o potencial que um conjunto de máquinas heterogêneas (formado por nós mono e multiprocessadores) oferece. Uma interessante alternativa para contornar essa limitação é apresentada na próxima seção.

\section{O escalonamento dinâmico}

Além de todas as construções que a linguagem CPAR oferece, vistas no Capítulo 3, este trabalho propõe e implementa o laço paralelo com escalonamento dinâmico. 
A sintaxe CPAR do comando é apresentada na Figura 5.11.

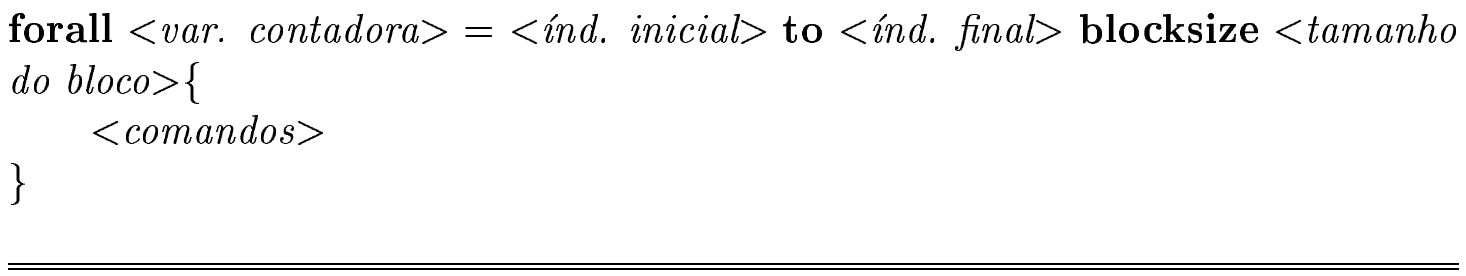

Figura 5.11: A sintaxe do laço paralelo com escalonamento dinâmico em CPAR.

Nessa estratégia, todos os executores da tarefa calculam o tamanho do bloco de iterações de acordo com todas as informações vistas no cálculo do escalonamento estático. A diferença está em um componente, o tamanho do bloco, inexistente no caso anterior.

$$
\begin{aligned}
& \text { bloco }=<\text { tamanho definido pelo programador }> \\
& \text { meu_inicial }=\text { inicial }+(\text { meu_id }-1) * \text { bloco }
\end{aligned}
$$

A expansão de um laço paralelo com escalonamento dinâmico é ilustrada na Figura 5.12. Os executores, ao terminarem o bloco de iterações atribuído, verificam se ainda restam blocos para execução. Através da chamada à GetBlock eles acionam o emissor do nó que envia uma mensagem para o comunicador do nó onde reside o executor pai. Neste local ocorre a centralização do controle dos blocos restantes. Ao receber o número do bloco, o comunicador do executor filho que solicitou a informação, o desbloqueia para que possa retomar a execução do trabalho.

A seqüência de eventos do protocolo de controle do escalonamento dinâmico é esquematizado na Figura 5.13. É importante registrar que, quando todos os executores residem no mesmo local (pai e filhos), não há necessidade de envio de mensagens, o controle é feito através de semáforos e variáveis compartilhadas internos ao sistema.

Pelo fato dos blocos serem atribuídos em tempo de execução, o trabalho será distribuído proporcionalmente à capacidade computacional do nó, evitando assim que executores que residem em máquinas mais velozes fiquem ociosos enquanto outros executores em máquinas menos potentes ainda executam blocos de iterações. 


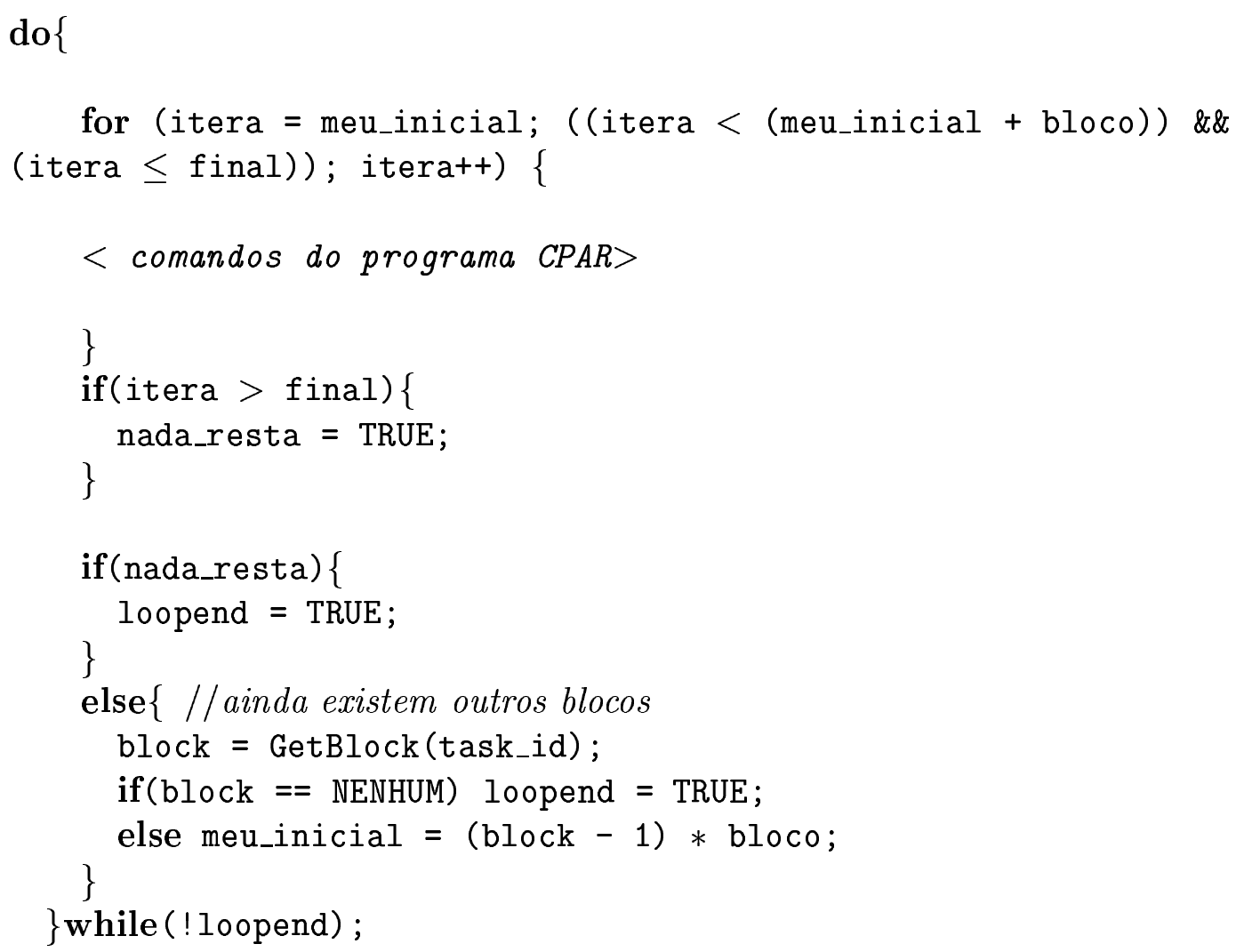

Figura 5.12: A expansão do laço paralelo com escalonamento dinâmico.

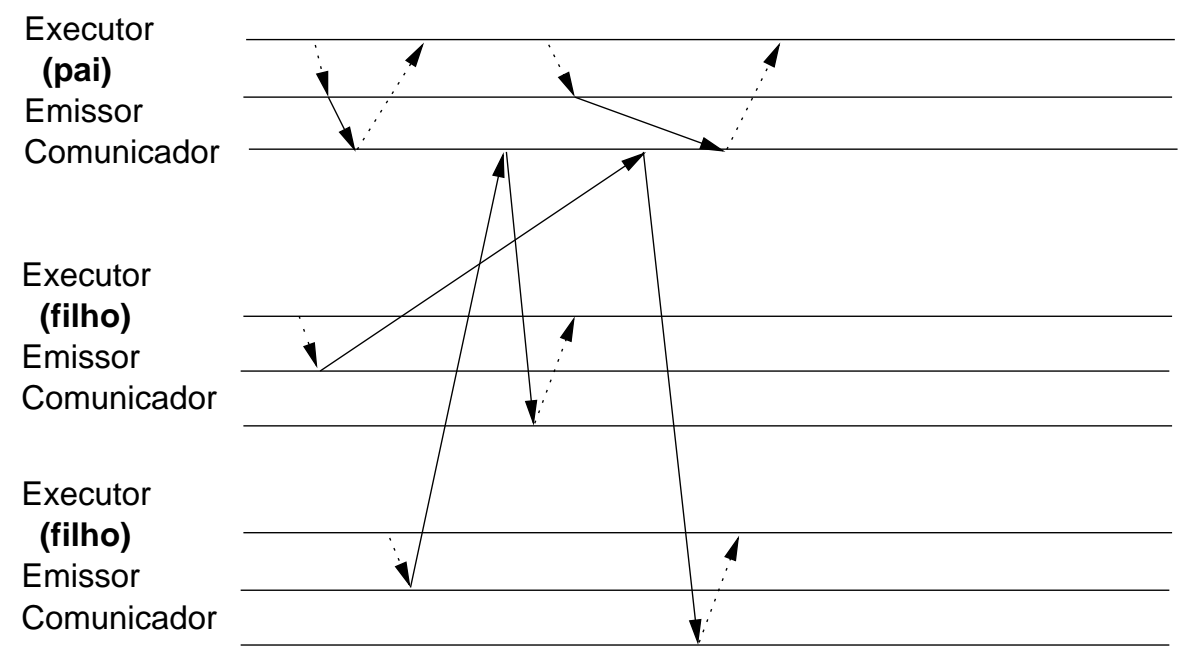

Figura 5.13: A ordenação dos eventos que compõem o controle de blocos no escalonamento dinâmico. 


\subsection{As variáveis compartilhadas dentro do siste- ma}

O oferecimento de uma abstração de memória compartilhada envolve não somente o compartilhamento das instruções de código que serão executadas por vários threads espalhados pelo sistema. O programa CPAR também manipula dados que, idealmente, devem estar atualizados sempre que forem alterados e que devem estar disponíveis sempre que forem lidos.

Para o programador, é totalmente transparente a localização das variáveis declaradas, bem como todo protocolo de atualização necessário para propagar o novo valor de uma variável compartilhada.

Está sendo dada ênfase nas variáveis compartilhadas pois, as variáveis privadas, independente de seu escopo de declaração no programa CPAR do usuário, têm o seu tratamento sob responsabilidade do compilador da linguagem C e são referenciadas normalmente no código pré-compilado. Todas as operações com estas variáveis privadas são feitas em memória local e, portanto, não afetarão outras porções de memória que residem remotamente.

Nas seções seguintes será detalhado cada aspecto que envolve o oferecimento da abstração das variáveis compartilhadas sobre uma plataforma composta por máquinas mono e multiprocessadoras interconectadas.

\subsubsection{A representação dos objetos}

Em geral as linguagens de programação oferecem ao programador duas classes de tipos de dados: os tipos básicos e os tipos derivados, que podem ser tanto agregados homogêneos de elementos do tipo simples como também heterogêneos.

Há duas questões a serem consideradas na representação dos objetos da linguagem: a modelagem desses objetos para uso do compilador (representação estática) e a implementação desses objetos de forma que seja possível serem manipulados em tempo de execução (representação dinâmica). 


\begin{tabular}{|l|l|}
\hline Tipos ANSI & Tipos MPI \\
\hline \hline unsigned char & MPI_UNSIGNED_CHAR \\
char & MPI_CHAR \\
signed char & MPI_CHAR \\
int & MPI_INT \\
unsigned int & MPI_UNSIGNED \\
signed int & MPI_INT \\
short int & MPI_SHORT \\
unsigned short int & MPI_UNSIGNED_SHORT \\
signed short int & MPI_SHORT \\
long int & MPI_LONG \\
signed long int & MPI_LONG_INT \\
unsigned long int & MPI_UNSIGNED_LONG \\
float & MPI_FLOAT \\
double & MPI_DOUBLE \\
long double & MPI_LONG_DOUBLE \\
& MPI_BYTE \\
\hline
\end{tabular}

Tabela 5.1: Tipos de dados definidos pelo padrão ANSI [Schildt, 1990] e pelo padrão MPI [LAM/MPI, 2003].

\section{Objetos de tipos básicos}

O sistema foi projetado para ser compatível com a linguagem CPAR que oferece os tipos básicos do padrão ANSI C ao programador (vide Tabela 5.1).

Uma variável de um tipo básico terá o seu valor propagado para outros nós do sistema através da biblioteca de comunicação MPI. Como visto na Tabela 5.1, há uma correspondência entre os tipos suportados pelo padrão ANSI C e os oferecidos pela implementação da biblioteca LAM-MPI.

\section{Objetos agregados homogêneos}

Uma matriz de $n$ dimensões é implementada através de uma seqüência de elementos que correspondem aos dados pertencentes às diversas colunas que compõem a matriz. Para obter o índice desse vetor de elementos que corresponda a ênupla de índices da matriz original deve ser utilizada uma fórmula de linearização.

Nosso trabalho considera que a política de alocação de memória utilizada pelo compilador C para objetos agregados seja a de organizar seqüencialmente os elementos da mesma linha e consecutivamente as várias linhas que compõem cada 
uma das dimensões de uma matriz.

Seja $M$ uma matriz de $n$ dimensões, $M\left[i_{1}: s_{1}, \ldots, i_{n}: s_{n}\right]$, cujos os limites inferiores dos índices são $i_{1}, \ldots, i_{n}$ e os superiores são $s_{1}, \ldots, s_{n}$. Para efetuar o cálculo de $E$, índice desse vetor de elementos correspondente a $M\left[j_{1}, j_{2}, \ldots, j_{n}\right]$, observe o detalhamento da fórmula nas etapas a seguir [Neto, 1987].

Considere que $E_{0}$ seja o endereço base da matriz (elemento $M\left[i_{1}, \ldots, i_{n}\right]$ e que cada elemento ocupe $p$ posições da memória.

1. calcula-se a amplitude de cada dimensão:

$$
a_{k}=s_{k}-i_{k}+1 \quad k=1, \ldots, n
$$

2. calculam-se os fatores que representam o número total de posições de memória ocupadas pelos elementos de matriz escolhidos variando-se os índices à direita daquele que representa cada uma das dimensões:

$$
\begin{gathered}
f_{k}=p * \prod_{m=k+1}^{n} a_{m} \quad k=1, \ldots, n-1 \\
f_{n}=p
\end{gathered}
$$

3. calcula-se a origem virtual $E_{v}$ da matriz:

$$
E_{v}=E_{0}-\sum_{k=1}^{n} f_{k} * i_{k}
$$

4. calcula-se finalmente o endereço $E$ desejado:

$$
E=E_{v}+\sum_{k=1}^{n} f_{k} * j_{k}
$$

A Seção 5.8.2 explica como atualizar e comunicar aos demais nós o novo valor de uma variável formada por uma agregação de elementos homogêneos. 


\section{Objetos de tipos heterogêneos}

A representação de agregados heterogêneos, tais como estruturas, envolve dois problemas: a representação dos seus dados na memória e a seleção dos campos de que a estrutura se compõem. Os campos de uma estrutura podem eventualmente ser, eles próprios, objetos agregados.

Os objetos heterogêneos são usualmente representados, em tempo de compilação, através de descritores que são construídos como estruturas de dados que representam grafos de relacionamento entre os elementos que compõem a estrutu-

ra. Cada um dos elementos é representado nessa estrutura de dados, através de um conjunto de atributos que indicam essencialmente o tipo do elemento, sua posição relativa dentro da estrutura e endereço de alocação na memória para campos estáticos.

Cabem às ações semânticas do compilador a criação das estruturas de dados que implementam os descritores, bem como efetuar a geração de código correspondente ao endereçamento de cada um dos seus campos.

\section{Exemplo de representação de objetos}

Como visto na Seção 5.8.1, a linguagem CPAR oferece ao programador a utilização dos tipos básicos da linguagem C (vide Tabela 5.1) e a definição de tipos compostos pelo programador. Esses tipos serão utilizados na declaração de variáveis tanto privadas como compartilhadas.

No exemplo da Figura 5.14, temos algumas definições de tipos e declaração de variáveis compartilhadas na linguagem CPAR. 


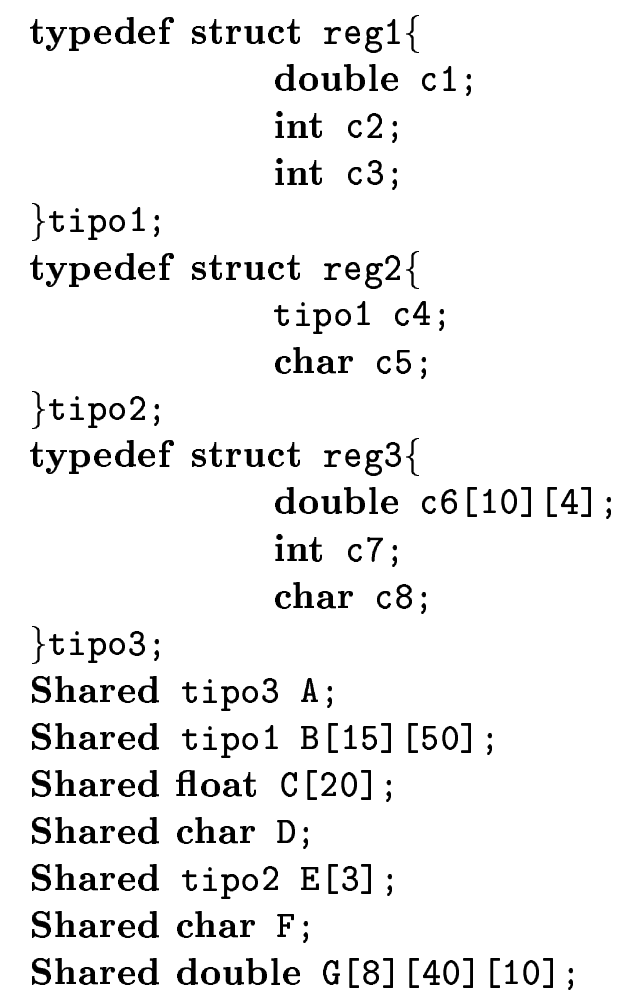

Figura 5.14: Exemplo de definição de tipos e declaração de variáveis compartilhadas em um programa CPAR.

A representação estática desses elementos é feita em tempo de compilação e dentro do nosso sistema é constituída pela Tabela de Variáveis Compartilhadas que, apesar do que o nome adotado sugere, também armazena informações sobre os tipos definidos pelo programador. Todos os nós do sistema terão essa tabela com todas as informações necessárias para manipular uma variável compartilhada. A estrutura dessa tabela é apresentada na Figura 5.15.

\begin{tabular}{|c|c|c|c|c|c|c|c|c|c|}
\hline \multirow{3}{*}{$\begin{array}{l}\text { Manipulador } \\
\text { [índice] }\end{array}$} & \multirow{2}{*}{ Identificador } & \multirow{2}{*}{ Tipo } & \multirow{2}{*}{$\begin{array}{l}\text { Dimensões/ } \\
\text { Campos }\end{array}$} & \multicolumn{3}{|c|}{ Fatores } & \multirow{2}{*}{$\begin{array}{c}\text { Campo } \\
\text { inicial }\end{array}$} & \multirow{2}{*}{$\begin{array}{l}\text { Endereço inicial } \\
\text { na memória (E0) }\end{array}$} & \multirow[t]{2}{*}{ Deslocamento } \\
\hline & & & & \begin{tabular}{l|l|}
$\mathrm{f} 1$ & $\mathrm{f} 2$ \\
\end{tabular} & 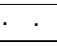 & fn & & & \\
\hline & & & & & & & & & \\
\hline
\end{tabular}

Figura 5.15: Estrutura da Tabela de Variáveis Compartilhadas.

A descrição de cada um dos campos é feita a seguir: 
Manipulador número inteiro que identifica unicamente uma variável, tipo ou campo.

Identificador cadeia de caracteres que compõem o nome.

Tipo tipo de dados primitivo (vide tipos ANSI C colocados na Tabela 5.1).

Dimensão ou Número de campos total de dimensões de um agregado homogêneo (matriz ou vetor) ou número total de campos no caso de um agregado heterogêneo (estrutura).

Fatores Número utilizado no cálculo da fórmula de linearização, necessário para obter-se o endereço de um elemento dentro de um agregado homogêneo (vide Equações 5.2 e 5.3).

Endereço do campo inicial No caso de uma linha da tabela conter um tipo definido pelo programador, este campo da tabela apontará para a linha que contém as informações referentes ao primeiro campo da estrutura.

Endereço inicial na memória Armazena o endereço da variável na memória. Constitui o endereço base, definido anteriormente como $E_{0}$.

Deslocamento Tamanho em número de bytes de cada campo de uma estrutura.

Os tipos e variáveis do exemplo exibido na Figura 5.14 seriam representados na Tabela de Variáveis Compartilhadas conforme visto na Tabela 5.2.

Após a introdução sobre representação das diversas formas de declarar uma variável compartilhada, será visto na seção seguinte como atualizar um campo ou o elemento de uma matriz multidimensional.

\subsubsection{A atualização de um elemento}

Para que uma variável compartilhada esteja atualizada em todos os nós necessários, as cópias em memória local deve receber o novo valor. A questão que se coloca nesse ponto é como acessar a posição correta, já que em diferentes máquinas podem 


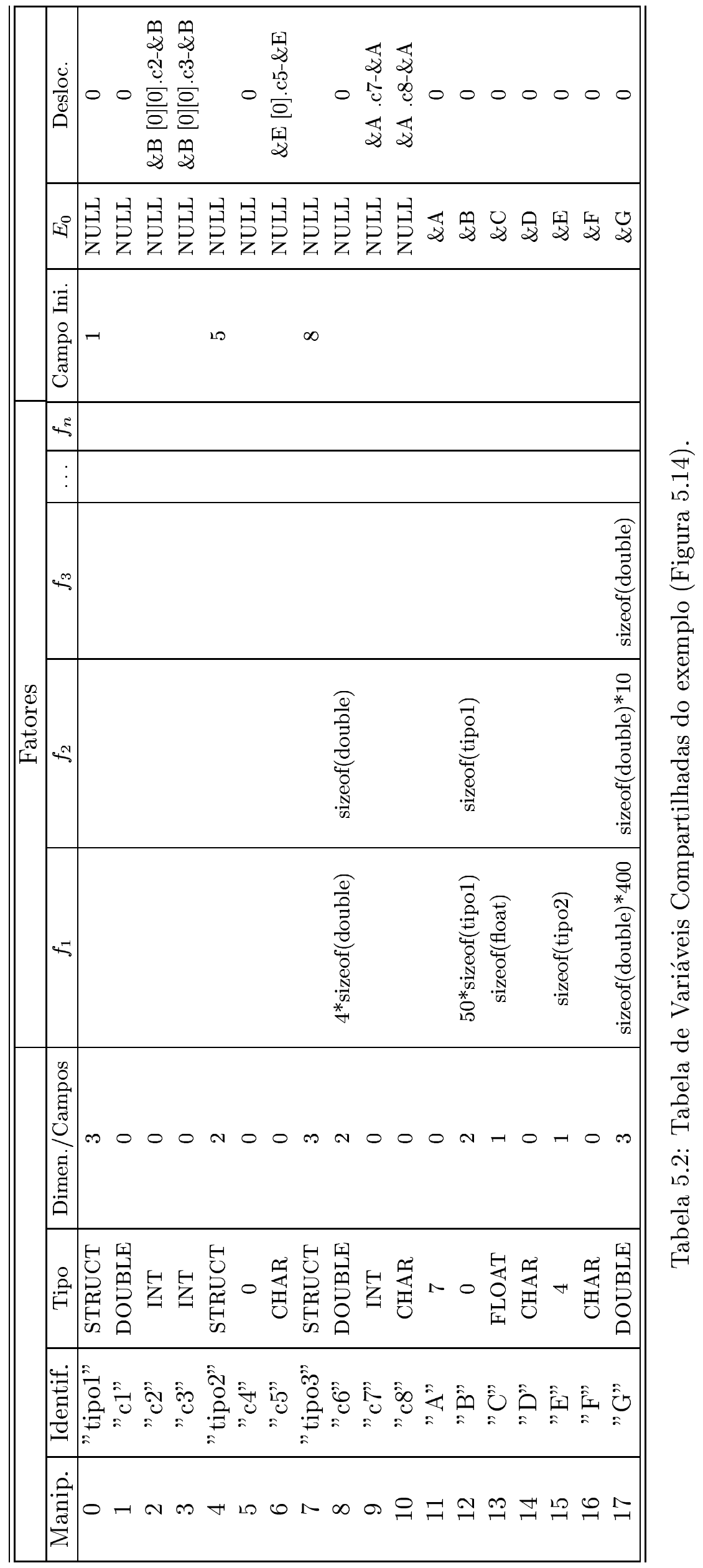


existir representações de tipos básicos com tamanhos diferentes e também variados alinhamentos.

A solução encontrada consiste em enviar na mensagem de atualização várias informações necessárias para o cálculo da fórmula de linearização. Entre elas podemos citar:

- tipo básico do campo ou do elemento;

- manipulador da variável (identificação única em todo sistema);

- o valor atualizado;

- no caso de ser uma variável de um tipo básico ou elemento de um agregado homogêneo, é enviado um pré-fator de deslocamento;

- na situação de uma variável de um tipo composto eram enviadas tantas indicações quantas forem necessárias para identificar o elemento básico (campo de uma estrutura), independente das peculiaridades do tipo definido.

Para as variáveis declaradas como Shared no exemplo colocado na Figura 5.14, teríamos o envio das informações conforme é apresentado na expansão do trecho de código que as atualiza (Figura 5.16).

Há uma distinção entre as informações sobre uma variável de um tipo homogêneo (seja básico ou agregado) e as de uma variável de tipo heterogêneo. No projeto e implementação dessa parte do sistema pretendeu-se diminuir ao máximo o tamanho da mensagem de atualização das variáveis do tipo que mais ocorre nos programas para que o tempo de transmissão impactasse menos.

Outra vantagem reside no fato dela trazer uma informação mais condensada em relação aos pré-fatores. A montagem do pré-fator é realizada em tempo de compilação (na expansão do código CPAR) e, com esse número sintetizado no envio da mensagem, há uma maior eficiência no cálculo do deslocamento em tempo de execução que processo na máquina alvo realiza.

O recebimento da mensagem no nó remoto, inicia o cálculo do endereço e a conseqüente escrita no endereço de memória local da variável. 


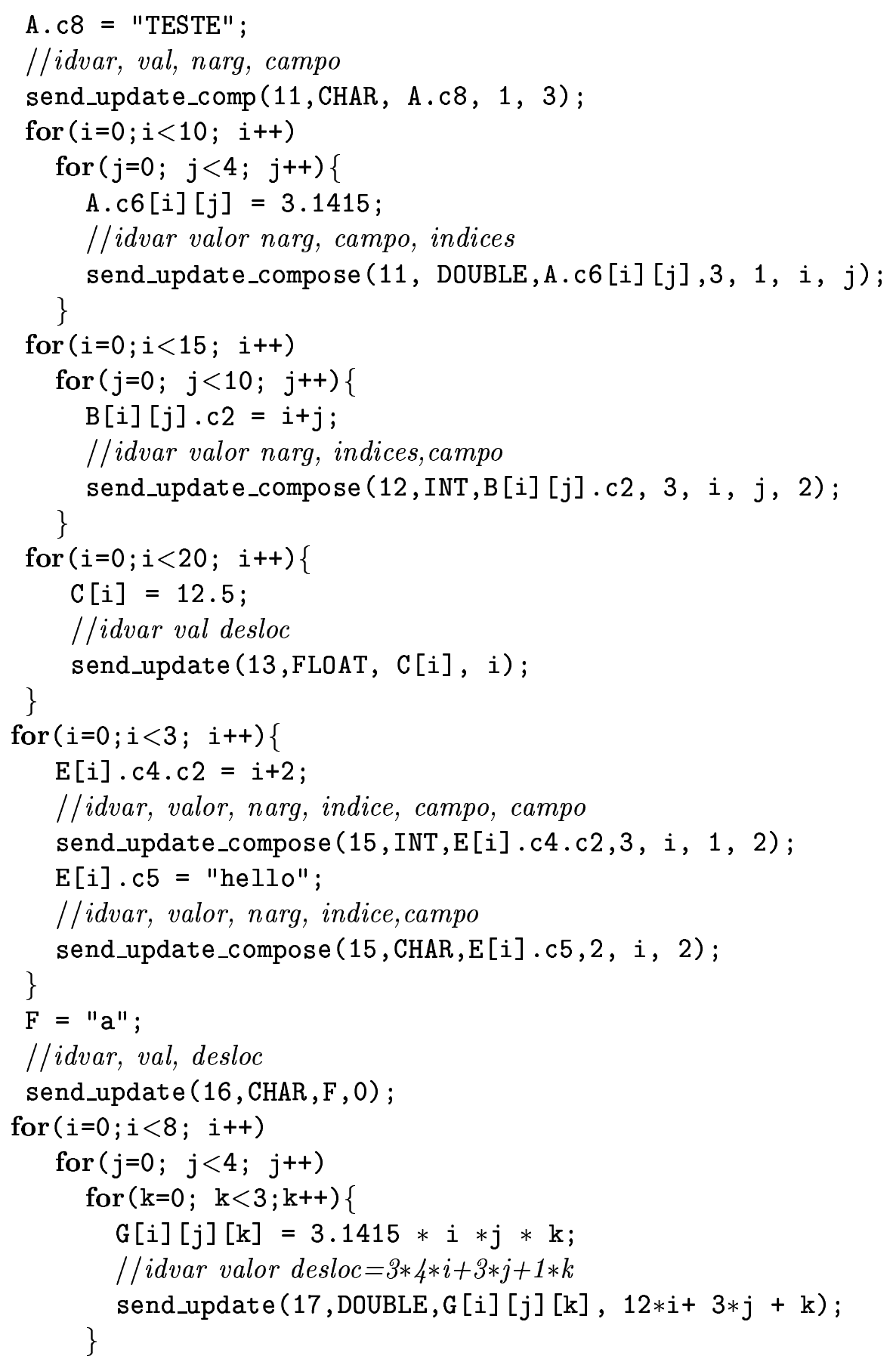

Figura 5.16: Exemplo das informações enviadas em uma atualização de variável compartilhada. 


\section{O esquema de buffers de atualização}

Para que não ocorra uma sobrecarga ao sistema causada pelo envio de cada mensagem de atualização, é utilizado um protocolo que define alguns pontos de propagação dentro do programa. Dessa forma, procura-se manter a consistência através da minimização do envio de mensagem.

A implementação desse protocolo envolve a utilização de buffers de armazenamento das mensagens de atualização. Na Figura 5.17 pode-se observar que, ao realizar a atualização de uma variável compartilhada, o Executor tanto escreve o valor na variável mantida em memória local, como envia essa e outras informações para o buffer de armazenamento. No momento apropriado, o processo Emissor vai ser acionado e este empacotará o buffer e o transmitirá para o destino indicado.

No local de recebimento está o processo Comunicador, que se encarregará de atualizar a posição de memória calculada através das informações constantes na mensagem e na Tabela de Variáveis Compartilhadas. Na Figura 5.18 observase que qualquer escrita realizada pelo Comunicador nessa porção de memória é visível para o(s) Executor(es) de um nó, pois trata-se de uma área compartilhada por ambos.

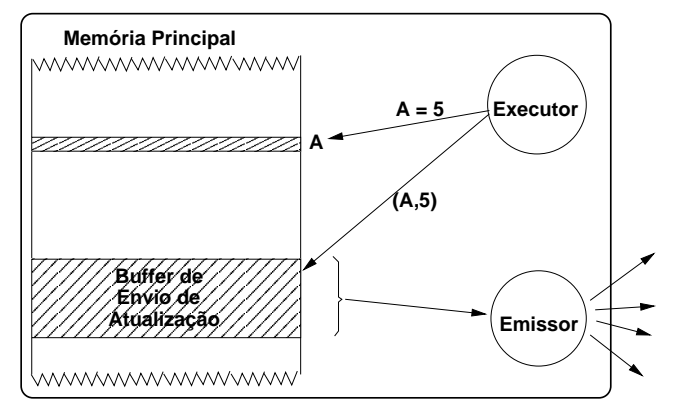

Figura 5.17: Regiões da memória que armazenam a atualização, manipuladas pelo processo Emissor e thread Executor.

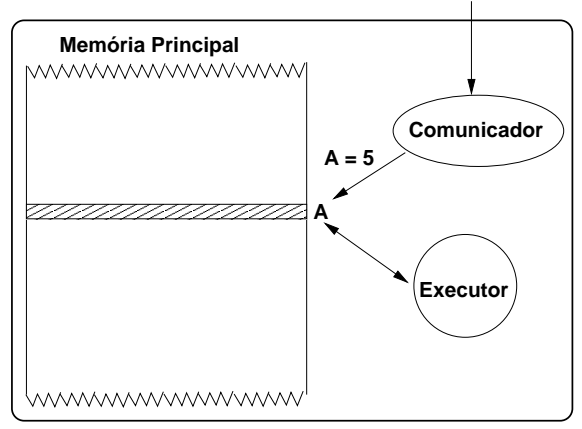

Figura 5.18: Recebimento de mensagem de atualização pelo processo Comunicador e escrita em área compartilhada com thread Executor de um nó. 


\section{A estrutura dos buffers de atualização}

A distinção do conteúdo das mensagens de atualização determinadas pelo tipo da variável (básico ou heterogêneo) implicará em duas estruturas de buffers diferentes: o conjunto Primitivo armazena as informações das variáveis de tipo básico/agregado homogêneo e o conjunto Composto guarda as mensagens que contém atualização de variáveis de tipo heterogêneo.

O conjunto Primitivo armazena o manipulador da variável, o valor atribuído e o deslocamento lógico (fator) a ser utilizado no cálculo do endereço. Para o conjunto Composto, tal sintetização de um fator não pode ser obtida, portanto todas as informações relativas à amplitude devem ser enviadas. Além dessas informações, logicamente será transmitido o novo valor da variável.

Além dessa divisão por tipo, existem conjunto de buffers relacionados a um determinado escopo de declaração da variável. Ou seja existem conjuntos de buffers Primitivos e Compostos para variáveis globais e outros conjuntos para as variáveis locais a uma determinada macrotarefa.

A criação de conjunto de buffers relacionado ao escopo de declaração foi uma necessidade imposta pelo protocolo de propagação de atualização que será discutido na próxima seção.

Além das classificações mencionadas anteriormente, foi implementado um rodízio de buffers, de forma que quando o processo Emissor estiver empacotando e enviando um buffer, o Executor não necessite parar sua execução para esperar pela liberação do espaço de armazenamento. O Executor prossegue sobre um segundo conjunto disponibilizado pela implementação do sistema de chaveamento de buffers de atualização.

\subsubsection{O protocolo de propagação de atualização}

Um dos pontos altos do desenvolvimento do trabalho e que, com certeza exigiu esforços consideráveis nas etapas de projeto e implementação, foi o oferecimento da transparência no acesso e na alteração de várias porções de memória espalhadas pelo sistema computacional. 
A abstração de uma memória compartilhada sobre uma rede de computadores envolve a implementação de um modelo de consistência (vide Capítulo 2). No caso particular deste trabalho de doutorado foi utilizado o modelo de consistência relaxada.

Um dos maiores desafios foi manter a consistência dos dados sem que prejuízos sérios ao desempenho fossem impostos pelo protocolo. Para evitar que houvesse uma excessiva troca de mensagens de atualização, foram definidos alguns pontos de propagação das atualizações empacotadas. Nas próximas seções esses pontos serão definidos e terão os argumentos que justificam a sua eficácia apresentados.

Além da definição dos pontos de propagação, também serão discutidas duas estratégias de distribuição dos pacotes de atualização que foram propostas, implementadas e avaliadas neste trabalho.

\section{Os pontos de propagação dentro da função principal}

Na execução da função principal do programa CPAR, somente as variáveis compartilhadas declaradas globalmente podem ser utilizadas. Não faz sentido oferecer declaração de variável compartilhada local à main, pois é um código executado seqüencialmente, não envolvendo assim compartilhamento, distribuição e concorrência no acesso aos dados locais.

Basicamente os dois pontos de verificação do buffer de atualização estão:

- antes do disparo da(s) instância(s) de uma macrotarefa, através da execução de um create e

- antes da liberação de acesso à uma seção crítica do programa, ou seja, antes da execução de um unlock.

Se há alguma mensagem dentro do buffer que guarda as atualizações às variáveis compartilhadas globais (indicadas na Figura 5.19 por ShG), o mesmo é empacotado e enviado para os locais apropriados. Não havendo atualização, nenhum tratamento e propagação de buffer é realizado. 
Nesse trecho de código há atualização de variável compartilhada global, mas como não existe uma outra linha de execução em paralelo, não há necessidade do uso de mecanismo de exlusão mútua (ex. semáforo).

Antes de serem criadas n instâncias de task1, a atualização anterior deve ser propagada aos nós para garantir que ela seja visível por todo sistema (principalmente naqueles que irão excutar task1).

No momento da execução desse trecho da função main, existirão n threads executando task2 e que podem estar manipulando a variável compartilhada global que main atualiza. Para que não haja inconsistências, o programador deve encerrar esse código dentro de uma seção crítica.

Pelo protocolo de atualição proposto e implementado, antes que uma próxima thread ganhe acesso à seção crítica onde está a operação de manipulação de variável compartilhada, deve ser realizada a propagação de atualização para os nós do sistema.

Antes de serem criadas $\mathrm{n}$ instâncias de task3 é verificado se houve manipulação de variável compartilhada global. Como no trecho seqüencial anterior não ocorreu, não será necessário propagar nenhuma mensagem pelo sistema.

Trecho de código onde variável compartilhada global é atualizada, mas o programador não necessita utilizar mecanismo de exclusão mútua. Não haverá propagação pois não será feito nenhum create e, conseqüentemente nenhum nó escravo do sistema a utilizará.

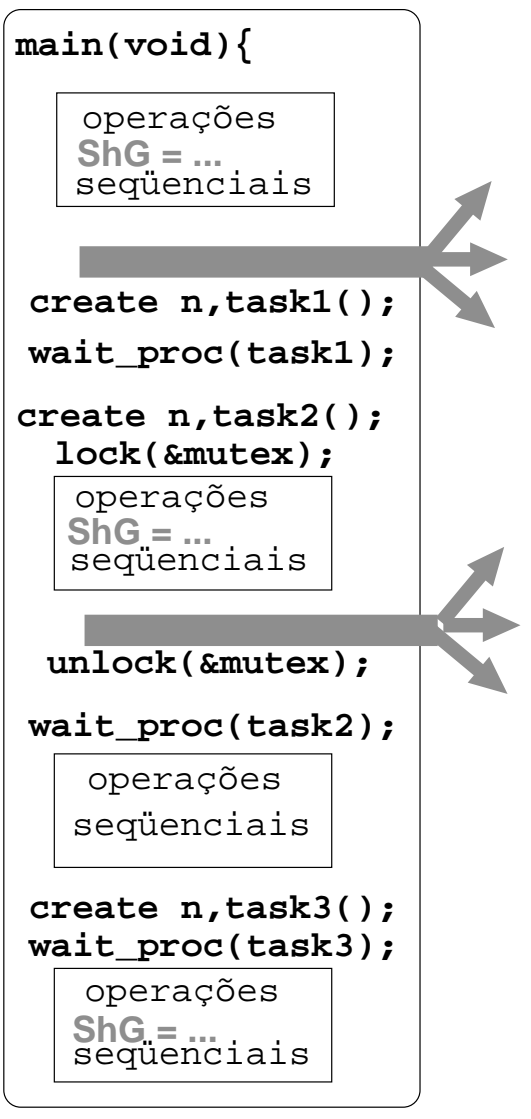

Figura 5.19: Pontos de propagação de atualização de variável dentro da função principal do programa do usuário.

Além desses dois pontos de verificação e possível propagação, um buffer pode ser enviado quando o total de mensagens alcança o limite de armazenamento do mesmo. Nesse momento é utilizado o mecanismo de chaveamento de buffers apresentado na seção anterior.

A Figura 5.19 discute cada ponto da função principal onde há atualização de uma variável compartilhada global e o seu respectivo ponto de verificação/propagação.

\section{Os pontos de propagação dentro de macrotarefa}

A linguagem CPAR permite que o programador declare e utilize variáveis compartilhadas no escopo de uma macrotarefa, além da possibilidade de manipular variáveis compartilhadas globais.

Na Figura 5.20, a atualização de uma variável compartilhada é representada por ShG (global) ou ShL (local). Nesse exemplo temos um primeiro trecho de 
código que vai ser executado seqüencialmente pelo Executor pai da tarefa. Terminado esse trecho, todos os Executores dividirão o trabalho das iterações de duas microtarefas. Primeiramente há execução do primeiro laço paralelo, todos se sincronizam ao término deste para poderem iniciar a execução do segundo laço. Há uma nova sincronização ao final do laço. Há um último trecho de código que não está inserido em nenhuma construção de microtarefa e por isso será executado de forma seqüencial novamente pelo pai.

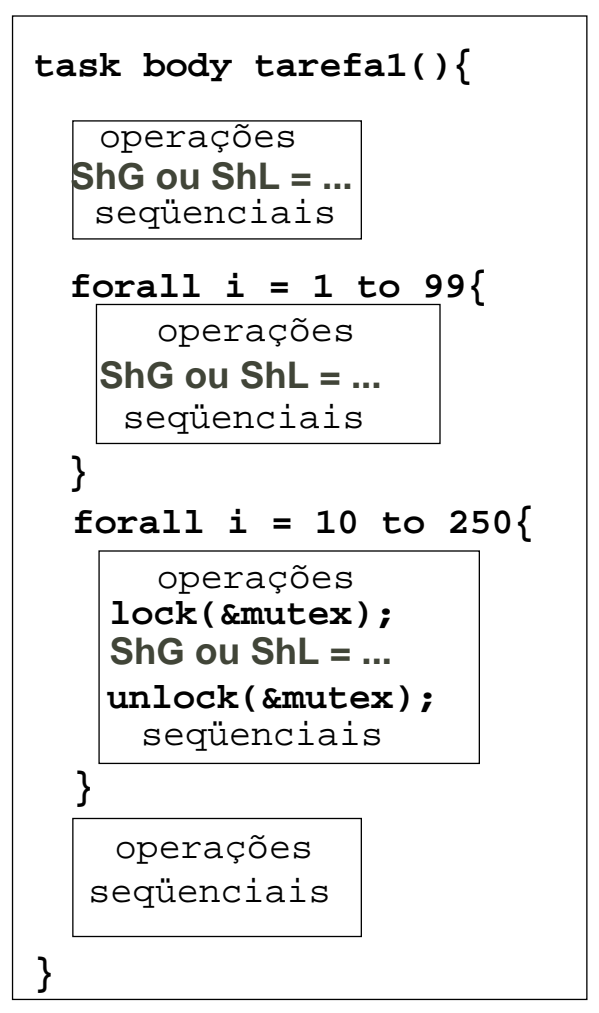

Figura 5.20: Manipulações de variáveis compartilhadas dentro de uma macrotarefa.

O código pré-compilado e expandido com as chamadas da biblioteca desenvolvidas neste trabalho é apresentado na Figura 5.21. Nele ficam mais explícitas as barreira de sincronização entre pai e filhos. Conforme ilustrado na figura, os pontos de verificação do buffer e propagação dentro da execução de uma macrotarefa são os seguintes:

- ao final de um trecho de operações executadas seqüencialmente,

- ao final da execução das iterações de um laço paralelo e 
- antes da liberação de acesso à uma seção crítica do programa, ou seja, antes da execução de um unlock.

Como discutido na seção anterior, um buffer também será propagado quando for alcançado o seu limite de armazenamento. Nesse caso, um segundo conjunto de buffers vai ser disponibilizado para o(s) Executor(es) enquanto o Emissor encarrega-se de empacotar e enviar o primeiro.

Ao projetar o envio das atualizações ocorridas durante a macrotarefa, verificouse a seguinte situação: um Executor insere atualização de variável local no buffer, ao mesmo tempo o Executor da função principal que reside nesse nó passa por um ponto de verificação e propagação. Será verificado que existe mensagem no buffer e ele será propagado, mesmo que a execução da tarefa não tenha passado pelo ponto de verificação e sem que o buffer esteja cheio e tenha que ser enviado. Para contornar essa questão foram construídos os conjuntos de buffers por escopo, como mencionado na Seção 5.8.2.

\section{Estratégias de distribuição}

Na abstração de memória compartilhada, uma atualização de uma variável global deve estar visível em todos os nós que compõem o sistema, assim como a escrita em uma variável compartilhada local deve ser propagada para todos os nós aos quais foi atribuída a execução da macrotarefa onde ela foi declarada.

A estratégia descrita é a de distribuição total, ou seja todos os participantes receberão a mensagem de atualização. Uma outra estratégia pretende explorar a situação onde apenas um nó do sistema centraliza o resultado da computação. É a estratégia de distribuição central, onde pretende-se um aumento no desempenho devido a diminuição do tráfego de mensagem.

Na distribuição central, a atualização de uma variável compartilhada global é enviada somente para o nó onde reside a execução da função principal do programa CPAR. No caso da variável compartilhada ter o seu escopo restrito à uma macrotarefa, sua atualização é somente propagada para o local onde reside o Executor pai da macrotarefa em questão. 
task body tarefal () \{

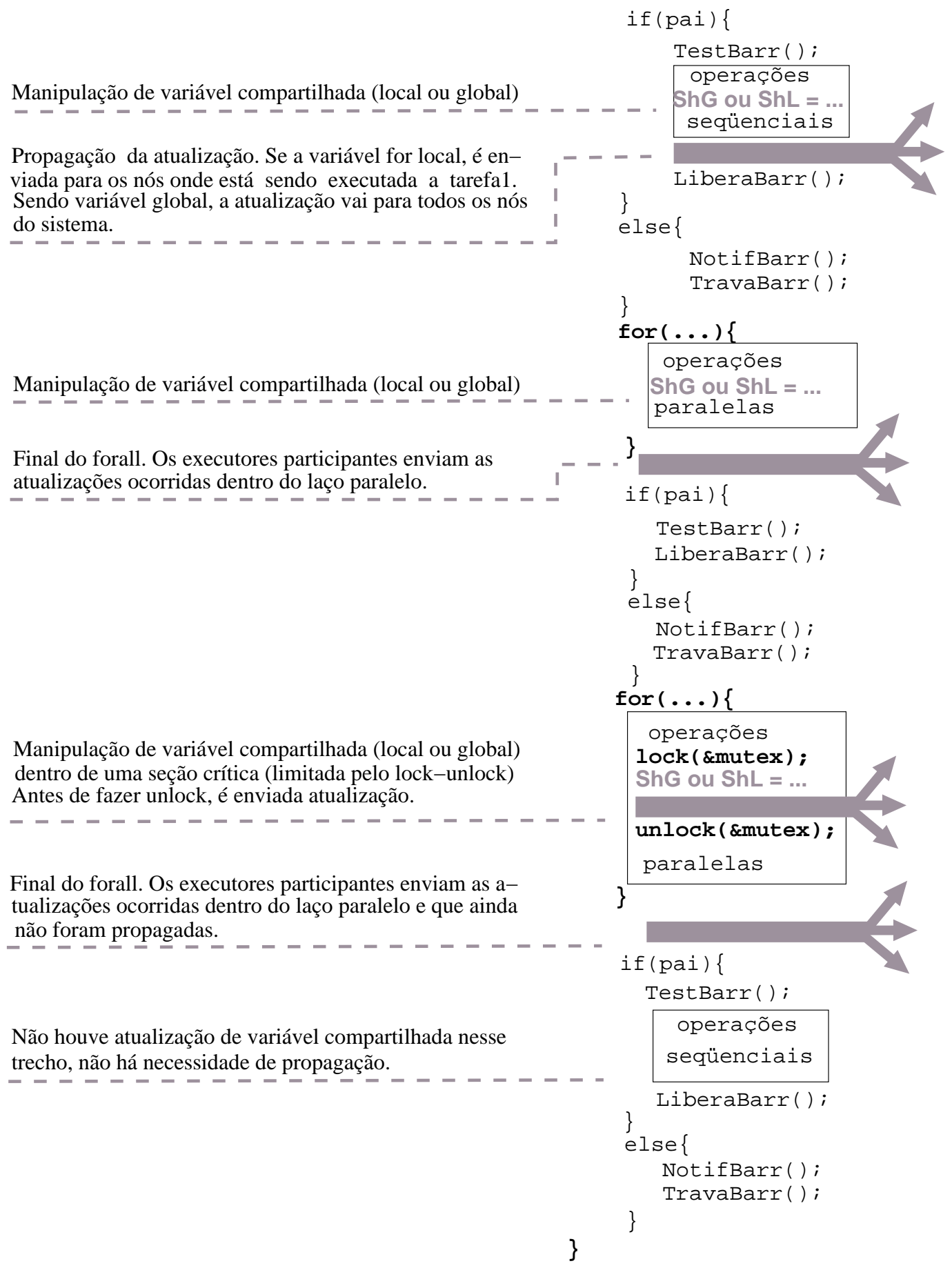

Figura 5.21: Pontos de propagação de atualização de variável dentro de uma macrotarefa. 
Shared int A;

Shared master int $B$;
/* variável compartilhada, distribuição total default*/

/* distribuição central*/

Figura 5.22: Sintaxe CPAR para declaração de variáveis compartilhadas segundo a estratégia de distribuição.

A distinção do tipo de distribuição é feita na declaração da variável, conforme ilustrado na Figura 5.22.

Neste trabalho foram implementadas e avaliadas as duas estratégias de distribuição apresentadas. Para oferecer essas duas estratégias, mais uma modificação na estrutura dos buffers de atualização fez-se necessária. Além de ter uma separação por tipo e pelo escopo da declaração o conjunto também deve ser oferecido para cada tipo de distribuição, pois com um único buffer de armazenamento das variáveis globais, na hora de atualizar uma variável de distribuição central o sistema não estaria propagando outra, de distribuição total, para os demais nós do sistema.

Tendo considerado isto, o formato final do envio de uma atualização para o buffer inclui os seguintes itens:

- Manipulador da variável.

- Escopo da declaração: Global ou Local, nesse último caso é informado o manipulador específico da macrotarefa.

- Tipo da distribuição.

- Tipo básico.

- Informações necessárias ao cálculo do endereço da variável.

- Valor atual. 


\subsection{Mecanismos de sincronização e exclusão mútua}

A linguagem CPAR disponibiliza alguns mecanismos de sincronização e exclusão mútua ao programador. O estágio atual da implementação do trabalho desenvolvido suporta semáforos, mas o projeto já prevê o oferecimento dos mecanismos de eventos e monitores.

\subsubsection{Semáforos}

O sistema possui uma tabela que armazena as seguintes informações dos semáforos declarados no programa do usuário:

- Estado: que pode assumir os valores Nenhum, Criado e Removido;

- Valor: valor do semáforo que é iniciado com create_sem e alterado com as operações de lock unlock;

- Ponteiros da fila: apontam para o início e para o final da fila que guarda a identificação do processo em espera.

Tais controles são gerenciados de forma centralizada e estão sob a responsabilidade dos processos Comunicadores. Se o semáforo é declarado globalmente ele está sob a responsabilidade do Comunicador do nó onde reside o Executor da função principal (o Executor Mestre). No caso de um semáforo local a uma macrotarefa, quem controla todas as operações sobre esse semáforo é o Comunicador do nó onde reside o Executor pai da tarefa.

\section{Eventos e Monitores}

Esses mecanismos podem ser facilmente oferecidos através de uma variação da implementação dos semáforos apresentada na seção anterior.

No caso do evento, pode-se associar uma fila de processos esperando por uma notificação que será enviada assim que o valor atingir 1. 
Para implementar o mecanismo de monitor, na expansão das rotinas internas seriam colocadas chamadas de lock e de unlock de um semáforo como visto na Seção 5.9.1.

\subsubsection{Barreiras Wait_Task e Wait_All}

Esses mecanismos controlam a sincronização de um ou vários fluxos de execução. No caso da barreira wait_task deve-se esperar a conclusão de uma tarefa específica e no caso da barreira wait_all a espera encerra-se quando todas as tarefas disparadas foram concluídas.

A implementação dos dois mecanismos é praticamente idêntica. O Executor Mestre ao executar a chamada da biblioteca correspondente a um dos casos ficará suspenso. O processo Comunicador daquele nó, ao receber uma mensagem de final de execução de tarefa, atualiza um controle existente na Tabela de Tarefas. Quando todas forem concluídas ele verifica se o Executor está esperando em um Wait_Task e o libera. Além de atualizar a tabela, o Comunicador Mestre também controla o número de tarefas em execução, quando esse valor chega a zero, ele libera o Executor se este estiver esperando dentro de um Wait_All.

\subsection{Coordenação e finalização}

Algumas chamadas à biblioteca não tem uma correspondência com o que é oferecido ao programador em CPAR. Tratam-se de primitivas de controle interno do sistema.

Nos códigos expandidos, pode-se notar a presença da chamada à End_Task no final do corpo de uma macrotarefa. A sua execução faz com que o processo Emissor envie mensagem que sinalize o término da execução de uma das instâncias de uma tarefa. O Comunicador no nó do pai coleta as várias sinalizações e depois envia uma mensagem indicando o término da tarefa como um todo. Além de haver a atualização de estruturas internas ao sistema, tal primitiva tem efeitos de coordenação da execução, como visto na discussão da Seção 5.9.2.

Outra importante primitiva é responsável pela sinalização do término da exe- 
cução. Por meio da chamada à End_Sys, o Executor Mestre, através de seu Emissor, propaga por todo o sistema a mensagem de encerramento. Nesse ponto, cada nó é desfeito: os buffers são desalocados, semáforos internos são destruídos, áreas de memória compartilhada são removidas e efetua o encerramento de threads e processos. 


\section{Capítulo 6}

\section{Análise dos Resultados}

As estratégias propostas e implementadas neste trabalho demandaram um número razoável de testes para que fosse caracterizado um comportamento do sistema CPAR-Cluster sob variadas condições da aplicação do usuário.

Nesse capítulo é descrito o ambiente computacional adotado nos testes, bem como são feitas considerações sobre cada versão dos testes principais. Ao apresentar os resultados das medições serão tecidas algumas análises e conclusões.

\subsection{Descrição dos Testes}

Os testes escolhidos procuram avaliar cada uma das estratégias de atualização que foram propostas e implementadas. Para se ter uma base adequada de comparação, foi selecionado o problema da multiplicação de matrizes que permite exemplificar de uma forma bastante simples diferentes perfis de atualização.

A sobrecarga gerada pelo protocolo de atualização implementado também é avaliada através da comparação entre versões da multiplicação de matrizes. Outro ponto que motivou a escolha da multiplicação de matrizes foi a independência das iterações que possibilita um confronto das diferentes estratégias de escalonamento de iterações do laço paralelo. Trata-se portanto de um problema que reúne, dentro de um algoritmo bastante resumido, diversas questões a serem analisadas.

Outro interessante problema, o do caixeiro viajante, permite-nos verificar o comportamento do sistema CPAR-Cluster diante do acesso às variáveis compartilhadas encerradas em uma seção crítica controlada por semáforos. 
Antes da apresentação de maiores detalhes envolvidos nos problemas específicos será feita a descrição da metodologia seguida para a realização dos testes.

\subsubsection{Metodologia}

Utilizamos nos testes a plataforma atualmente disponível no LASB, constituída por dois clusters, conforme ilustrado na Figura 6.1.

Cluster Taurus Composto por 16 nós Intel Celeron de $433 \mathrm{MHz}, 128 \mathrm{MB}$ de RAM e um nó SMP com 4 processadores Pentium II Xeon de $400 \mathrm{MHz}$, 1MB de cache, $256 \mathrm{MB}$ de RAM. Todos têm instalados RedHat Linux 8.0 e LAM-MPI 6.5.9.

Cluster Bio Composto por 8 nós SMP, cada um com dois processadores AMD Athlon MP 1800+, com clock de 1553 MHz, 1 Gbyte de memória RAM Possui o mesmo sistema operacional e a mesma plataforma MPI (implementação e versão) que o cluster Taurus.

Todos os nós estão conectados por rede Fast Ethernet. Para os dois clusters existe uma máquina de entrada comum. Esse nó não é utilizado para processamento das tarefas, ele é voltado para a coordenação dos dois aglomerados.

Foi executada a versão seqüencial em uma das máquinas monoprocessadoras, na SMP com 4 processadores e em uma máquina SMP de dois processadores. Os testes com o sistema CPAR-Cluster foram realizados sobre as seguintes configurações:

- Homogêneas: um nó quad, um nó dual, quatro duais, oito duais, 16 monos.

- Heterogêneas: um quad e oito duais, um quad e dezesseis monos, um quad juntamente com 8 duais e mais 16 monos.

Foram realizadas de vinte a trinta execuções dos programas das três versões da multiplicação de matrizes e do algoritmo do caixeiro viajante. Foram calculados a variância e o intervalo de confiança dos dados. 


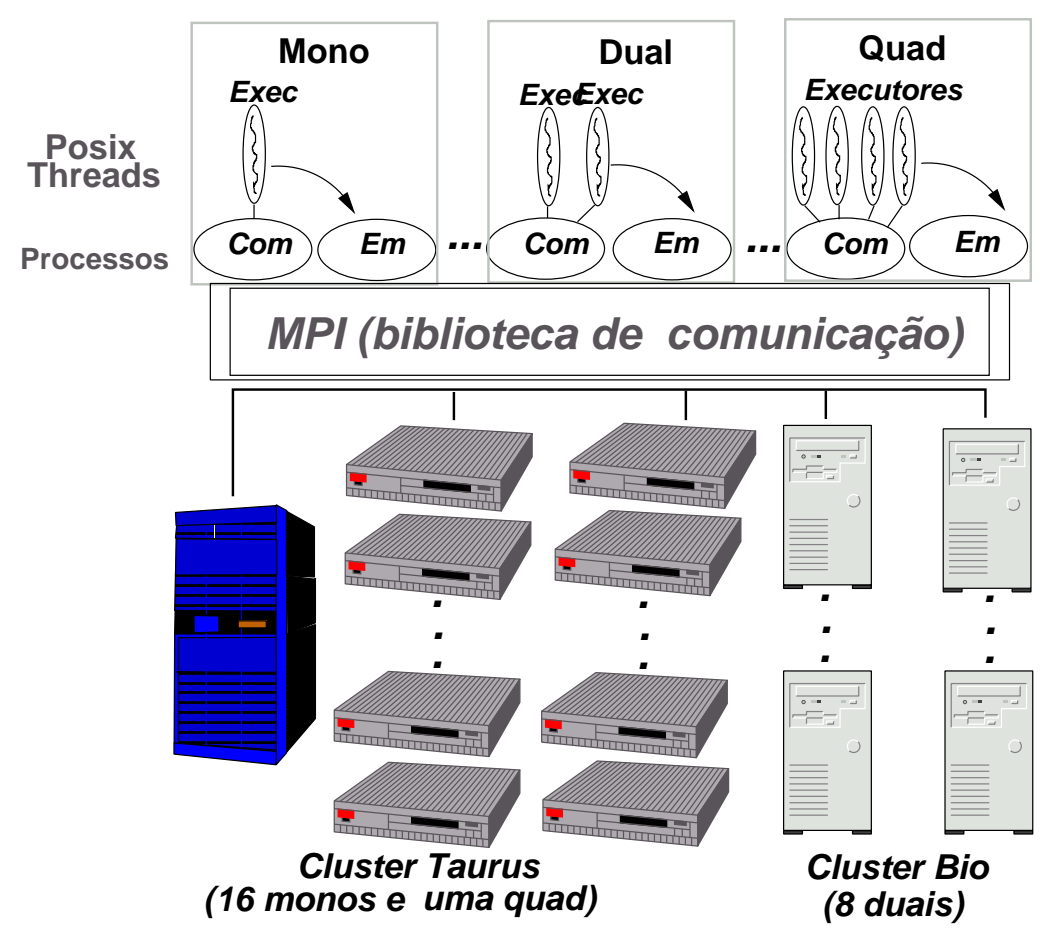

Figura 6.1: $\mathrm{O}$ ambiente utilizado na realização dos testes.

Encontram-se no Anexo $\mathrm{C}$ os códigos expandidos utilizados nos testes. Por questão de espaço, somente serão apresentados neste capítulo os programas escritos em CPAR.

\subsubsection{Multiplicação de Matrizes}

Nessa seção serão apresentadas as três versões de um programa de multiplicação de matrizes. A primeira pretende investigar o comportamento do sistema sob intensa troca de mensagens de atualização, a segunda foi desenvolvida para verificar a estratégia de distribuição centralizada e a última avaliará somente a sobrecarga gerada pela coordenação do sistema, pois mensagens de atualização não serão geradas.

\section{Versão com Atualização em todos os nós (Global Total)}

O primeiro teste descrito na Figura 6.2 realiza a multiplicação das matrizes quadradas A e B e coloca o resultado na matriz C, ambas declaradas pelo programador como variáveis compartilhadas globais. 


\section{\#define SIZE 2000 \\ \#define NPROC 4}

Shared double A[SIZE];

Shared double B [SIZE];

Shared double C[SIZE];

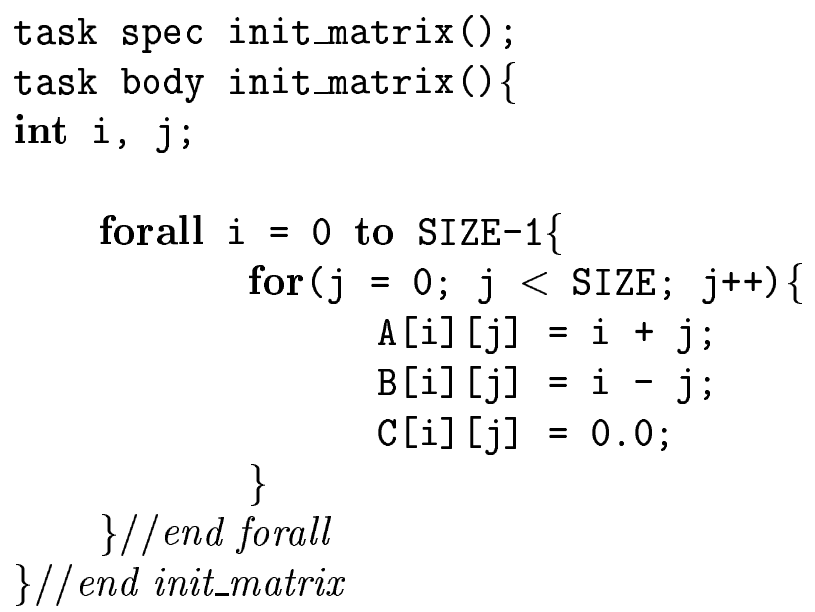

void main () \{

alloc_proc(NPROC) ;

create NPROC, init_matrix();

wait_proc( init_matrix );

create NPROC, multiplica_matrix();

wait_proc( multiplica_matrix );

\}

Figura 6.2: Programa CPAR que calcula a multiplicação de matrizes quadradas com a utilização de variáveis compartilhadas globais e com distribuição total. 
Para o CPAR-Cluster oferecer essa abstração ao usuário, cada elemento da matriz C, ao ser calculado, é colocado no buffer de atualização. Ao se fazer o somatório, o resultado obtido em cada etapa será enviado para o buffer, conseqüentemente existirá um grande volume de dados trafegando pela rede e uma grande sobrecarga de atualização no nó receptor. Todas essas escritas consecutivas a um mesmo elemento serão realizadas no destino.

Outro dado que agrava esse quadro é a distribuição total que é adotada por omissão pelo sistema, ou seja, todos os nós estarão enviando para os demais. Haverá um número acentuado de colisões e retransmissões.

Uma interessante alternativa a esse caso é a exploração da localidade. Como pode ser observado na Figura 6.3, se introduzirmos uma variável privada temporária que receba o somatório, apenas o valor final será escrito na variável compartilhada. Isso diminui consideravelmente o tamanho da mensagem e a complexidade da atualização no receptor.

O pré-compilador da linguagem CPAR para o sistema CPAR-Cluster poderia automatizar essa detecção e utilizar uma variável temporária para tornar a execução mais eficiente, pois é extremamente custoso e algumas vezes até inviável utilizar o sistema sem que essa exploração de localidade seja feita. Pelo motivo levantado, os testes e comparações serão realizados sob essa condição.

\subsubsection{Versão com atualização em um nó (Global Mestre)}

Para avaliarmos a estratégia de distribuição central, desenvolvemos e testamos o programa ilustrado na Figura 6.4. Nesse caso, a variável global compartilhada C terá as atualizações enviadas para o nó onde reside o Executor Mestre do sistema.

As demais variáveis compartilhadas globais terão as atualizações enviadas para todos os nós do sistema, como no caso da versão apresentada anteriormente.

\subsubsection{Versão sem Variáveis Compartilhadas (Local)}

Para avaliação do impacto da troca de mensagens de atualização foi desenvolvida uma versão que não utiliza variável compartilhada. As matrizes A e B são iniciadas 


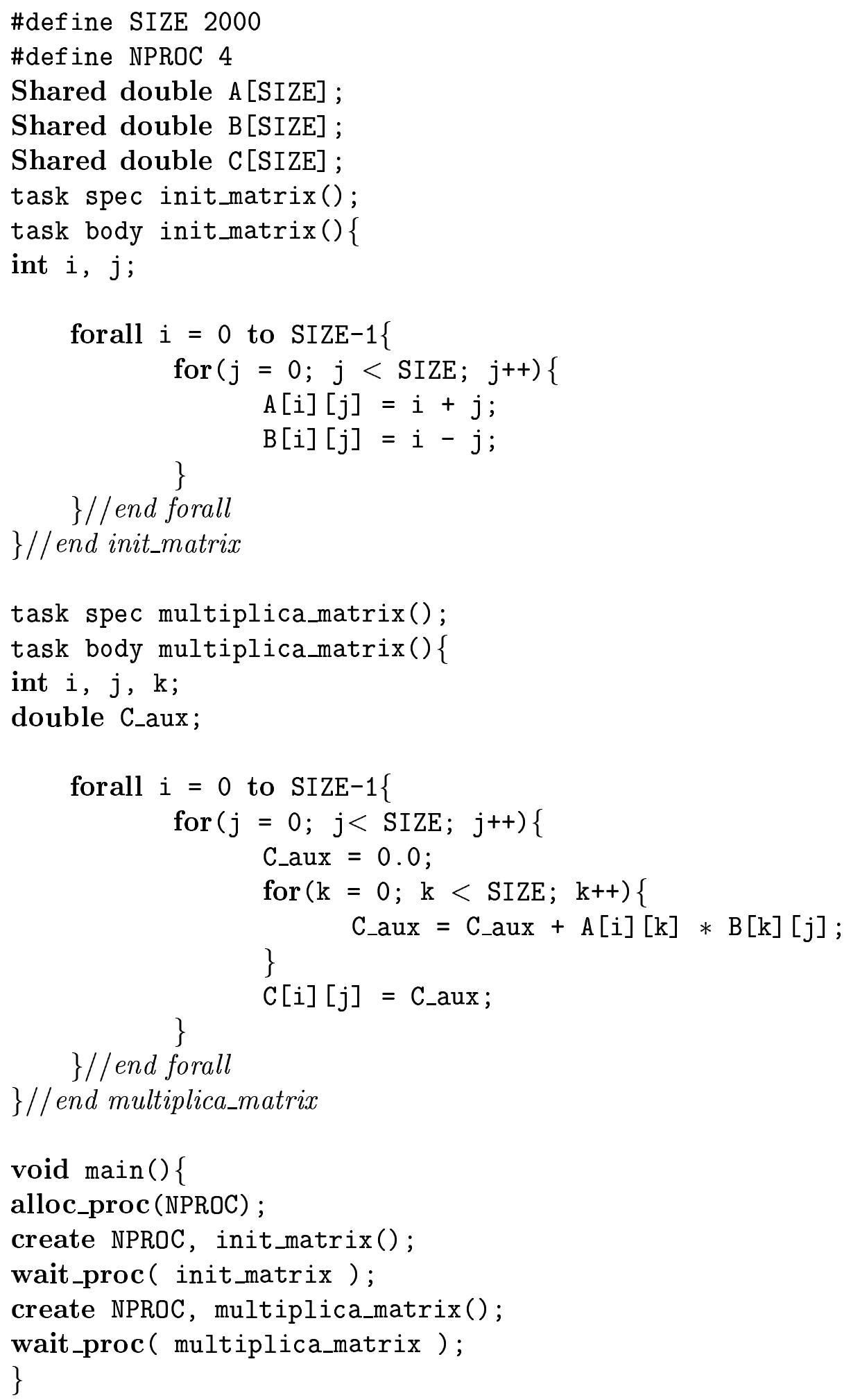

Figura 6.3: Programa CPAR que calcula a multiplicação de matrizes quadradas com a utilização de variáveis globais compartilhadas e com distribuição total. Há exploração da localidade. 
\#define SIZE 2000

\#define NPROC 4

Shared double A[SIZE];

Shared double B [SIZE];

Shared master double C [SIZE];

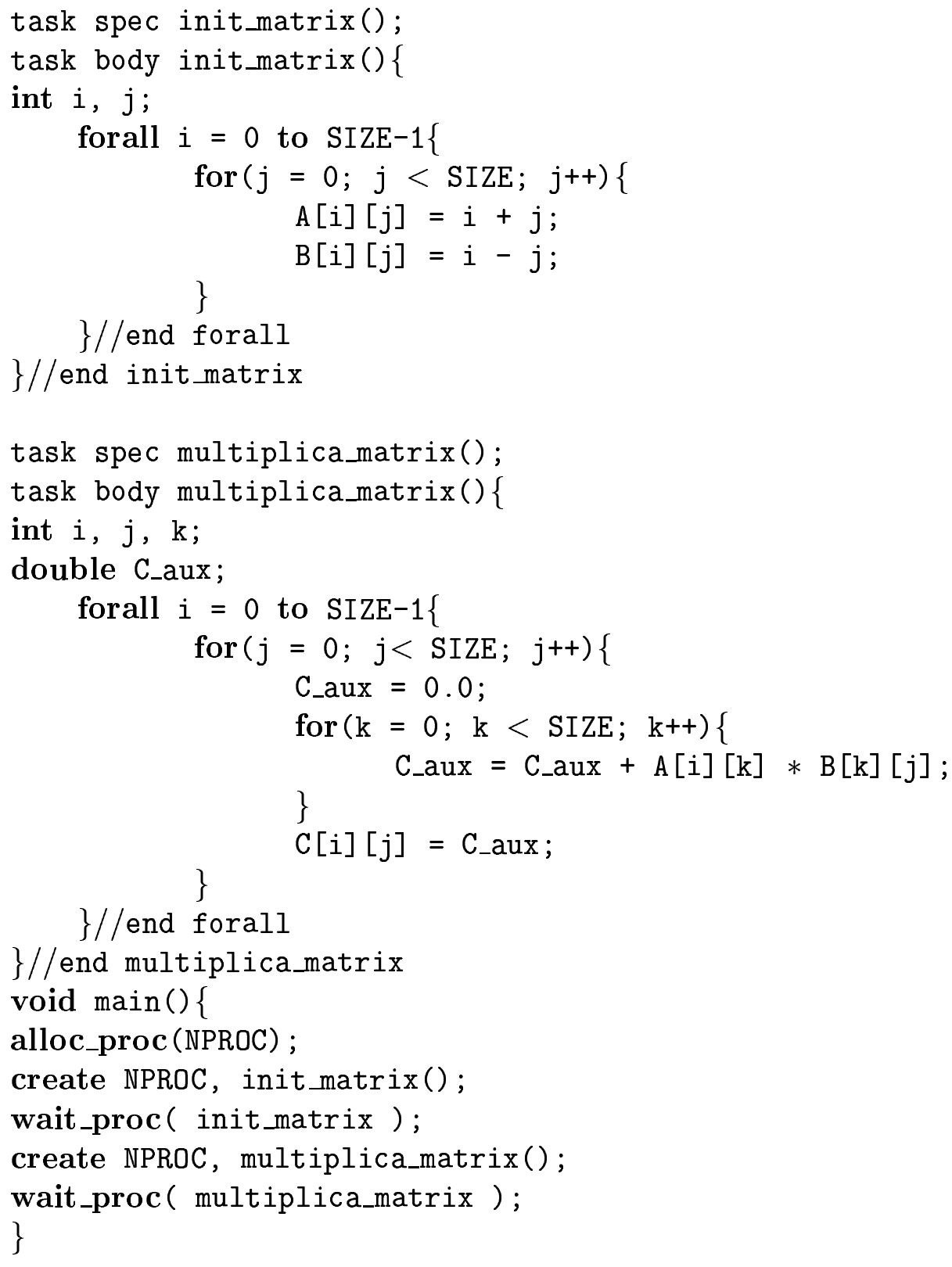

Figura 6.4: Programa CPAR que calcula a multiplicação de matrizes quadradas com a utilização de variáveis globais compartilhadas e com distribuição central. Há exploração da localidade. 
em cada local e a matriz $\mathrm{C}$ é dividida em partes para que cada nó calcule mas não havendo a necessidade de transmissão dos valores.

O código CPAR dessa versão é ilustrado na Figura 6.5. Observe a declaração das variáveis globais e também a diferença da iniciação, já que todo nó precisa ter sua cópia local.

\subsubsection{O Problema do Caixeiro Viajante}

O algoritmo adotado para solução do problema do Caixeiro Viajante [Ball, 1991], sendo designado a partir desse ponto do texto pela abreviação TSP ${ }^{1}$, é apresentado em CPAR em anexo.

Existe uma tabela de distância entre várias cidades que é ordenada de forma decrescente de acordo com a distância a partir da cidade. Obtida essa tabela, é gerada uma fila de trabalhos. Cada trabalho, ou job como colocado no algoritmo, é constituído por sua distância atual e o caminho parcial percorrido até aquele ponto. Esse caminho parcial é uma combinação de três cidades, sendo a primeira sempre fixa (o ponto de partida).

A cada executor caberá verificar a distância toda de um determinado caminho, trabalhando sobre o caminho parcial que retirou da fila. Sendo maior que a distância mínima conhecida, o caminho é descartado. No caso do caminho ser o menor conhecido até então, a distância do mesmo é comunicada para todos os nós.

$\mathrm{Na}$ implementação do teste foram definidas duas seções críticas: uma para controlar o acesso à estrutura da fila de trabalhos para que os executores não tomem trabalhos repetidos e outra seção crítica para controle de acesso à variável compartilhada que armazena o resultado da distância mínima calculada. Ambas seções críticas estão encerradas por semáforos binários, também conhecidos como mutexes.

\footnotetext{
${ }^{1}$ Do inglês Travelling Salesman Problem
} 


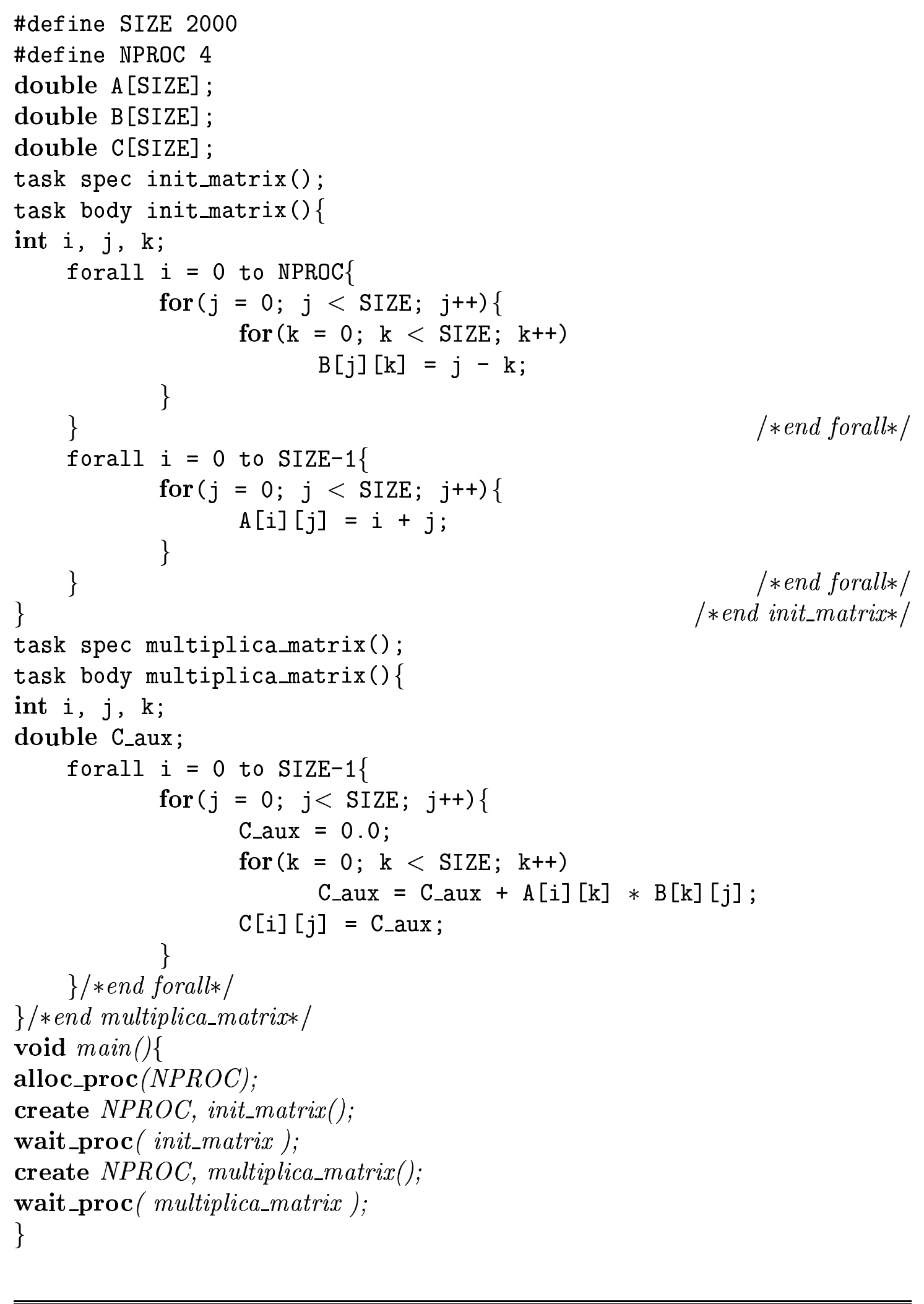

Figura 6.5: Programa CPAR que calcula a multiplicação de matrizes quadradas com a utilização de variáveis globais privadas. Há exploração da localidade. 


\subsection{Resultados Obtidos e Análise}

Os resultados obtidos nos testes foram classificados de acordo com o aspecto do sistema CPAR-Cluster a ser analisado e serão discutidos nas próximas seções: a sobrecarga de troca de mensagens de atualização, a sobrecarga da coordenação do laço paralelo, as estratégias de escalonamento de iterações e o mecanismo de exclusão mútua.

\subsubsection{Sobrecarga imposta pela troca de mensagens de atu- alização}

Para avaliarmos o impacto que a troca de mensagens de atualização tem sobre o tempo de execução, foram confrontados os tempos obtidos na execução das versões da multiplicação de matrizes com variáveis compartilhadas com o algoritmo que utiliza exclusivamente variáveis privadas.

No pior caso de tráfego de mensagens (variável compartilhada global com distribuição total) qualquer nó que atualiza a variável deverá difundir essa mensagem para todos os nós do sistema.

A Figura 6.6 representa os tempos médios de execução da multiplicação de matrizes de ordem 2000 de acordo com as três versões utilizadas. Nesse gráfico não está sendo considerado o tempo de iniciação das matrizes, apenas a multiplicação. Os ganhos de desenpenho obtidos são ilustrados na Figura 6.7.

Constata-se pelos gráficos que a troca de mensagens de atualização não representa um impacto significativo na maior parte das configurações. A única configuração que apresenta uma perda considerável é aquela composta por um único nó SMP com quatro processadores.

Acredita-se que pelo fato de uma máquina quad conter um nó mestre virtual (composto por dois processos e um thread) e também um nó virtual escravo (composto por dois processos e quatro threads) acarrete em uma contenção do barramento alta pelo uso das unidades de processamento. Por essa razão verificase que os tempos médios de execução da versão com atualização total e da versão 


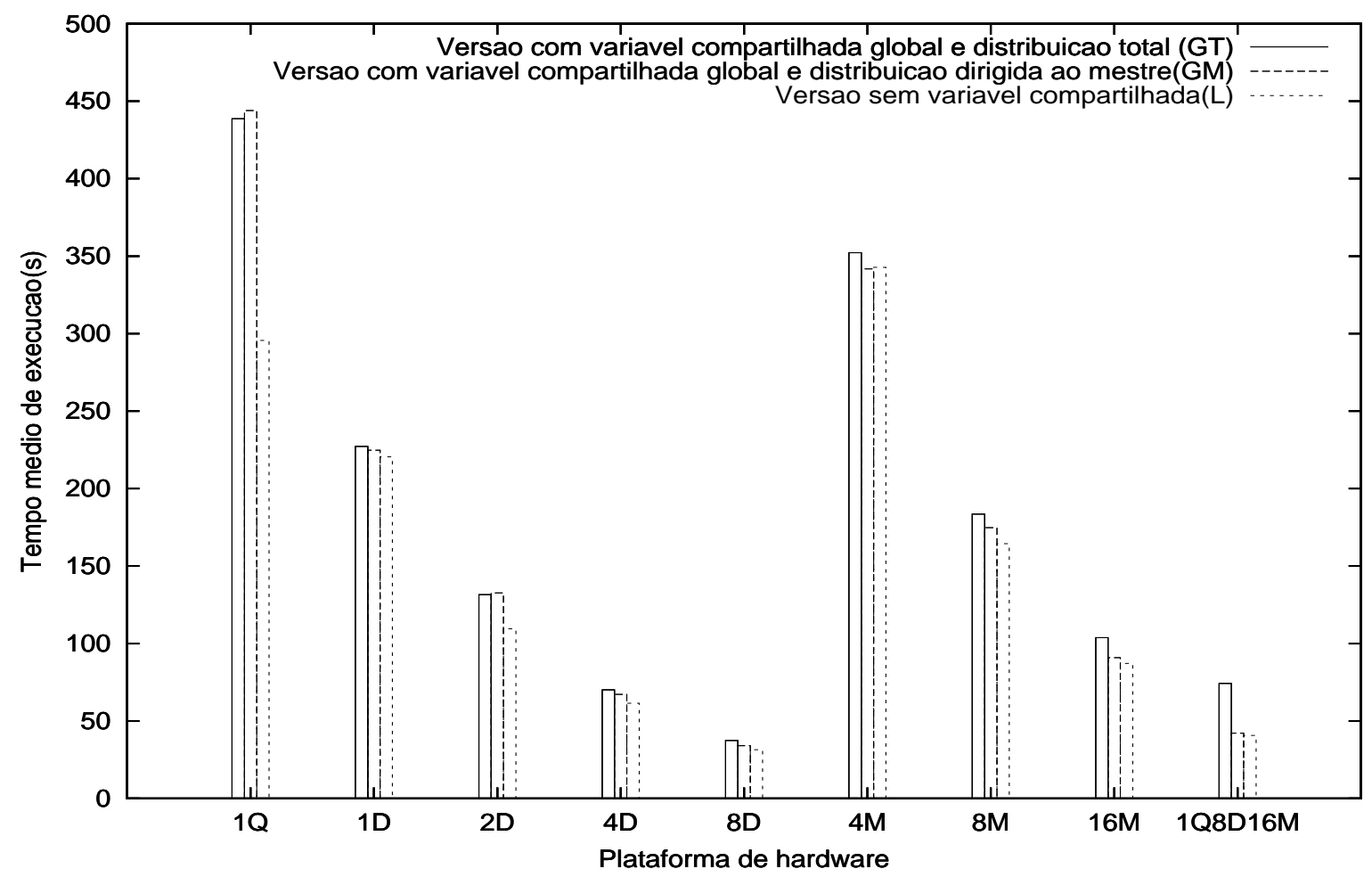

Figura 6.6: Tempo de execução médio das versões de multiplicação de matrizes de ordem 2000 sobre diferentes configurações.

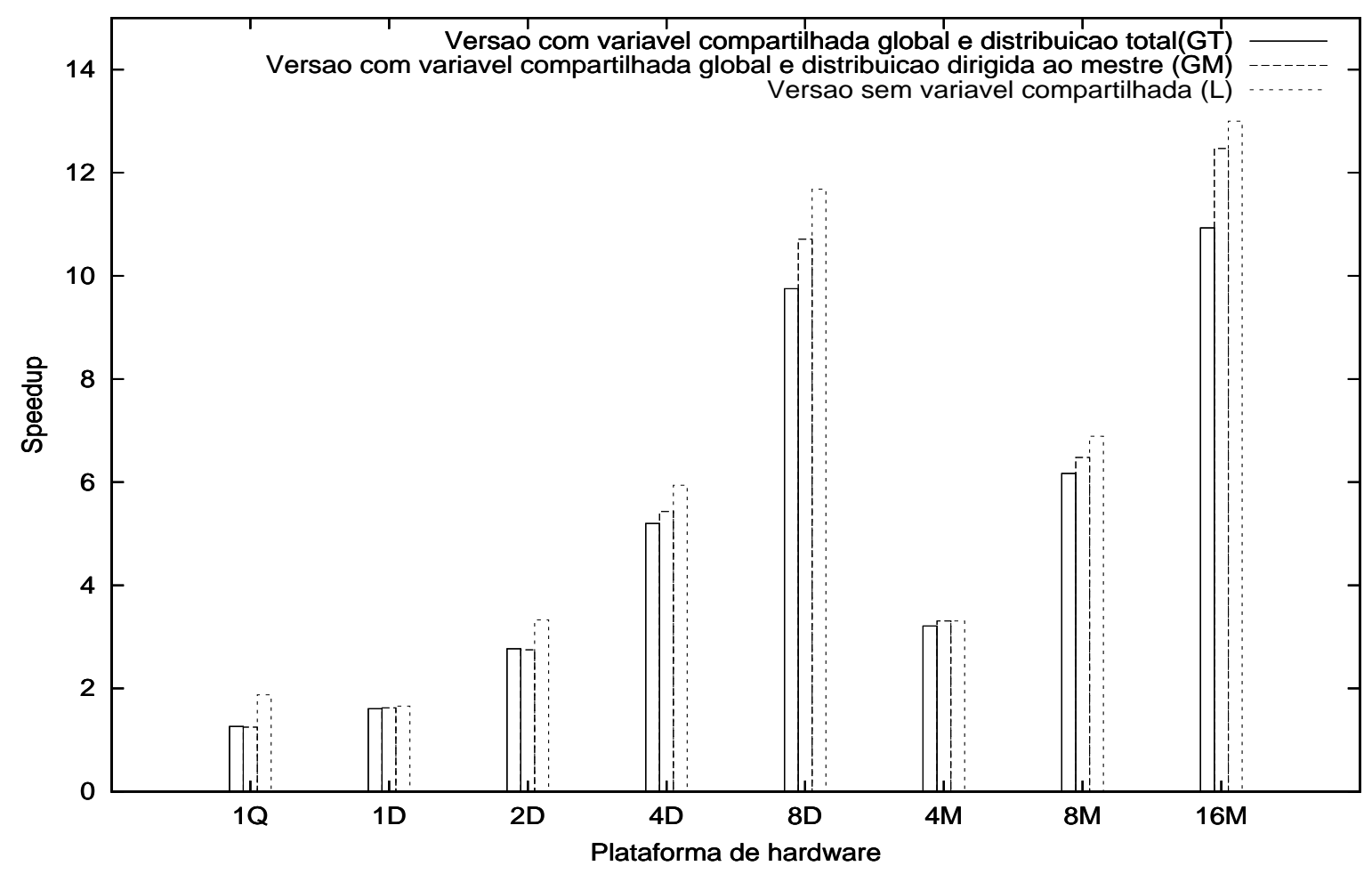

Figura 6.7: Speedup obtido na execução das versões de multiplicação de matrizes de ordem 2000 sobre diferentes configurações. 
com atualização central tenham sido próximos.

Apesar da diferença no caso específico da máquina quad, verificamos que utilizando uma máquina dual e acionando nela também um mestre e um escravo, a diferença quanto à troca de mensagem de atualização não ocasiona um tempo de execução da tarefa muito maior em relação à versão sem envio de atualização.

Para se concluir que o protocolo de atualização representa um peso para o caso de configuração composta por um único nó que acumula o papel de mestre e escravo, seriam necessários testes em máquinas com mais de quatro processadores e infelizmente não foi possível.

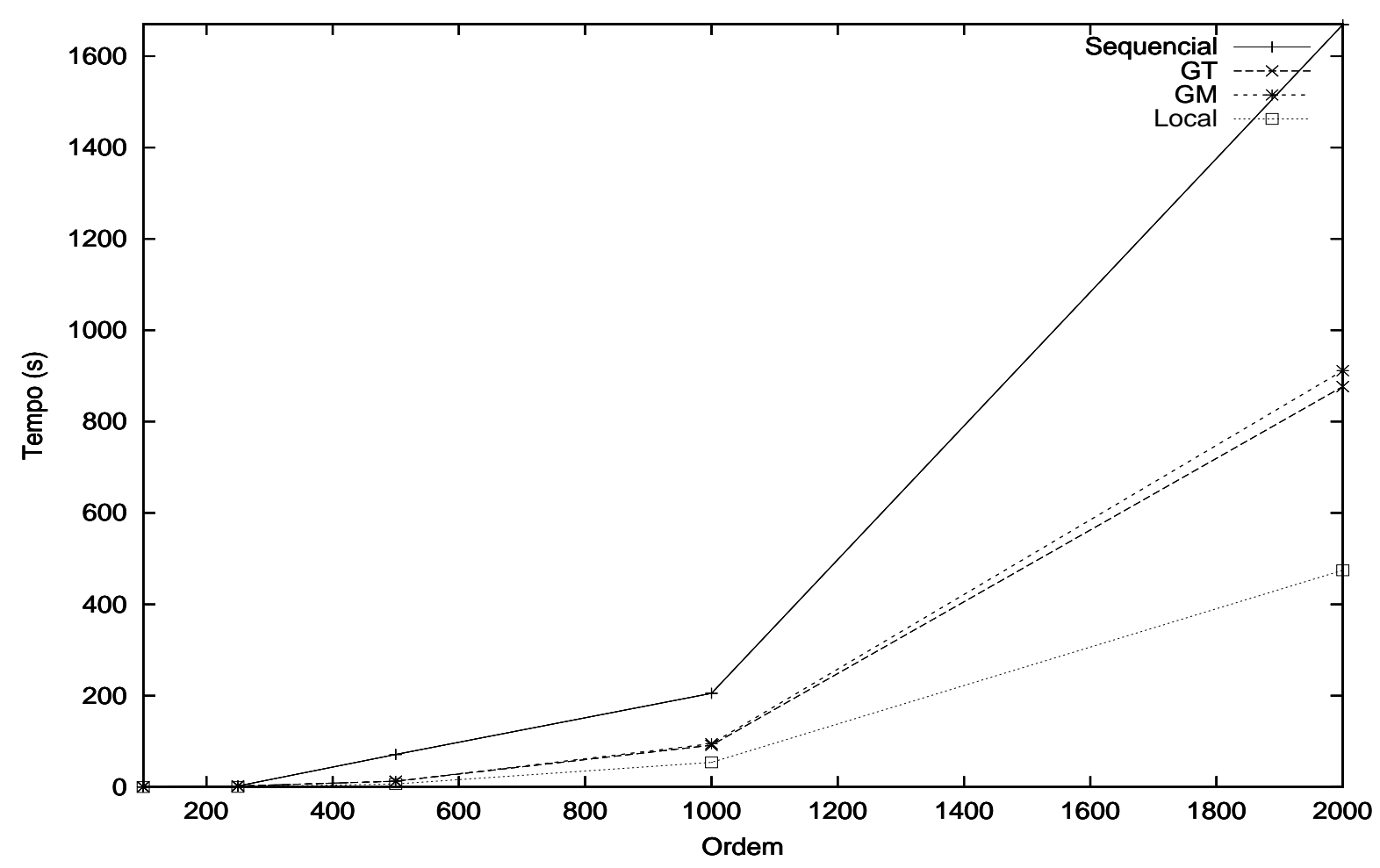

Figura 6.8: Tempo de execução médio das versões de multiplicação de matrizes de ordem de 100 a 2000 sobre a configuração formada por uma máquina SMP com quatro processadores

Mesmo com os pontos levantados anteriormente, é interessante notar que a execução da multiplicação de matrizes sobre o sistema CPAR-Cluster em uma máquina quad (acumulando o papel de mestre e escravo) apresentou um desempenho satisfatório em relação ao seqüencial. O nível de speedup e demais informações 


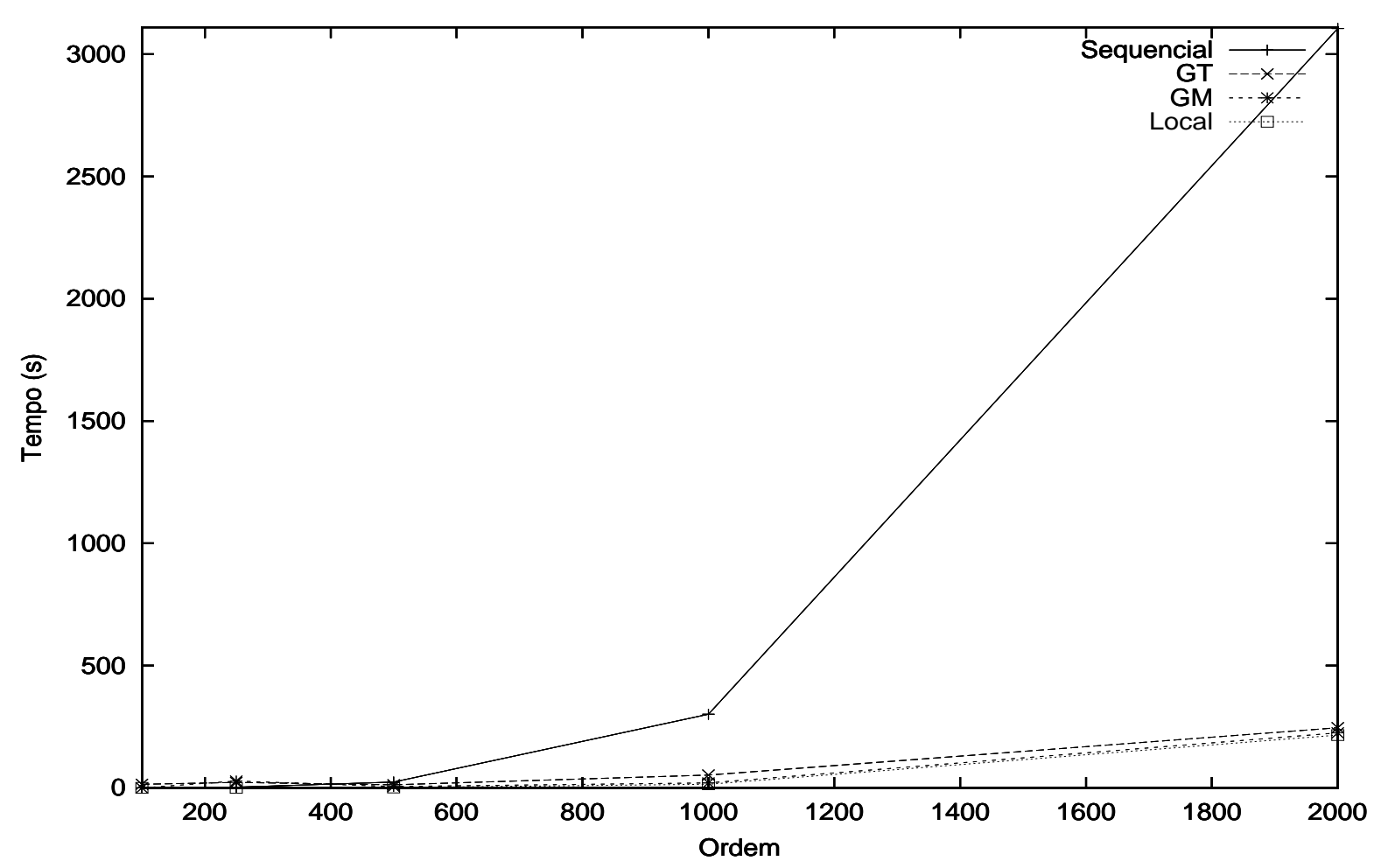

Figura 6.9: Tempo de execução médio das versões de multiplicação de matrizes de ordem de 100 a 2000 sobre a configuração formada por dezesseis máquinas monoprocessadoras.

sobre tempos médios de execução estão na Tabela 6.1. O tempo médio de execução dos vários algoritmos também está representado na Figura 6.8.

Os dados referentes às execuções nas demais configurações estão nas Tabelas 6.2 (uma dual), 6.4 (quatro duais), 6.6 (8 duais), 6.8 (16 monos) e 6.9 (uma quad oito duais e dezesseis monos).

A comparação do desempenho obtido nas três versões em relação ao seqüencial é apresentada nas Figuras: 6.10 para a configuração com oito duais, 6.9 para configuração com dezesseis monos.

Outra comparação interessante, a que confronta os tempos médios de execução dos algoritmos que apresentam diferentes distribuições (total ou central), demonstra uma leve superioridade da estratégia que indica que a atualização deve ocorrer em apenas um nó do sistema. Representa mais uma indicação que o protocolo de atualização não apresenta uma sobrecarga séria à execução. 


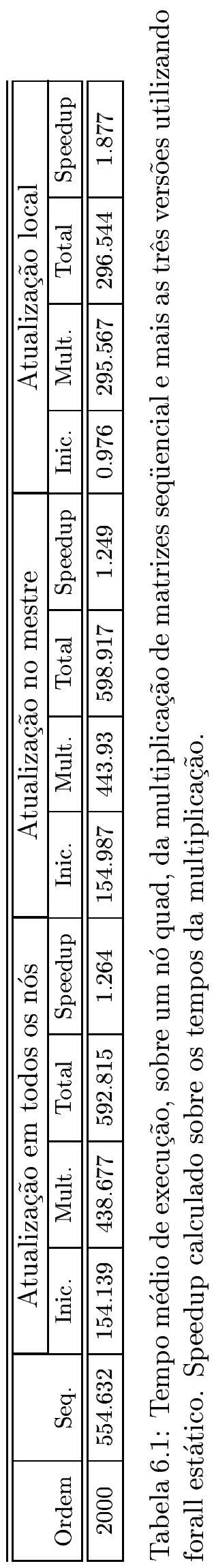




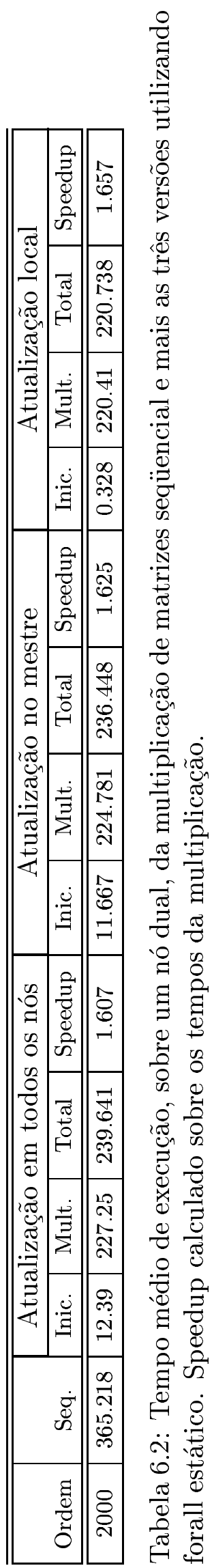




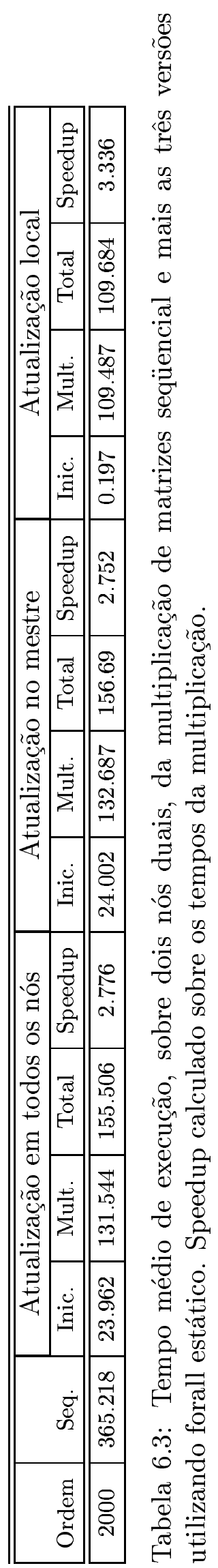




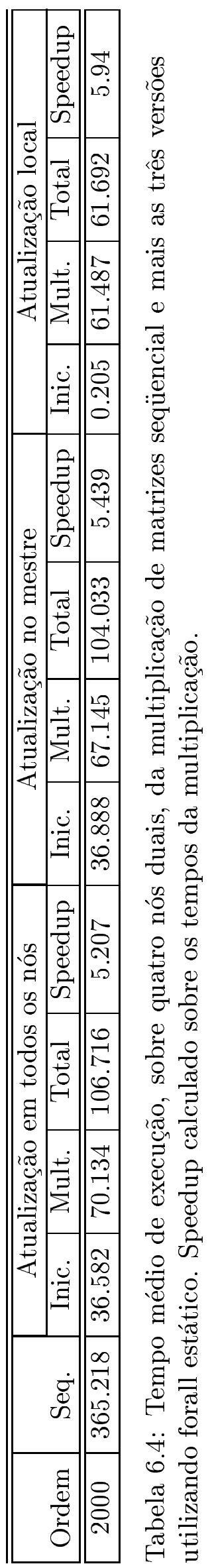




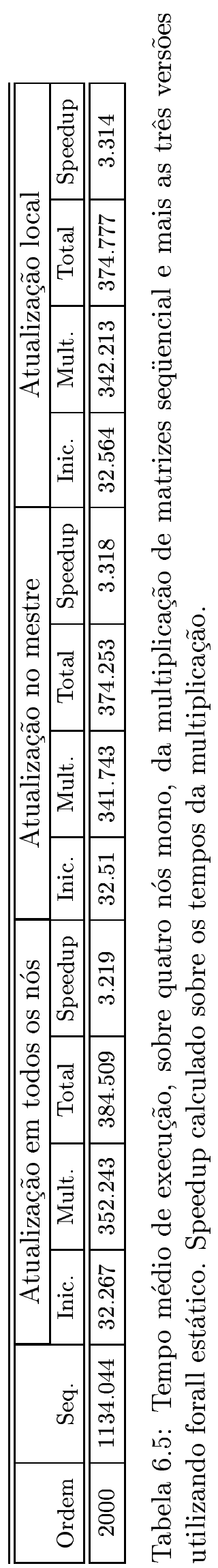




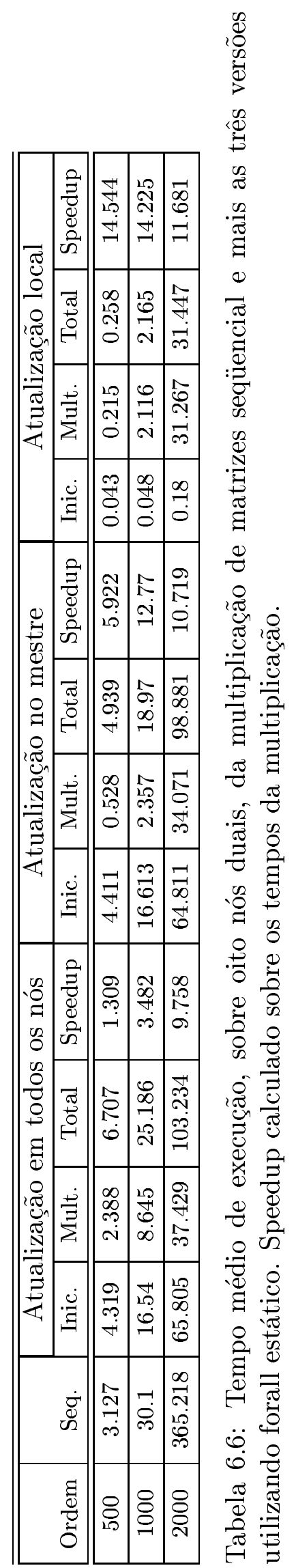




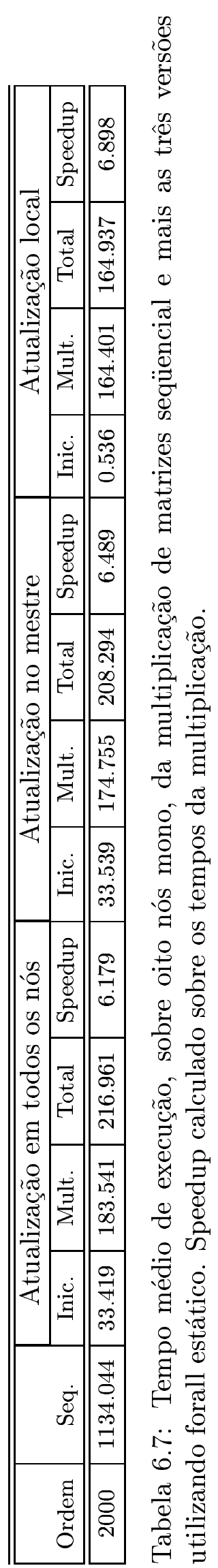




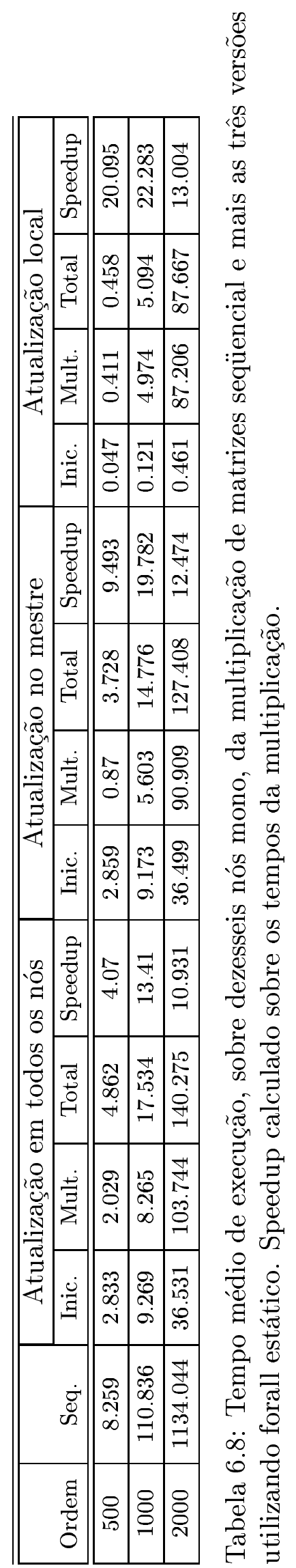




\begin{tabular}{|c|c|c|c|c|c|c|c|c|c|}
\hline \hline \multirow{2}{*}{ Ordem } & \multicolumn{2}{|c|}{ Atualização em todos os nós } & \multicolumn{2}{|c|}{ Atualizac̃ão no mestre } & \multicolumn{3}{|c|}{ Local } \\
\cline { 2 - 10 } & Inic. & Mult. & Total & Inic. & Mult. & Total & Inic. & Mult. & Total \\
\hline \hline 500 & 7.893 & 4.346 & 12.239 & 7.855 & 0.965 & 8.82 & 0.053 & 0.456 & 0.51 \\
\hline 1000 & 31.298 & 16.008 & 47.305 & 31.295 & 4.868 & 36.163 & 0.185 & 3.742 & 3.927 \\
\hline 2000 & 125.503 & 74.199 & 199.702 & 125.587 & 42.078 & 167.665 & 0.667 & 40.641 & 41.308 \\
\hline
\end{tabular}

Tabela 6.9: Tempo médio de execução, sobre um nó quad oito nós duais e dezesseis nós mono, da multiplicação de matrizes seqüencial e mais as três versões utilizando forall estático.

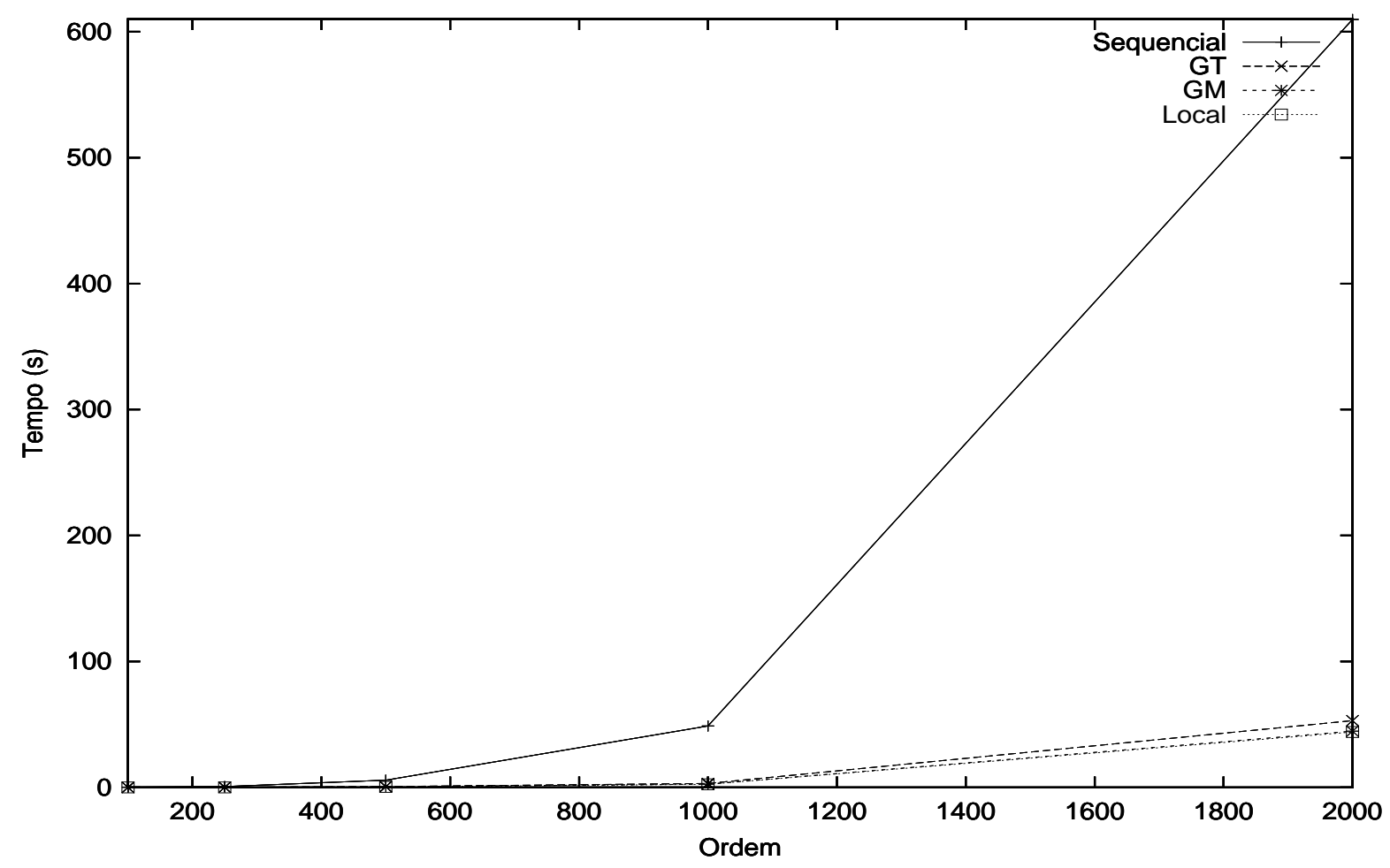

Figura 6.10: Tempo de execução médio das versões de multiplicação de matrizes de ordem de 100 a 2000 sobre a configuração formada por oito máquinas SMP com dois processadores. 


\subsubsection{Sobrecarga imposta pela coordenação do forall}

Para que seja possível a execução coordenada das iterações de um laço paralelo, deve haver uma sincronização dos executores envolvidos para que todos iniciem ao mesmo tempo e também no fim, para que o laço seja considerado concluído quando o último executor tiver executado suas iterações.

Essa sincronização é implementada por uma barreira e seu protocolo foi apresentado na Seção 5.7.

$\mathrm{Na}$ iniciação da versão sem variáveis compartilhadas há um processamento pequeno (atribuição de valores) e a sobrecarga da coordenação do forall fica mais evidenciada, pois nesse caso, não há nenhum peso da comunicação de atualizações.

Considerando a configuração composta por dezesseis máquinas monoprocessadoras, é possível verificar na Tabela 6.8, através do tempo médio de execução da iniciação das matrizes na versão sem variáveis compartilhadas, que a sobrecarga da sincronização de um forall é mínima, pois dentro na versão utilizada existem quatro barreiras, relativas aos dois laços paralelos da tarefa de iniciação.

\subsubsection{Escalonamento de iterações}

A estratégia de escalonamento estático das iterações de um laço paralelo foi utilizada nas três versões da multiplicação de matrizes. Para avaliarmos a estratégia de escalonamento dinâmico, executamos a versão de multiplicação com atualização em nó central.

Era esperado um ganho da estratégia dinâmica em relação à estratégia de escalonamento estático, principalmente em configurações que apresentassem heterogeneidade nos nós. Esse ganho foi constatado através dos resultados apresentados na Tabela 6.10 (um quad, dezesseis monos e oito duais). 


\begin{tabular}{|c|c|c|c|}
\hline \hline Blocksize & Inic. & Mult. & Total \\
\hline \hline 5 & 96.783 & 23.198 & 119.981 \\
10 & 97.628 & 24.57 & 122.198 \\
20 & 98.051 & 28.588 & 126.639 \\
\hline forall est.(bloco=56) & 125.587 & 42.078 & 167.665 \\
\hline
\end{tabular}

Tabela 6.10: Tempo médio de execução, sobre um nó quad, dezesseis nós mono e oito nós duais, da versão de multiplicação de matrizes de ordem 2000, com atualização em nó central e variados tamanhos de blocos para o forall dinâmico. Comparação do tempo médio obtido para a mesma versão de multiplicação, sobre a mesma plataforma, mas com utilização do forall estático.

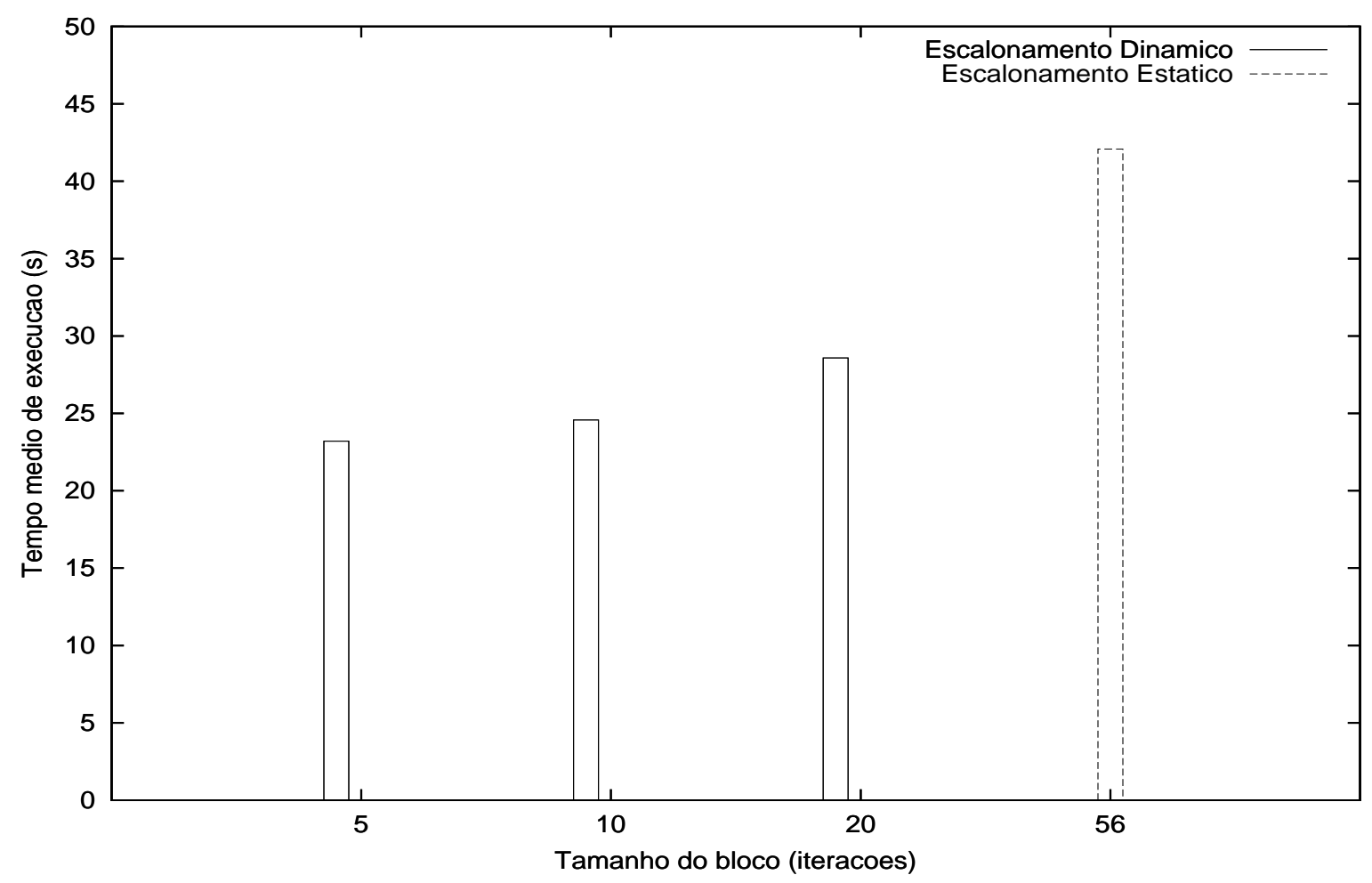

Figura 6.11: Comparação dos tempos médios de execução da multiplicação de matrizes utilizando estratégias de escalonamento dinâmico e estático. 


\subsubsection{Semáforos}

A implementação do TSP utilizou dois semáforos para controle de seções críticas. De acordo com o protocolo de atualização do sistema CPAR-Cluster, as atualizações das variáveis compartilhadas ocorridas são enviadas antes da execução de um unlock. Somada a essa sobrecarga, existe também a troca de mensagens para obtenção do ganho de acesso a um semáforo.

Pelos resultados apresentados na Tabela 6.11, verificamos um ganho considerável da execução sobre o sistema CPAR-Cluster. Um dado interessante é que o tempo médio apresentado para configuração com 36 nós não teve a diminuição esperada, isso é explicado pois na execução sobre plataforma homogênea foi utilizada uma opção de otimização da camada MPI e sobre a configuração heterogênea isso não era possível de ser realizado.

\begin{tabular}{|c|c|c|}
\hline \hline Configuração & Tempo & Speedup \\
\hline \hline TSP seq. em mono & 4408.663 & \\
\hline TSP seq. em dual & 1220.813 & \\
\hline TSP seq. em quad & 4762.026 & \\
\hline TSP em 16 monos & 324.268 & 13.595 \\
\hline TSP em 8 duais & 102.247 & 11.939 \\
\hline TSP em 1Quad 8 Duais 16 Monos & 207.071 & - \\
\hline
\end{tabular}

Tabela 6.11: Tempo médio de execução em segundos do TSP para 23 cidades em diversas configurações 


\section{Capítulo 7 Conclusões}

Os resultados obtidos e a experiência adquirida durante o desenvolvimento do sistema de execução CPAR-Cluster levam-nos a algumas reflexões sobre o trabalho realizado, como também a sugestões de extensões e trabalhos futuros.

\subsection{Conclusões do trabalho}

Como constatado por vários desenvolvedores de DSM's, independente do nível onde fora oferecido, projetar e implementar um sistema que ofereça a abstração de memória compartilhada sobre um aglomerado de computadores é uma tarefa árdua [Iguma, 1997, Marino, 2001]. O processo de construção do sistema CPAR-Cluster não constituiu exceção à regra.

Ao término desta etapa, verifica-se que o sistema constitui um ambiente de execução adequado à programação paralela sobre uma rede de nós heterogêneos na quantidade de processadores.

Para se obter uma caracterização do comportamento do CPAR-Cluster, foram realizados testes sobre variadas configurações que abrangeram desde um único nó SMP com dois processadores até uma combinação de vinte e cinco máquinas que totalizava o oferecimento de trinta e seis processadores de diferentes fabricantes e velocidades de clock.

A avaliação do sistema comprovou a validade das estratégias propostas em [Sato, 1995, Iguma, 1997, Craveiro, 2001]. Decisões de projeto e de implementação adotadas nesse trabalho indicam que o desempenho obtido deveu-se principalmente 
a uma adequada sobreposição da computação e da comunicação oferecida pelo modelo de execução proposto e implementado com primitivas MPI e Pthreads.

Alguns resultados porém indicamos que ajustes no modelo de execução sobre um único nó SMP com um maior número de processadores talvez sejam necessários. A alta contenção no acesso aos recursos da máquina (processadores, barramento, memória) sinaliza uma possível diminuição no número de executores escravos em uma configuração com a característica descrita.

\subsection{Contribuições}

Através de uma implementação no nível de biblioteca, sem alterações ao sistema operacional e nem utilização de recursos especializados no nível de hardware, o sistema CPAR-Cluster oferece uma abstração de memória compartilhada sobre um aglomerado formado por máquinas mono e multiprocessadores.

Pelos resultados obtidos e analisados no Capítulo 6, verificamos que os seguintes objetivos foram alcançados:

- o adequado comportamento das estratégias de atualização de variáveis compartilhadas de acordo com a distribuição de dados,

- apresentação de critérios de distribuição de dados que otimizaram o desempenho da aplicação,

- proposição e implementação de uma política de escalonamento das tarefas e de processamento que explorou o poder computacional de um conjunto de máquinas mono e multiprocessadoras interligadas.

Os trabalhos com abordagem similar [Tanaka et al., 1998, I., 2003], apresentam ganhos interessantes através da utilização de uma rede de alta velocidade, tal como Myrinet. No nosso trabalho utilizamos uma infra-estrutura de menor custo e maior

latência (Fast Ethernet, 100 Mbits) e os resultados obtidos apontam para ganhos de desempenho satisfatórios. 
Pelos pontos apresentados, conclui-se que o CPAR-Cluster constitui uma ferramenta apropriada ao desenvolvimento de programas para aglomerados heterogêneos, de forma que a extração do desempenho não dependa da utilização de recursos de hardware ou software básico sofisticados ou complexos.

\subsection{Trabalhos futuros}

Este trabalho não teve a pretensão de esgotar o assunto sobre o tema e, também por restrições de tempo, alguns aspectos não foram abordados. Nessa seção serão descritos alguns pontos que merecem atenção e futuro tratamento.

\section{A construção do compilador}

Está em desenvolvimento o pré-compilador da linguagem CPAR para incorporação das chamadas ao sistema CPAR-Cluster. Algumas otimizações são necessárias como, por exemplo, a exploração da localidade de referência, discutido na Seção 6.1.2. Otimizações adicionais estão sendo levantadas e serão objeto de estudo de um trabalho de doutorado já em andamento.

\section{Escalonamento e balanceamento}

Algumas considerações tecidas na Seção 4.2.1 propõem melhorias no esquema de escalonamento de macrotarefas a partir da captação de informações sobre o poder computacional de cada nó do cluster através da execução de pequenos benchmarks destinados a esse fim.

Além da montagem e utilização das informações desse mapeamento do cluster, pretende-se também incorporar um mecanismo que obtém informação, em tempo de execução do sistema, da carga nos nós gerada por outros usuários. A disponibilização dessas importantes informações adicionais em um algoritmo de escalonamento de macrotarefa e balanceamento de carga são os objetivos de um projeto de formatura atualmente em curso. 


\section{Tolerância a defeitos}

Outro ponto importante refere-se à incorporação de aspectos de tolerância a defeitos e análise do seu oferecimento no desempenho geral do sistema. Seria interessante oferecer ao usuário do sistema diferentes níveis de robustez e também a opção de ajustá-lo de acordo com a necessidade da aplicação.

\section{Heterogeneidade de sistema operacional}

Um primeiro passo para obtenção de uma plataforma heterogênea no nível de sistema operacional seria portar a atual implementação do CPAR-Cluster, que utiliza POSIX Threads, para uma implementação que explore os recursos Thread e Fiber nativos do sistema operacional Microsoft Windows [Solomon and Russinovich, 2000]. Existe um mestrado em andamento que contempla esse projeto.

Um segundo trabalho que integraria as implementações citadas teria como principal objetivo oferecer a característica da interoperabilidade. Ou seja, o conceito da portabilidade deve ser estendido para permitir que os executáveis continuem a comunicarem-se mesmo sobre diferentes arquiteturas, sistemas operacionais e implementações do padrão MPI. Atualmente existe um esforço da comunidade científica para incorporar a interoperabilidade ao padrão MPI, trata-se do protocolo IMPI (Interoperable MPI) [Devaney et al., 2000]. Através dessa camada, variadas implementações do MPI podem constituir um único comunicador [George and Hagedorn, 2000].

\section{Metacomputação ou Grid Computing}

Continuando na exploração da interoperabilidade, uma nova linha de pesquisa iniciaria esforços no sentido de oferecer uma abstração de um metacomputador. A metacomputação ou grid computing é a tendência atual na área de sistemas paralelos e distribuídos que transporta a idéia de um único e poderoso supercomputador formado potencialmente por centena de milhares de computadores que estão conectados de alguma maneira unificada [Buyya, 1999]. 


\section{BIBLIOGRAFIA}

[Arantes, 1996] Arantes, L. B. (1996). Suporte para processamento para programação paralela no pardigma de variáveis compartilhadas sobre sistemas com memória compartilhada distribuída. Master's thesis, Escola Politécnica da USP.

[Ball, 1991] Ball, H. E. (1991). Programming Distributed Systems. Prentice-Hall.

[Bisiani and Forin, 1988] Bisiani, R. and Forin, A. (1988). Multilingual parallel programming of heterogeneous machines. IEEE Transactions on Computers, 37(8):930-945.

[Bisiani and Ravishankar, 1990] Bisiani, R. and Ravishankar, M. (1990). Plus: A distributed shared-memory system. In Proceedings 17th ACM Symp. Computer Architecture, pages 115-124. IEEE CS Press.

[Buyya, 1999] Buyya, R., editor (1999). High Performance Cluster Computing., volume Volume 1: Architecture and Systems. Prentice Hall PTR.

[Carriero and Gelernter, 1990] Carriero, N. and Gelernter, D. (1990). How to write parallel programs: a first course. MIT Press.

[Computing, 1994] Computing, P. (1994). Edição especial: Message passing interfaces.

[Consortium, 2002] Consortium, P. C. (2002). Pc cluster consortium. http://www.pccluster.org.

[Craveiro, 2001] Craveiro, G. S. (2001). Um ambiente para programação paralela com variáveis compartilhadas em sistemas distribuídos heterogêneos. Exame de Qualificação de Doutorado.

[CSM, 1998] CSM (1998). History of changes put into version 2 and 3 of PVM. Computer Science and Mathematics Division, Oak Ridge National Laboratory, http: //www . epm. ornl.gov/pvm/changes .html. Características do PVM desde a versão 2.0 até a 3.4.0.

[Delp, 1988] Delp, G. (1988). The Architecture and Implementation of Memnet: A High-Speed Shared Memory Computer Communication Network. PhD thesis, University of Delaware.

[Devaney et al., 2000] Devaney, J. E., George, W. L., Hagedorn, J. G., and Ketcham, P. M. (2000). IMPI: Interoperable Message Passing Interface. http://impi.nist.gov/IMPI/. Protocol Version 0.0. 
[Dietz, 1998] Dietz, H. (1998). Clusters of linux systems. http://yara.ecn.purdue.edu/ pplinux/PPHOWTO/pphowto-3.html.

[Fleisch and Popek, 1989] Fleisch, B. and Popek, G. (1989). Mirage: A coherent distributed shared memory desing. In Proceedings 14th ACM Symp. Operating System Principles, pages 211-223. ACM.

[Forum, 1998] Forum, M. (1998). MPI-2: Extensions to the Message-Passing Interface. http://www.mpi-forum.org/docs/mpi-20-html/mpi2-report.html.

[Geist et al., 1994] Geist, A.and Beguelin, A., Dongarra, J., Jiang, W., Manchek, R., and Sunderam, V. (1994). PVM: Parallel Virtual Machine. http: //www . netlib.org/pvm3/book/pvm-book.html.

[George and Hagedorn, 2000] George, W. L. and Hagedorn, J. G.and Devaney, J. E. (2000). IMPI: Making mpi interoperable. Journal of Research of the National Institute of Standards and Technology, 105(3):343-348. http://www.nist.gov/jres.

[I., 2003] I., E. (2003). Cxc by engineered intelligence. http://www.engineeredintelligence.com.

[Iftode and Singh, 1999] Iftode, L. and Singh, J. P. (1999). Shared virtual memory: Progress and challenges. Proc. of the IEEE, Special Issue on Distributed Shared Memory, 87(3):498-507.

[Iguma, 1997] Iguma, D. (1997). Aspectos de implementaçãoo de um ambiente para programação paralela com variáveis compartilhadas em sistemas distribuídos. Master's thesis, Escola Politécnica da Universidade de São Paulo.

[LAM/MPI, 2003] LAM/MPI (2003). LAM/MPI Parallel Computing. http://www . lam-mpi .org/.

[Lamport, 1979] Lamport, L. (1979). How to make a multiprocessor computer that correctly executes multiprocessor programs. IEEE Transactions on Computers.

[Lenoski et al., 1990] Lenoski, D., Laudon, J., Gharachorloo, K., Gupta, A., and Hennessy, J. (1990). The directory-based cache coherence protocol for the dash multiprocessor. In Proceedings 17th ACM Symp. Computer Architecture, pages 148-159, New York, NY, USA. IEEE CS Press, ACM Press.

[Li and Hudak, 1989] Li, K. and Hudak, P. (1989). Memory coherence in shared virtual memory systems. ACM Transactions on Computer Systems, 7(4):321359.

[Liang, 1997] Liang, W. (1997). Adsmith: An object-based distributed shared memory system on PVM.

[Marino, 2001] Marino, M. D. (2001). Construção e Avaliação comparativa de um sistema DSM. PhD thesis, Escola Politécnica da USP. 
[Neto, 1987] Neto, J. J. (1987). Introdução à Compilação. Livros Técnicos e Científicos.

[Nichols et al., 1996] Nichols, B., Buttlar, D., and Farrell, J. P. (1996). Pthreads Programming A POSIX Standard for Better Multiprocessing. O' Reilly.

[Nitzberg and Lo, 1991] Nitzberg, B. and Lo, V. (1991). Distributed shared memory: A survey of issues and algorithms. IEEE Computer, pages 52-60.

[OpenMP, 2003] OpenMP (2003). http://www.openmp.org.

[Pinheiro and Bianchini, 1998] Pinheiro, E. and Bianchini, R. (1998). Nomad: Um sistema operacional eficiente para clusters de uni e multiprocessadores. In Anais do Simposio Brasileiro de Arquitetura de Computadores.

[Samanta et al., 1998] Samanta, R., Bilas, A., Iftode, L., and Singh, J. P. (1998). Home-based SVM protocols for SMP clusters: Desing and performance. In Proceedings of the 4th International Symposium on High-Performance Computer Architecture.

[Sato, 1991] Sato, L. M. (1991). Sistema de programação e processamento para sistema multiprocessadores. In Anais do VI Simpósio Brasileiro de Engenharia de Software.

[Sato, 1995] Sato, L. M. (1995). Ambientes de programação para sistemas paralelos $e$ distribuídos. $\mathrm{PhD}$ thesis, Escola Politécnica da Universidade de São Paulo.

[Sato et al., 1999] Sato, M., Satoh, S., Kusano, K., and Tanaka, Y. (1999). Design of OpenMP compiler for an SMP cluster. In EWOMP '99, pages 32-39.

[Schildt, 1990] Schildt, H. (1990). C, completo e total. Makron, McGraw-Hill.

[Shi et al., 1998] Shi, W., Hu, W., and Tang, Z. (1998). Shared virtual memory: A survey. Technical Report 980005, Center of High Performance Computing, Institute of Computing Technology, Chinese Academy of Sciences.

[Silberschatz A., 2002] Silberschatz A., Galvin P. B., G. G. (2002). Operating System Concepts. John Wiley \& Sons, Inc., sexta ed. edition.

[Solomon and Russinovich, 2000] Solomon, D. A. and Russinovich, M. E. (2000). Inside Microsoft Windows 2000. Microsoft Press.

[Tanaka et al., 1998] Tanaka, Y., Matsuda, M., Ando, M., Kubota, K., and Sato, M. (1998). Compas: A pentium pro PC-based SMP cluster and its experience. In IPPS/SPDP Workshops, pages 486-497.

[Tanaka et al., 1999] Tanaka, Y., Matsuda, M., Kubota, K., and Sato, M. (1999). High Performance Cluster Computing, volume Volume 1: Architecture and Systems, chapter 28, pages 646-660. Prentice Hall PTR. 
[W. Hu and Tang, 1998] W. Hu, W. S. and Tang, Z. (1998). A lock-based cache coherence protocol for scope consistency. Journal of Computer Science and Technology, 13(2):97-109.

[Zhu et al., 1992] Zhu, S., Stumm, M., Li, K., and Wortman, D. (1992). Heterogeneous distributed shared memory. IEEE Transactions on Parallel and Distributed Systems, 3(5):540-554. 


\section{APÊNDICE A \\ O Algoritmo de Escalonamento}

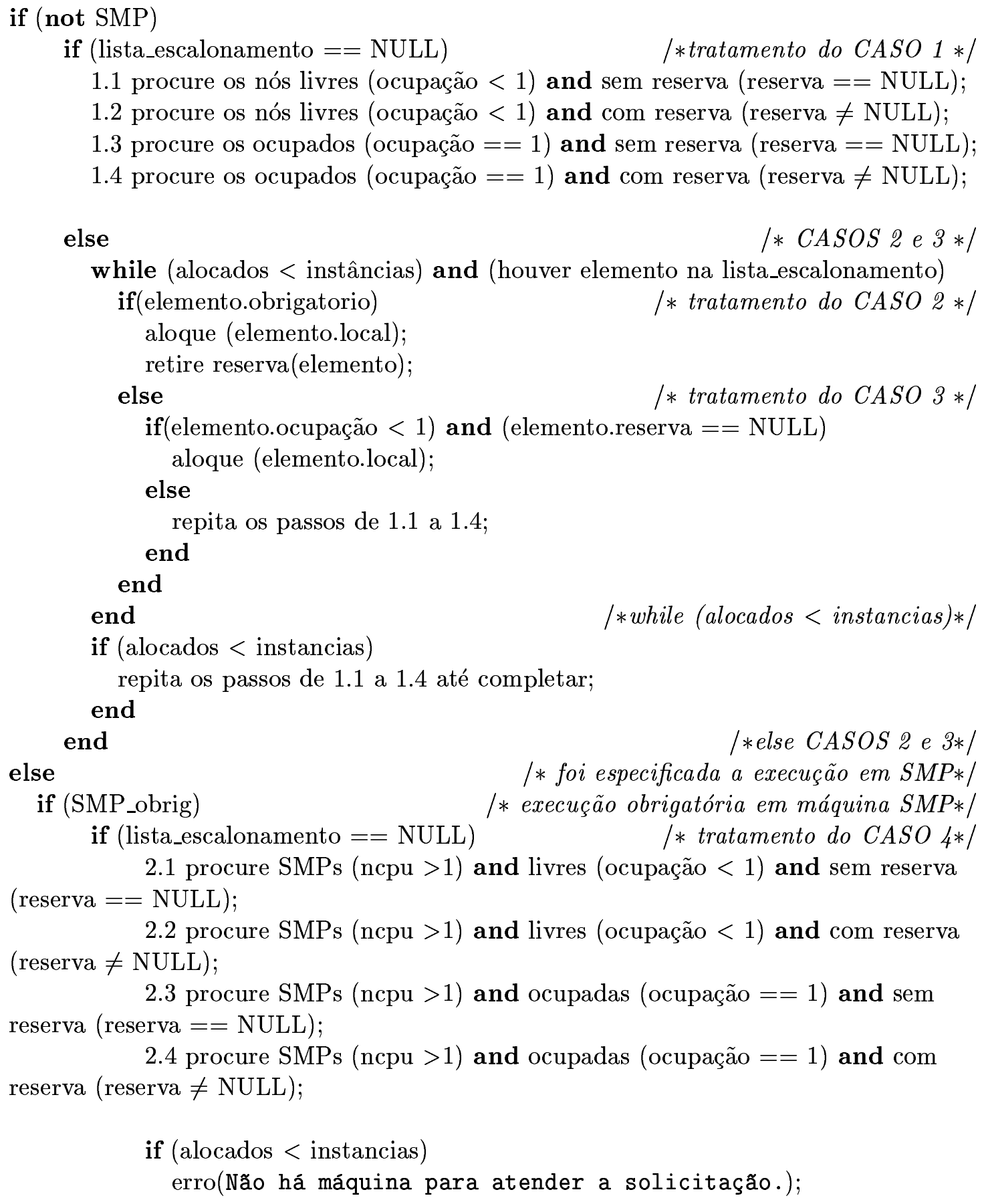


end

else $\quad / *$ CASOS 5 e $6 * 1$

while (alocados $<$ instâncias) and (houver elemento na

lista_escalonamento)

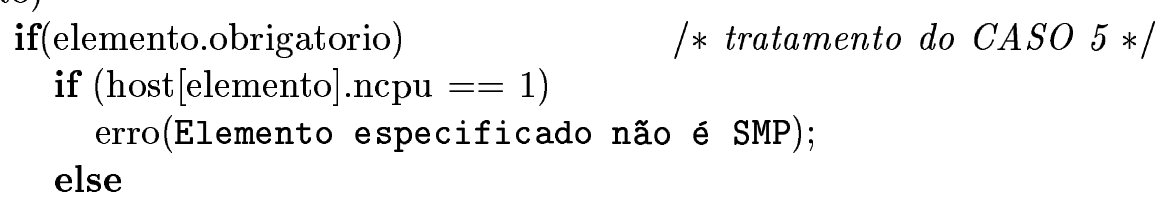

aloque (elemento.local);

retire reserva(elemento);

end

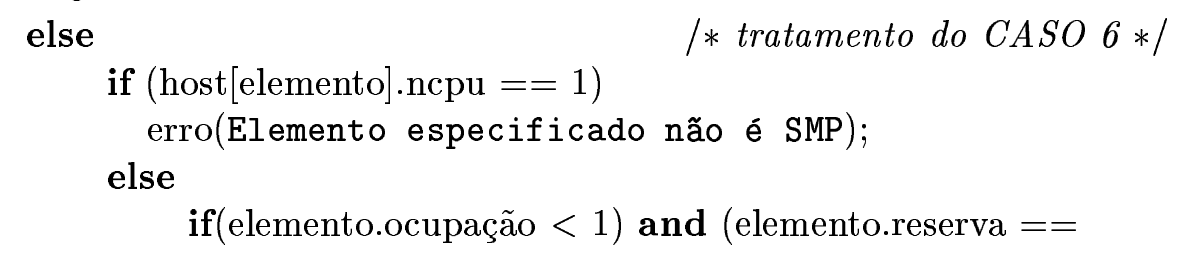

NULL)

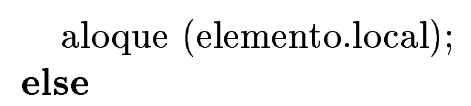

while (alocados < instâncias) and (houver elemento na

lista_escalonamento) and (notSMP_ANALISADOS)

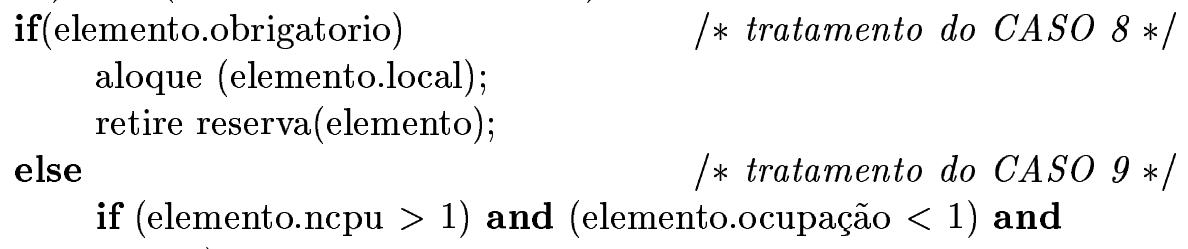




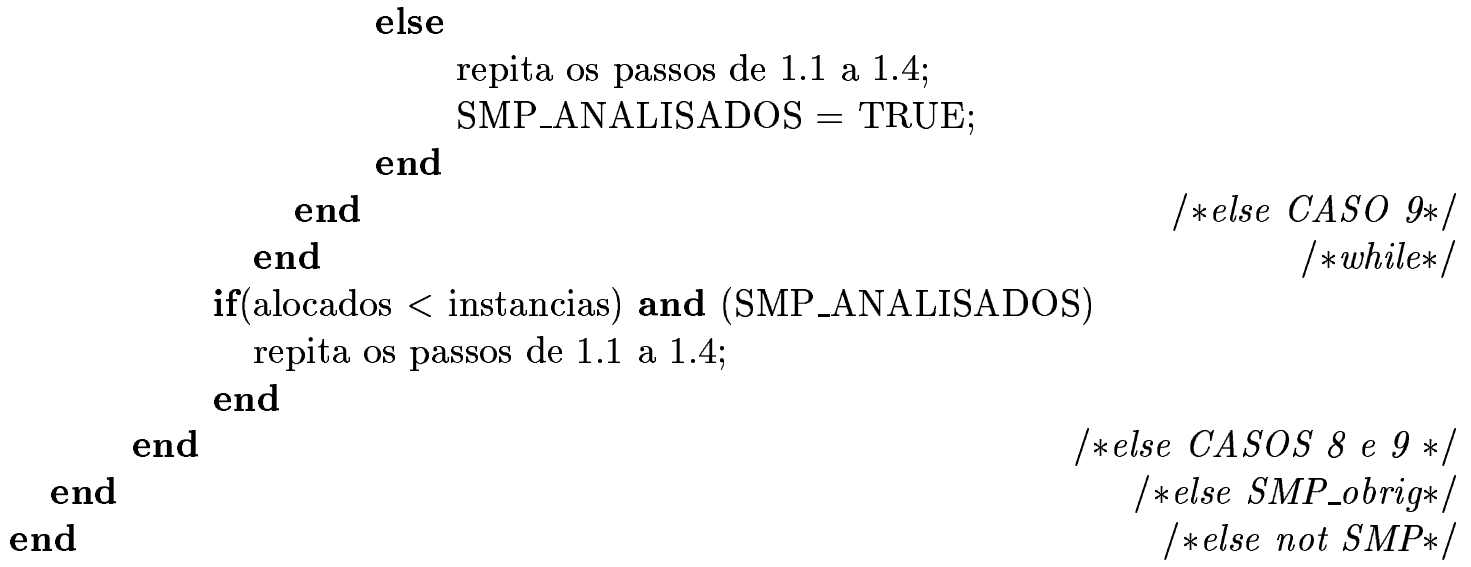




\section{ApÊNDICE B Código CPAR TSP}

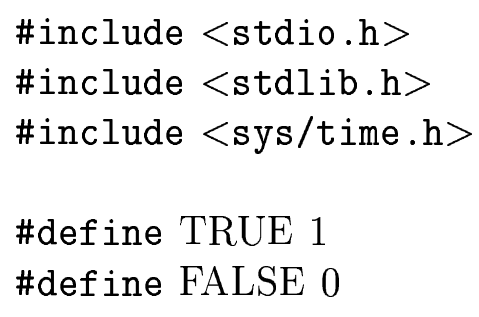

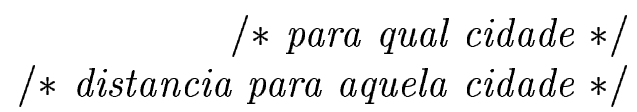

typedef struct enfileira

\{

int path[1001]; $\quad$ /* o caminho parcial da rota $* /$ int len;

struct enfileira $*$ prox; /* o tamanho parcial da rota */ \}IdentEnfileira;

/*item com as informações sobre a fila*/

typedef struct Fila_Queue \{

IdentEnfileira $*$ IniFila; IdentEnfileira $*$ FimFila; Fila;

shared int Queue[900][31]; shared int tamanho_fila;
/* fila de jobs */ /* tamanho da fila de jobs */

task spec worker(numcidades,maxhops,arqcid); 
/* funcao que completa o caminho e verifica se o caminho eh bom */

void tsp(hops,tam,rota,numcidades,MinimaDist,MinPath,atualiza,DistTab) int hops;

/* numero de cidades no caminho */

int tam;

int rota[];

/* tam parcial do caminho */

int numcidades;

/* vetor com a rota parcial */

int $*$ MinimaDist;

int MinPath[];

Semaph atualiza;

Par DistTab[40][40];

\{

int me,city, dist, $\mathrm{i}, \mathrm{j}$;

if $($ tam $\geq *$ MinimaDist $) \quad / *$ percurso parcial maior do que o melhor $* /$ \{

/* printf("Percurso Maior : \%d \n", tam); */

\}

else

/* o percurso parcial eh menor (por enquanto) */

\{

if $($ hops $==$ numcidades $) \quad$ /* encontrou-se um caminho melhor $* /$ \{

$\operatorname{lock}(\& a t u a l i z a)$

if $(\operatorname{tam}<*$ MinimaDist $) \quad / *$ confere o tamanho $* /$

\{

/* printf("Mudou \%d \n", tam);*/

$*$ MinimaDist $=$ tam;

for $(\mathrm{i}=1 ; \mathrm{i} \leq$ numcidades $; \mathrm{i}++)$

$\operatorname{MinPath}[\mathrm{i}]=\operatorname{rota}[\mathrm{i}]$;

\}

unlock(\&atualiza);

\}else

/* ainda ha cidade para colocar no caminho */

\{

me $=\operatorname{rota}[$ hops $] ; / *$ ultima cidade $* /$

for $(\mathrm{i}=1 ; \mathrm{i} \leq$ numcidades $; \mathrm{i}++)$

\{

city $=$ DistTab[me][i].cidade; / * indice da cidade */

if( !present(city,hops,rota) ) ～/ * cidade nao esta no caminho */ \{

$\operatorname{rota}[$ hops +1$]=$ city;

dist=DistTab[me][i].dist;

tsp(hops+1, tam+dist, rota, numcidades, MinimaDist,

MinPath, atualiza, DistTab);

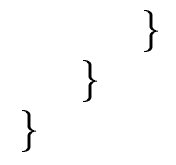




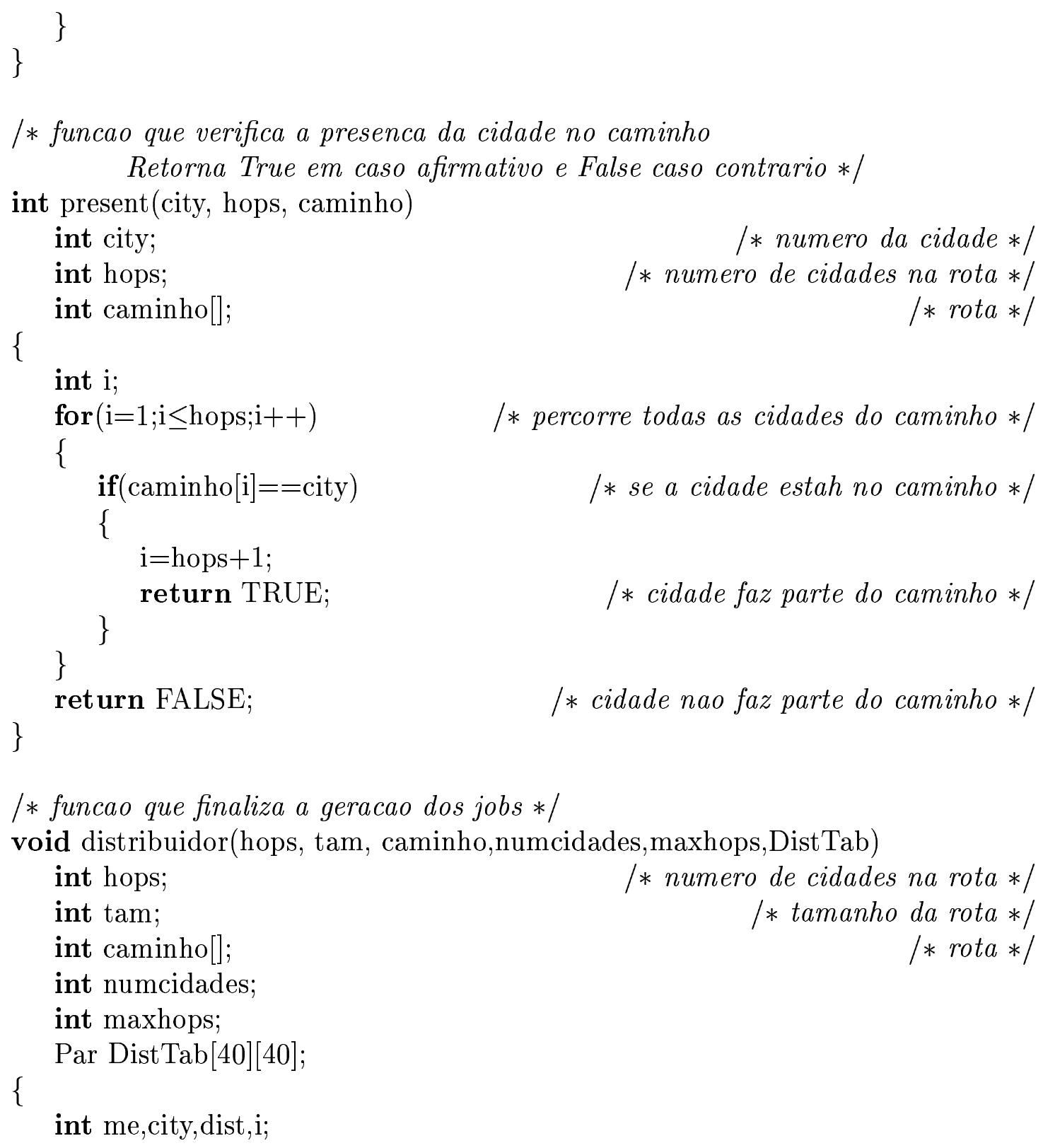




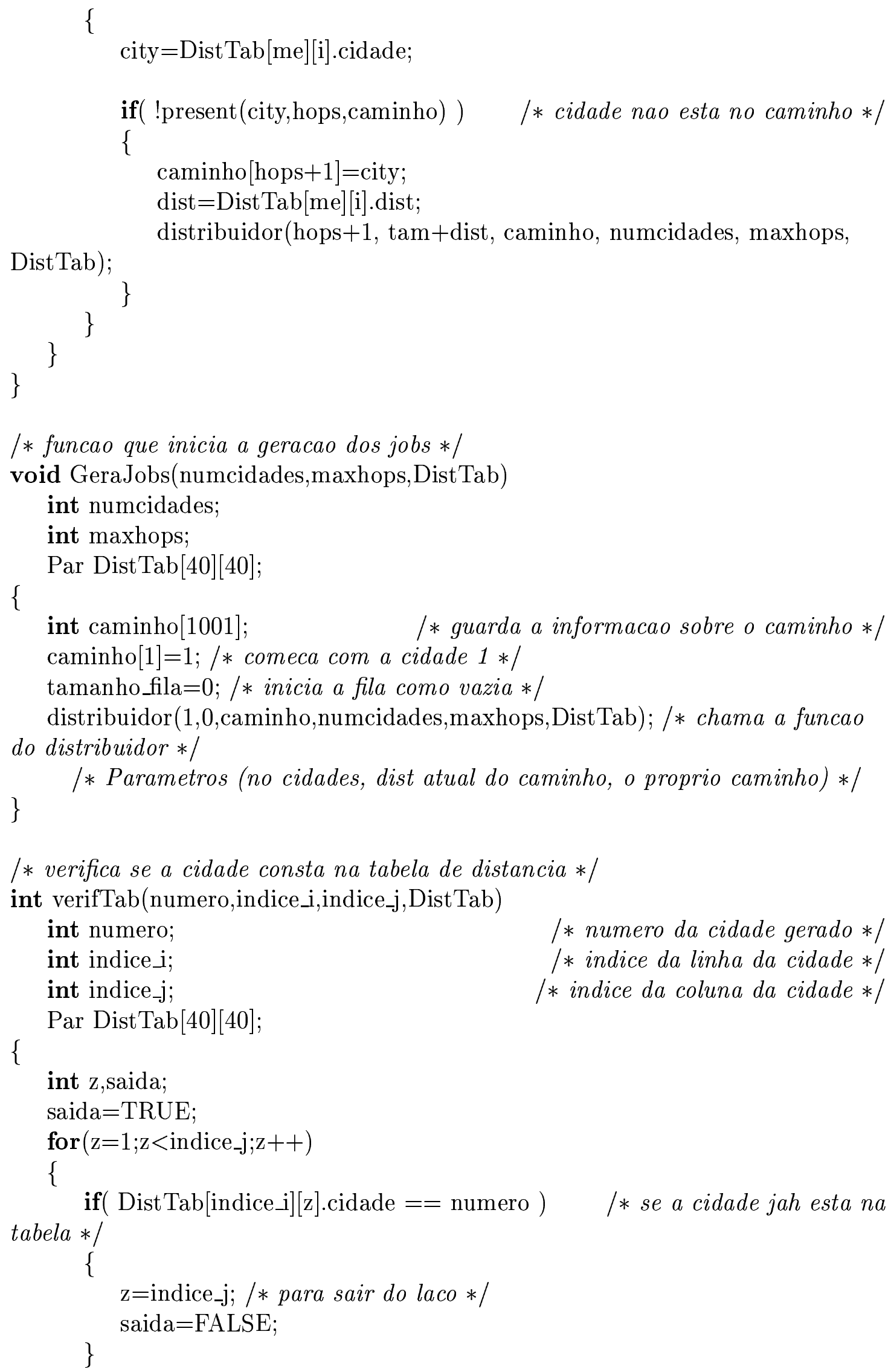




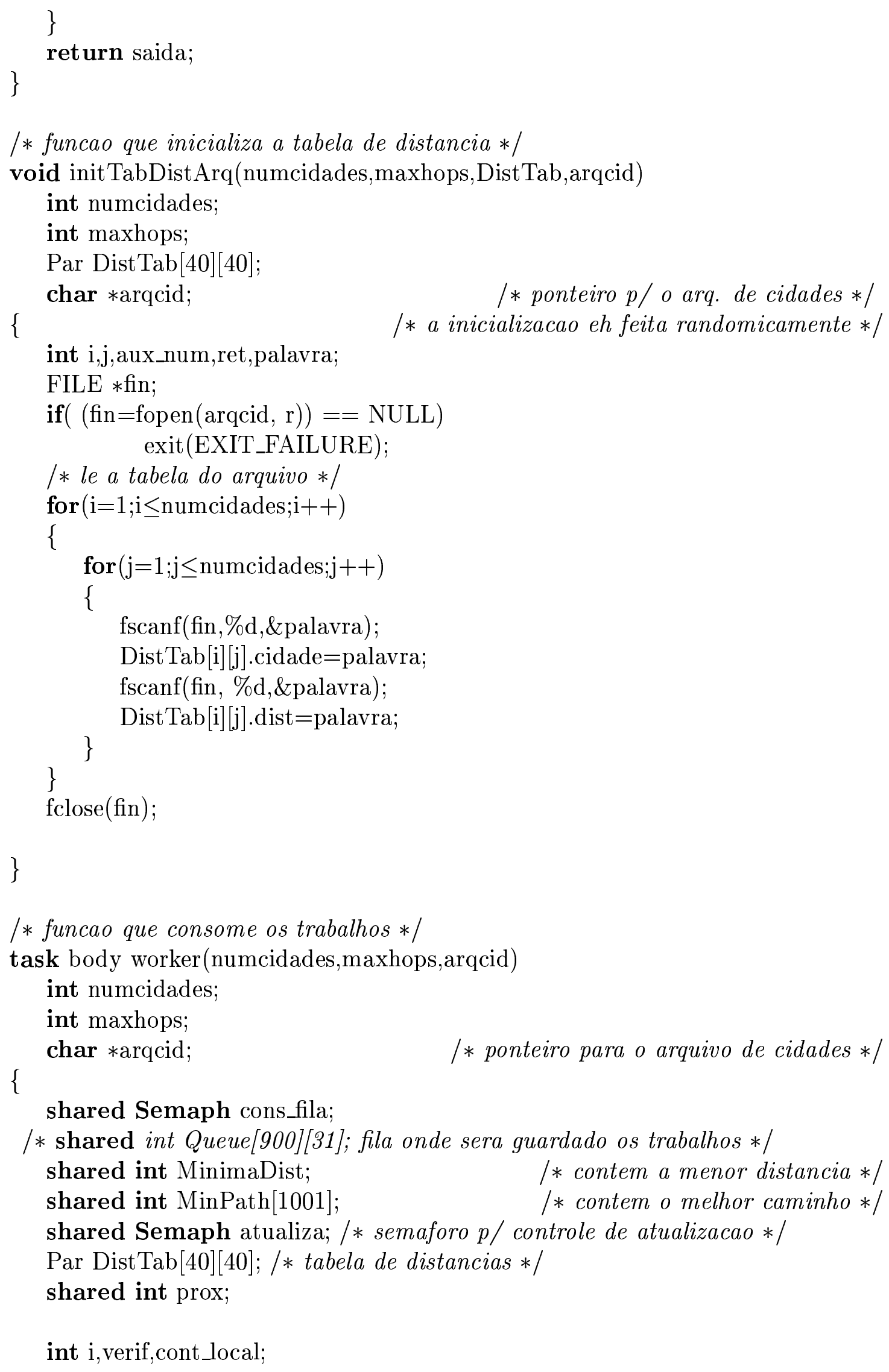


struct timeval start_time, end_time;

double exe_time;

MinimaDist $=\mathrm{INF} ; / *$ inicializa com infinito para o custo do melhor caminho */

create_sem(\&atualiza, 1$)$;

initTabDistArq(numcidades,maxhops,DistTab,arqcid); /* inicializa a tabela de distancia $* /$

GeraJobs(numcidades,maxhops,DistTab); /* funcao para gerar os jobs */

/* Inicio da Parte Paralela */

create_sem(\&cons_fila,1);

$\operatorname{lock}(\&$ cons_fila);

prox $=0 ; / *$ contador para saber a quant. de jobs executados $* /$

unlock(\&cons_fila);

forall $\mathrm{i}=0$ to $3 / *$ numero de processadores $* /$

\{

verif=TRUE; /* variavel que verifica se ha elementos na fila */

/* todos os executores iniciam a Tabela de Distancias */

initTabDistArq(numcidades,maxhops,DistTab,arqcid); /* inicializa a

tabela de distancia $* /$

while(verif)

\{

/* enquento houver trabalho na fila*/

lock(\&cons_fila); /* bloqueia o semaforo para consumir um trabalho da fila */

if $($ prox $==$ tamanho_fila $) \quad$ /* nao ha mais job na fila $* /$ verif $=$ FALSE;

else

\{

cont $\_$local $=$prox; $/ *$ indice do job a ser executado $* /$

prox ++ ;

\}

unlock(\&cons_fila);

if(verif)

/* envia o job para o tsp */

\{

tsp(maxhops,Queue[cont_local][0],Queue[cont_local],numcidades,\&MinimaDist,MinPa

\}

/* funcao com No cidades na rota, tamanho da rota e a rota */ 


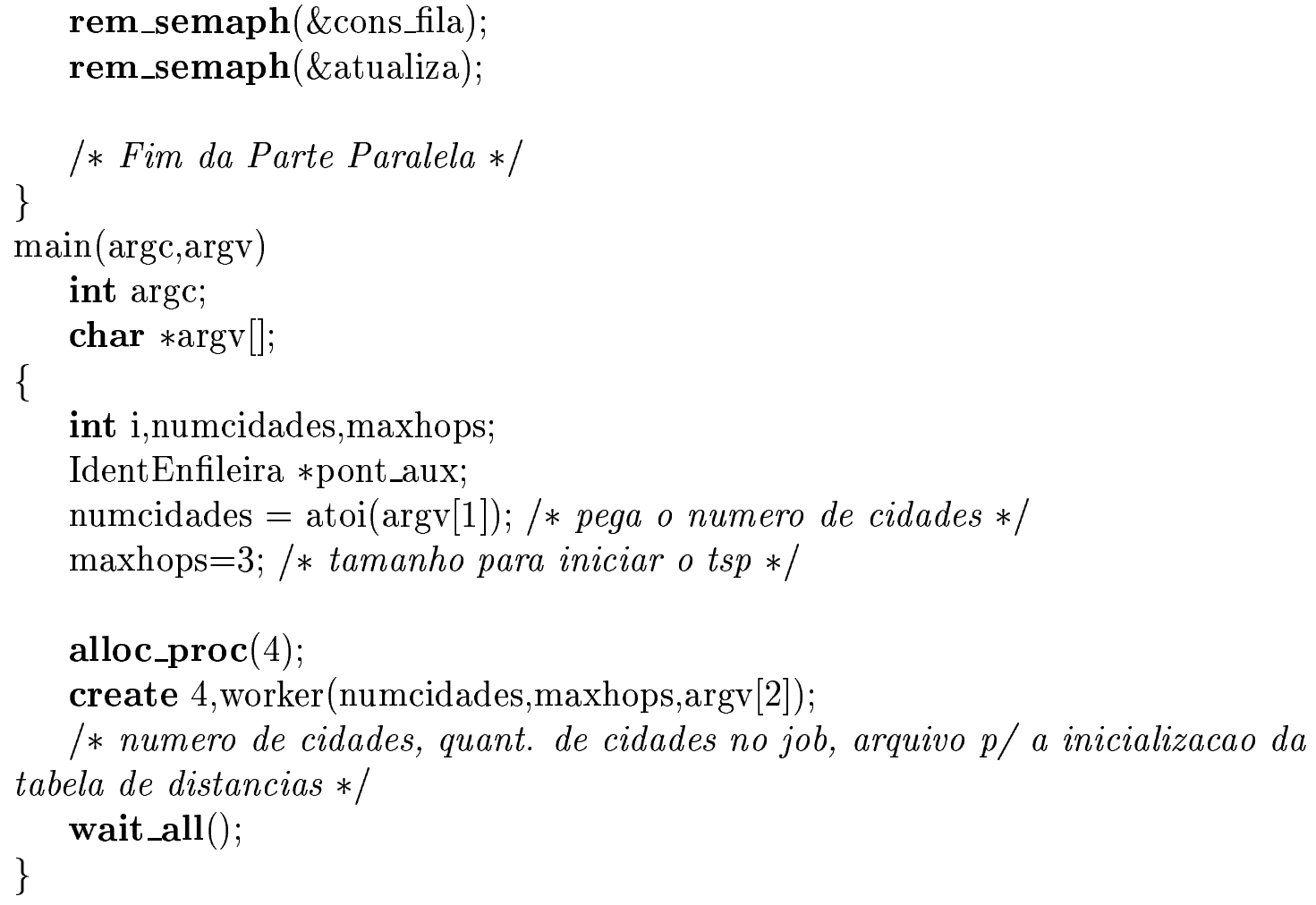




\section{APÊNDICE C Códigos EXPANDIDOs DOS PROGRAMAS DE TESTE}

\section{C.1 Tabela de Variáveis Compartilhadas dos pro- gramas de multiplicação de matrizes}

As versões que declaram as matrizes como variáveis compartilhadas possuem uma tabela gerada em tempo de compilação. As informações dessa tabela se encontram em dois arquivos: um de prototipação e outro contedo a declaração das variáveis e a própria tabela.

\section{C.1.1 O arquivo de prototipação}

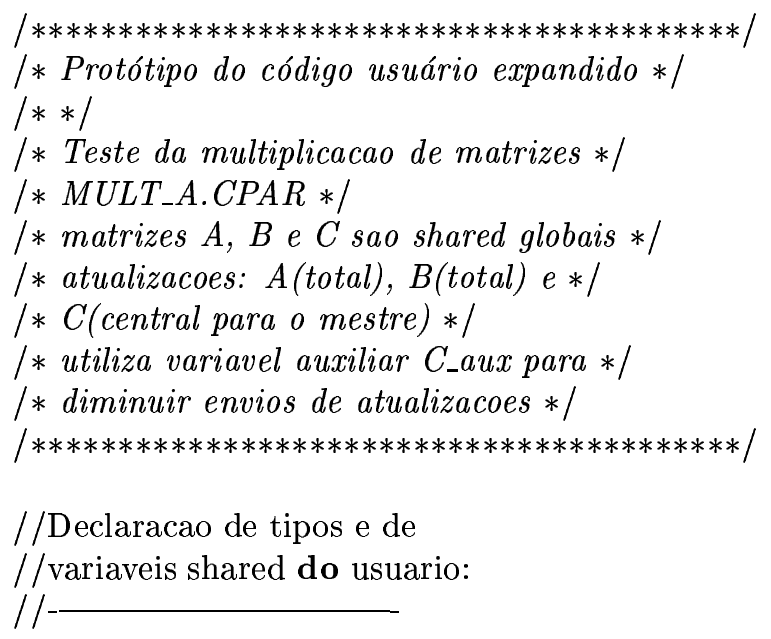

\#def ine SIZE 2000

extern double A[SIZE][SIZE];

extern double $\mathrm{B}$ [SIZE] [SIZE];

extern double C[SIZE][SIZE];

\section{C.1.2 O arquivo de declaração e a tabela}




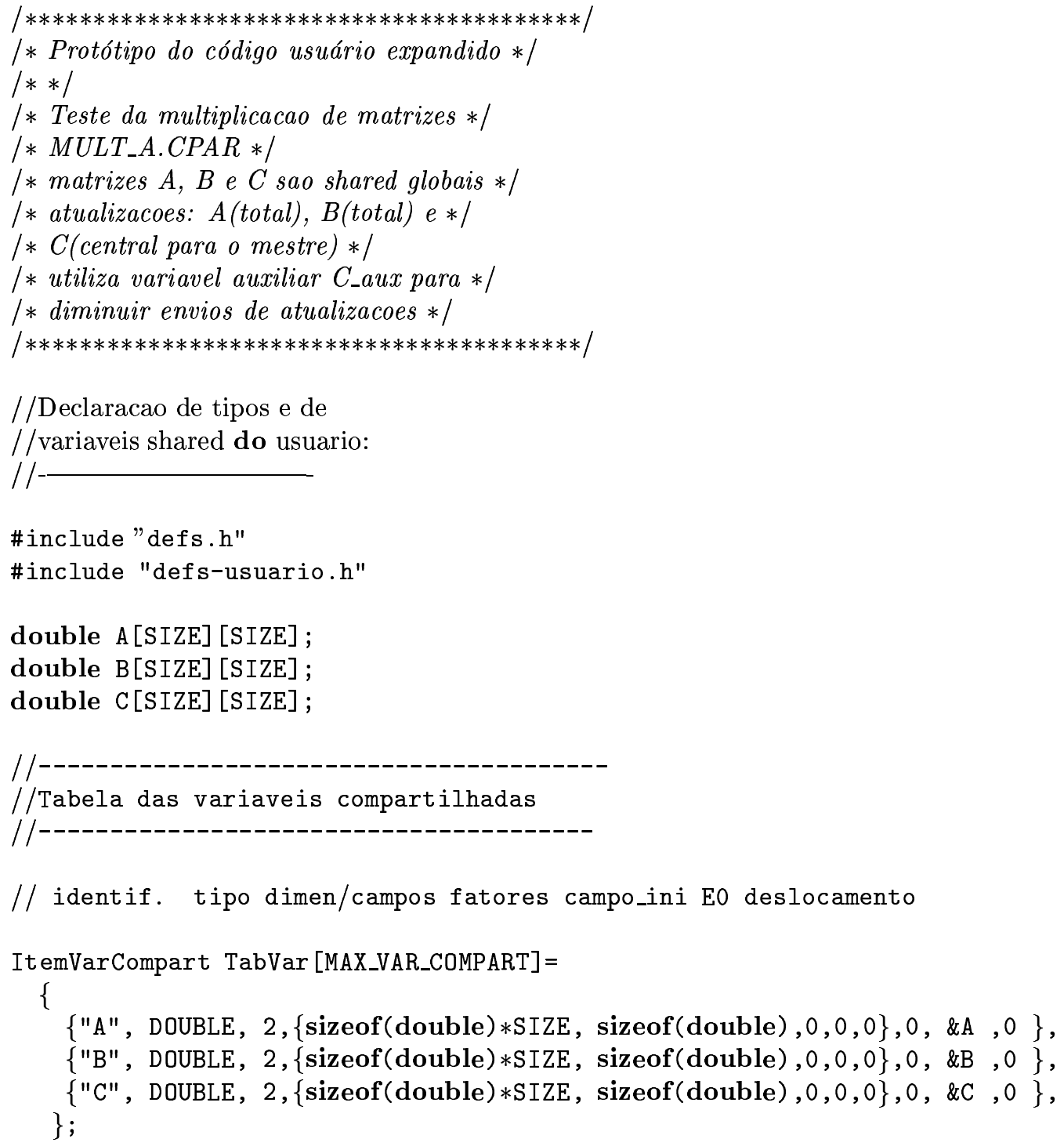

\section{C.2 Multiplicação de Matrizes versão com atua- lização em todos os nós e sem variável auxi- liar}

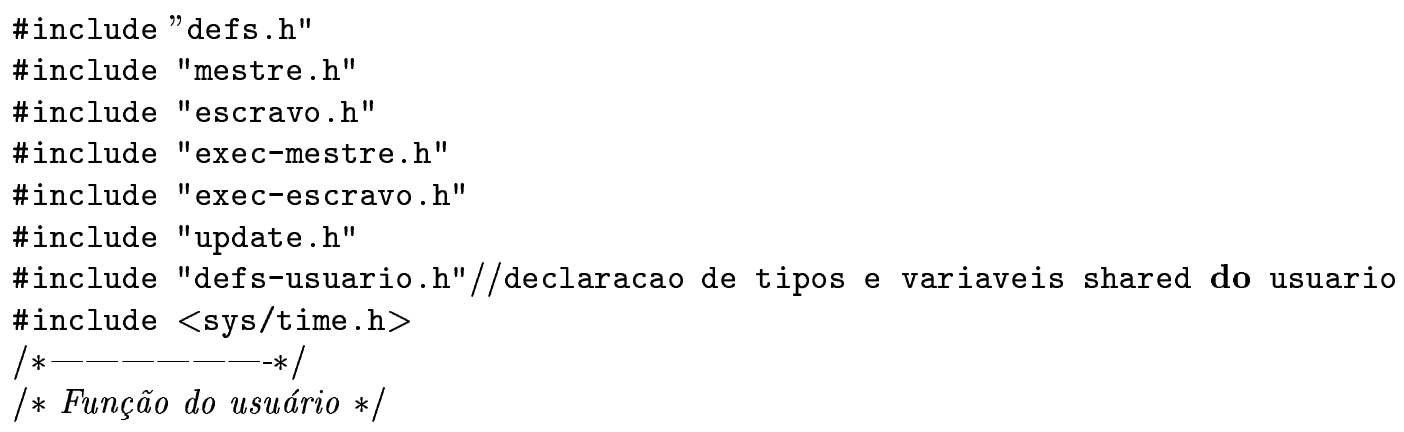




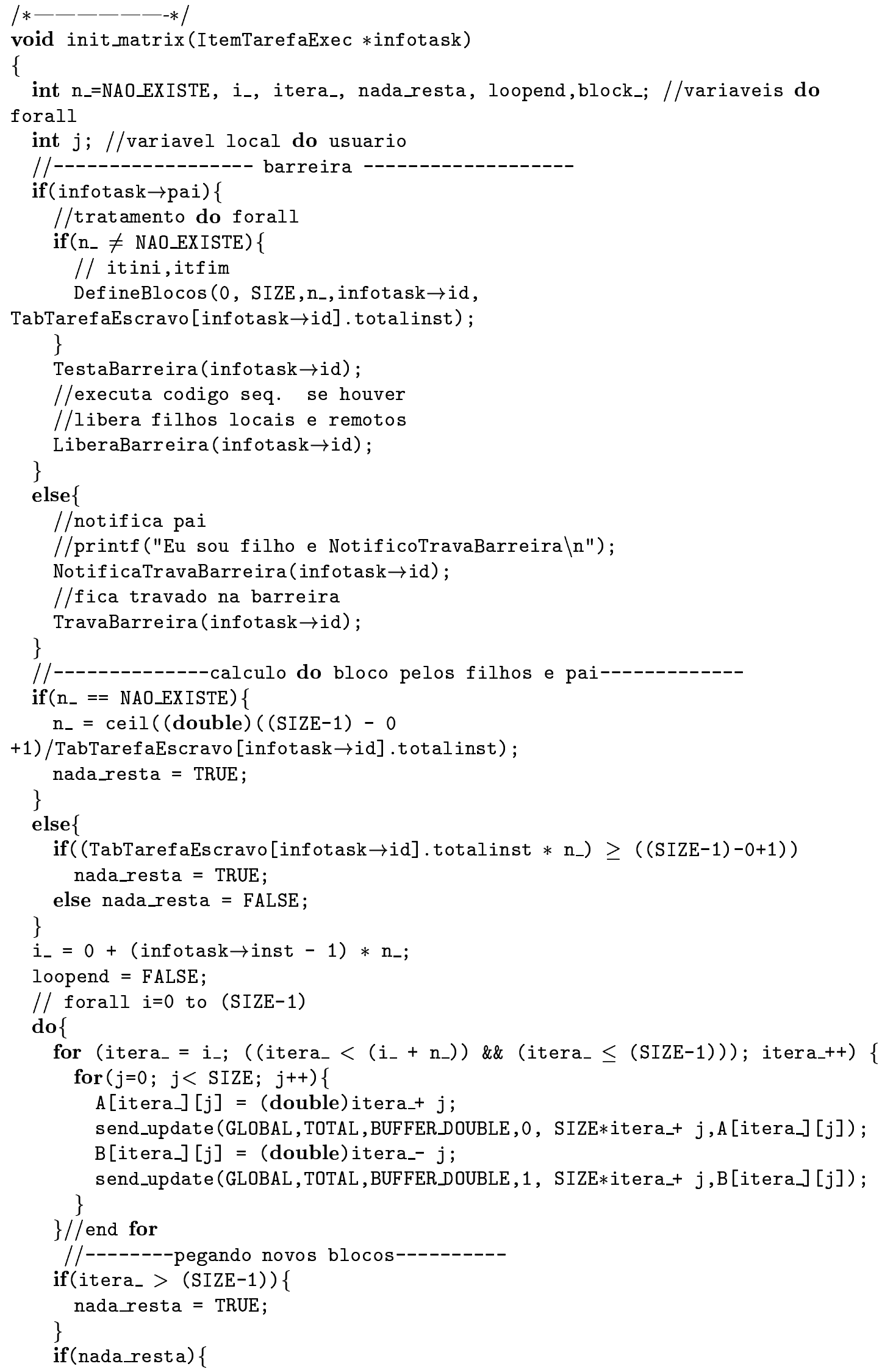




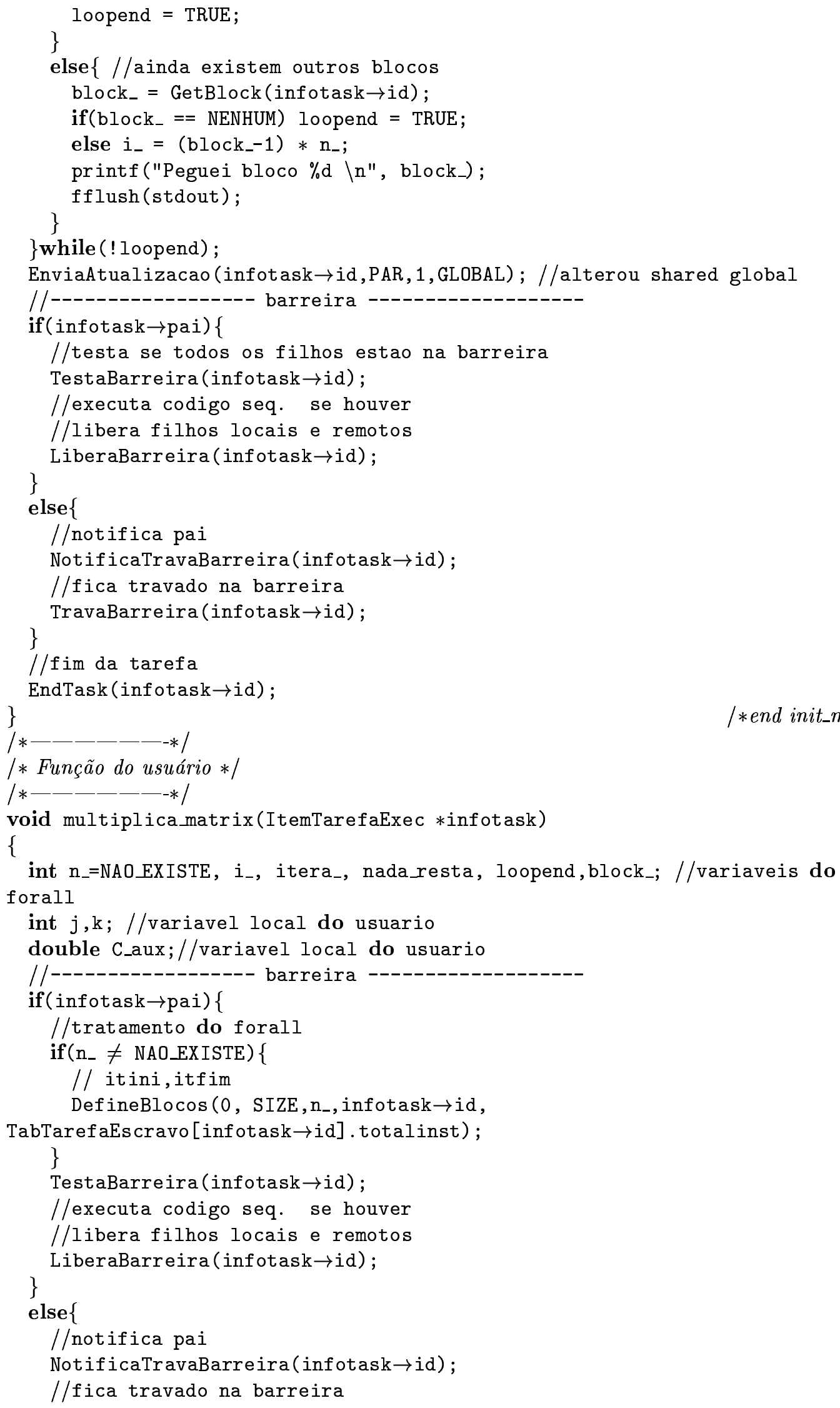




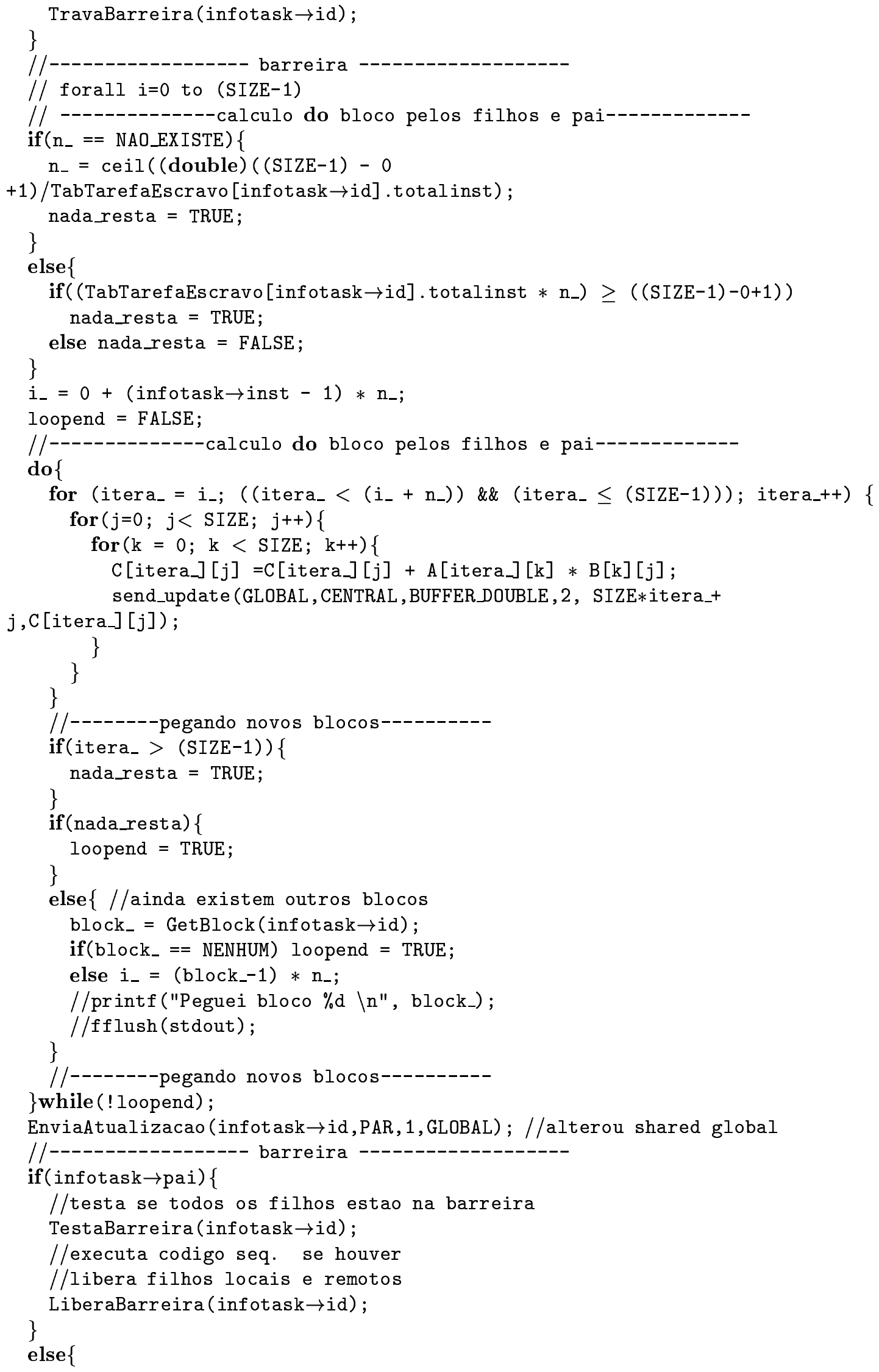




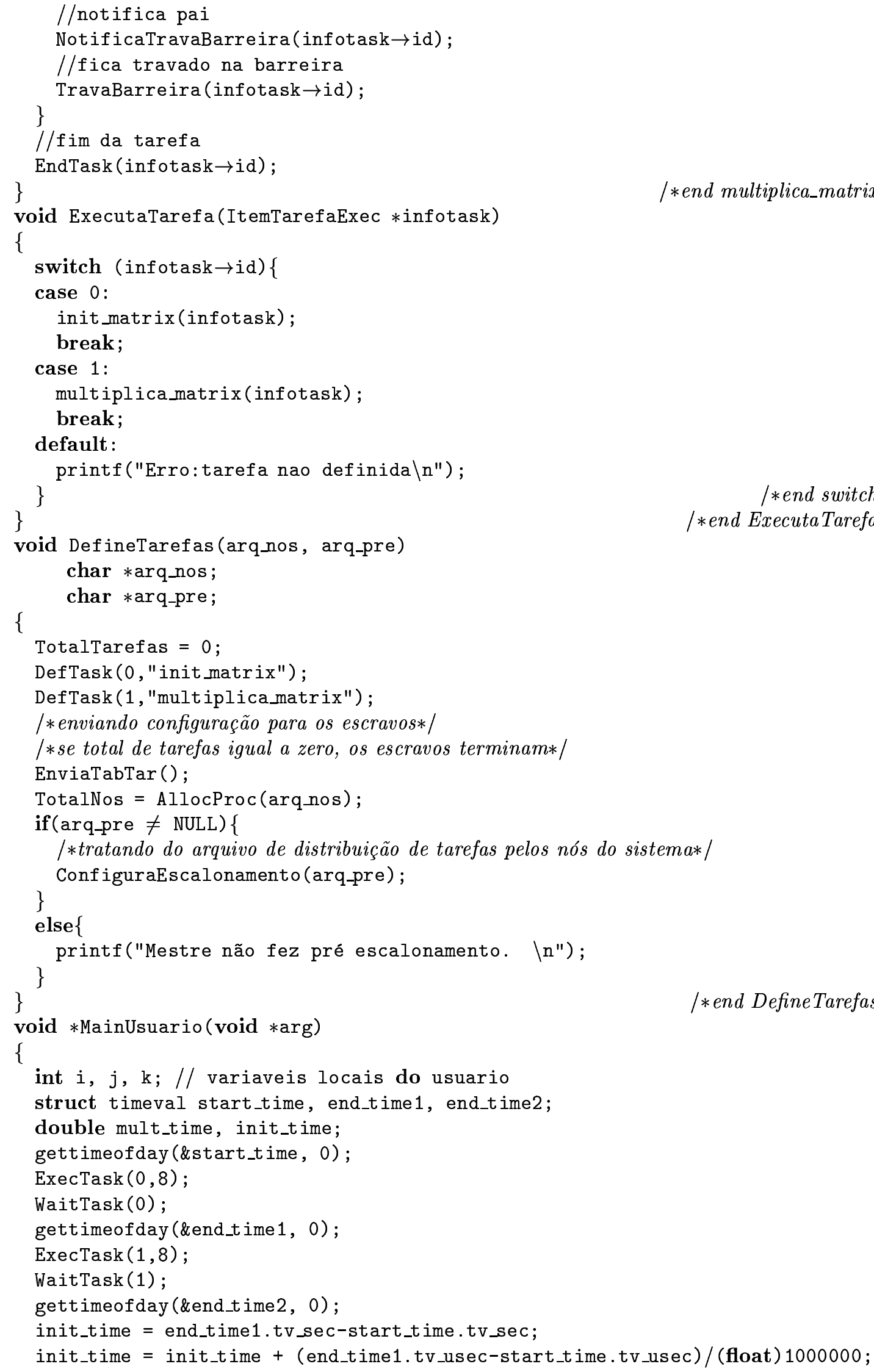




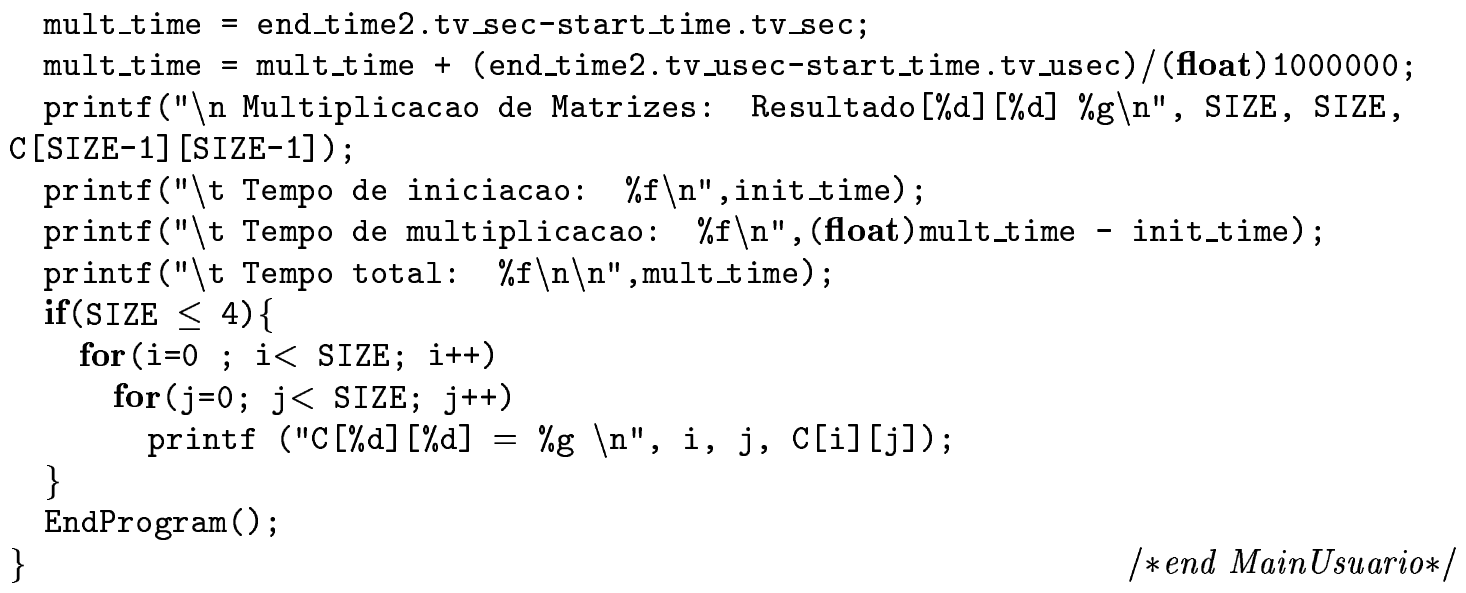

\section{C.3 Multiplicação de Matrizes versão com atua- lização em todos os nós e com variável auxi- liar}

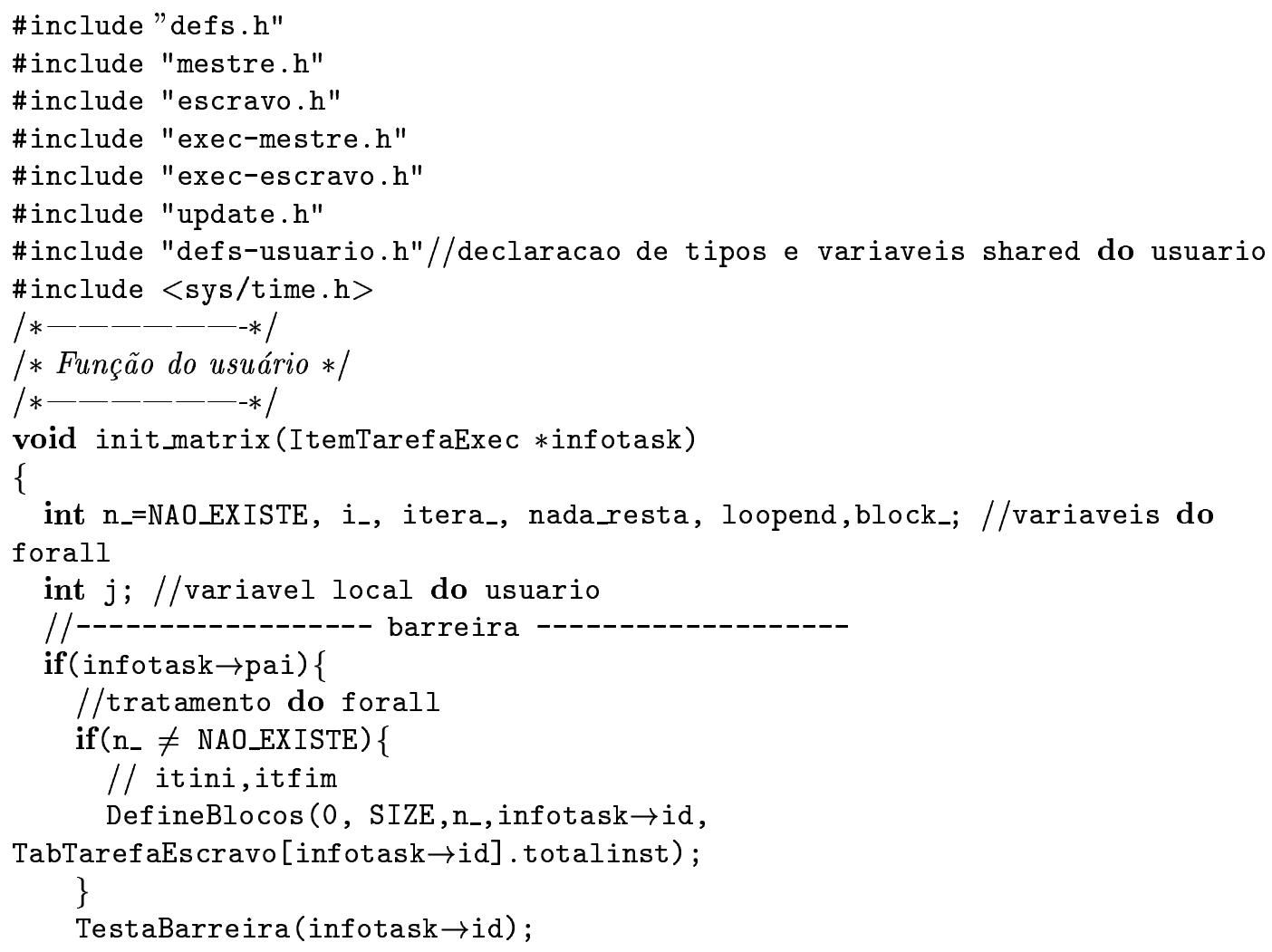




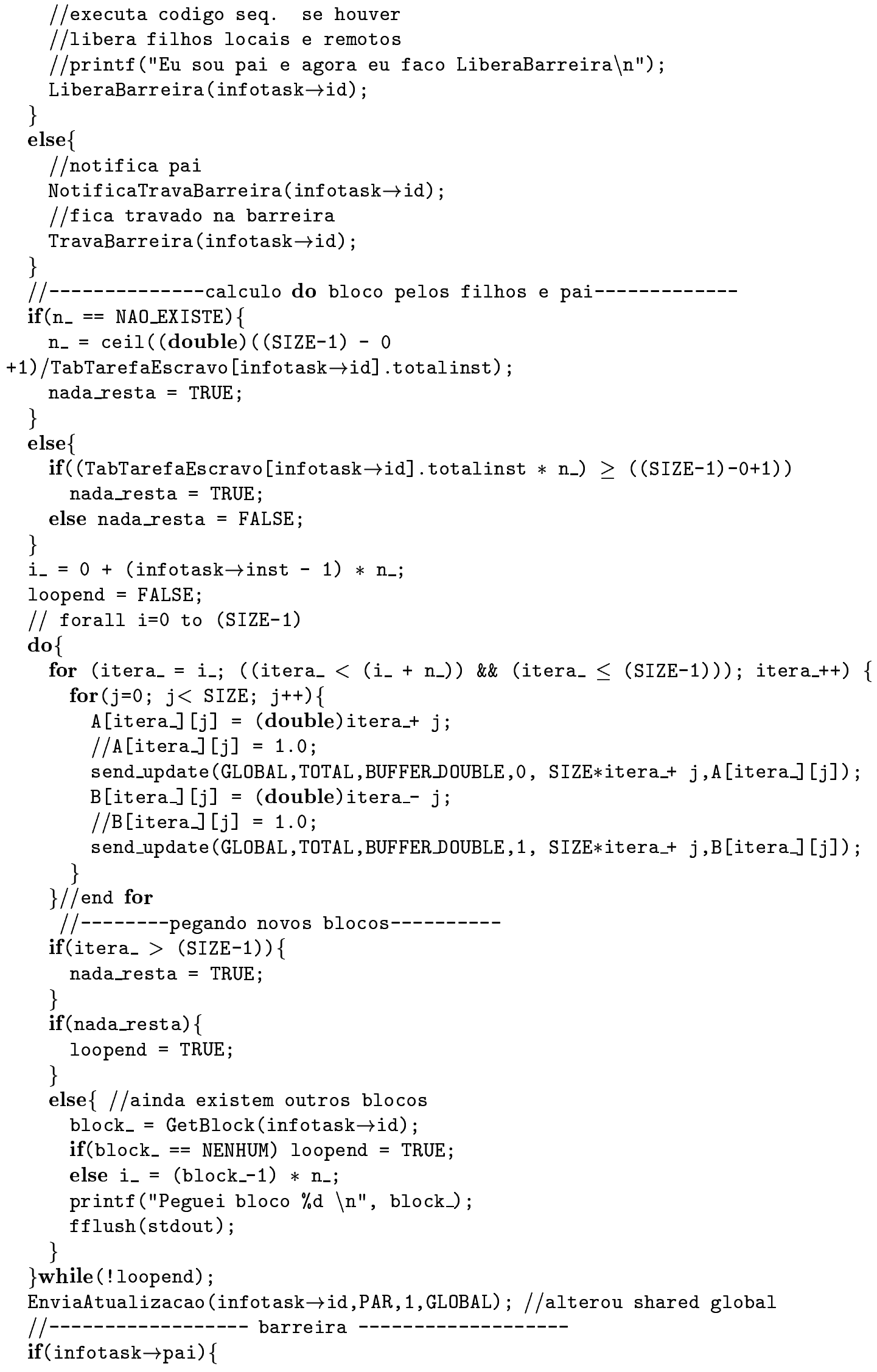




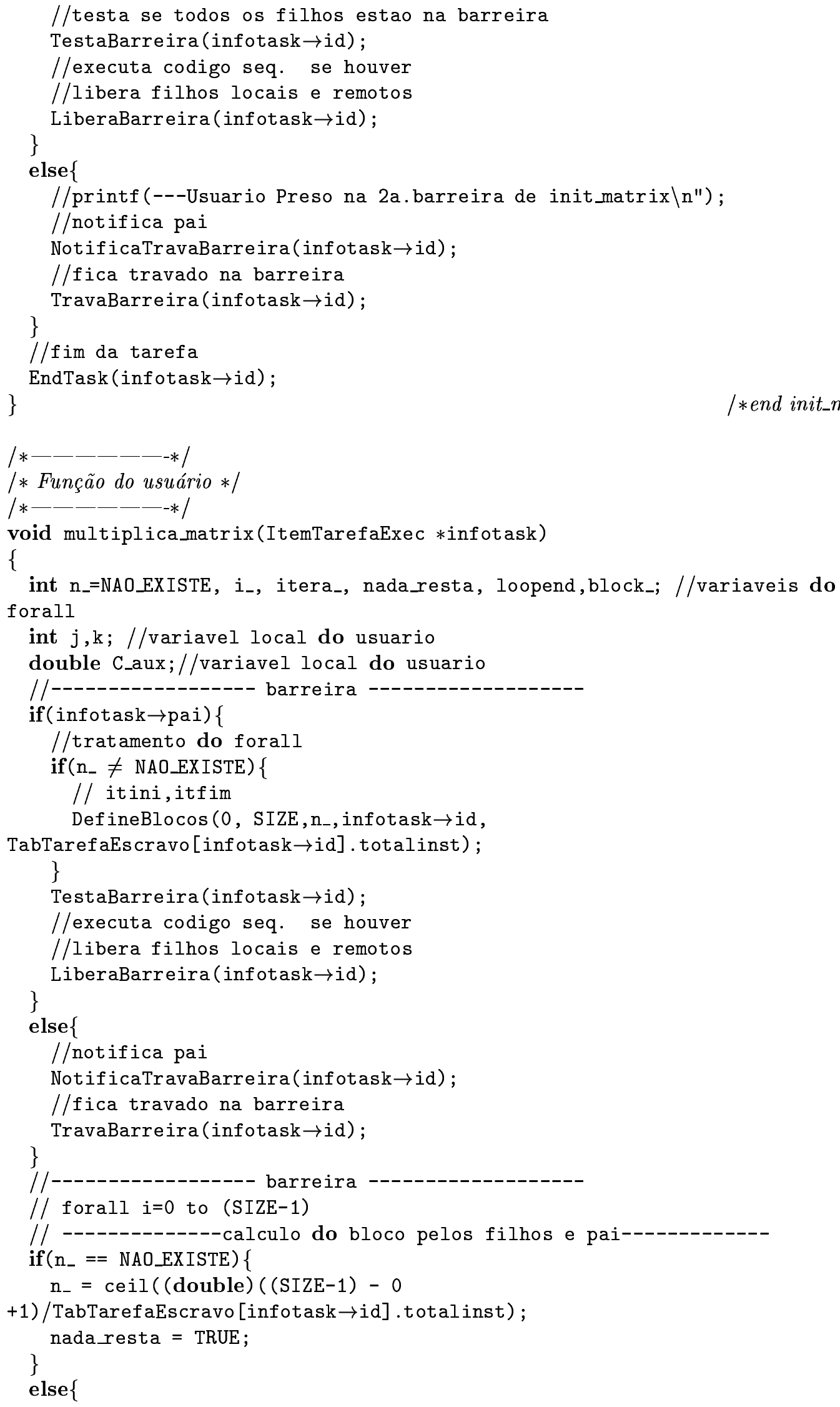




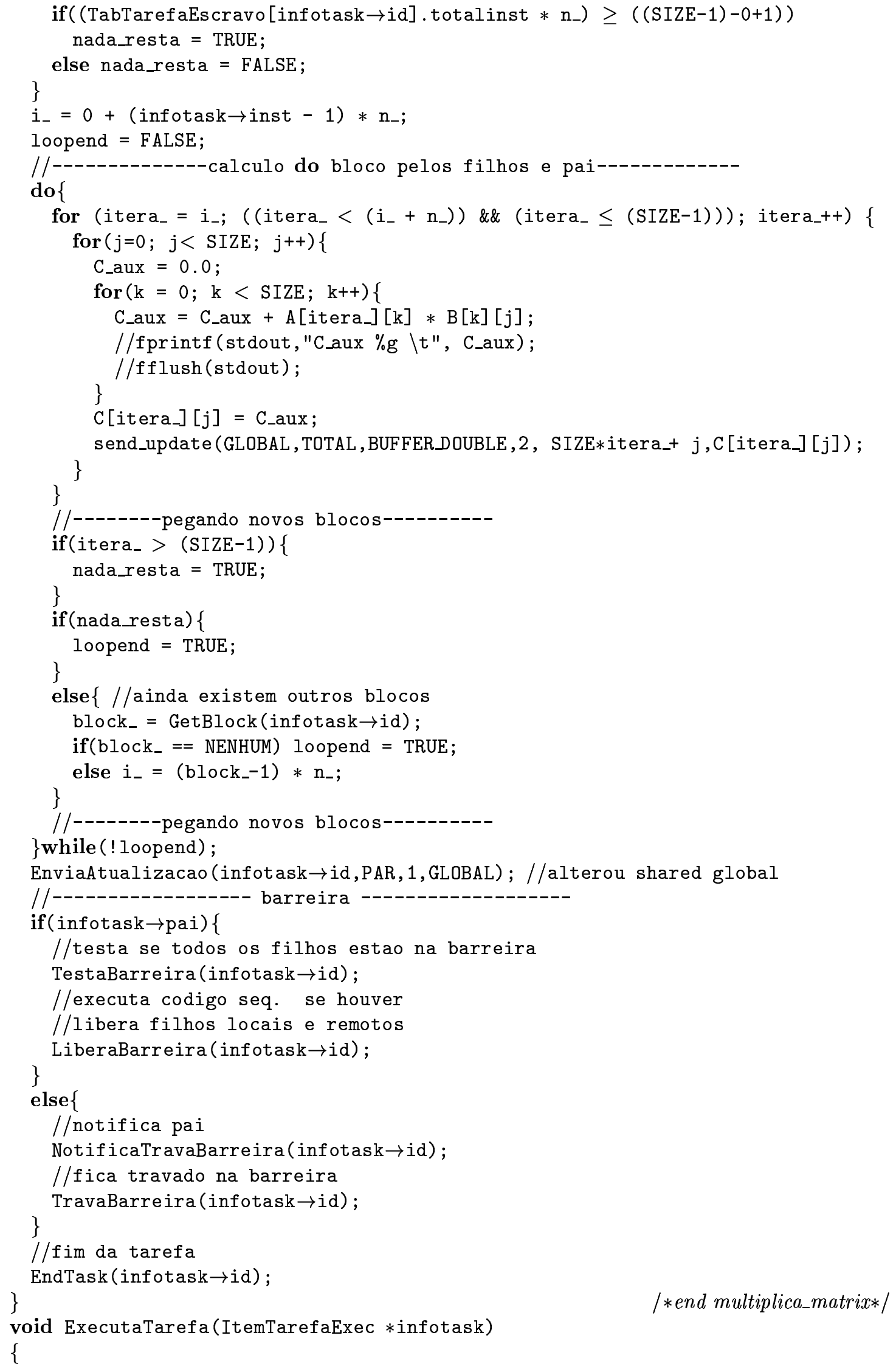




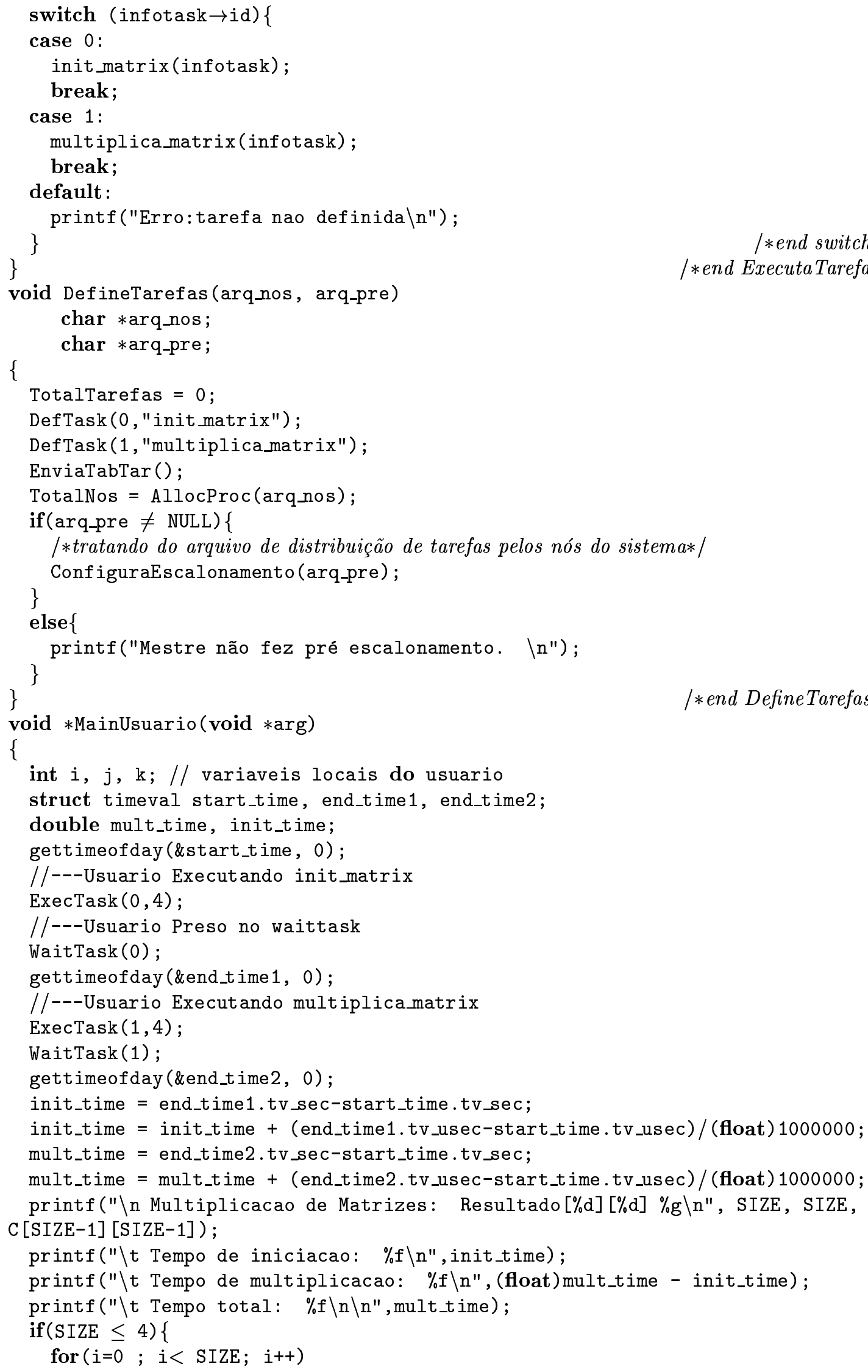




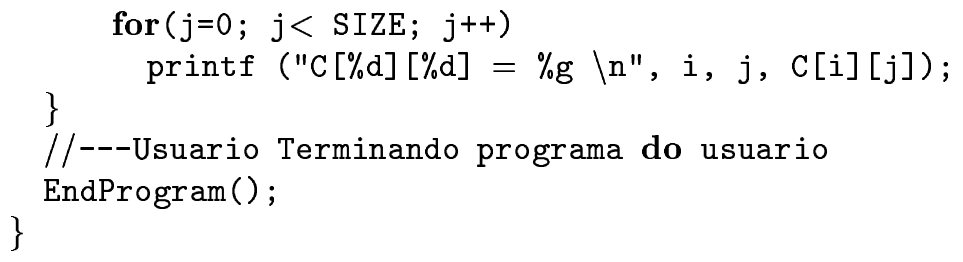

/*end MainUsuario*/

\section{C.4 Multiplicação de Matrizes versão com atu- alização somente no mestre e com variável auxiliar}

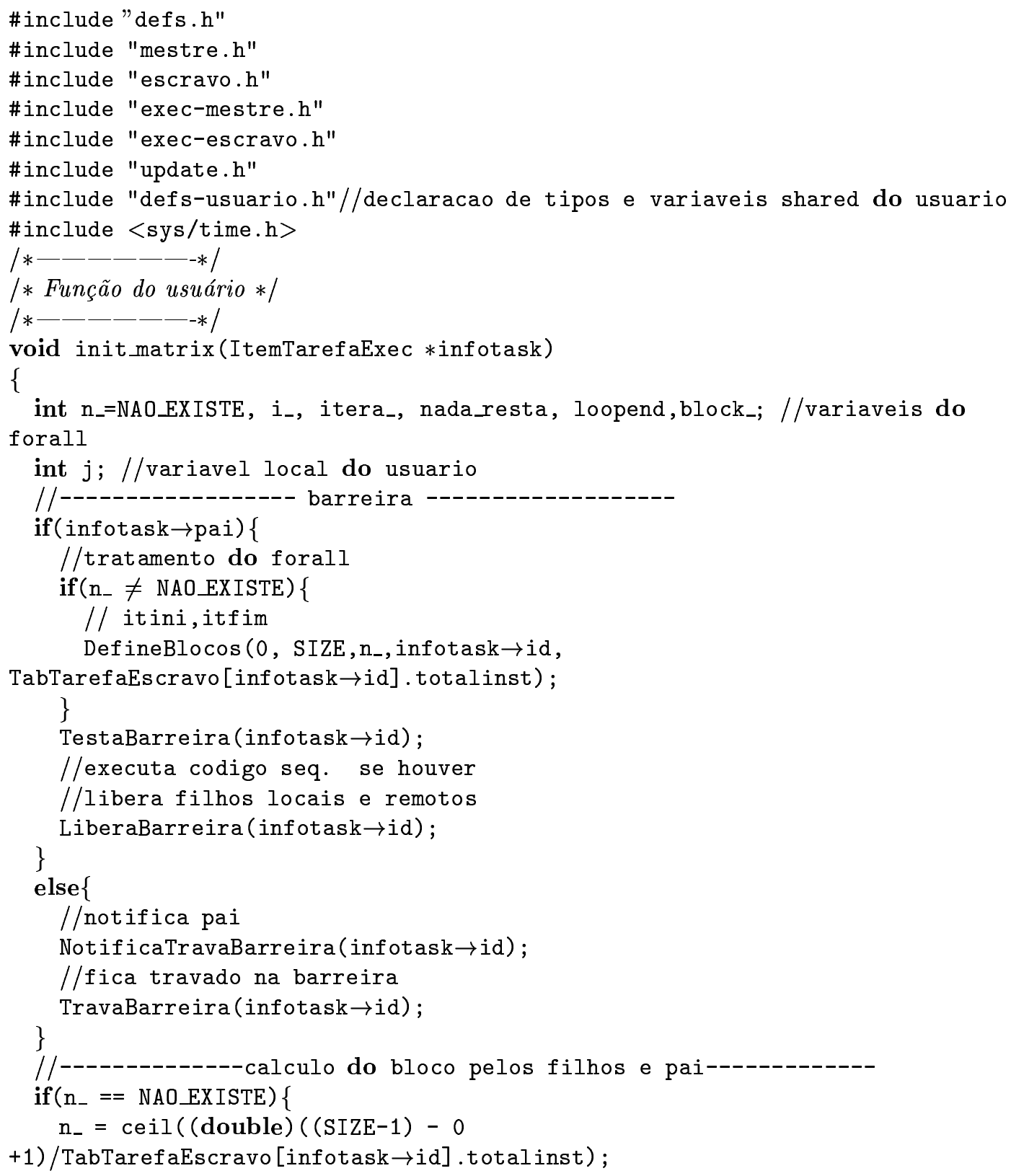




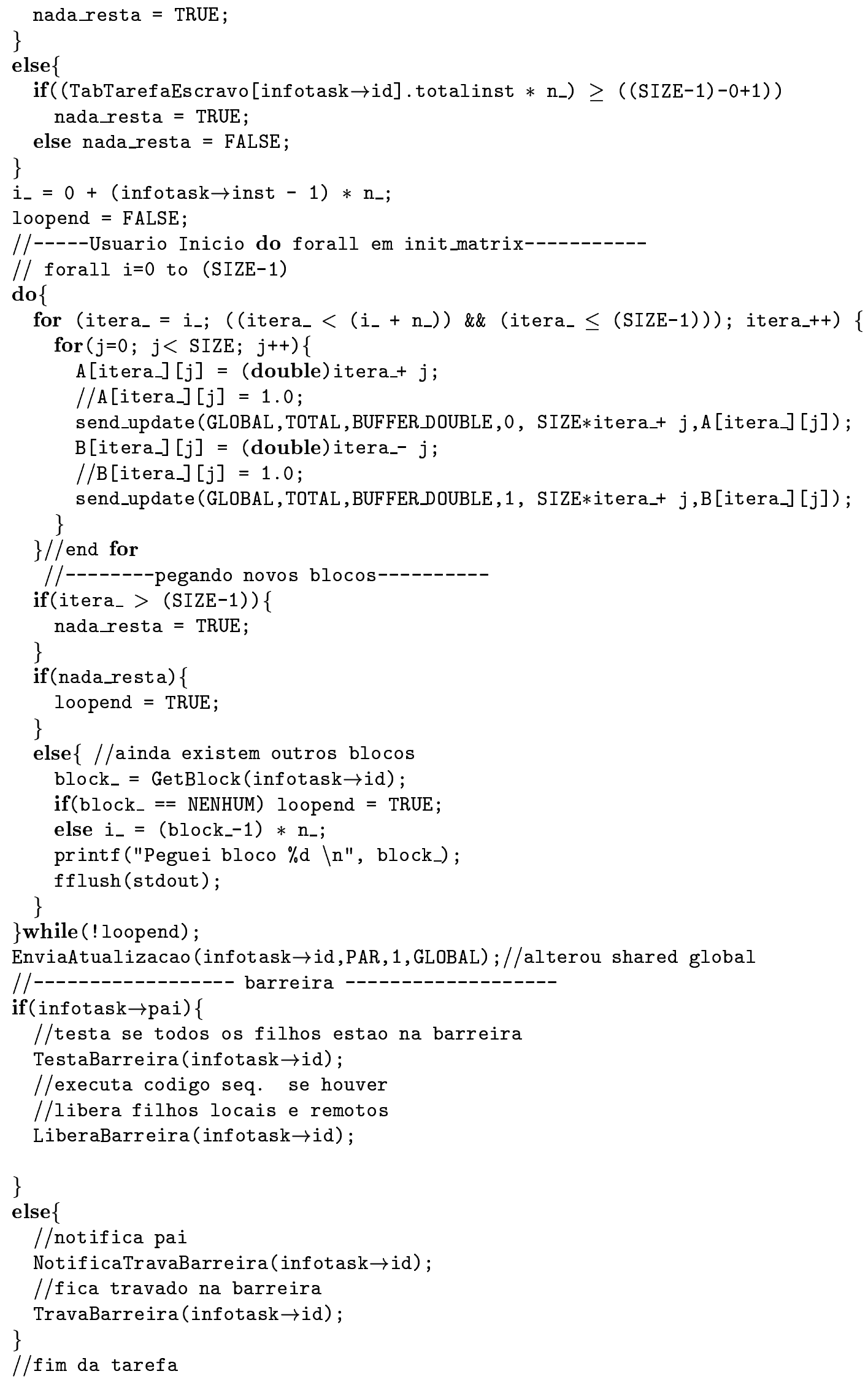




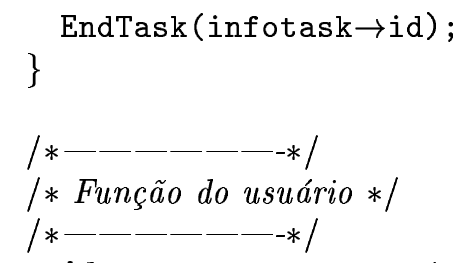

|*end init_matrix*/

void multiplicamatrix (ItemTarefaExec $*$ infotask)

\{

int $\mathrm{n}_{-}=$NAO_EXISTE, $i_{-}$, itera ${ }_{-}$, nada_resta, loopend,block_; //variaveis do forall

int $\mathrm{j,k}$; //variavel local do usuario

double C_aux;//variavel local do usuario

//---------------- barreira -----------------

if (infotask $\rightarrow$ pai) \{

//tratamento do forall

if $\left(\mathrm{n}_{-} \neq\right.$NAO_EXISTE) \{

//itini,itfim

DefineBlocos (0, SIZE, $n_{-}$, infotask $\rightarrow$ id,

TabTarefaEscravo [infotask $\rightarrow$ id] . totalinst);

\}

TestaBarreira (infotask $\rightarrow$ id);

//executa codigo seq. se houver

//libera filhos locais e remotos

\}

LiberaBarreira (infotask $\rightarrow$ id) ;

else \{

//notifica pai

NotificaTravaBarreira(infotask $\rightarrow$ id);

//fica travado na barreira

\}

TravaBarreira (infotask $\rightarrow$ id);

//------------------ barreira -------------------

//---Usuario Inicio do forall em mult_matrix------

$/ /$ forall $i=0$ to (SIZE-1)

// -------------calculo do bloco pelos filhos e pai-------------

if $\left(\mathrm{n}_{-}==\right.$NAO_EXISTE $)\{$

$\mathrm{n}_{-}=\operatorname{ceil}(($ double $)(($ SIZE- -1$)-0$

+1) (TabTaref aEscravo [infotask $\rightarrow$ id] . totalinst);

nada_resta $=$ TRUE;

\}

else \{

if $\left(\left(\right.\right.$ TabTarefaEscravo $\left[\right.$ infotask $\rightarrow$ id] .totalinst $\left.* \mathrm{n}_{-}\right) \geq(($SIZE-1) $-0+1))$

nada_resta $=$ TRUE;

else nada_resta $=$ FALSE;

\}

$i_{-}=0+($ infotask $\rightarrow$ inst -1$) * \mathrm{n}_{-}$;

loopend $=$ FALSE;

//-------------calculo do bloco pelos filhos e pai-------------

do \{

for $\left(\right.$ itera $a_{-}=i_{-} ;\left(\left(\right.\right.$itera $\left.a_{-}<\left(i_{-}+n_{-}\right)\right)$\&\& $($itera $-\leq($SIZE-1) $))$; itera_++) \{

for $(j=0 ; j<\operatorname{SIZE} ; j++)\{$

C_aux $=0.0$;

for $(\mathrm{k}=0 ; \mathrm{k}<\mathrm{SIZE} ; \mathrm{k}++)\{$

C_aux $=$ C_aux + A [itera $][\mathrm{k}] * B[\mathrm{k}][j]$; 


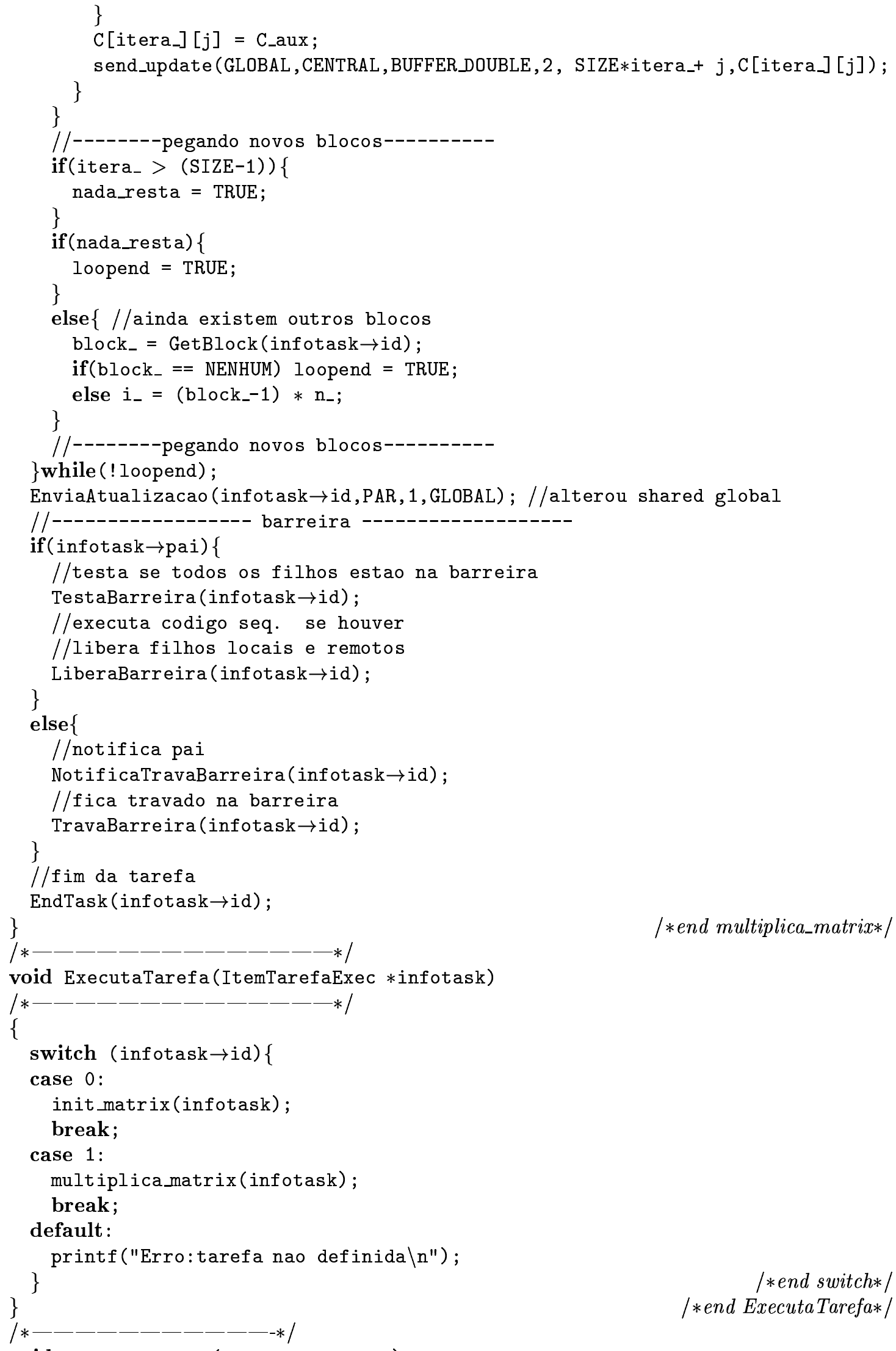




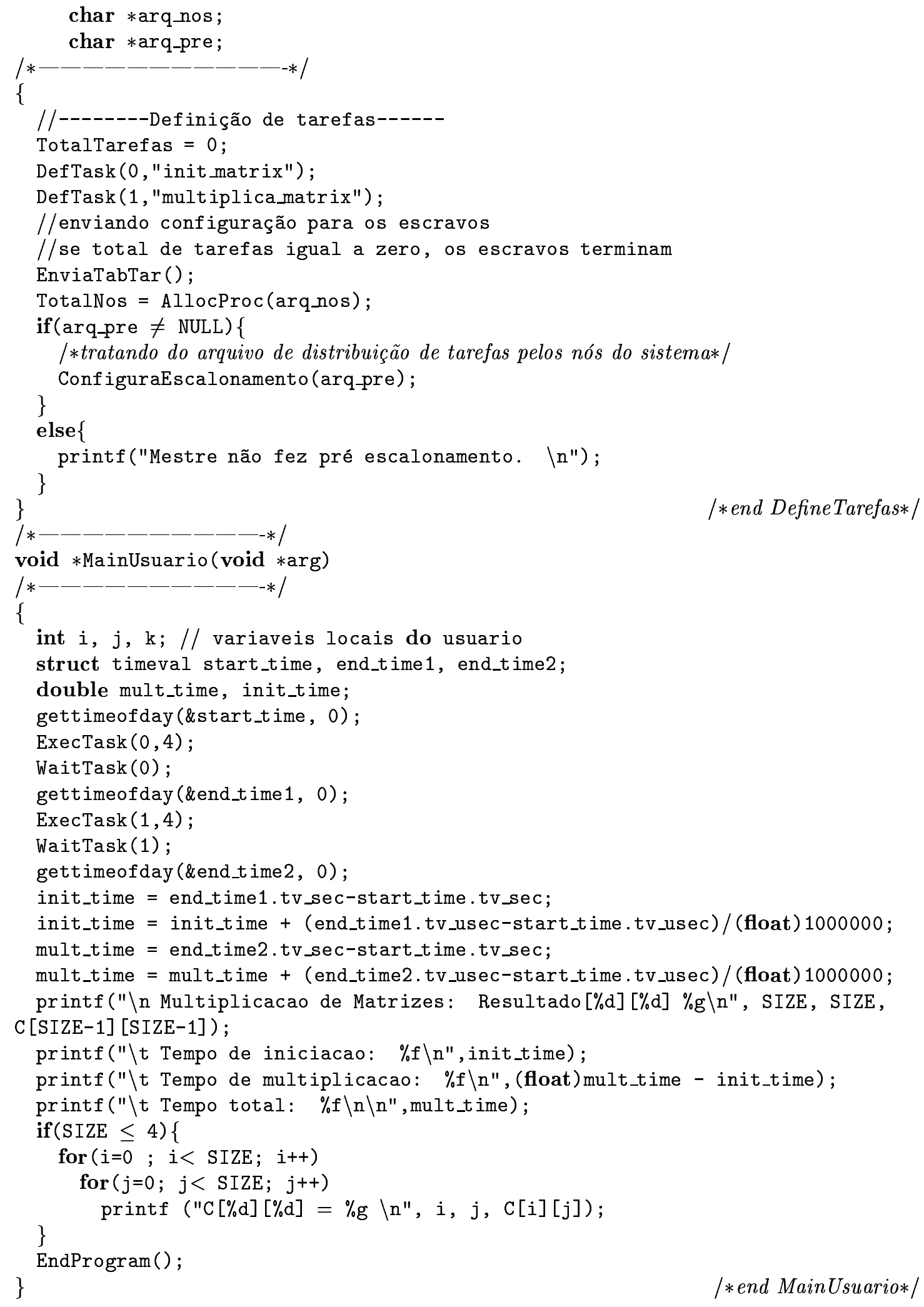




\section{C.5 Multiplicação de Matrizes versão sem envio de mensagem de atualização e com variável auxiliar}

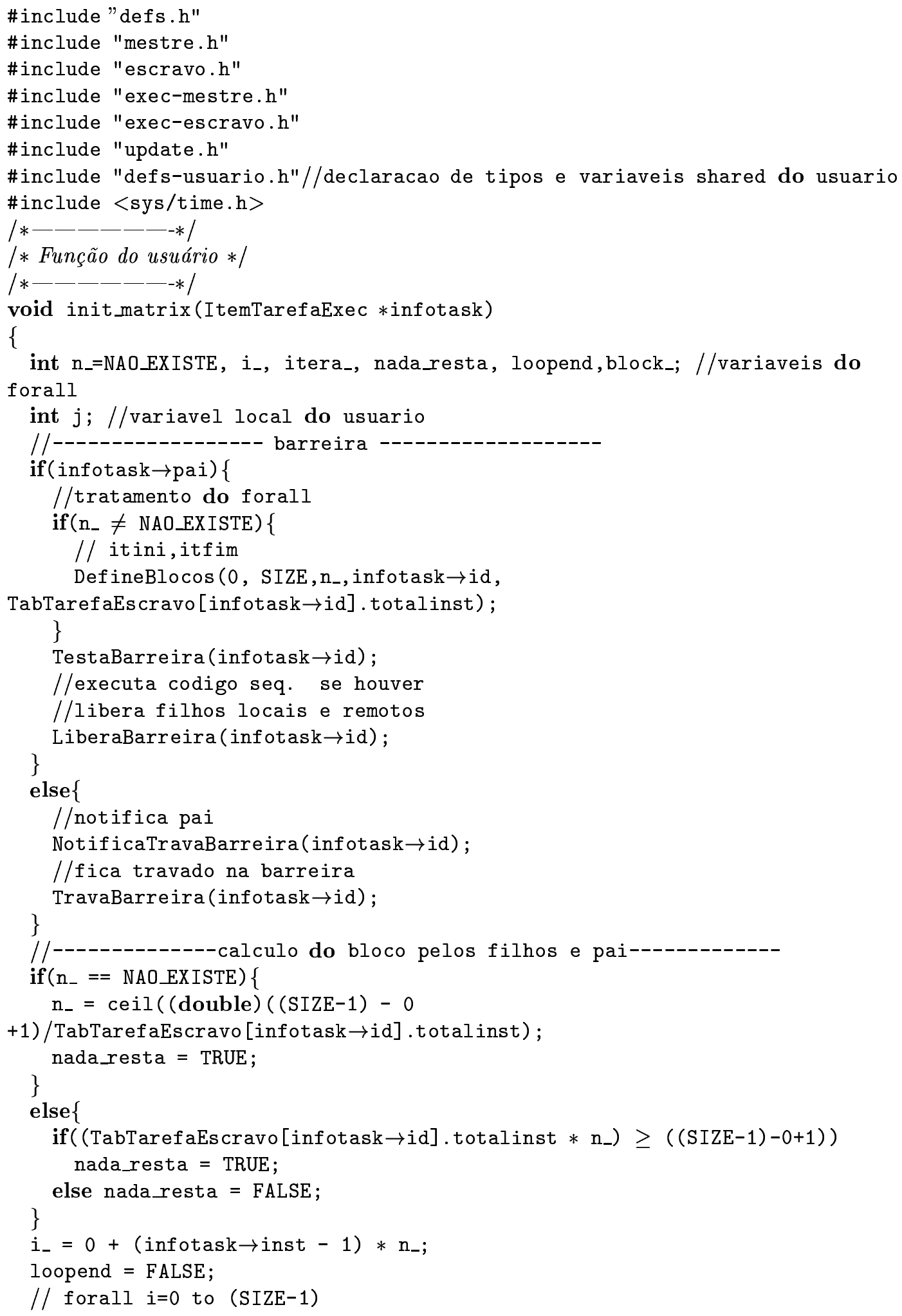




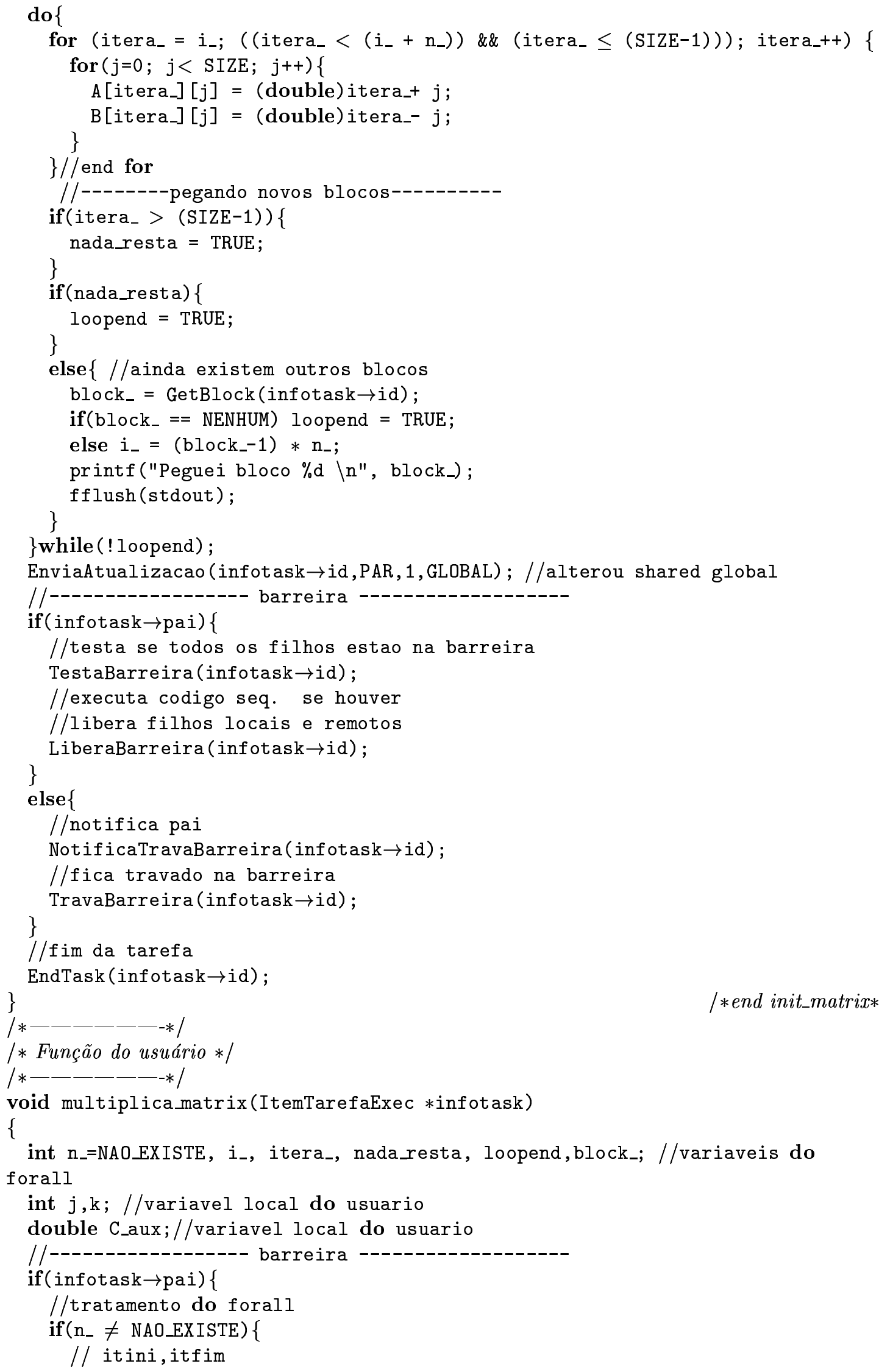




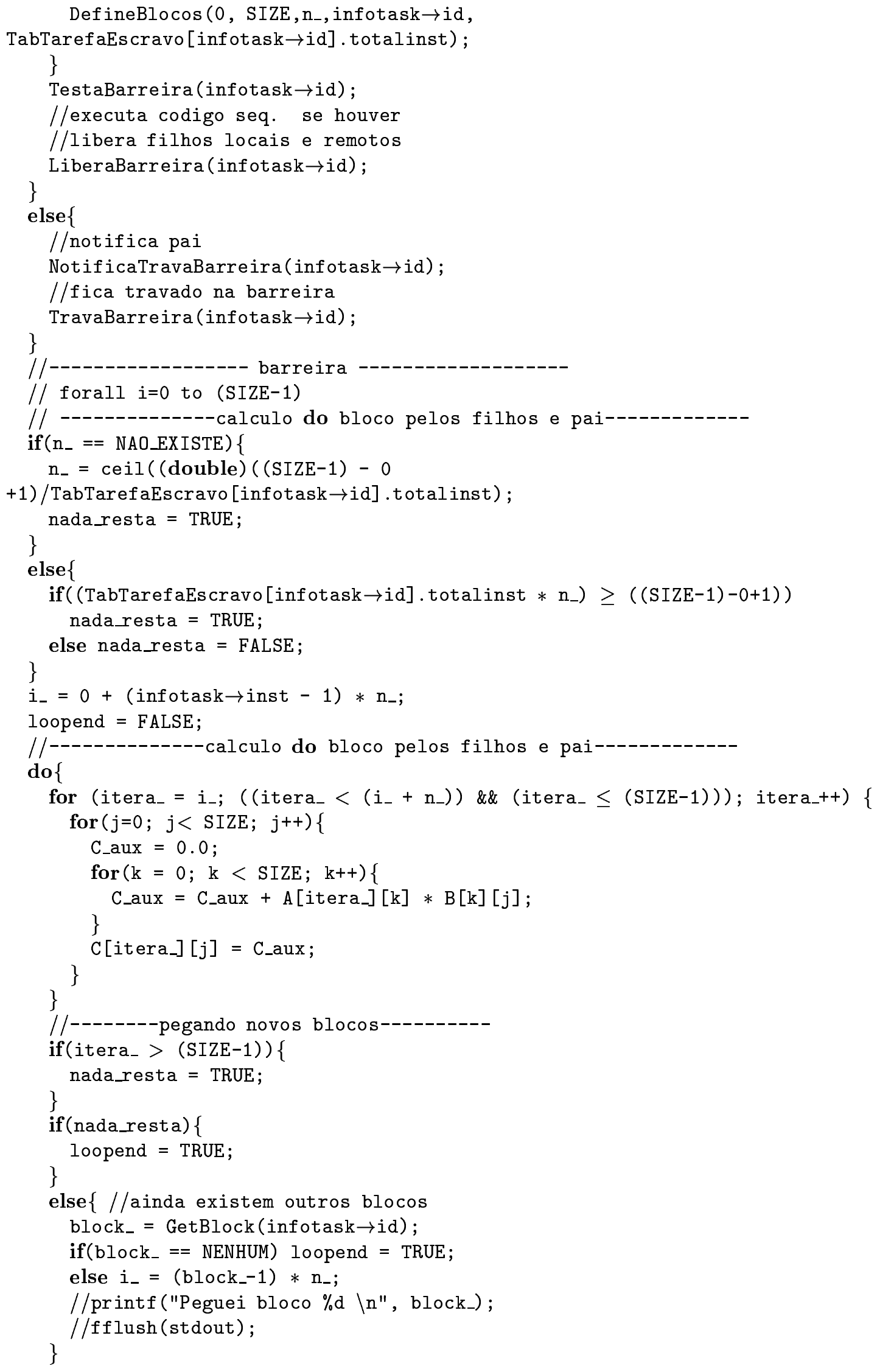




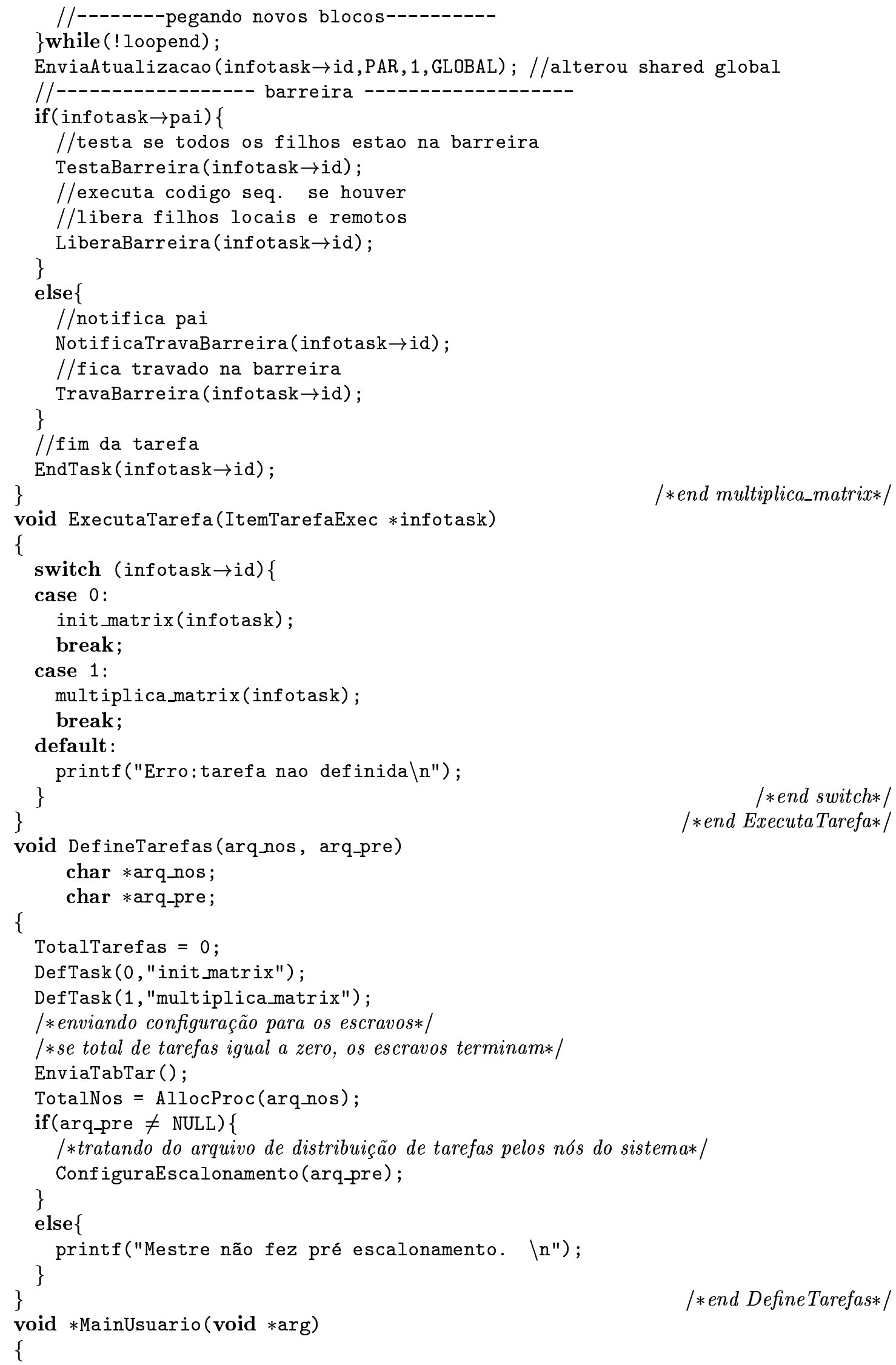




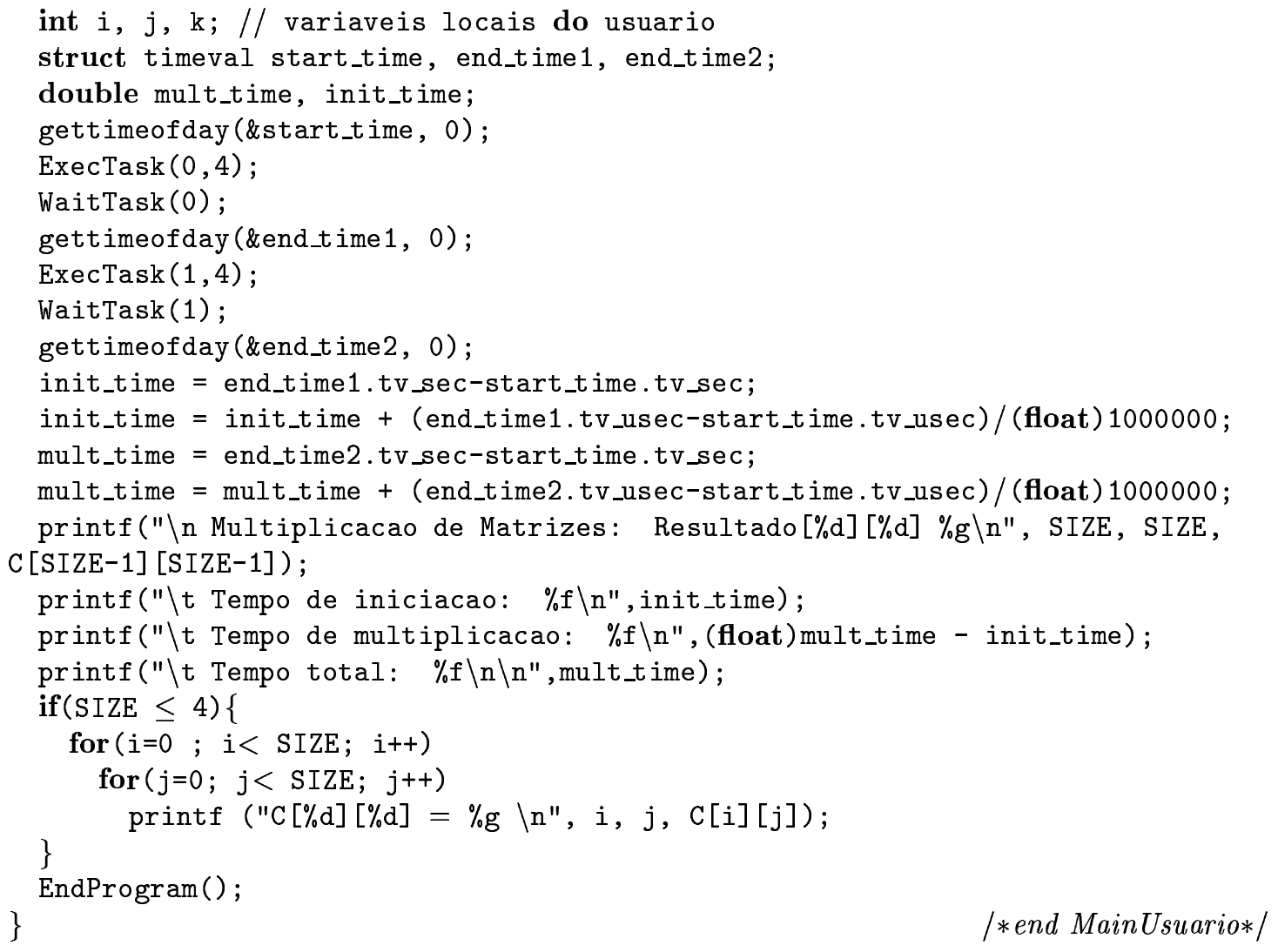

\section{C.6 Tabela de Variáveis Compartilhadas do pro- grama TSP}

\section{C.6.1 O arquivo de prototipação}

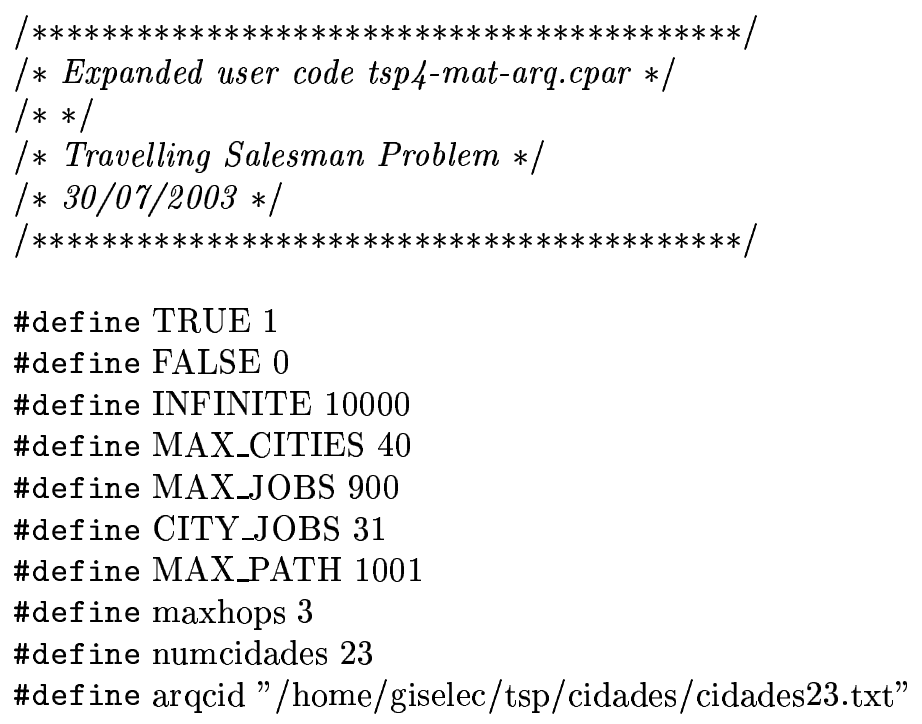


//-_--Shareds estao no var-usuario.c

//shared int MinimaDist;

//shared int MinPath[MAX_PATH];

//shared int prox;

//shared int Queue[MAX_JOBS][CITY_JOBS];

//shared int tamanho_fila;

extern int MinimaDist;

extern int MinPath[MAX_PATH];

extern int prox;

extern int Queue[MAX_JOBS][CITY_JOBS];

extern int tamanho_fila;

//-_--Semaforos tem um tratamento especial

//-_--ja estao mapeados dentro do sistema

//-_-na tabela Semaforos[escopo][idsemaforo]

//shared Semaph cons_fila;

//shared Semaph atualiza;
/* contem a menor distancia $*$ /

/* contem o melhor caminho */

/* fila de jobs */

/* tamanho da fila de jobs */

/* contem a menor distancia */

/* contem o melhor caminho */ /* fila de jobs */

/* tamanho da fila de jobs */

/* tamanho da fila de jobs */

/* semaforo p/ controle de atualizacao*/

\section{C.6.2 O arquivo de declaração e a tabela}

|********************************************** /

/* Expanded user code tsp4-mat-arq.cpar $*$ /

$|* *|$

/* Travelling Salesman Problem */

/*30/07/2003*/

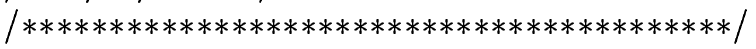

\#include "defs.h"

\#include "defs-usuario.h"

//Declaracao de tipos e de

//variaveis shared do usuario:

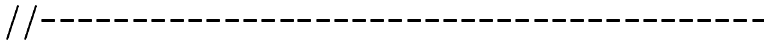

//shared int MinimaDist;

//shared intMinPath [MAX_PATH] ;

//shared intprox;

//shared intQueue[MAX_JOBS] [CITY_JOBS] ;

//shared inttamanhofila;

int MinimaDist;

int MinPath [MAX_PATH] ;

int prox;

int Queue[MAX_JOBS] [CITY_JOBS] ;

int tamanhofila;

//--------Semaforos tem um tratamento especial

//--------ja estao mapeados dentro do sistema

//-------na tabela Semaforos [escopo] [idsemaforo]
/* contem a menor distancia */ /* contem o melhor caminho */

/ fila de jobs */ /* tamanho da fila de jobs */

/* contem a menor distancia */ /* contem o melhor caminho */ /* fila de jobs */

/* tamanho da fila de jobs */

/* tamanho da fila de jobs */ 
//shared Semaph cons_fila;

//shared Semaph atualiza;

/* semaforo $p /$ controle de atualizacao*/

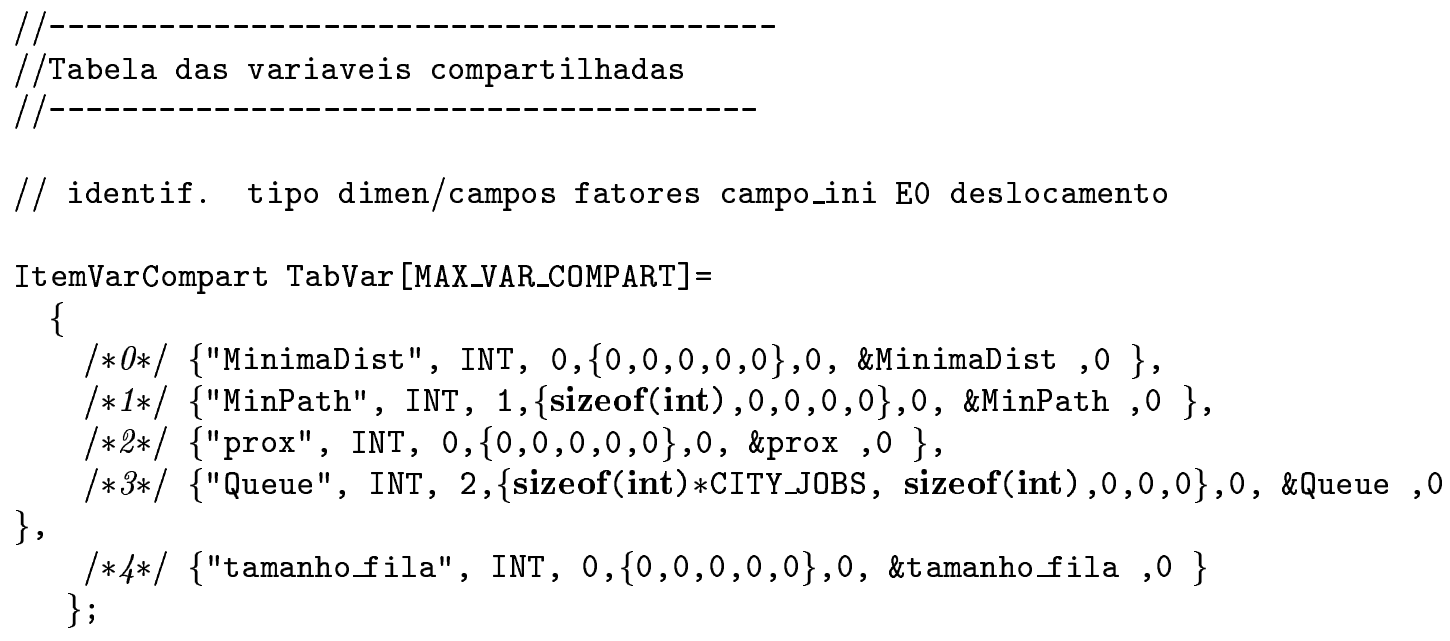

\section{C.7 A expansão do programa CPAR TSP}

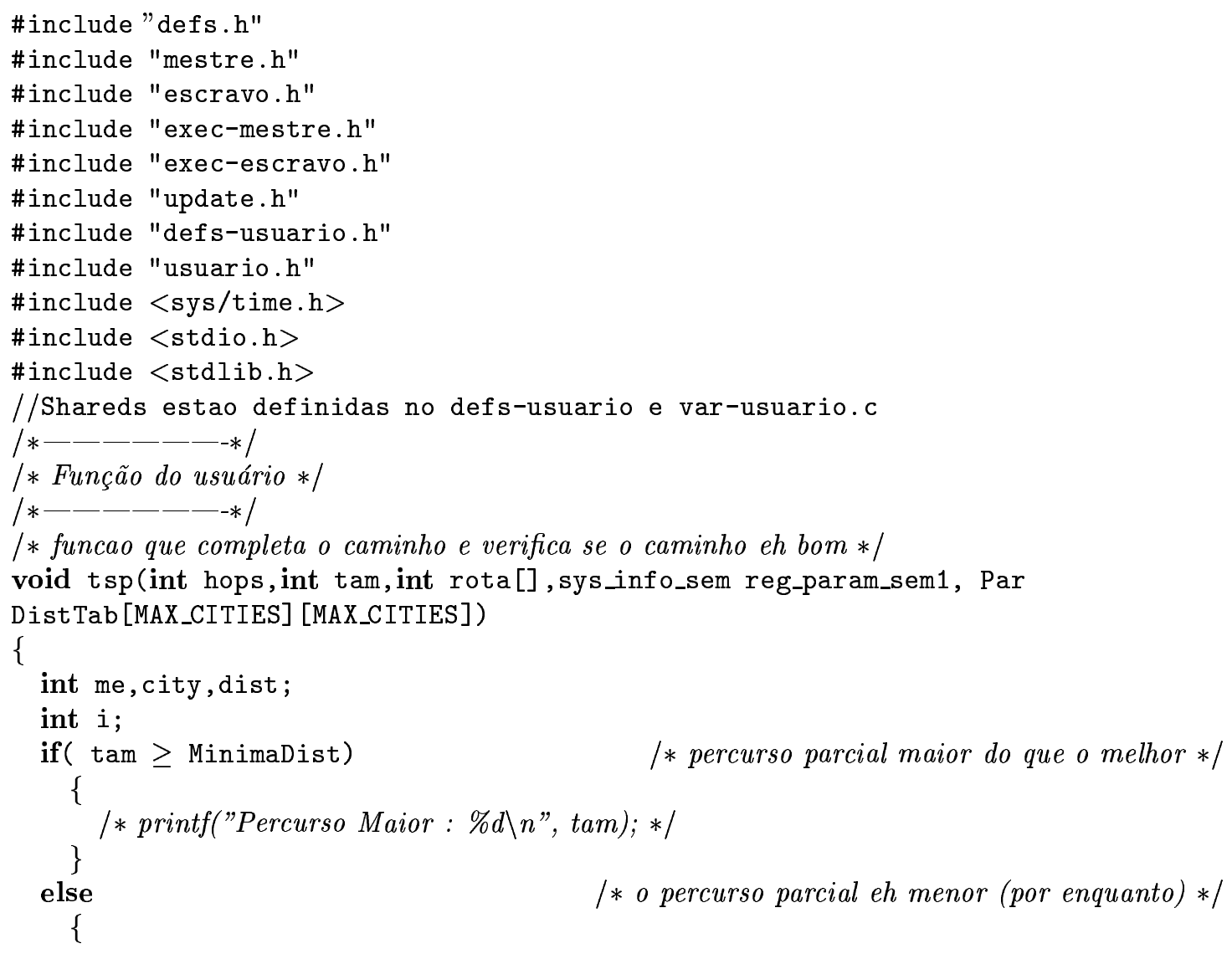




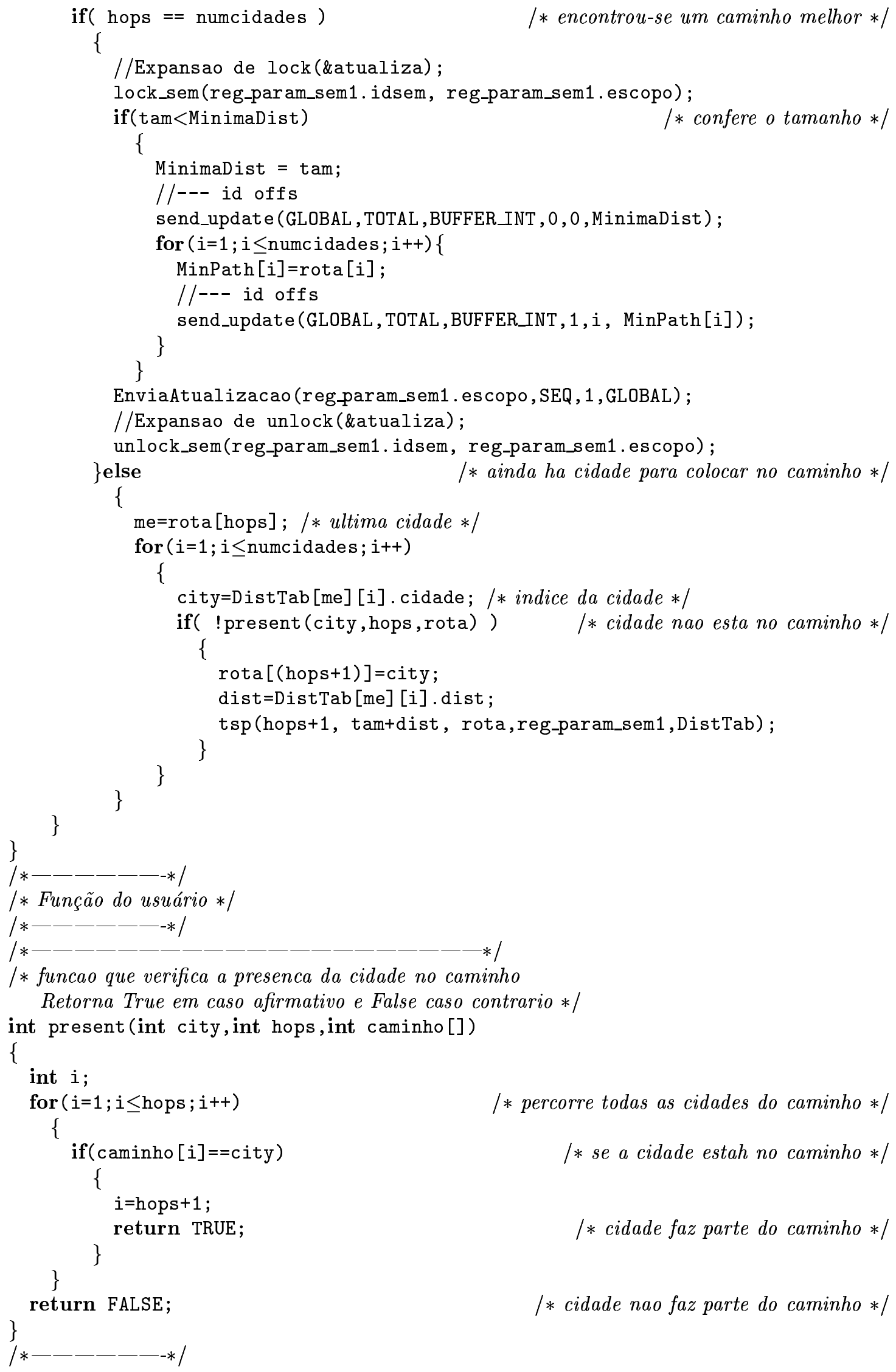




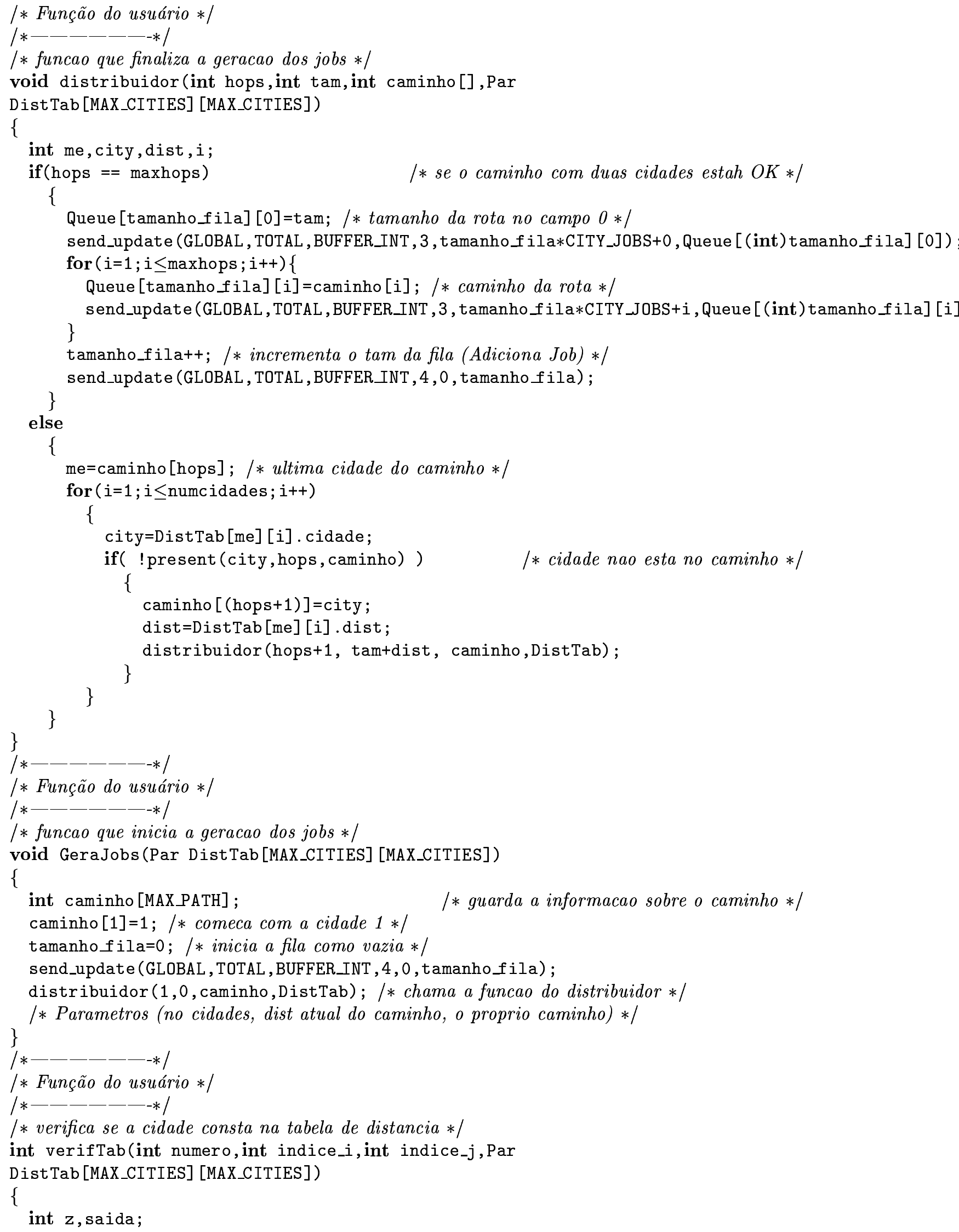




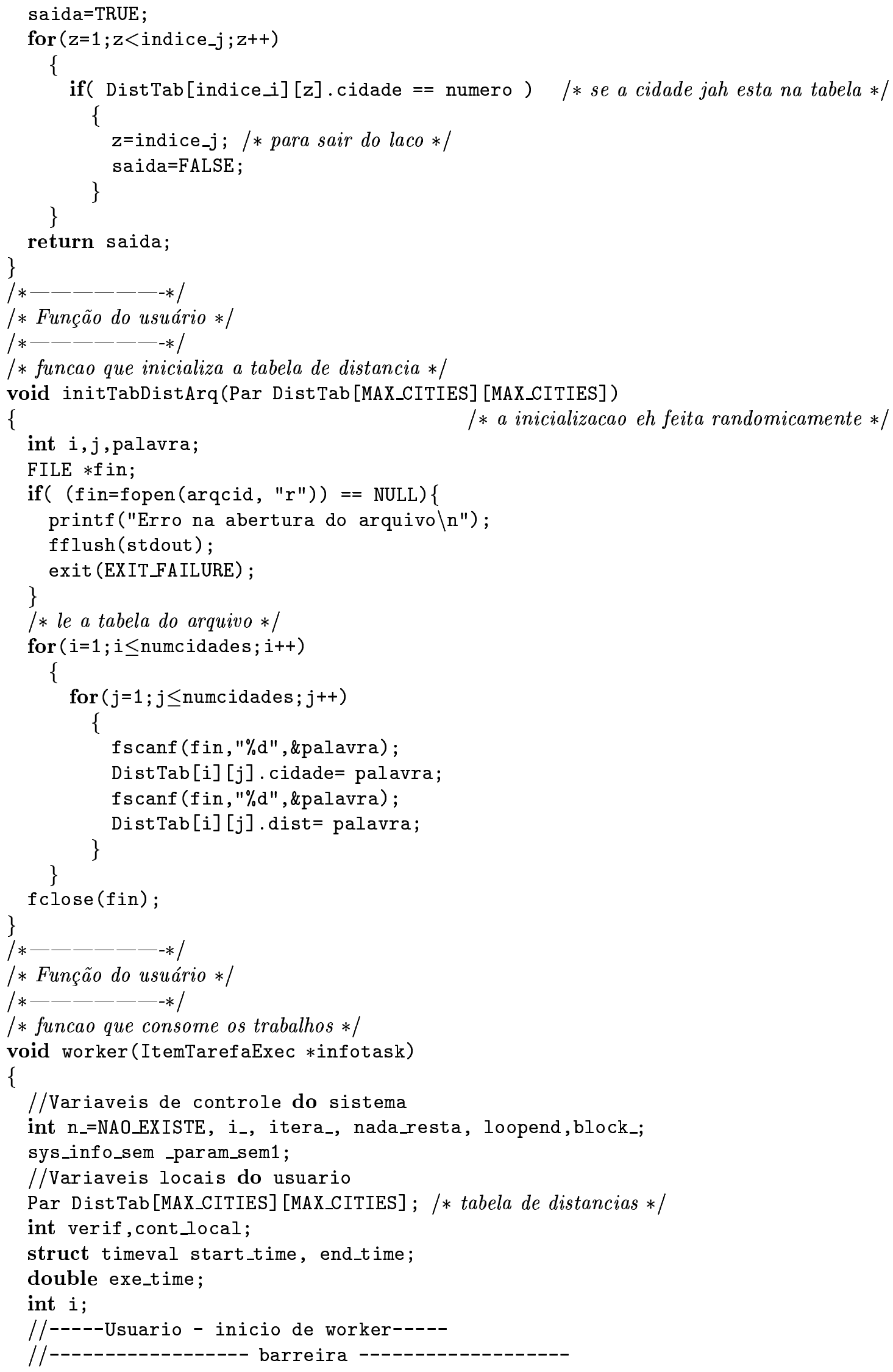




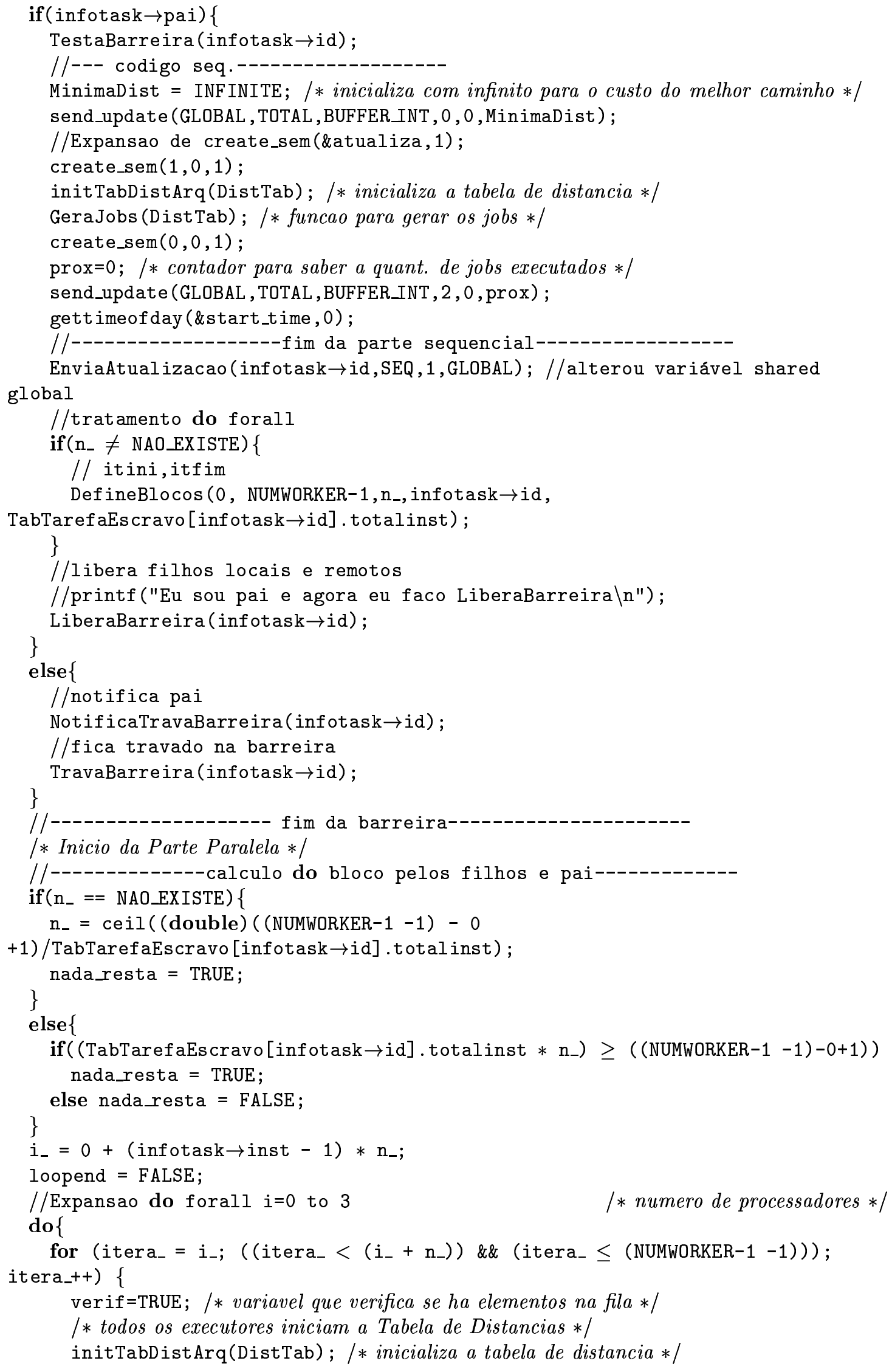




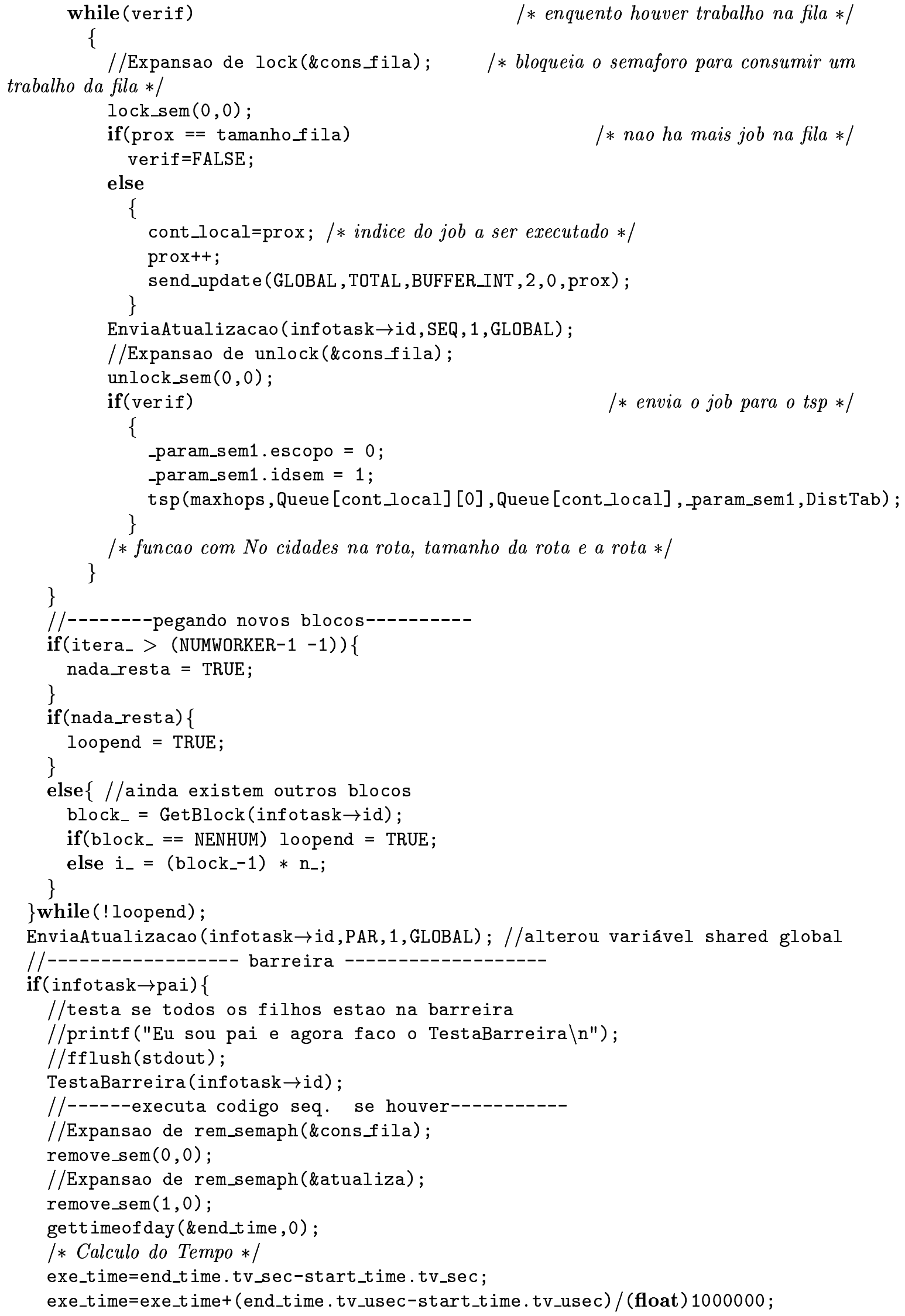




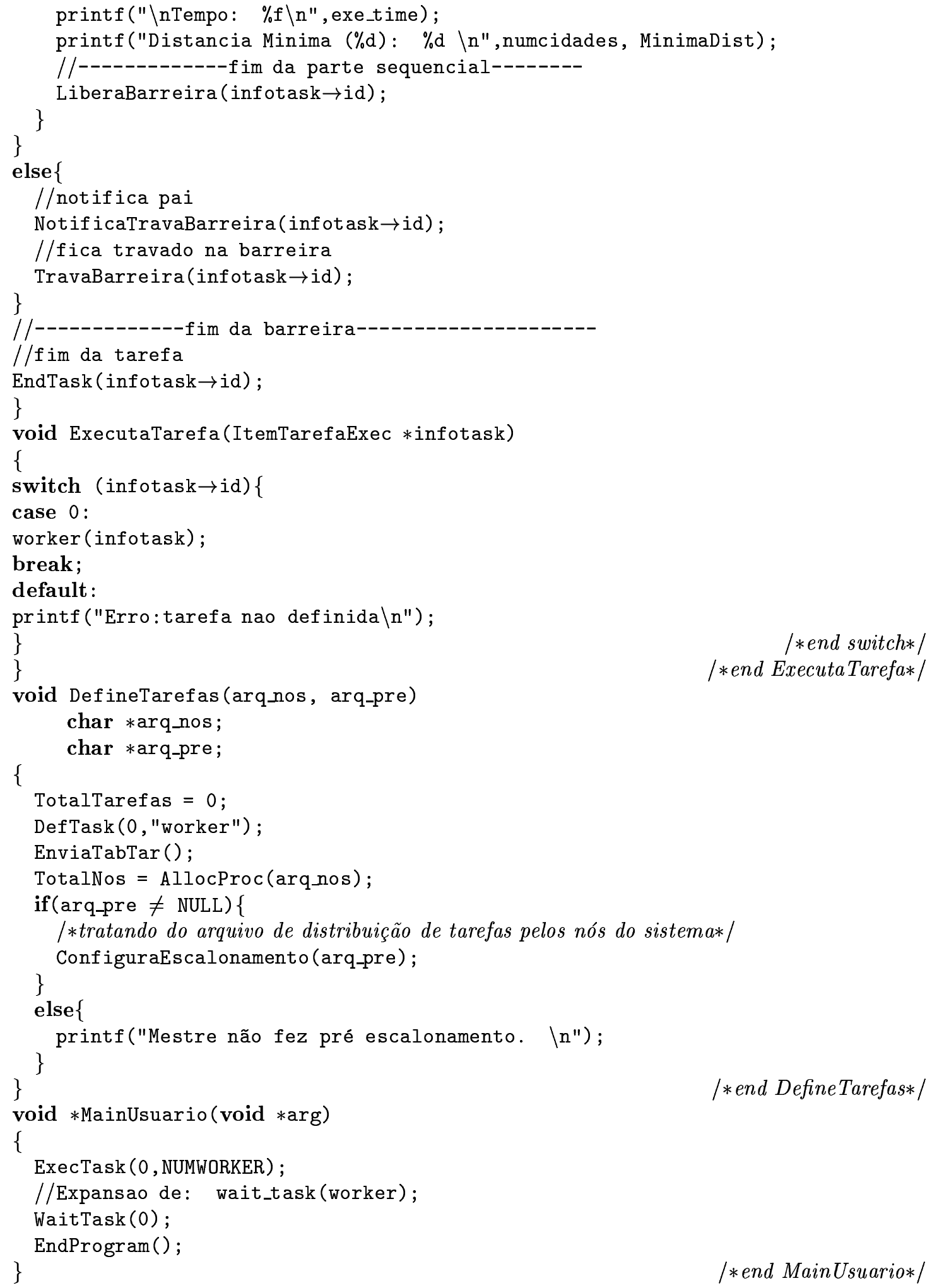

